UC-NRLF

|

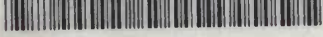

\title{
\$B $304 \quad 140$
}

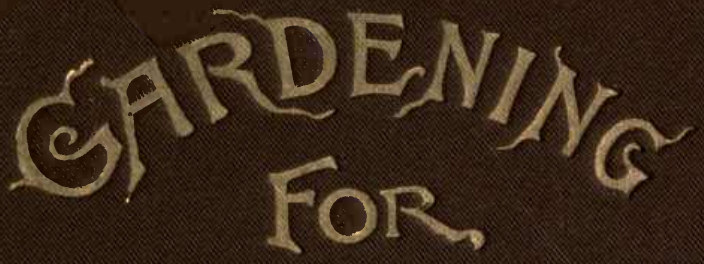

$$
\text { PŔ्र्FIT }
$$

$=$

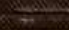




\section{GIFT OF}

Thomas H. Means
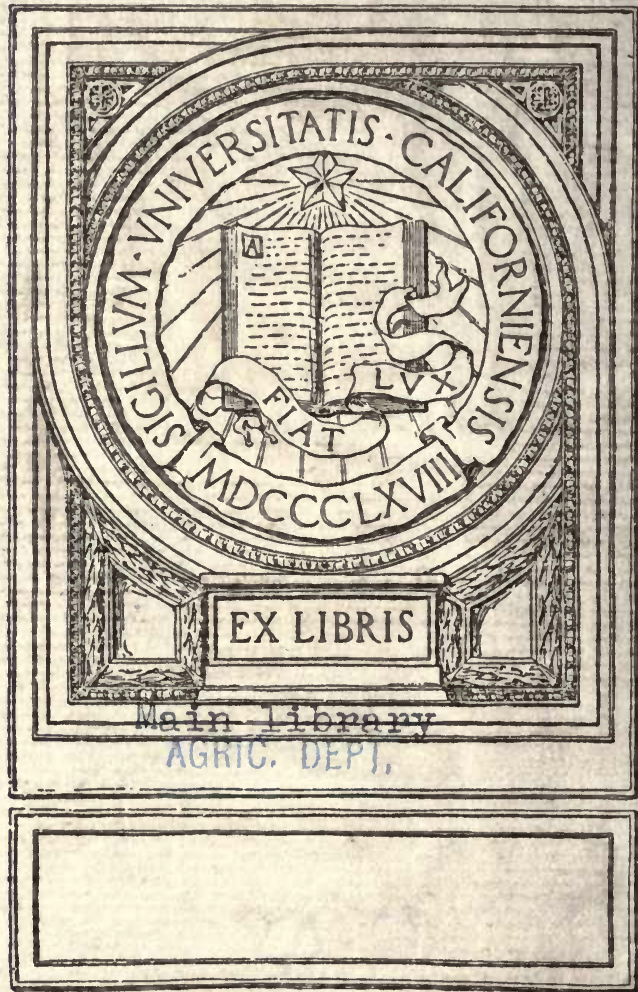


Thos NNneaus Jan. 2.1906. 



\section{GARDENING FOR PROFIT;}

a guide to The successful Cultivation

OF THE

\section{MARKET AND FAMILY GARDEN.}

ENTIRELY NEW AND GREATLY ENLARGED.

BY

PETER HENDERSON,

JERSEY CITY HEIGHTS, N. J.

ILLUSTRATED WITH NUMEROUS NEW ENGRAVINGS,

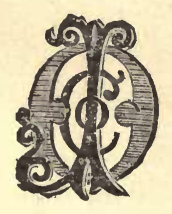

NEW YORK :

O. JUDD CO., DAVID W. JUDD, Pres'T, 751 B R O A D A $\mathrm{Y}$.

$188 \%$. 


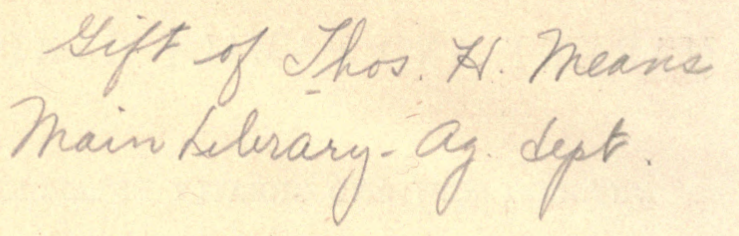

Entered, according to Act of Congress, in the year 1886, by the

O. JUDD CO.,

In the Office of the Librarian of Congress, at Washington. 


\section{O N T E N TS.}

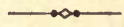

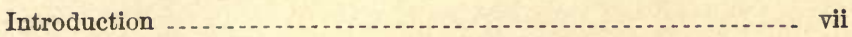

Preface to Second Edition ....................................... $x$

Preface to Third Edition.................................... xi

ChAPTER I.

The Men Fitted for the Business of Gardening 13

CHAPTER II.

The Amount of Capital Required and Workingु Force per Acre 17

CHAPTER III.

Profits of Market Gardening 20

CHAPTER IV.

Location, Situation and Laying Out 23

Chapter V.

Soil, Drainage and Preparation 25

Chapter VI.

Manures

CHAPter VII.

The Use and Management of Cold Frames

Chapter VIII.

Formation and Management of Hot-Beds

Chapter IX.

Forcing-Pits for Greenhouses

Chapter $\mathbf{X}$.

Wide Greenhouses for Forcing Vegetable Crops 73

Chapter XI.

Seeds and Seed Raising 89 (III) 


\section{Chapter XII.}

The Use of the Feet in Sowing and Planting

Chapter XIII.

How, When and Where to Sow Seeds 103

Chapter XIV.

Transplanting 114

Chapter XV.

Vegetables-Their Varieties and Cultivation 117

Chapter XVI.

When to Sow and PIant in the Southern States 311

Chapter XVII.

Packing Vegetables for Shipping 816

Chapter XVIII.

Preservation of Vegetables in Winter 317

Chapter XIX.

Insects 319

Chapter XX.

Culture of Small Fruits 325

Chapter XXI.

Implements 344

Monthly Calendar 359 


\section{L L C S T R A T O N S.}

Asparagus Beetle

128

Rake, Steel

350

Asparagus, Manner of Planting 123

Roller, Garden ............... 351

Drains, Board.

Spade, Ames First Quality.... 346

Flat Stone ...............

Pump, Force, Douglas ....... 66

Rubble ................... 30

Tile, Horseshoe _......... 29

Forcing-pits, Heated by Flue.

Forcing-pits, Heated by Water

Pipes

Straw-mat, Making a .......... 61

SMALL FRUITS.

Greenhouse Heated by Flue .. 86

End Section ............. 87

Greenhouse for Forcing Vegetables 73

Cross Section ............ 74

Glazing, Improved Method of IMPLENENTS.

Asparagus Buncher .......... 355

Asparagus Knife............ 355

Dibber. . . . . . . . . . . . . 356

Drill, Wheel-hoe, Cultivator

and Plow Combined........ 354

Fork, Digging ............. 346

Garden Line Reel ............ 355

Harrow, Acme . . . . . . . . . . . . 348

Disc _.......... 349

Garden .................. 346

Triangular Adjustable _. . 347

Hoe and Cultivator, Horse, Planet Jr. . . . . . . . . . . . 357

Uouble-wheel .......... 354

Prong _..... 350

Scuffle _.............. 350

Horseradish Grater....... . . . . 356

Marker, Double............. . 352

Rapp's Adjustable ........ 352

Plow, Miner's Subsoil ......... 345

Roland Chilled.......... 344

Skeleton .............. 347

Slip Share for........... 345

Blackberry, Kittatinny _...... 335

Wilson -................. 335

Gooseberry, Houghton's Seed-

ling ................ 340

Grape, Niagara .............. 341

Raspberry, Cuthbert ......... 337

Gregg .................... 338

Hansell . . . . . . . . . . 338

Strawberry, Jersey Red_.... _. 331

Sharpless ................. 332

The Jewel _............. 333

The Henderson ......... 329

VEGETABLES, VARIETIES OF :

Artichoke, Green Globe ..... 129

Jerusalem _............. 130

Bean, Earliest Red Valentine - 133

Golden Wax .............. 135

Lima, Jersey Extra Early- 137

Beet, Egyptian Turnip ....... 140

Beet .................. 140

Eclipse ... . . . . . . . . 140

Long Smooth Blood...... 141

Borecole, German Greens..... 143

Brussels Sprouts .............. 146

Cabbage, American Drumhead

Savoy -................ 167

Early Jersey Wakefield: . - 162

Henderson's Early Summer .................. 164

Late Flat Dutch . ........ 166

Carrot, Danver's .............. 172

Long Red Stump-rooted.. 172

Orange Improved ........ 172 
Cauliflower, Henderson's Early

Snowball ................. 168

Celery after Handling........ 177

Earthed up ............ 178

Stored for Winter......... 181

Henderson's Golden Dwarf 185 Henderson's Half Dwarf.. 188

White Plume ............ 186

Celeriac _..._............ 188

Dwarf Apple-shaped ..... 190

Corn, Sweet, Marblehead.....- 198

Minnesota ............. 198

Stowell's Evergreen...... 198

Cucumber, Early Russian .... 202

Gherkin ............... 202

Improved White Spine . . 202

Egg Plant, Black Pekin ....... 205

New York Improved . . . . . 205

Endive, Green Curled ......... 207

Horseradish ................... 211

Set . . . . . 209

Kohlrabi.................. 212

Leek, Musselburg............. 214

Lettuce, Black Seeded Simpson 220

Early Curled Simpson ...- 219

New York ..... . . . . . . . . 222

Paris White Cos.......... 222

Salamander ............. 221

Melon, Musk, Baltimore _..... 229

Golden Netted Gem ...... 228

Hackensack .............. 228

Montreal Market......... 229

Melon, Water, Icing .......... 232

Scaly Bark ............... 232

Striped Gypsy ............. 231

Mushrooms _................. 235

Onion, Extra Early Flat Bed 251
Onion, Giant Rocea .......... 253

Large Red Wethersfield _. $\$ 51$

Southport Large Yellow

Globe ................ 252

White Portugal .......... 253

White Tripoli............ 254

Yellow Globe Danvers ... . 252

Parsley, Emerald .............. 256

Pea, American Wonder....... 262

First of All ............ 260

Stratagem .............. 263

Potato, Clark's No. 1. _...... 269

Empire State............ 268

Perfect Peachblow ....... 2\%

Radish, Beckert's Chartier .... 276

Early Round Dark Red_.. 277

French Breakfast ......... 277

Long Scarlet Short-top ... 275

White-topped Turnip ..... $27 \gamma$

Yellow Summer Turnip .. 2\%7 Rhubarb, St. Martin's ......... 281

Salsify _.................... 282

Sea Kale _... . . .

Spinach, Long Standing ....... 289

Norfolk Savoy-leaved .... 288

Thick-leaved ............. 289

Squash, Essex Hybrid. ........ 293

Hubbard...... . . . . . . . . . . 294

White Bush Scalloped.... 293

Tomato, Mikado .............. 302

Perfection ............... 303

Turnip, Extra Early Milan _. _ 305

Purple-top White Globe_- 306

Ruta Baga, Improved American Purple-top ... 307

White Egg ............. 305

Wagon, Market ............... 353 


\section{INTRODUCTION.}

I hope it is no egotism to state that in both the Floral and Vegetable departments of Horticulture, in which I have been engaged for the past eighteen years, I have been entirely successful. Now, we know that success only is the test of good generalship, and it follows that, having been successful, I have thus earned my title to merit. From this stanapoint, I claim che right to attempt the instruction of the student of horticulture in the tactics of that field.

We have very few works, either agricultural or horticultural, by American authors, whose writers are practical men, and fewer still of these who are men that have "risen from the ranks." The majority of such authors being ex-editors, lawyers, merchants, etc., men of means and education, who, engaging in the business as a pastime, in a year or two generously conclude to give the public the berefit of their experience.

The practical farmer or gardener readily detects the ring of this spurious metal, and excusably looks upon all such instructors with contempt. To this cause, perhaps more than any other, may be attributed the widespread prejudice against book-farming and book-gardening, by which thousands shut themselves off from information, the possession of which might save years of useless toil and privation.

(VII) 
I have some pride, under present circumstances in saying that I have had a working experience in all departments of gardening, from my earliest boyhood, and even to-day am far more at home in its manual operations than its literature, and have only been induced to write the following pages at the repeated solicitations of friends and correspondents, to whose inquiries, relative to commercial gardening, my time will no longer allow me to reply individually. I have endeavored, in this work, to be as concise and clear as possible, avoiding all abstruse or theoretical questions, which too often serve only to confuse and dishearten the man who seeks only for the instruction that shall enable him to practice.

Although the directions given are mainly for the market garden, or for operations on a large scale, yet the amateur or private gardener will find no difficulty in modifying them to suit the smallest requirements. The commercial gardener, from the keen competition ever going on in the vicinity of large cities, is, in his operations, taxed to his utmost ingenuity to get at the most expeditious and economical methods to produce the finest crops-methods that we believe to be superior to those in general use in private gardens, and which may, with profit, be followed.

Our estimates of labor, I trust, will not be overlooked; for I know it is no uncommon thing for gentlemen to expect their gardeners to do impossibilities in this way. The private garden cannot be properly cropped and cared for with less labor than can our market gardens, and these, we know, require nearly the labor of one man to an acre, and that, too, with every labor-saving arrange- 
ment in practice. When the care of greenhouses, or graperies, is in addition to this, extra labor must be given accordingly, or something must suffer.

The greatest difficulty that has presented itself to me in giving the directions for operations, has been the dates ; in a country having such an area and diversity of temperature as ours, directions could not well be given for the extremes, so as the best thing to be done under the circumstances, I have taken the latitude of New York as a basis, and my readers must modify my instructions to suit their locality. The number of varieties of each regetable described here is very small in comparison with those that are known, or the seeds of which are offered for sale. I have given only such as I have found most serviceable. Those who wish for a more extended list are referred to the seed catalogues.

Jersey City Heights, N. J., December 1st, 1866. 


\section{PREFACE TO SECOND EDITION.}

It is now seven years since I wrote "Gardening for Profit," and, although it has met with a reception that has been exceedingly flattering, I have ever since felt that it was too hurriedly done, and far from complete. The suggestions and queries made to me by some of the many thousands of its readers, have been the means of developing many new ideas and plans for better cultivation, which I have the pleasure to embody in this edition. A new edition of a work of this kind becnmes necessary every few years, to enable it to keep pace with the improvement in varieties, as well as in modes of culture. In the present edition, the part of the work treating of varieties has been carefully revised, and we believe the kinds described to be, as a whole, the best in their respective classes this day in use, either for private or commercial purposes. It is gratifying to know, by letters from every section of the country, that the publication of this work has been the means of helping to success thousands of inexperienced cultivators of the soil, of both classes-those "Gardening for Pleasure," as well as those "Gardening for Profit." It is true that some that have been induced to engage in the business by reading my book have failed. Such must ever be the case-less or more-in every business ; but I have gocd reason to believe that the percentage of failures gardening is less than that in almost any other business.

Peter Henderson.

Jersey City Heights, N. J., January, $18 \% 4$. 


\section{PREFACE TO THIRD EDITION.}

It is twenty years since "Gardening for Profit" was first written, and twelve years since the second edition was issued. The lapse of a dozen years is too long between editions of a work of this character, for new methods of culture, new and improved varieties of regetables and fruits are yearly coming into use, but my life has been more than an ordinarily busy one, and I have never been able, until now, to find sufficient time to get out another edition as full and complete as the necessities of the widely extending nuture of the business demands. The present edition, it will be seen, has a much wider scope than either of the former editions, embracing as it does not only the forcing under glass of some important fruits and regetables not before touched upon, but also detailing the methods of culture of the leading small fruits, which properly come under the head of "Gardening for Profit."

At the present writing, the business of gardening in such large cities as New York, Philadelphia, Boston or Chicago, is by no means so profitable as formerly, mainly owing to the vast competition from the Southern States, but that it is yet far more profitable than farm operations for the capital and labor employed-in almost every section of the country-cannot be doubted. There are thousands of farmers adjacent to the smaller towns, villages, hotels, watering places, and summer boardinghouses, where the want at the table of fresh vegetables and fruits is most conspicuous. In many such places it is unquestionable that if the farmer would devote a few (xI) 
acres to the culitivation of fruits or vegetables, or both, the chances are more than equal that he would find it to be more profitable than ten times the amount of land cultivated in the ordinary farm crops. I have had letters from thousands of men, who, following the instructions of the former editions of "Gardening for Profit," have thanked me for inducing them to start in this safe and profitable business.

Jersey City Heights, N. J.,

\section{Peter Henderson.}

December 15th, 1886. 


\section{GARDENING FOR PROFIT.}

\section{H A P T E R I.}

\section{THE MEN FIT'TED FOR THE BUSINESS OF GARDENING.}

Although we shall here show the business of gardening to be a profitable one, let no man deceive himself by supposing that these profits are attainable without steady personal application.

Having been long known as extensively engaged in the business, I am applied to by scores every season, asking how they can make their lands available for garden purposes. The majority of these are eity merchants who, for investment or in anticipation of a rural retreat in the antumn of their days, have purchased a country place, and in the meantime they wish to make it pay. They have read or heard that market gardening is profitable, and they think it an easy matter to hire a gardener to work the place while they attend their own mercantile duties as beiore. They are usually gentlemen of horticultural tendencies, read all the magazines and books on the subject, and from the knowledge thus obtained, plume themselves with the conceit that they are able to guide the machine. 
Many hunaireds from our large cities delude themselves in this way every season in different departments of horticulture-perhaps more in the culture of fruits than of vegetables. I have no doubt that thousands of acres are annually planted, that in three years afterwards are abandoned, and the golden dreams of these sanguine gentlemen forever dissipated. Although the workers of the soil will not, as a class, compare in intelligence with the mercantile men of the cities, it is a mistake to suppose that this want of education or intelligence is much of a drawback when it comes to cultivating strawberries or cabbages. True, the untutored mind does not so readily comprehend theoretical or scientific knowledge, but for that very reason it becomes more thoroughly practical, and I must say that, as far as my experience has gone (without being thought for a moment to derogate against the utility of a true scientific knowledge in all matters pertaining to the soil), that any common laborer with ordinary sagacity and twelve months' working in a garden would have a far better chance of success, other things being equal, than another without the practice, even if he had all the writings, from Liebig's down, at his fingers' ends. Not that a life-long practice is absolutely necessary to success, for I can see from where I write the homes of at least half a dozen men, all now well to do in the world, not one of whom had any knowledge of gardening, either practical or theoretical, when they started the business, but they were all active working men, "actual settlers," and depended alone on their own heads and hands for success, and not on the doubtful judgment and industry of a hired gardener, who had no further interest in the work than his monthly salary.

"D. H." writes me thus: "I am a book-keeper with a salary from which I can save b'it little; but 
by rigid economy during a series of years, I have scraped together $\$ 2,000$. My health is only ordinary. With that capital can I succeed as a market gardener by hiring an experienced gardener?" This inquiry is a type of hundreds I now receive annually, and to which may be given this general reply: From the nature of the question, no rery definite answer can be given, though I would say that the chances are two to one against success. It is a well-known fact that the chances of success in mercantile business are even far less than this. "D. H." may be a capital book-kesper, yet it is doubtful if he has the necessary endurance to stand the wear on the constitution that market gardening involves. If he concludes to start at gardening, he is more likely than not to select a soil entirely unsuited to the purpose. In most sectioas of the country there are fewer soils suitable for the cultivation of regetables than there are those that are unsuitable. Again, he is an educated man, and this very fact would be rather against him than otherwise, as it would naturally incline him to refined society and associations, in which, I am sorry to say, the beginner in market gardening cannot afford to indulge. The hiring of an "experienced gardener", would take all the cream off of the profits. Experienced market gardeners are exceedingly scarce. Our laborers in the market gardens are generally an ignorant class with very little ambition, and not one in a hundred of them is fit to manage. Though employing seventy hands myself, I have often been sadly at a loss to select from them a suitable man as foreman, though many of them had been with me for years. When one shows the necessary ability, his services are much sought after, and he readily commands $\$ 500$ or $\$ 600$ a year and board. Clerks, bookkeepers, and city-bred men generally wie not the ones 
likely to be successful as workers of the soil. Few of them have any conception of the labor required to be done to insure success. I started business in Jersey City, at the age of twenty-three, with a capital of $\$ 500$, which it had taken me three years to make as a working gardener. For the first five years that I was in business, I can safely say that we worked, on an average, sixteen hours a day, winter and summer, with scarcely a day for recreation. Now, the majority of clerks, book-keepers or salesmen do not work much more than half that time, and few of them could endure this lengthened strain in a summer's sun, and without this endurance success is out of the question; for all beginners to-day must do as I did, until they get their heads above water, or else, such is the competition, they must go to the wall in the business. I therefore cantion all such who are not in robust health to avoid either farming or gardening if their necessities require them to make a living thereby. That the work of the gardener is conducive to health, when that has not been impaired, there is no question; but the long hours of labor and the exposure necessary to success, must tell against a feeble constitution.

The business of market gardening, though pleasant, healthful, and profitable, is a laborious one, from which any one not accustomed to manual labor would quickly shrink. The labor is not what may be termed heavy, but the hours are long-not less than an average of twelve hours a day, winter and summer. No one should begin it after passing the meridian of life; neither is it fitted for men of weak or feeble physical organization, for it is emphatically a business in which one has to rough it. In summer planting, when it is of the utmost importince to get the plants in while it rams, we repeatedly work for hours in 
drenching rains, and woe be to the "boss" or ioreman who would superintend the operation under the protection of an umbrella. He must take his chances with the rank and file, or his prestige as a commander is gone.

\section{CHA P T E R I I.}

\section{THE AMOUNT OF CAPITAL REQUIRED AND WORKING FORCE PER ACRE.}

The small amount of cupital required to begin farming operations, creates great misconception of what is necessary for commercial gardening; for, judging from the small number of acres wanted for commencing a garden, many suppose that a few hundred dollars is all sufficient for a market gardener. For want of information on this subject, hundreds have failed, after years of toil and privation. At present prices (1886), no one would be safe to start the business of vegetable market gardening, in the manner it is carried on in the neighborhood of New York, with a capital of less than $\$ 300$ per acre, for anything less than ten acres; if on a larger scale, it might not require quite so much. The first, season rarely pays more than current expenses, and the capital of $\$ 300$ per acre is all absorbed in horses, wagons, glass, manures, etc. If the capital be insufficient to procure these properly, the chance of success is correspondingly diminished.

I can call to mind at least a dozen cases that have occurred in my immediate neighborhood within the last ten years, where steady, industrious men have utterly failed, and lost every dollar they possessed, merely by attempting the business with insufficient capital. A few years ago a man called upon me and stated thas he was about 
to become my neighbor; that he had leased a place of twenty acres alongside of mine for ten years, for $\$ 600$ per year, for the purpose of growing vegetables, and asked me what I thought of his bargain. I replied that the place was cheap enough, only I was afraid he had got too much land for that purpose if he attempted the working of it all. I further asked him what amount of capital he had, and he told me that he had about $\$ 1,000$. I said that I was sorry to discourage him, but that it was better for him to know that the amount was entirely inadequate to begin with, and that there was not one chance in fifty that he would succeed, and that it would be better, even then, to relinquish the attempt; but he had paid $\$ 150$ for a quarter's rent in advance, and could not be persuadea from making the attempt. The resnlt was as I expected ; he began operations in March, his little capital was almost swallowed up in the first two months, and the few crops he had put in were so inferior that they were hardly worth sending to market. Without money to pay for help, his place got enveloped in weeds, and by September of the same year he abandoned the undertaking.

Had the same amount of capital and the same energy been expended on three or four acres, there is hardly a doubt that success would have followed. Those who wish to live by gardening, cannot be too often told the danger of spreading over too large an area, more particularly in starting. With a small capital, two or three acres may be profitably worked; while if ten or twelve were attempted with the same amount, it would most likely result in failure. Many would suppose that if three acres could be leased for $\$ 100$ per year, that twenty acres would be cheaper at $\$ 500$; nothing can be more erroneous, unless the enterprise be backed up with the necessary capital $-\$ 300$ per acre. For be it known, that the rental or interest on the ground used for gardening operations is usually only about ten per cent. of the wozising expenses, 
so that an apparently cheap rent, or cheap purchase, does not very materially affect the result. It is very different from farming operations, where often the rent or interest on purchase money amounts to nearly half the expenses.

The number of men employed throughout the year on a market garden of ten acres, within three miles of market, planted in close crop, averages seven; this number is varied in proportion. somewhat, according to the quantity of glass in use. I have generally employed more than that-fully a man to an acre-but that was in consequence of having in use more than the ordinary proportion of sashes. This may seem to many an unnecessary force for such a small area, but all our experience proves that any attempt to work with less will be unprofitable. What with the large quantity of manure indispensable, seventyfive tons per acre; the close planting of the crops, so that every foot will tell ; the immense handling preparatory for market, to be done on a double crop each season, one marketed in mid-summer, another in fall and winter, a large and continued amount of labor is required. On lands within a short distance of market-say two milestwo horses are suflicient; but when double that distance, three are necessary. When three animals are required it is most profitable to use a team of mules to do the plowing and heavy hauling of manure, etc., and do the marketing by a strong, active horse. Every operation in cultivating the ground is done by horse labor whenever practicable to do so; but it must be remembered that the crops of a garden are very different from those of a farm; the land is in most cases (particularly for the first crops) planted so close that nothing will do to work with but the hoe or hand cultivator (See Implements). 


\section{H A P T E R I I . \\ PROFITS OF MARKET GARDENING.}

This is rather a difficult if not a delicate matter to touch, as the profits are so large in some instances as almost to exceed belief, and so trifling under other conditions as to be hardly worth naming. These latter conditions, however, are generally where men have started on unsuitable soils, too far from market, or without money enough to have ever got thoroughly under way. But as the object of this work is to endeavor to show how the business can be made a profitable one, I will endeavor to approximate to our average profits per acre. As a rule it may be premised that for every additional acre over ten, the profits per acre will to some extent diminish, from the fact that a larger area cannot be so thoroughly worked as a smaller one; besides, there will often be a loss in price by having to crowd larger quantities of produce into market and to leave it in the hands of inexperienced salesmen. The majority of our products are quickly perishable and must be sold when ready.

The average profits for the past ten years on all well cultivated market gardens in this vicinity have only been about $\$ 200$ per acre. For the five years from 1861 to 1866 they were perhaps twice that amount; but those were years of "war prices," such as we will be well content never to see again. These profits are for the products of the open gardens only, not of the frames or forcing-pits, which are alluded to elsewhere. These amounts are for the neighborhood of New York, and, I think, from the vast competition in business, are now a low arerage for the majority of towns and cities throughout the country. Certain it is that from our 
lands, even at a value of from $\$ 1,000$ to $\$ 5,000$ per acre, we can (and do) profitably grow and supply the majority of towns within fifty miles around New York with fresh vegetables. In these cases, no doubt, the consumer pays full double the price that the raiser receives, for they generally pass through the hands of two classes of "middlemen" before they reach the consumer, besides which, there are extra charges for packing, shipping and freight. Thus the consumer in a country town, where land often is not as much in value per acre as it is here per lot, pays twice the value for his partially stale vegetables or fruits, which he receives rarely sooner than twenty-four hours after they are gathered.

In most of such towns market gardening, carried on after our manner, would unquestionably be highly remunerative; for if these articles were offered to the consumer fresh from the gardens, he would certainly be willing to pay more for his home-grown products than for the bruised and battered ones that are freighted from the metropolis. Take, for example, the article of Celery, which pays us very well at two cents per root. There is hardly a city or town in the country, except New York, but where it sells for twice, and in some cases six times, that price per root; yet the great bulk of this article sold in Philadelphia is sent from New York, for which the consumer must pay at least double the price paid here, for it is a bulky and expensive article to pack and ship, and must of a necessity pay a profit both to the agent here and in Philadelphia, which of course comes out of the pocket of the consumer. This is only one of many such articles of which the culture is imperfectly understood, and which the great market of New York is looked to for a supply.

The following will show the rate of receipts and 
expenditures for one acre of a few of the leading articles we cultivate, taking the average of the past ten years, from the grounds that have been brought up to the proper standard of fertility necessary to the market garden :

EXPENDITURES FOR ONE ACRE.

Labor $\$ 480$

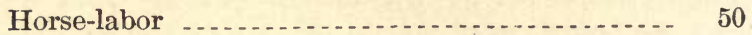

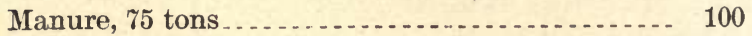

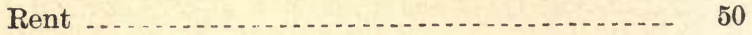

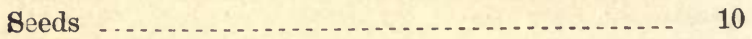

Wear and Tear of Tools, etc. ................. 10

Cost of Carriage to Market and Selling........... 100

$\$ 800$

RECEIPTS FOR ONE ACRE.

12,000 Early Cabbages, at 4 cents per head . . . . . . \$480

14,000 Lettuce, at 1 cent per head .............. 140

30,000 Celery, at 2 cents per head ........... 600

$\$ 1,220$

800

$\$ 420$

The rotation crops of Early Beets or Onions, followed by Horseradish or Sweet Herbs as a second crop, give nearly the same results. 


\section{H A P T E R I V.}

\section{LOCATION, SITUATION AND LAYING OUT.}

Location.-Before deciding on the spot for a garden, too much caution cannot be used in selecting the locality. Mistakes in this matter are often the sole cause of want of success, even when all other conditions are favorable. It is always better to pay a rent or interest of $\$ 50$, or even $\$ 100$, per acre on land one or two miles from market than to take the same quality of land six or seven miles distant for nothing; for the extra expense of teaming, procuring manure, and often greater difficulty of obtaining labor, far more than counterbalance the difference in the rental of the land. Another great object in being near the market is that one can thereby take advantage of the condition of prices, which often in perishable commodities like garden produce is very variable. It not infrequently happens that, from scarcity or an unusual demand, there will be a difference of $\$ 15$ or $\$ 20$ per load, even in one day; hence, if near a market, larger quantities can be thrown in than if at a distance, and the advantage of higher rates be taken.

This disadvantage in distance only holds good for perishable articles that are bulky.' The lighter and valuable crops, such as Tomatoes, Cucumbers, Lettuce, Radishes, etc., from more southern and earlier localities are grown often hundreds of miles distant and freighted to market at a handsome profit. So with the less perishable articles, such as dry roots of Carrots, Beets, Parsnips, Horserarish, etc. But the necessity for nearness to market for the bulky and perishable crops, such as Cabbage, Lettuce and Celcry, is of importance. 
Situatron AND LAYING-oct. - It is not always that choice can be made in the situation of or aspect of the ground; but whenever it can be made, a level spot should be selected, but if there be any slope, let it be to the south. Shelter is of great importance in producing early crops, and if a position can be found where the wind is broken off by woods or hills to the north or northwest, such a situation would be very desirable. In the absence of this we find it necessary to protect, at least, our forcing and framing grounds, with high board fences, or, better yet, be'ts of Norway spruce. The most convenient shape of the garden is a square or oblong form; if.square, a road twelve feet wide should be made through the center, intersected by another road of similar width; but if oblong, one road of the same width running through the center in a plot of ten acres will be sufficient.

Vegetable House, Wells, Etc.-Connected with c7ery market garden is a vegetable house, usually about twenty-five feet square, having a frost-proof cellar, over which is the vegetable or washing house. In the second story is a loft for seeds, storage, etc. Immediately outside the vegetable house is the well, from which the water is pumped to a tub in one corner of the building, on each side of which are erected benches of convenient height, on which the workmen tie and wash the vegetables preparatory to sending them to market. 


\section{H $\triangle$ P T E R V.}

\section{SOIL, DRAINAGE AND PREPARATION.}

In the course of an experience of nearly forty years as a market gardener, in the neighborhood of New York, I have had, in the prosecution of the business, the opportunity of reclaiming large tracts of very different varities of soil. Some of these, almost the first season, yielded a handsome profit, while with others, the labor of years, and the expenditure of large sums in extra manuring and draining, have never been able to bring these uncongenial soils up to the proper standard of productiveness.

On many occasions I have referred to the great importance of selecting a proper quality of soil for all gardening and farming operations, and the fact cannot be too often nor too forcibly impressed that success hinges more directly upon this than on anything else. 'Thousands are every year ruined by a bad selection of soil. I have scores come to me in the course of every season for advice in this matter of soils, but in most instances the advice is asked too late; the majority of the applicants having been unfortunate enough to buy or rent land that they had been led to believe was excellent, but only " run down." "In my opinion this widespread notion of "exhausted lands" is, to a great extent, a fallacy, and that most of the lands said to be so exhausted never were good, and nothing short of spreading a good soil over them a foot thick would ever make them available.

The practical test of the importance of a good soil for market garden operations is clearly shown in a score of cases in my vicinity. Wherever a man of ordinary industry and intelligence has been fortunate enough to locate on land that is naturally good, his success has been certain, while others that have not been able to procure such land have had to struggle far harder for less returns; in 
some few instances entire failure has been the case, for the reason that the soil started on was untitted for the purpose.

The variety of soil that we value above all others is an alluvial saline deposit, rarely found over more than a mile inland from the tide mark. It is of dark heavy loam, containing throughout a large mixture of decomposing oyster and other shells; it averages from ten to thirty inches deep, orerlaying a subsoil of yellow sandy loam. The next kest variety is somewhat lighter soil, both in color and specific gravity, from eight to fifteen inches deep, having a similar subsoil to the above. 'Then we have a still lighter soil, in both senses of the term, in which the sand predominates over the loam, and laying on a subsoil of pure sand; this variety of soil is well adapted for Melons, Cucumbers, Sweet Potatoes, Radishes and Tomatoes, but is almost useless for growing crops of Onions, Cabbages or Velery. We have still another kind of soil, which I place last, as being of the least value for the purpose of growing vegetables; this variety, singularly enough, is found on the highest points only, its color being somewhat lighter than that of the variety first mentioned; it is what is termed a clayey loam, averaging ten inches in depth, under which is a thick stratum of stiff bluish clay. With a subsoil of this nature it is almost useless to attempt to grow early vegetables for market purposes.

I have just such a soil as the last mentioned, thoroughly drained three feet deep, the drains only eighteen feet apart, and yet in another garden that I work, having the two first named soils and only one mile distant, manured and cultivated the same in all respects, fruits and vegetables are ready from five to ten days earlier. But for the succession, or second crops, such as Celery, etc., this stiff, cold soil is just what is wanted; earliness with these is not the object, and its "coldness" is congenial to the 
roots of the liste crop. But if selection can be made for general purposes, choose a rather dark-colored loamy soil, neither "sandy" nor "clayey," as deep as can be found, but not less than twelve inches. If it overlay a sandy loam of yellowish color, through which water will pass freely, you have struck the right spot, and abundant crops can be raised under proper management. When selecting land, do not be deceived by any one who tells you that if not naturally good, the soil may be made so hy cultivation and manure. These will help, certainly, but only as education improves the shallow mind. Luxuriant crops can no more be expected from a thin and poor soil-no matter how much it is cultivated-than fertile ideas from a shallow brain, educate it as you will. The best guide in the selection of land for garden purposes is to closely examine and compare the crops on lands adjacent ; if, under ordinary culture, you see these lands producing good crops of Corn, Wheat, or Potatoes, or where the meadows give two or three tons of Hay to the acre, it is reasonable to expect that land on the same level as that in question will be of similar quality. But should the land to be selected for garden purposes be in a region where there is nothing but timber or the natural grasses to guide, then the best thing to do is to carefully dig in different parts of the land to ascertain the depth and quality of the top soil, and above all the texture of the subsoil, which, if it be of stiff, adhesive clay, such as bricks could be made from, turn back at once and let that soil alone, if desired for garden work. 'To the entirely inexperienced person, who is about to lease or purchise land for garden work, I would adrise him to get, if possible, an entirely disinterested practical farmer or gardener to examine the soil and general surroundings of the locality before entering on the undertaking; for, as before said, the quality of the soil is all important to success. 
Drainage. - Every operator in the soil concedes the importance of drainage, yet it is really astonishing to observe how men will work wet lands, year after year, wasting annually, by loss of crops, twice the amount required to thoroughly drain. A most industrious German, in this vicinity, cultivated about eight acres for three years, barely making a living; his soil was an excellent loam, but two-thirds of it was so "sponey" that he could never get it plowed until all his neighbor's had their crops planted. Driving past one day I hailed him, asking him why he was so late in getting in his crop, when he explained that if he had begun sooner his horses would havie "bogged" so he might never have got them ont again. I suggested draining, but he replied that would never pay on a leased place; he had started on a ten years' lease, which had only seven years more to run, and that he would only be improving it for his landlord, who would allow him nothing for such improvement. After some further conversation I asked him to jump into my wagon, and in ten minntes we alighted at a market garden that had, six years before, been just such a swamp hole as his own, but now (the middle of May) was luxuriant with regetation. I explained to him what its former condition had been, and that the investing of $\$ 500$ in drain tiles would, in twelve months, put his in the same condition. He, being a shrewd man, acted on the advice, and at the termination of his lease purchased and paid for his eight acres $\$ 12,000$, the saving oi six years on his drained garden. This was in war times, when prices for all products were double what they are now. I honestly believe that had he gone on without draining he would not have made $\$ 1,200$ in twelve years, far less $\$ 12,000$ in six years. My friend attributes his whole success in life to our accidental meeting and conversation that May morning, and consequently I have no stauncher friend on earth than he. 
The modes of draining must be guided to a great extent by circumstances. Wherever stones are abundant on land, the most economical way to dispose of them is to use them for drainage.. 1.have also used with great success in a wet, sandy subsoil, where digging was easily done, brush from adjacent woods, cut off and trodden firmly two feet deep in the bottom of drains five feet deep, overlaying the brush with straw or meadow hay before covering in. Drains so made have answered well for nearly a dozen years, and in situations where no other material offers, they will at least answer a temporary purpose. But unquestionably, when at a!l attainable at anything like reasonable cost, the cheapest and most thorough draining is by tile. We use here the ordinary horseshoe or

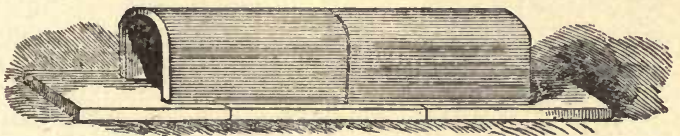

Fig. 1.- Horseshoe tiLE.

round tile-three-inch size for the laterals, and from five to six inch for the mains. On stiff, clayey soils we make our lateral drains three feet deep and from fifteen to eighteen feet apart; on soils with less compact subsoils, twenty to twenty-five feet distant. We find it cheaper to use the horseshoe than the sole tile. In lieu of the sole we cut common hemlock boards in four pieces-that is, cut them throngh the middle-and split these again, making a board thus cut run about fifty feet. These are placed in the bottom of the drains and prevent the cagging of the tiles in any particular spot that might be soft (figure 1). We are particularly careful to place, after setting, a piece of sod, grass down, over the joinings of the tiles to prevent the soil from getting in and stopping up the drainage.

The manner of constructing stone drains is gov- 
erned by the character of the stone on hand; if round, they are best made as rubble drains (figure 2), but if flat, which is much the best, they are made as represented by figure 3 ; but in either case the same care must be exercised in covering over the top thoroughly with sod, shavings, straw or some similar material, in quantity sufficient to prevent the soil from washing in and filling up the cavity.

Cheap drains of hemlock boards are found to be very useful for wet lands and can often be obtained when the regular tiles cannot. They are usually less costly and are more quickly laid. Such drains are usu-

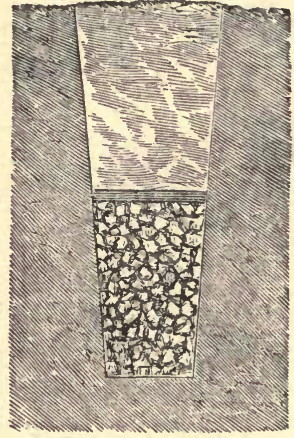

Fig. 2.-RUBBLE DRATN.

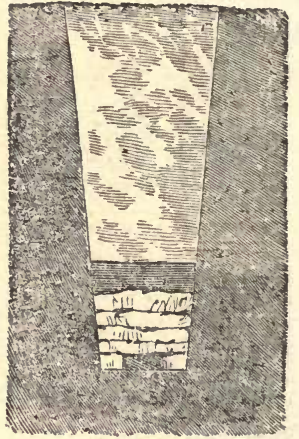

Fig. 3. -FLAT STONE DRATN.

ally made triangular, with three boards three or four inches wide, nailed edge to edge, or the better way is to put the cover on the top of the drain crosswise (fig. 4). This gives more openings through which the water may enter the drain, and also makes them stronger. Where roads cross a drain of this kind, it is safer to make them in this way and also to lay a plank upon the drain to distribute the pressure. Every precaution shouid be taken to have the work of draining thoroughly done. It is costly work, and if one little blunder is made, everything may be spoiled, for a drain 
is like a chain, and if an obstruction occurs it is like a link hroken-the drain is rendered useless, like the chain.

Preparation of the Ground.-Assuming that the ground on which the garden is to be formed is in sod, the best time to begin operations is in September, October, or November. If draining is necessary, that should be first completed. Before the sod is plowed, it would greatly assist its rotting, if horse manure can be obtained, to spread it orer the surface to the depth of two or three inches. In plowing the sod under, care should be taken to have it laid as flat as possible. This can be best done by plowing shallow; and at this time there is no particular necessity for deep plowing. After plowing we

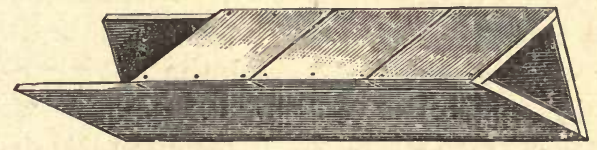

Fig. 4. -BOARD DRATN.

find it advantageous to flatten down the furrows by running over with the back of the common harrow, or, better yet, with the shortened blades of the Acme harrow (see implements). This mellows the soil, so that it fills up the crevices left between the furrows, and hastens the decomposition of the sod. If the plowing has been done early enough in the fall, so that the sod has had time to rot the same season, it will facilitate the operations of next spring to cross plow and thoroughly harrow; but if too late, this had better be deferred until spring. After the ground has been well broken up by this second plowing and harrowing, it should again be manured over the whole surface with rough stable manure, as much as can well be procured-there is rarely danger of 
getting too much-and the third plowing takes place, followed this time by the subsoil plow if time will permit. I have always found it best in breaking in new ground, to crop with Potatoes, Corn, or late Cabbages the first season, unless by preparation in early fall it has acquired the proper mellow state necessary for crops of garden vegetables or small fruits; but it rarely happens that any amount of labor or manuring can so prepare the ground the first season as to bring it to that high degree of tilth necessary for growing garden vegetables as they should be grown, and any attempt to do so will result in a meagre crop, which will not pay-at least in such districts as New York, where there is always abundance of products of the first quality. It must not be expected that the crops of Potatoes, etc., will give much profit for this unusual outlay in preparation and manure, for they certainly will not, and the beginner must be content to wait for his profits until the second season. These are certain to be realized if these preparations have been properly made. Hence will be seen the necessity for capital in this business, for the returus, though highly remunerative, are not always quick. 


\section{H A P'T E R VI.}

\section{MANURES.}

The quantity, quality, and proper application of manures is of the utmost importance in all gardening operations, and few have any conception of the immense quantity necessary to produce the heavy crops seen in our market gardens. Of stable or barn-yard manure, from fifty to one hundred tons per acre is used, and prepared, for at least six months previonsly, by thoroughly turning and breaking up to prevent its heating unduly. The nsual method is to have the manure yard formed in a low part of the garden, but if there is no natural depression, one may be made by digging out an area fifty by one hundred feet and from eighteen to twenty-four inches deep, and enclosing it by a fence abont six feet in height. The wagons are driven alongside, and the green manure thrown into the enclosure, care being taken to have it spread regularly; hogs are usually kept upon the manure in numbers sufficient to break it up, they being fed in part by the refuse vegetables and weeds of the garden.

The manure of horses is most valued, as we consider it, weight for weight, worth about one-fourth more than that of cows or hogs; on stiff soils it is of much more benefit as a pulverizer. There are many articles-the refuse of manufactures-that are still wasted, that have great value as manures. Among others, and of first importance, is the refuse hops from the breweries. It is twenty years ago since they first began to be used in our gardens about New York; at first they were to be had at almost every brewery without cost, but the demand has so increased that the price to-day ranges even higher than that of the best stable manure. Aside from its high fertilizing properties, it is excellent for breaking up and pulcerizing the soil, and as a top-dressing or mulching, 
either to protect from the sun in summer, or from the frost in winter, it has no equal. From my experience with this fertilizer, I consider it to be of nearly double the value of that of stable manure. It requires to be composted in the same manner as other manures; it heats rapidly, and must be either spread regularly orer the hog yard, or else turned once in two weeks to prevent " firefang" from violent heating.

Another valuable refuse from our manufactories is the shavings and scrapings from horn or whalebone manuiactories. 'The best way to render these most available is to eompost them thoroughly with hot manure, in the proportion of one ton of shavings to fifteen of manure; the heated manure extracts the oil from the shavings, which is intermingled with the whole. I have on several occasions seen the mixture of five tons of whalebone shavings with our ordinary stable manure make $\$ 400$ per acre difference in the value of the crop; but of course such manufactories are not common, and it is only in certain localities that this fertilizer can be had.

Another valuable fertilizer from manufactories is "sugar house scum," which is composed largely of blood, charcoal, and saccharine refuse; as it heats violently, instead of being thrown in heaps by itself, it should be composted with equal quantities of soil or muck, and turned frequently, so that the whole is thoroughly mixed ; when thus composted, it makes an excellent manure at twenty tons per acre ; it is best applied by lightly plowing, or deeply harrowing-in.

Of concentrated manures, perhaps the best for general purposes is pure Perurian guano ; this for general crops, when used without the addition of stable manures, is put on at the rate of from 1,000 to 1,200 pounds per acre ; it is first pounded to powder, so that it can be regularly sown over the surface after plowing ; it is then thoroughly harrowed in, and the crop is sown or planted at once. In 
my experience, the next best concentrated fertilizer is bone dust, or flour of bone; in careful experiments with our crops of cauliflower and cabbage, we applied it in the same manner as guano, but at the rate of nearly 2,000 pounds per acre, and it gave most satisfactory results, surpassing those of guano, where that had been used at the rate of 1,200 pounds per acre. In applying manures to the soil, we have long ago discovered the great importance of an alternation of different kinds. When I first began business as a market gardener I had opportunities of getting large quantities of night soil from the scavengers of Jersey City; this was mixed with stable manure, charcoal, sawdust, or any other absorbent most convenient, and applied, so mixed, at the rate of about thirty tons per acre. The crops raised with this mauure were enormous, for two or three years, but it gradually began to lose effect, and in five years from the time we began to use it, it required nearly double the weight of this compost to produce even an average crop. I then abandoned the use of night soil and applied refuse hops instead, at the rate of about sixty tons per acro, with marked improvement; but this was for the first and second years only, the third year showing a falling off. About this time our prejudices against the use of concentrated manures for market gardening began to give way, and at first we applied guano together with manure at the rate of 300 pounds per acre, which we found to pay; and the next season guano was used at the rate of 1,200 pounds per acre with very satisfactory results. Since then our practice has been a systematic alternation of manures, which I am convinced is of quite as much importance to the production of uniform crops of first quality, as is the alternation of varieties of the different kinds of regetables.

It is a grave blunder to attempt to grow vegetable crops without the use of manures of the varions kinds in 
about the proportions I have named. I never yet saw soil of any kind that had borne a crop of vegetables that would produce as good a crop the next season without the use of manure, no matter how "rich" the soil may be thought to be. An illustration of this came under my observation a few years ago. One of my neighbors, a market gardener of nearly twenty years' experience, and whose grounds had always been a perfect model of productiveness, had it in prospect to run a sixty-foot street through his grounds. 'Thinking his land sufficiently rich to carry through a crop of Cabbages without manure, he thought it useless to waste moncy by using guano on that portion on which the street was to be, but on each side, sowed guano at the rate of 1,200 pounòs per acre, and planted the whole with Early Cabbages. The effect was the most marked I ever saw. That portion on which the guano had been used sold off readily at $\$ 12$ per hundred, or about $\$ 1,400$ per acre, both price and crop being more than an average-this was the era of high prices-but the portion from which the guano had been withheld, hardly averaged $\$ 3$ per hundred. The street occupied fully an acre of ground, so that my friend actually lost over $\$ 1,000$ in crop by withholding $\$ 60$ for manure. Another neighbor, whose lease had only one year to run, and who also unwisely coneluded that it would be foolish to waste manure on his last crop, planted and sower all without it. The result was, as his experience should have taught him, a crop of inferior quality in every article grown and loss on his eight acres of probably $\$ 2,000$ for that season. The comparative value of manures must be regulated by the cost. If rotted stable manure, whether from horses or cows, can be delivered on the ground at $\$ 3$ per ton, it is about as valuable for fertilizing purposes as Peruvian guano at $\$ 65$ per ton, or pure bone dust at $\$ 40$ per ton. It is better than either of these or any other concentrated fertilizer, from tho 
fact of its mechanical action on the land-that is, its effect, from its light, porous nature, in aerating and pulverizing the soil. Guano, bone dust, or other fine commercial fertilizers act only as such, without in any way assisting to improve what may be called the mechanical condition of the soil.

All experienced cultivators know that the first year that land is broken up from sod, if proper culture has been given by thorough plowing and harrowing (provided the land is drained artificially or naturally, so as to bo free from water and relieve it from "sourness"), the land is in better condition for any crop than land that has been continuously cropped withont a rest. The market gardeners in the vicinity of New York are now so well convinced of this that when twenty acres are under cultivation at least five acres are continually kept in grain, clover, or grass, to be broken up snccessively every second or third year, so as to bring the land into the condition that nothing else but rotted, pulverized sod will accomplish. This is done in cases where land is as valuable as $\$ 500$ per acre, experience having proved that with one-quarter of the land "resting under grass" more profit can be made than if the whole were under culture.

When the rotation by placing a portinn of the land under grass cannot be done, then it is absolutely necessary to use stable manure, at least to some extent, if the best results are desired, for continuous cropping of the soil. Where concentrated fertilizers only are used, they will not continue to give satisfactory results after the grass roots or other organic matter has passed from the soil, all of which will usually be entirely gone by the third or fourth year after breaking up. I have long held the opinion that the idea of lands having been permanently exhausted by tobacco or other crops is a fallacy. What gives rise to this belief, I think, is the 
fact that when lands are first broken up from the forest or meadow lands, for three or four years the organic matter in the soil-the roots of grasses, leares, etc. - not only serves to feed the crops, but it keeps the soil in a better state of pulverization, or what might be called aerated condition, than when in the course of cropping for a few years it has passed away. Stable manure best supplies this want; but on farm lands away from towns, it is not often that enough can be obtained to have any appreciable effect on the soil, and hence artificial fertilizcrs are resorted to, which often fail, not from any fault in themselves, but from the fact that, exerting little mechanical influence on the land, it becomes compacted or sodden, the air cannot get to the roots, and hence failure or partial failure of crop. Thus we see that to have the best results from commercial fertilizers it is of great importance to have the land rested by a crep of grain or grass every three or four year's.

The best known fertilizers of commerce are Peruvian guano and bone dust, though there are numbers of others, such as fish guano, dry blood fertilizer, blood and bone fertilizer, with the various brands of superphosphates, all of more or less value for fertilizing purposes. It is useless to go over the list, and we will contine ourselves to the relative merits of pure Peruvian guano and pure bone dust. Guano at $\$ 65$ per ton we consider relatively equal in ralue to bone dust at $\$ 40$ per ton, for in the lower priced article we find that we have to increase the quantity to produce the same result. Whatever kind of concentrated fertilizer is used, we find it well repays the labor to prepare it in the following manner before it is used on the land :

To every bushel of guano or bone dust add three bushels of either leaf mold from the woods, well pulverized dry muck, sweepings from a paved street, stable manure so rotted as to be like pulverized muck, or, if neither of 
these can be obtained, any loamy soil will do; but in every case the material to mix the fertilizers with must be fairly dry and never in a condition of mud, the meaning of the operation being that the material used is to act as a temporary absorbent for the fertilizer. The compost must be thoroughly mixed, and if guano is used, it being sometimes lumpy, it must be broken up to dust before being mixed with the absorbent.

The main object of this operation is for the better separation and division of the fertilizer, so that when appiied to the soil it can be more readily distributed. Our experiments have repeatedly shown that this method of using concentrated fertilizers materially increases their value-probably twenty per cent. The mixing should be done a few months previous to spring, and it should, after being mixed, be packed away in barrels and kept in some dry shed or cellar until wanted for use. Thus mixed, it is particularly beneficial on lawns or other grass lands. The quantity of concentrated fertilizer to be used is often perplexing to beginners. We give the following as the best rules we know, all derived from our own practice in growing fruits, flowers and vegetables:

Taking guano as a basis, we would recommend for all vegetable and fruit crops, if earliness and good quality are desired, the use of not less than 1,200 pounds per acre (an acre contains 4,840 square yards), mixed with two tons of either of the materials before recommended. Of bone dust about one ton per acre should be used, mixed with three tons of soil or of the other materials named.

For market garden vegetable crops in the vicinity of New York, this quantity of guano or bone dust is harrowed in, after twenty-five or thirty tons of stable manure have first been plowed in, so that the actual cost of manuring each acre is not less than $\$ 100$, and often $\$ 150$.

When fertilizers are used alone, without being mixed with the absorbent, they should be sown on the soil, after 
plowing or spading, about thick enough to just color the surface, or about as thick as sand or sawdust is strewn on a floor. This quantity is ueed broadcast by sowing on the ground after plowing and deeply and thoroughly harrowing it in ; when applied in hills or drills, from 100 to 300 pounds should be used to the acre, according to the distance of these apart, mixing well with the soil.

When well-rotted stable manure is procurable at a cost not to exceed $\$ 3$ per ton, delivered on the ground, whether from horses or cows, it is preferable to any concentrated fertilizer. Rotted stable manure, to producs full crops, should be spread on the ground not less than three inches thick (our market gardeners use from fifty to seventy-five tons of well-rotted stable manure per acre, when no concentrated fertilizer is used), and should be thoroughly mixed with the soil by plowing.

The manure from the chicken or pigeon house is very valuable, and when composted as directed for bone dust and guano, has at least one-third their value. Castor-oil pomace is also valuable in about the same proportion.

Poudretre is the name given to a commercial fertilizer, the composition of which is night soil, and dried swamp muck or charcoal dust as an absorbent. It is sold at about $\$ 12$ to $\$ 15$ per ton, and at that price may be equal in value, if too much of the absorbing material is not used, to bone dust at $\$ 40$ per ton.

SALT has little or no value as a fertilizer, except as a mcdium of absorbing moisture; for experience shows that soils impregnated by saline matter are no more fertile than those inland out of the reach of such an atmosphere.

Muck is the name given to a deposit usually largely composed of vegetable matter, found in swamps or in hollows in forest lands. Of itself it has usually but little of fertilizing property, but, from its porous nature, when 
dry, it is one of the best materials to use to mix with other manures as an absorbent. It can be used to great advantage if dug out in winter and piled up in narrow ridges, so that it can be partly dried and "sweetened" in summer. Thus dried, if mixed with stable manure, or, better yet, thrown in layers of three or four inches thick in the cattle or hog yard, where it can be trodden down and incorporated with the manure, the value of the manure thus treated will be nearly doubled.

In reply to questions that I receive by the hundred each season, asking whether or not it is worth while to use the so-called special fertilizers claimed to be suited to the wants of particular plants, such as the "Potato Fertılizer," "Cabbage Fertilizer," "Strawberry Fertilizer," "Rose Fertilizer," etc., I can only give this general answer, that while these manures may suit the plants they are claimed to be "special" for, I have little doubt that either one would suit equally well for the others, or if all were mixed together, the mixture would be found to answer the purpose for each kind of crop just as well as if kept separate and applied to the crop it was named for. These hair-splitting distinctions are not recognized to be of any value by one practical farmer or gardener in a hundred; for a little experience soon shows that pure bone dust or well-rotted stable manure answers for all crops nearly alike, no matter what they are. These special fertilizers for special crops are gradually increasing in number, so that some dealers now offer fifty kinds, different brands being offered for plants belonging to the same family. There is an ignorant assumption in this, and any cultivator of ordinary intelligence cannot fail to see that the motive in so doing is to strike as broad a swath as possible, so that a larger number of customers may be reached and a higher price obtained.

One of my neighbors called the other: day and informed me that his Lettuce crop, in his greenhouse, was failing. 
and asked me what I thought of the "Lettuce Fertilizer" that was offered in a circular that contained some fifty other "specials." An inquiry developed the fact that he had been keeping his Lettuce crop at a night temperature of sixty-five degrees in January-ten to fifteen degrees too high for the welfare of the crop-so that there was just about as much chance of the special "Lettuce Fertilizer" helping the crop as there would be of giving health to a man in the last stages of consumption by feeding him beef-steak. I merely mention this incident to show how, and in what manner, the sellers of these special fertilizers obtain customers, even among practical gardeners.

Lime or MarL. - I have always held that lime and marl have no direct fertilizing properties in themselves, except so far as they act to correct the acidity of the soil, or to lighten heavy soils, or to give adhesiveness to soils that are too light. In fact, I believe they are valuable for their mechanical effects on almost every soil, unless such as lie along the sea coast, and in some cases a considerable distance inland ; on such soils there is no benefit to be derived from the application of lime. In applying lime dust-whether from limestone or oyster shellsit should be put on after plowing, at the rate of not less than 100 bushels per acre, and then well harrowed in, so as to thoroughly mix it with the soil for four or five inches below the surface.

Gas Lime is often very liberally offered by the gas companies; it is a dangerous material and had better never be touched by the market gardener. I well remember applying it to a piece of ground, which was so poisoned by the noxious gases that it did not regain its fertility for three years.

Cotton-Seed Meal, mixed with one-third of any high grade of phosphate, is almost exclusively used by the market gardeners of Charleston and Savannah, where 
the mixture costs about $\$ 30$ per ton. Plowed in broadcast, at the rate of from two to three tons per acre, it is believed to be, for that section, the best and cheapest fertilizer of any kind.

Plaster is one of those fertilizers which have a remarkable effect upon some soils, while in other places it has no effect at all. Where the soils are benefited by it, it is of course advisable to use it. Its greatest effect is upon clover, and where clover is used as a means of improving land, plaster is indispensable. It is one of the cheapest of all fertilizers and should by all means be used where it is beneficial.

Wood AsHes are largely used by farmers as a topdressing for meadows, spread on at the rate of fifty bushels per acre. The leached ashes that are brought to New York by the boat load, are sold at from fifteen to twenty cents per bushel, and, of late years, some of our gardeners have been using them instead of bone dust or guano as an addition to stable manure, harrowing them in after plowing at the rate of from 150 to 200 bushels per acre; a lesser quantity (say one half) of unleached ashes would answer the same purpose.

Green Manuring.-The practice of growing crops for the purpose of plowing them under to fertilize the soil is often turned to very great advantage. To procure an adequate supply of manure is often a very costly process. But a crop that may be easily grown in a few weeks, and then turned under, may furnish to the soil as much fertilizing matter as eight or ten tons of manure; and the process may often be repeated two or three times in one year. For instance, if land is plowed in October and sown to rye, the rye may be turned under in May or June, and corn may be planted. This will be in full growth early in August, when it may also be turned under, furnishing ten or twelve tons more of 
valuable matter. In turning under so tall a crop as corn or rye the plow should be run across the rows, and a heavy chain looped from the plow beam, just ahead of the standard, to the land side end of the inner whiffletree. This loop drags in the furrow, so as to catch the falling corn or rye, and pulls it down and into the furrow so that the soil covers it. It should then be smoothed - down with the back of the ordinary harrow or by the shortened blades of the Acme Harrow, so as to fill up the crevices, and thus quickly induce the rotting of the green crop.

\section{H A P T E R VII.}

\section{THE USE AND MANAGEMENT OF COLD FRAMES.}

We use cold frames for preserving Cauliflower, Cabbage and Lettuce plants during the winter, and the forwarding of Lettuce and Cucumbers in spring and summer.

To make the matter as clear as possible, we will suppose that the market gardener, having five or six acres of land, has provided himself with 100 of three by six foot sashes. The Cauliflower, Cabbage, or Lettuce plants, which they are intended to cover in winter, should be sown in the open garden from the 15th to the 20th of September in the latitude of New York; farther north, earlier; farther south, later. This matter of time of sowing is of rital importance; for if too early, many of them will run to seed and of course are useless; again, if sowing is done too late, cold weather sets in and the piants have not time to get strong enough to stand the winter. The Early Jersey Wakefield is the variety used almost exclusively for raising cold frame plants. Our famous "Early Summer Cabbage" is never so safe to 
carry over in cold frames, unless, indeed, it is sown very late; for example, when we sow the Wakefield here on the 15th of September, the Early Summer is not sown until ten or fifteen days later.

Millions of this favorite variety for the South have been lost by running to seed from having been sown too early. On this subject I will give my views at length in another portion of this chapter.

When the young. Cabbage plants are of sufficient size, which they will be in about a month from the time of sowing, they must be repianted in the boxes or frames, to be covered by the sashes as winter advances.

'The boxes or frames we use are simply two boards, running parallel, and nailed to posts to secure them in line. The one for the back is ten or twelve inches wide, and that for the front seven or eight inches, to give the sashes, when placed upon them, pitch enough to carry off rain, and to betrer catch the sun's rays. The length of the frame or box may be regulated by the position in which it is placed ; a convenient length is fifty or sixty feet, requiring eighteen or twenty sashes.

Shelter from the northwest is of great importance, and if the ground is not sheltered naturally, a board fence six feet in height is almost indispensable. 'The sashes should face south or southeast. Each three by six foot sash will hold five hundred plants of Cabbage or, Cauliflower, and about eight hundred of Lettuce. These numbers will determine the proper distance apart for those who have not had experience. It should never be lost sight of that these plants are almost hardy, and consequently will stand severe freezing without injury, but to insure this condition they must be treated as their nature demands; that is, after planting the Cabbage, Lettuce or Canliflower-which will be about the middle or end of October-the sashes need not be put on for a month or six weeks after, unless a rery cold spell comes for a 
day or two, which somctimes happens; but if they have to be thus temporarily protected, be careful to strip off the sashes again, so as to harden the plants for cold weather. In cold weather, even on clear winter days, when the thermometer marks fifteen or twenty degrees in the shade, they must be abundantly aired, either by tilting up the sash at the back, or, better still, when the day is mild, by stripping the sash off entirely. With this hardening process there is no necessity for any other corering but the sash. In our locality we occasionally have the thermometer from five to ten degrees below zero for a day or two together, yet in all our time we have never used mats, shutters, or any covering except the glass, and I do not think we lose more than two per cent., although in sections where the thermometer falls to twenty or thirty degrees below zero, mats or shutters will be necessary. They rarely pass through a winter, however, without having the stems split by the frost, even with us, but that does no injury, provided when planting out in the open field they are so set that the split part is in the ground. Cauliflower is more tender than Cabbage or Lettuce, and the sashes must be covered with mats. Some may think that the raising of plants in this manner must involve considerable trouble, but when they are informed that the Cabbage and Lettuce plants so raised and planted ont in March or April, not infrequently bring $\$ 600$ per acre before the middle of July, giving us time to follow up with Celery for a second crop, it will be seen that the practice is not unprofitable.

But we have not yet done with the use of the sashes ; to make them still available, spare boxes or frames are made, in all respects similar to those in use for the Cabbage plants. These frames should be covered up during winter with straw or leaves in depth sufficient to keep the ground from freezing, so that they may be got at and be in condition to be planted with Lettuce by the end of 
February or the first of March. By this time the weather is always mild enough to allow the sashes to be taken off from the Cabbage and Lettuce plants (if they have been properly hardened), and they are now transferred to the spare frames to cover and forward the Lettuce. Under each sash we plant fifty Lettuce plants, having the ground first well enriched by digging in about three inches of well-rotted manure. The management of the Lettuce for heading is in all respects similar to that used in preserving the plants in winter; the only thing to be attended to being to give abundance of air, and on the occasion of rain to remove the sashes entirely, so that the ground may receive a good soaking, which will tend to promote a more rapid and luxuriant growth.

The crop of Lettuce is fit for market in about six weeks from time of planting, which is always two or three weeks sooner than that from the open ground. The average price for all planted is about $\$ 4$ per hundred at wholesale, so that again, with little trouble, our crop gives us $\$ 2$ per sash in six weeks.

I believe this second use of the sash is not much practiced outside of this district, most gardeners having the opinion that the winter plants of Cabbage or Lettuce would be injured by their complete exposure to the weather at as early a date as the first of March. In fact, here we have still a few old fogies among us, whose timidity or obstinacy in this matter prevents them from making this double use of their sashes, which thereby causes them an annual loss of $\$ 2$ per sash, and as some of them have over a thousand sashes the loss is of some magnitude.

In my own practice $I$ have made my sashes do double duty in this way for fifteen years; the number when I first started being fifty, increasing until at one time I had 3,000 sashes in use. Yet in all that time $I$ have only once had my plants so exposed injured, and then 
only a limited number, which I had neglected to sufficiently harden by airing.

We have still another use of the sashes to detail. Our Lettuce being cut out by middle of Nay, we then plant five or six sceds of the Improved White Spine Cucumber in the center of each sash. At that season they come up at once, protected by the corering at night. The sashes are left on until the middle of June, when the crop begins to be sold. The management of the $\mathrm{Cu}$ cumber crop as regards airing is hardly different from that of the Lettuce, except in its early stage of growth it requires to be kept warmer. Being a tropical plant, it is very impatient of being chilled, but in warm days airing should never bo neglected, as the concentration of the sun's rays on the glass would raise the temperature to an extent to injure, if not entirely destroy, the crop. This third use of the sashes I have never yet made so profitable as the second, because the crop has to compete against Southern grown Cucumbers, although it has always been sufficient to make it well worth the labor.

'There are a few men here who make a profitable business from the use of sashes only, haring no ground except that occupied by the frames. In this way the winter crop of Cauliflower or Cabbage plants is sold at an average of $\$ 3$ per sash in March or April ; the Lettuce at \$2 per sash in May, and the Cucumbers at $\$ 1$ per sash in June, making an average of $\$ 6$ per sash for the season; and it must be remembered that these are wholesale prices, and that, too, in the market of New York, where there is great competition. There is no doubt that in hundreds of cities and towns of the Union the same use of sashes would double or treble these results.

Cold frames are also used for sowing the seeds of Cabbage, Canliflower and Lettuce, instead of hot-beds. If the frames are closely shut up and covered at night by mats, the plants will be but little later than those from 
the hot-beds, and are raised with far less trouble. The time of sowing is about February 1st. In sections of the country where these plants cannot be set out before May it is useless to raise them in hot-beds. On the other hand, in the Southern States, where in the months of February and March there are no frosts, by adopting the same care in covering up at night, the seeds of Tomatoes, Peppers and Egg-plants, and the sprouts from Sweet Potatoes, can be forwarded with much less trouble in the cold frames than in the hot-bed.

I am sometimes asked the question, how much freezing and thawing plants of Lettuce, Cabbages, etc., will stand without being destroyed. I have always taken the ground that the freezing and tharing, instead of being injurious, is a necessity for their safety. In doing so I know I run in direct opposition to a large majority of my brethren, but the experience of over a quarter of a century, yearly increasing in extent, assures me that I am correct, and I am further confirmed in my opinion by knowing that there is not a market gardener in this vicinity but whose practice in the management of cold . frames is the same as my own; though if the question was asked some of them if thawing and freezing did not injure plants, the answer might be in the affirmative, so universally has the dogma been acepted.

Again : "How long ean frozen plants be kept from the light when covered up with snow?" Much would depend on atmospheric conditions. If the plants were hard frozen when the snow covered up the sashes, then they might safely remain three or four weeks thus covered, without light; but if the ground was not frozen when the snow fell, then the snow must be remored from the sashes in three or four days, unless the fall has been so slight that light can get throngh to the plants. 
PROTECTING CLOTH IN LIEU OF SASHES.

In many sections of the country it is difficult to get sashes, and with many, too, their cost is such as to make them unattainable. To such the use of this new protecting cloth will be a great boon, particularly in the Southern States, where only a slight protection is needed to ward off frost for a few nights. In the winter of 1886 millions of Cabbage and Cauliflower plants were lost in Georgia, South Carolina and Florida that might have been saved by the use of this cloth for protection. In our experiments with it the past winter, we found that while the thermometer stood at twenty-five degrees above zero, under this covering the temperature was thirty degrees above zero, while under the protection of sashes it was thirty-two degrees, or but two degrees more. All experienced cultivators know that the difference of five degrees in temperature in most cases would save nearly all the plants exposed in the open air from the danger of injury hy frost. Could the orange trees of Florida the past winter have been enveloped in protecting cloth, I doubt if a bud would have been injured. Of course, in that case, it would have been impracticable to do so ; but it is easily practicable to protect lowgrowing plants, such as Cabbage plants or fruiting Strawberry crops. A gentleman from Florida told me last winter that he has repeatedly saved his crop of Strawberries-covering an acre while in bloom-from early frost, by the use of ordinary cotton cloth, thereby vastly increasing the value of his crop. This protecting cloth, while being no cheaper than ordinary grades of cotton cloth, has the advantage in being so prepared that it is mildew-proof, and with ordinary care will last for five years. It is made in yard widths and can be shaped for use according to circumstances. Probably the simplest plan is to tack it to a light frame three by six 
feet and use it just as sashes are used. Such "sashes," made of protecting cloth, would cost not more than twenty cenls each, while glass sashes cost (to say wothing of expense in freighting) $\$ 2$ each. Besides, in the hands of inexperienced cultivators, the protecting cloth is safest, for if this covering is left on in the day-time when the sun is shining, there is comparatively little rise of temperature underneath it, while it is well known that if ventilation of flames covered by glass sashes is not carefully attended to, the crop beneath may be quickly ruined by the sun's rays acting on the glass and raising the temperature.

The past spring (beginning about middle of March), we covered a lot of Cabbage plants with the protecting cloth for three weeks-never once taking it off night or day-and the plants were nearly as good as those covered by sashes, where daily attention had been given to ventilation. Not only will this cloth be found most useful in the winter in the Southern States, to guard against sudden snaps of frost, but to such as raise spring plants of Cabbages, Lettuce, Cauliflowers or Tomatoes, requiring protection in spring at the North, it will be found an excellent substitute for sashes. I do not recommend the use of the protecting cloth in lieu of sashes in the winter months; it would not answer in heavy snow. But for all spring work, from March to June, it will in most cases answer every purpose.

\section{SPRING RAISING OF CABBAGE, CAULIFLOWER AND LETTUCE.}

The question is put to me many hundreds of times every season as to what is the best method to produce plants of Cabbage, Cauliflower and Lettuce for early spring planting. Although we still grow several hundred thousands of fall sown plants annually (which are wintered over in cold frames), yet increased experience 
appears to show that plants grown in the manner below described, which we have practiced for the past five years, can be done cheaper, and, at the same time, will produce nearly as good plants as by the old method of wintering over in cold frames.

For our latitude, we make our first sowing on February 1st in our greenhouses, where the temperature will average about seventy degrees; that is, about sixty degrees at night, and about eighty degrees during the day. Where there is not the convenience of a greenhouse, a hot-bed will answer the same purpose. A hot-bed, made with manure, about two feet deep, in a proper manner, produces just about the same temperature and general conditions as will a well-appointed greenhouse. We find it more convenient to sow the seed in shallow boxes, which are made by cutting the ordinary soap boxes into three pieces, which gives us a depth of about two inches for soil in each box. We tise any light, rich soil for the purpose, sowing enough seed in each box to produce 1,000 or 1,500 plants, or, if grown in the hot-bed without the box, each three by six foot sash should grow about 5,000 plants ; but we find it more convenient to use the boxes than to sow in the soil put direct on the bench of the greenhouse, or on the manure of the hot-bed. The plants sown on February 1st, in a temperature averaging seventy degrees, will give plants fit to transplant in about three or four weeks. We then use the same shallow boxes, putting in the bottom of each about one inch of wellrotted stable manure. Orer that we place an inch of any ordinary light, rich soil, smoothing it so as to have it as level as possible. In these boxes, which are fourteen by twenty inches, we put an average of about 150 plants. The boxes are then taken direct to the ordinary cold frames, which, however, have been protected with manure, as it would not do to put the boxes of tender plants on a frozen surface. It is very easy to keep the frost 
out of these cold frames by putting on three or four inches of dry leaves or manure before the soil freezes up, and placing the sash on the frames two or three weeks before they are to be used. In this way they will keep perfectly free from frost, and can be used at any time during the winter. The boxes should be placed as close to each other in the cold frames as they will stand; about eight boxes fills a sash, thus holding about 1,200 plants. If the sun is bright, it is well to shade them for a few days until they take root; but the most important point of all is to cover the sashes with straw mats at night so securely that no frost will reach them in the cold frames. For the past three years we have each season grown about half a million of Cabbage, Cauliflower and Lettuce plants in this way, and have had no trouble to keep them from freezing by carefully matting up, even when the thermorneter has reached zero.

Plants sown on the 1st of February are transplanted into the boxes about the 1st of March, and are at once placed in the cold frames, and will be fine to transplant to the open ground any time after the 1st of April if they have been carefully attended to by watering, airing and protection from frost. As I have before said, these dates refer particularly to the vicinity of New York City, where we can usually plant out in the open ground all kinds of Cabbage, Cauliflower and Lettuce plants about April 1st. If in districts where they cannot be planted nut sooner than the middle of April, then the sowing should not be made before the 15th of February, and the process of transplanting, etc., gone through as before stated, so that the plants will be in condition to set in the open ground by the 15th of April. If in sections where Cabbages cannot be planted in the open ground before the 1st of May, then the sowing should be delayed until nearly the 1st of March, and the process of transplanting in the frames the same. There are some sec- 
tions in the Southern States, of course, where these directions would not apply, where the sowing would need to be done as early, perhaps, as the 1st of December; and as it takes about two months from the time of sowing until they are fit to plant in the field, plants sown the 1st of December in Southern States would be fit to set out by February 1st. It will be understood that there would be no necessity for sowing in hot-bed or greenhouse in such a climate as Florida. The protection of glass in an ordinary cold frame would give about the same average of temperature there in the winter months as we would have in the north by artificial heat. In most of the Southern States, in my opinion, the protecting cloth before alluded to would answer all the purposes of glass sashes-and even in the North, when mats are used, "sashes" made of protecting cloth might be used instead of glass. There is another and simpler process of raising Cabbage plants; that is, by sowing the seed in the cold frames direct. This is done here usually about the 15th of February or 1st of March, in as warm and sheltered a place as can be found for the frames. I saw one of my neighbors have a fine lot grown in that way last year. He had taken a crop of Head Lettuce out of his frames about the 15th of February, dug and raked the ground and sowed his Cabbage seeds in rows about five inches apart, sowing enough to give about 1,500 plants under each three by six sash. He matted up carefully, giving ventilation to the sashes whenever the weather would permit, and about the 1st of April he had fine plants, fit to go into the open ground right from where they were sown; not quite so good, of course, as if they had been transplanted, but still much better than the ordinary hot-bed plants, which are generally too much drawn and too tender to stand cold weather until quite late in the season. If care is used to so cover up these cold frames when the plants 
have been transplanted in the boxes, or sown as described abore, there is hardly a chance but that excellent plants will be produced, as there is far less risk in the handling of them than those from the hot-bed. A very important point to always observe is, to cover them so that the frost will not get to them. In some sections it might be necessary to use a light shutter placed over the sash, and then throw over them the heary straw mats, at the same time covering up the alleys between the frames to the top of the board with dry leaves or ordinary stable manure, so as to prevent the frost striking through the boardis into the plants. It is difficult to explain these operations as clearly by writing as we would like, and if any of our customers would take the time to come and see our operations when we are at work, during the months of February or March, they can get a better knowledge by seeing them done on the spot. Our greenhouses and grounds are within forty minutes' time of our store, at Nos. 35 and 37 Cortlandt Street, New York, and if any one wishing to see our operations will call there, they will be giren a card giving directions how to reach the place, which is located on the Jersey City Heights, two miles from the Jersey City Ferry. 


\section{CHAPTER VIII.}

\section{FORMATION AND MANAGEMENT OF HOT-BEDS.}

Although we do not consider hot-beds so convenient or even economical in the long run as the forcing-houses, elsewhere described, yet, as beginners in the business are usually not over-supplied with means, and as hot-beds are to be had at much less first cost than the forcing-houses, we give a description of their formation and management. The most convenient sash for the hot-bed is the three by six foot sash, made out of one inch and a half pine, costing here, at present prices, when painted and glazed, from $\$ 2$ to $\$ 3$ each, according to quality.

The frame for the hot-bed is usually made movable, in lengths which three sashes will cover, making, when complete, a box-like structure, nine feet long (the wia th of three sashes, three feet wide), and six feet wide (the length of the sashes); at the bottom or lower part the plank should be fifteen or eighteen inches high; the back or top, twenty-four inches; so that when the sashes are placed on, it will give them the necessary angle to receire the sun's rays and throw off the rain. The sashes should be made as tight fitting as they will easily work, and the plank forming the sides of the box should be high enough to cover the thickness of the sash, in order to prevent the cold air from penetrating. The hot-bed (formed on the surface) on which the frame and sashes are placed should not be less than four feet in depth of hot manure, and should project beyond the frame-work at least twelve inches on all sides; that is, if the three sash-frame work measures six feet by nine, the hot-bed on which it is to be placed should be made eight feet by eleven. 'This is one style of hot-bed frame, and the one most commonly used in private gardens; but in our market gardens, where a large surface is used, our necessities compel us 
to adopt a far more economical mode, both in the cost of the frame-work and heating material. This is done somewhat after the manner adopted for cold frames. Parallel excavations are made, usually in lengths of sixty feet, two and a half feet deep, and six feet wide; the sides of these pits are boarded up with any rough boarding, nailed to posts, and raised above the surface eighteen inches at the back and twelve inches at front. Strips are stretched across, on which the sashes rest, wide enough to receive the edges of the two sashes where they meet, and allow of a piece of about an inch in width between them, so that the sash can be shoved backward and forward and be kept in place in giving air, etc.

The heating material to form the hot-bed should be horse dung, fresh from the stables, adding to which, when accessible, about one-half its bulk of leaves from the woods. The manure and leaves should be well mixed and trodäen down in successive layers, forming a conical heap, large enough to generate fermentation in severe winter weather. Care must be taken that the material is not allowed to lie scattered and get frozen, else great delay will ensue before heat can be gencrated. A few days after the pile has been thrown together, and a lively fermentation has taken place, which will be indicated by the escape of steam from the heap, it should be again turned over and carefully shaken out, formed again into a pile, and left until the second fermentation occurs, which will be usually in two or three days. It may now be placed in the pit, or on the surface for the hot-bed already alluded to, being regularly beaten down by the back of the fork, and trodden so that it is uniformly of the same solidity, and to the required depth, two and a half feet. The sashes are now placed on the frames and kept close until the heat rises; at this time a thermometer, plunged in the heating material, should indicate about 100 degrees, but this is too hot for almost any reg- 
etable growth, and besides the rank steam given out by the fermentation should be allowed to escape before operations of sowing or planting begin. Beginners are very apt to be impatient in the matter of hot-beds, and often lose the first crop by planting or sowing before the violent heat has subsided, which it generally will do in about three days, if the heating material has been sufficiently prepared. As soon as the thermometer in the frame recedes to ninety degrees, soil should be placed on to the depth of five or six inches. This soil must be previously prepared, of one-third well-rotted manure (or, if procurable, rotted refuse hops from breweries), and two-thirds good loam, spread regularly over the surface of the manure in the hot-bed.

We use hot-beds for various purposes. One of the most important uses is the forcing of Lettuce; this is planted in the hot-beds (from plants grown in the cold frames), fifty under each sash, the first crop by second week in Jannary ; it is covered at night by straw mats, and is usually marketable by the first of March. At that season Lettuce is always scarce, and will average, if properly grown, $\$ 6$ per hundred, or $\$ 3$ per sash. The crop is cut out by the first week in March, giving plenty of time to plant the same bed again with Lettuce; but now it is no longer a hot-bed, for by this time the heat from the dung is exhausted, and it is treated exactly as described in the chapter on Cold Frames.

Another use for the hot-bed is the raising of Tomato, and Egg, and Pepper plants. The bed should be prepared for these not sooner than the second week in March, with the temperature about the same as before described. In sowing, it is well to cover the seed, not more than a quarter of an inch, with some rery light mold ; nothing is better than leaf mold and sand, patting it gently with the back of the spade. From the time the seed is sown, attention to airing, during the hot part of 
the day, and covering up at night, is essential, and also that the soil be never allowed to get dry. Water, however, must be applied with judgment, as there is just as much danger from soaking the soil too mich. Water should be applied with a fine rose watering pot, and if the water is heated to a temperature of eighty or ninety degrees, all the better. The temperature at night may range from fifty-five to sixty-five degrees, and during the day from seventy to eighty degrees. As soon as the seedling plants are an inch or two high, which will be in four or five weeks, they must be taken up and re-planted in a more extensive hot-bed, for they now require room. Tomatoes should be planted of a width to give serentyfive or 100 in each sash. Pepper and Egg Plants do better if planted in small flower pots (three-inch), as they are more difficult to transplant; they may now also be kept a little closer in the hot-bed than the Tomatoes, as they require more heat. After transplanting, great care is necessary that they always be immediately watered, and shaded from the sun until they have struck root, which will be in two or three days after transplanting.

The hot-bed is also the medium for procuring us Cabbage, Cauliflower and Lettuce plants for early outside planting, when not convenient to winter them over as described in the uses of cold frames. The seeds of these are sown about the last week in February, are treated in all respects as regards covering up at night as the Tomatoes, etc., but, being plants of greater hardiness, require more air during the day. They will be fit to plant in the open garden by the middle of April. The beds they are taken from are usually employed for re-planting 'Tomatoes, which it is not safe to plant in the open ground here before the middle of May. A more detailed account of how to raise Cauliflower and Lettuce plants will be found in the Chapter under that head. 
Sweet Potato plants are almost universally raised in hot-beds; but, as this is a plant that luxuriates in a high temperature, the hot-bed shonld not be formed to start them until the middle of April. The soil should be a mixture of sand and leaf mold, laid on of the usual thickness on the hot-bed, six inches. The roots are placed close together, and the same sandy compost sifted over them to the depth of twa inches. Some split the large ones lengthwise and place them flat side down. They should not be watered until they start to grow. They are fit to plant out about six weeks after starting.

Two most essential points in working hot-beds are in covering up at night and in giving air during the day. It often happens that a few mild nights in Mareh or April delude us into the belief that all the cold weather is over, and the covering up is in consequence either carelessly performed or abandoned. Every season shows us scores of victims to this mistake, who by one cold night lose the whole labors of the season. It is always safest to cover up tender plants, such as Tomatoes, Sweet Potatoes, etc., until the 10th of May in this latitude, and the more hardy plants, such as Cabbage, to the 1st of April, when raised in hot-beds. Even if there is no danger from freezing, it will give a more uniform temperature, and consequently conduce to a more healthy growth. The want of close attention in airing is equally dangerons. Often an hour's delay in raising the sashes will result in the scorching up of the whole contents of the hot-bed, and irregularity of airing will always produce "drawn" and spindling plants, even when they are not entirely killed. The thermometer is the only safe guide, and should be regularly consulted, and whenever it indicates seventy-five degrees, it is safe to admit more or less of the outer air, proportioned of course to the condition of the atmosphere. If there be bright sunshine and cold wind, very little will suffice; if calm, mild, and sunny, 
admit larger quantities. If the days are warm, say sixty in the shade, in March or April, the sashes covering Cabbage, Cauliflower or Lettuce plants may be stripped entirely off, and also from 'Tomatoes in April and May when the thermometer is at seventy degrees in the shade, covering up at night, of course.

Coverings for Protection Against Frost.-To cover up hot-bed sashes we use either light pine shutters or straw mats. 'The shutters are made the exact size of the sash. There is no necessity of their being more than

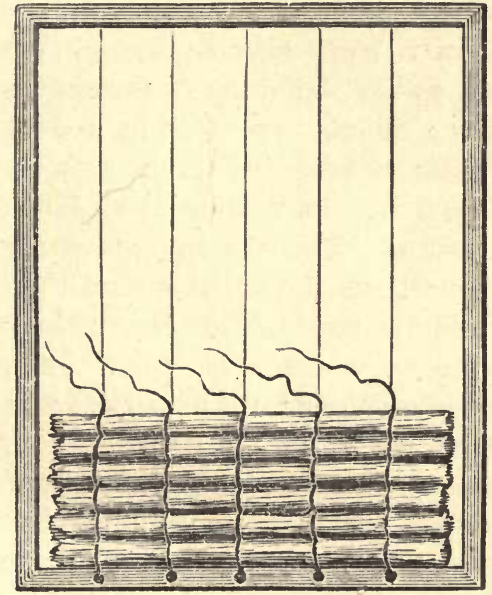

Fig. 5.-MAKING A straW-Mat.

half an inch in thickness, as that is quite as effective in keeping out the cold as two inches would be, and they are much cheaper and more convenient to handle. Straw mats are, however, by far the warmest covering, and in hot-bed culture are almost indispensable. They are always made at home, during wet days or in stormy weather in winter. The manner of making them is very simple,

* and will readily be learned at the first attempt. The 
"uprights" or warps are formed of five strands of a tarred string known as "marline." 'These are tightly strained ten inches apart by being attached to five strong nails at bottom of a wall, corresponciing with the same number seven feet from the bottom. Against these strings (beginning at the bottom) are laid small handfuls of rye straw, the butt ends out, as long and straight as can be procured. This is secured to the uprights by a lighter kind of tarred string by taking a single turn around the upright and the straw, and so continued until the mat is finished. Some use a frame to which the strings forming the warp are attached, as shown in figure 5. This allows the operator to have his work upright or horizontal, as may be most convenient. 'Two workmen will make about five mats in a day. When finished, the mats should be seren feet in length and four and a half feet in width, two being sufficient to cover three sashes. The reason for having them made one foot longer than the sash is that there may be six inches to overlap at top and bottom, which are the most necessary points to secure from frost. In making these mats they may be constructed of sedge from the marshes or salt meadow hay when rye straw cannot be procured. It is important, however, that they may be made as light as possible, one inch in thickness being quite sufficient. By care in handling them, these mats will last for six or eight years. 


\section{H A P T E R I .}

\section{FORCING-PITS OR GREENHOUSES.}

In another chapter it will be found that we now recommend using wider greenhouses with fixed roofs for growing vegetables, but as many have loose sashes that they may wish to utilize in constructing greenhouses, we will still retain the description given in the earlier editions of this work.

Forcing-pits and greenhouses of the style about to be described, whenever the greater expense in their erection is not a consideration, are, in our experience, far superior, and in the course of five or six years more economical for all purposes of forcing or forwarding vegetables than the hot-bed or cold frame. Figure 6 represents the end section and ground plan of the style we have in use, and which may be adapted to any plant that requires artificial heat and protection of glass. The pits represented by this plan are 100 feet in length, and each eleven feet wide inside. The heating is accomplished by one of Hitching's patent boilers, $C$, heating about 1,200 feet of four-inch pipe. The glass roof, $E$, is formed of portable sashes, six by three feet. Each alternate sash is screwed down, the others being movable, so as to give adundance of air. The movable sash is elevated, to admit air, by a flat iron bar fifteen inches long, attached to the sash by a staple. Into this bar is punched three holes, so as to regulate the admission of the air as required. When the sash is shut down the bar is hooked on to a pin which secures it in place, so that the sash cannot be moved by wind. I am thus particular in describing what may seem a simple matter, but this system of airing is not common, and we made some stupid blunders before we hit on our present plan, which is cheap, simple 


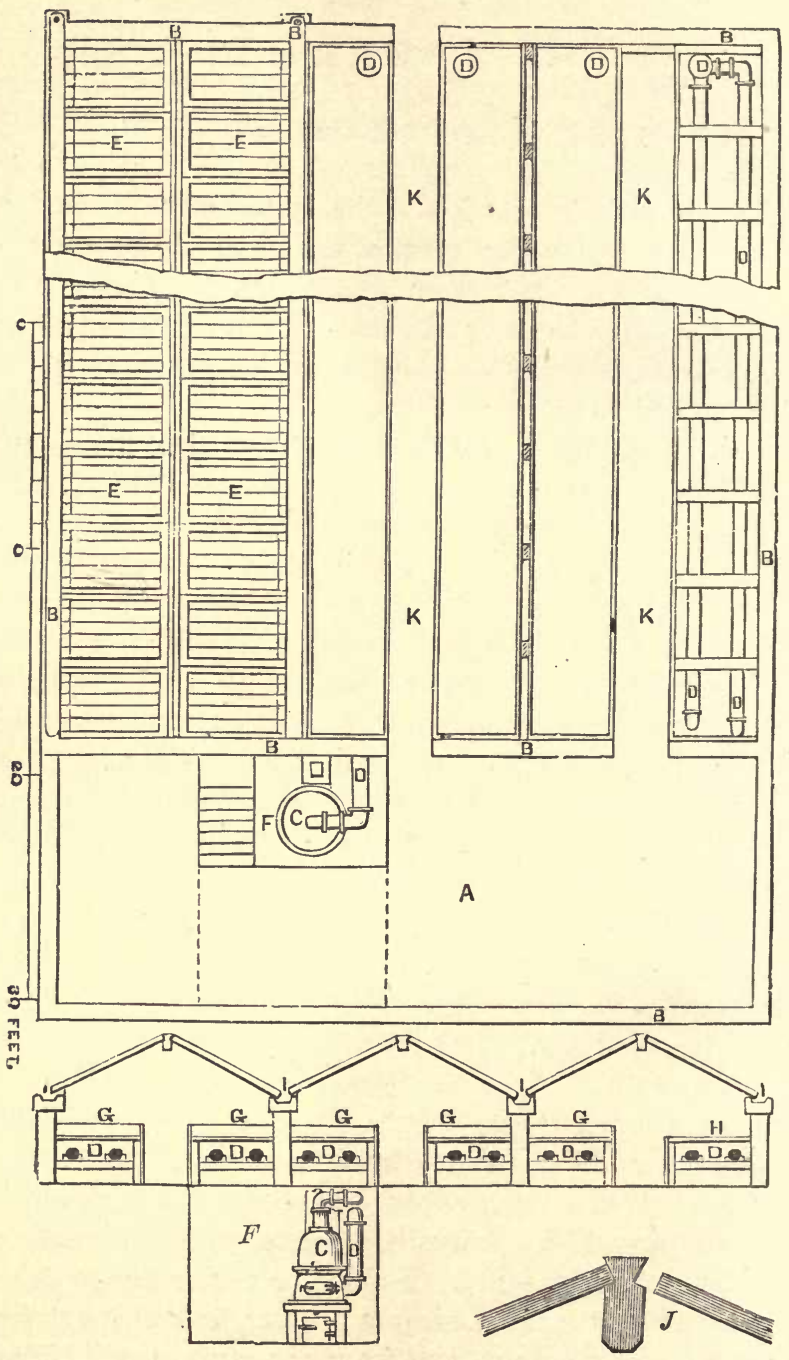

Fig. 6.- END SECTION AND GROUND PLAN OF FORCING-PITS HEATED BY WATER PIPES. 
and very effective. The movable sash is not hinged at the bottom, but is held in place by two small plates of iron screwed on the gutter plate. The ridge-poles are cut out of the shape shown at $J$, and the sashes lie on the shoulder. The interior arrangement of the pits will be easily understood by the end section. $G$ shows the bench or table as it is completed, which is filled with five or six inches of soil, in which the Lettuce, etc., are to be grown. This shows the boxing-in of the pipes, $D$, to give "bottom heat" to the cuttings, seeds or plants that are placed on the bench; but on the sides of the bench, along the walk, one plank is hinged throughout the house, so that it may be let down when required and permit the escape of heat into the greenhouse. The walks through the house, $K$, aire two feet wide. A brick shed, $A$, covers the boiler-pit, $F^{\prime}$, and is attached to the north end of the pits. Besides breaking the wind at this vulnerable point, we find this shed a most excellent place for many purposes, as it is kept from freezing by the heat that escapes from the boilerpit, which would otherwise be lost. This heat may be turned to a very profitable account in forcing Mushrooms or Rhubarb, if desired for that purpose.

The system of attaching three pits together is now almost universally adopted by commercial gardeners in all houses erected during the past twenty-five years in the neighborhood of New York ; it has great advantages over the detached system, being less expensive in heating, more saving of space, and, above all, far more economical in cost of construction. I prefer having only three together, for the reason that when we have the snow to clear away it is quickly done by being shoveled from the two valleys or furrows over the ridges; althongh we have one grower in this neighborhood who has twelve connected houses, and finds but little trouble with snow. Our snows being mostly from the north, the shed breaks 
them off in a great measure, and what blows over blows mostly off through the valley between the sashes. The water from the gutter is led into a cistern, at the south end of the greenhouses, of a capacity of not less than 3,000 cubic feet - if 5,000 , all the better ; to this is connected a Douglas Force Pump, figure 7, with 150 feet of one and a half inch hose, and to the end of the hose is attached a heary sprinkler. One man pumps, and another regulates the water and sprinkles it over the plants. My establishment in 1866 contained over an acre of glass, and yet, by this labor-saving arrangement, all the plants were thoroughly drenched with watcr by two men in four hours. Befure adopting this method of watering, at least four of the hands were employed the whole day during the spring months in watering, and then the work was not done half so well. There is nothing that I have ever done, connected with horticultural operations, that has been so entirely satisfactory as this 
method of watering. Now, 1886, we are fortunate enough to have the city water, and can drench four acres of plants grown under glass in ten hours.

In these pits may be propagated and grown Roses and all kinds of greenhouse and bedding plants of every description, in the best possible manner. But as our present purpose is only with vegetables, I will endeavor to describe our mode of operations with some of these. Lettuce, from the great quantities consumed in all large cities, is now, and will be likely to be, one of the most profitable vegetables to force, for the reason that from its soft and bulky character it cannot be so safely or cheaply shipped from the South as many other kinds of regetables. We begin, for our first crop, by sowing the seed about the 20th of August, in the open ground, of the Boston Market, Black-Seeded Butter and Curled Simpson sorts, using by far the greatest proportion of the first named, as it forms a solid head quicker and can be planted closer. These are planted on the benches of the forcing-house in five or six weeks after, at about six or eight inches apart each way, on well enriched soil, placed on the benches to the depth of five or six inches. At this season no "forcing" is requirer, and the sashes should be kept raised to admit air, night and day, until frosts begin to be severe; then they should be shut up at night, but no fire heat should be applied until the weather has been severe enough to indicate thirty-eight or forty degrees inside the pits, and even then very slightly, for if they can be brought to maturity at this season without the temperature exceeding fifty degrees at night (by fire heat), the crop will be all the better. The great thing in forcing all plants of this hardy nature being to avoid a high temperature, the temperature when steady firing is begun in the winter months, should average fifty degrees as near as possible.

Of late years, Lettuce plants, when grown under glass, 
have occasionally become affected by a species of mildew or rust, which, beginning in the center of the plant, quickly spreads over the whole and destroys it. I am not certain of the cause and can offer no cure-except to advise that great care should be taken to have the plants grown freely and without any sudden check by chilling or by the extremes of drouth and moisture. We find in the culture of plants under glass that some species are particularly sensitive to such checks-some varieties of the Rose, for instance, if, when in a particular condition of growth, the temperature for a few hours is reduced from sixty-five to forty degrees at night, or if a frosty southeast wind is allowed to play on the leaves for even ten minutes, or if allowed to dry so that the plant wilts, mildew will to a certainty be developed in twenty-four hours. The Verbena, Heliotrope and Petunia, when subjected to ill usage, become badly rusted. Therefore, I am inclined to think that the Lettuce disease is also caused by some ill usage at some period of its growth, for we find that it is rarely seen when the crop is grown in the open ground in spring or summer. The preventive suggested is that plants to be forced should be prepared so carefully that no sudden check is given, and also that the soil used on the benches be fresh, and the manure used be thoroughly rotted and well mixed through the soil.

To Check the Aphis or Greenfly. - Fumigating with tobacco should be done twice each week, beginning the very day the plants are planted in the bench. In fumigating we use refuse tobacco stems, about two pounds (dry) for every 1,000 square feet of glass, damping, however, before using, so as to get the greatest amount of smoke. For fuller particulars on this head see chapter on "Wide Greenhouses for Forcing Vegetables."

The first crop is ready about Norember $1 \mathrm{st}$, and is cut off and sold in two weeks; the soil on the benches is 
slightly manured, dug up, and again planted (from plants sown in cold frames, or in boxes in the same pit) about September 20th. 'This second, or' winter' crop, requires more attention in growing, both in firing, watering, and airing, as it matures about January 1st, and consequently has had to be cared for during a cold part of the year. The third crop, treated exactly as the second, is planted as soon as the other is cut off, and matures about April 1st. We now vary the use of the pit, by planting at distances of about three feet apart along the center of the bench, plants of the White Spine Cucumber, from seed sown about April 1st, in a corner of the pit that has been kept closer and warmer than that for the Lettuce; these are planted in pots about three inches in diameter, and by the time the benches are cleared in May are fine strong plants, that give a full crop during the month of June-fully a month sooner than from the open ground. The combined value of these four crops will average abont $\$ 400$, for a structure 100 feet in length by eleven feet in width. The estimated expense of cultivation is :

Interest on $\$ 700$, cost of construction, at 10 per cent. $\$ 70.00$

Coal, five tons.

Labor, Manure, etc .

Receipts

Net Profit

$\$ 200.00$

These forcing-pits are likewise used for starting seeds of Tomato, Egg, Pepper, Cabbage, and Cauliflower, and sprouting Sweet Potatoes, which is done with far less risk and in a much better manner than can be accomplished by the hot-bed. One great advantage is, that by being able to walk inside of them, these pits are accessible in all weathers, while with the hot-bed or frames we are in winter often debarred from examination for whole days together. 
At present prices, in this locality, these pits cost about $\$ 7$ per lineal foot, everything complete, put up in the way indicated by the plan in a plain substantial manner. But those whose circumstances do not admit of the expense of heating by hot water (which is nearly half the cost of the whole), may put up structures of exactly the same character, and heat them by the common smoke flue at an expense of from $\$ 4$ to $\$ 5$ per lineal foot, in the manner shown by the plan, figure 8 . It will be seen by this sketch that two flues only are used for the three pits, each passing first up under the bench on the outside houses, is carried along the end and returned through the middle houses; this equalizes the temperature in all three, for the outside houses get only one run of the flue, but it being directly from the fire gives about the same heat to the outside houses as two runs in the middle house, which, being a greater distance from the fire, are much colder. Three attached houses, heated thus, should not be over fifty foet long in this latitude. Southward they may be sixty feet and northward forty feet. Peculiarities of locality have much to do with the heating; in positions particularly sheltered from the northwest, the same amount of flue will heat sixty feet quite as easily as in exposed places it will heat forty. The proper way of constructing the furnace and flue is of importance enough to require a description, which is given at length on page $8 \%$ As far as possible, let the instructions there given be followed to the letter, as they are such as long and very extensive experience in the use of flues for greenhouse heating has shown to be such as rarely fail to give the very best results. 'Twenty-five years ago nearly all the greenhouses used for commercial purposes were heated by flues. In my own practice I used no other mode of heating until 1860, and grew plants quite as well there as we do to-day. One of the largest rosegrowing firms in this country still uses flues only, with 
FORCING-PITS OR GREENHOUSES.
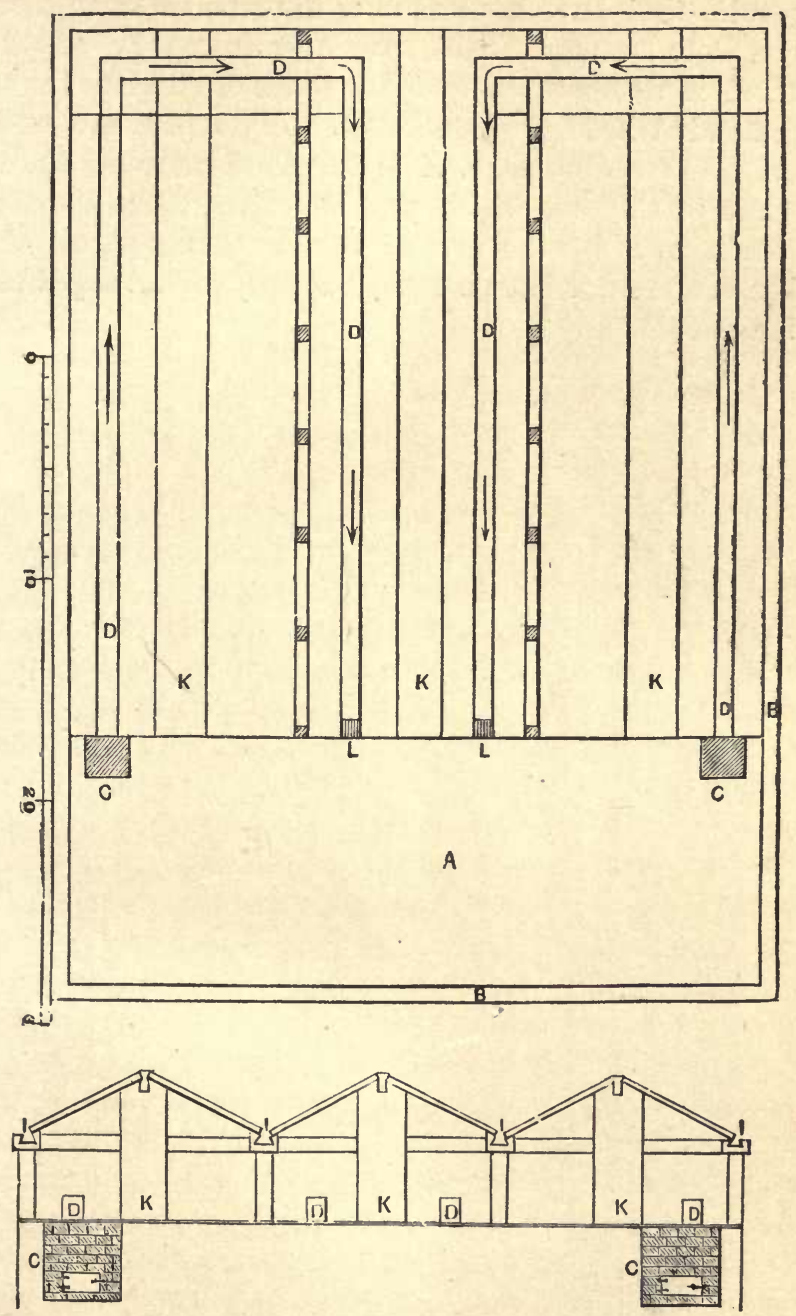

Fig. 8. -END-SECTION AND GROUND PLAN OF FORCING-PITS HEATED BY FLUE. 
results that have been such as to make their business a complete success. Still, whenever it can be afforded, there is no question that hot water or steam is the best method of heating greenhouses. In the plan and section on the preceding page, $A$ is the shed enclosing the furnaces, $C C$, from which pass the flues, $D$, in the direction shown by the arrows to the chimneys, $L$. The benches are not shown here, but they are arranged as in figure 6 . 


\section{CH A P T E $\mathrm{X}$.}

\section{WIDE GREENHOUSES FOR}

\section{FORCING VEGETABLE CROPS.}

Since "Gardening for Profit" was first written, larger experience has shown that greenhouse structures for forcing vegetables cannot only be erected cheaper when made twenty or twentytwo feet wide, instead of ten or eleven feet as then in use, but from the larger volume of air they contain, which when once heated better resists the cold outer air, less artificial heat is necessary. So well convinced were we of the advantages of the wider structure, that six years ago we removed all our old eleven foot houses (covering nearly an acre in glass) and replaced them with greenhouses averaging twenty feet wide by 100 feet in length. John Hudson, of Jersey City, New Jersey, one of the most successful of all our market gardeners in the vicinity of New York, constructed, the past season, six greenhouses, each 150 feet long by twenty-two feet wide, plans of which are given in figures 9 and 10. The cost of these greenhouses complete, with ventilating apparatus, heating, benches, etc., was about $\$ 10,000$,

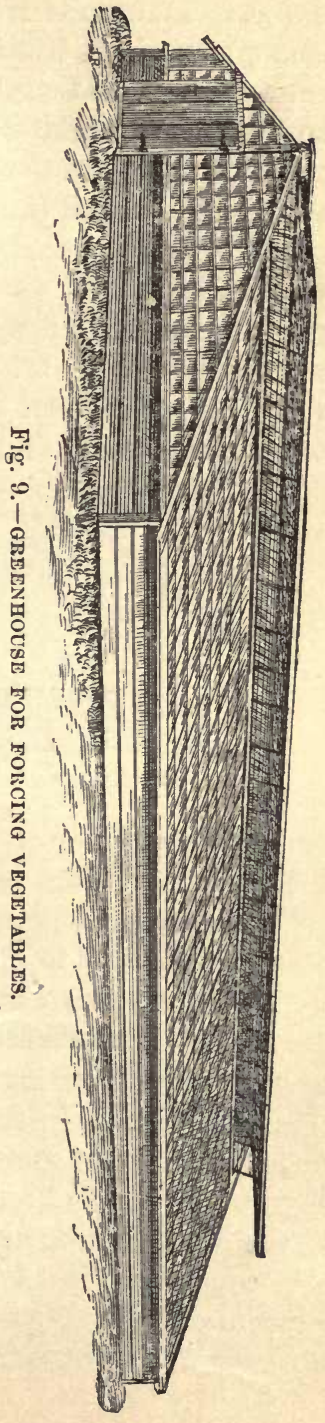


or about $\$ 10$ per running foot. The structure is very simple. The walls front and rear are constructed of cedar posts, about five to six inches in diameter, placed four feet apart and sunk three feet in the ground. On the outside of these are nailed rough hemlock boards, against which a layer of asphalt or tarred paper is tacked, over which is nailed the ordinary weather boarding. Such a wall will resist cold better than an eight-inch brick wall, and will last twenty-five years if kept painted. A very common error is to build the wooden wall of a greenhouse hollow and fill the space with sawdust. This should never be done, as it is more expensive, and is by no means so good as the plan here given. It will be

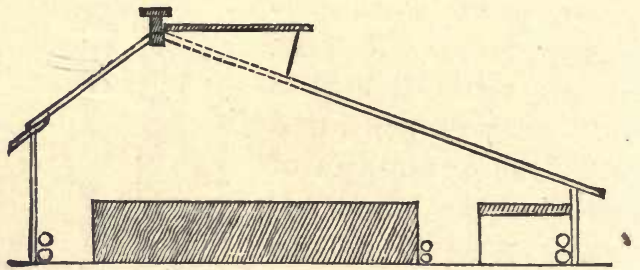

Fig. 10.-CROSS-SECTION OF FORCING-HOUSE.

seen by the engraving, figure 10, that these greenhouses of Mr. Hudson's are heated with hot water, the six O's in the engraving representing six runs of four-inch pipe, which is sufficient to give a night temperature of fortyfire or fifty degrees when the thermometer is ten below zero, which is a sufficient night temperature in the winter months for growing such crops as Lettuce and Radishes. Of course in the day-time, when the sun shines, the temperature of such a house will run fifteen or twenty degrees higher; and ventilation should not be given until the temperature reaches seventy degrees. The great point to be considered in forcing crops of Lettuce or Radishes in greenhouses is, if possible, not to let the night temperature exceed fifty degrees. Of course this cannot be helped 
in the fall months, when the temperature outside is often much higher than fifty at night ; but in such cases, during the months of October and November, the ventilating sashes should be left up so as to keep the temperature at night as low as practicable. Often the entire first crops of Lettuce are lost for want of this precaution. Further experience has also taught us the necessity of using glass of a larger size. The size most used is twelve by sixteen, put in the twelve inch way. The object of the larger glass is to obtain the greatest amount of light. In glaz-

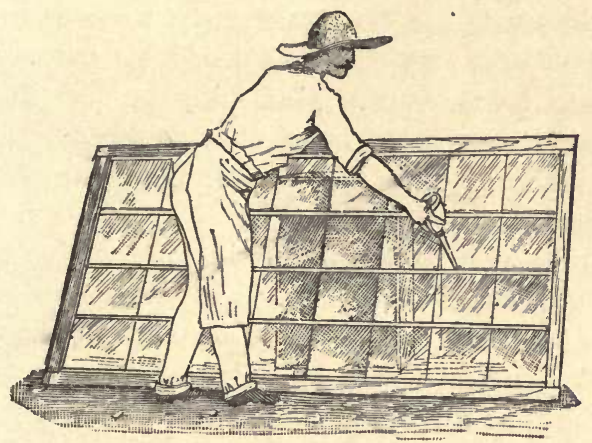

Fig. 11.-IMProved METHOD OF GLAZING.

ing, the method now almost universally adopted is to bed the glass in putty and tack it on the upper side with large glazing points, using no putty on top. The glazing points are triangular, one corner of which is turned down, so that when it is driven in it fits against the lower edge of each pane and prevents it from slipping down. A great mistake is often made in giving the glass too much lap. It should just be given enough to cover the edge of the pane below from one-eighth to one-quarter of an inch. If given much more the water gets between the panes and when it freezes cracks the glass.

It has been found that wher the glass lies on the sashbars thus imbedded, the putty soon rots or wears out, 
and water gets in, and not only loosens the glass, but rots the bar as well. A most simple plan to obviate this is to pour along the junction of the bar with the glass a thin line of white lead in oil, over which is shaken dry white sand. This hardens and makes a cement that effectually checks all leakage. It is quickly done. The engraving, figure 11, shows how the portable sash is held and the application made from the oil-can containing the thin white lead. I have seen glass so cemented that has stood for ten years still in perfect order, and it looked as if it would stand for ten years more without further repair. This plan, which is but little known as yet, is of the greatest importance. Had I known of it thirty years ago, I would have saved many thousands of dollars in repairing, besides having the plants under this water-tight glazing in better condition.

It will be seen that two of the hot water pipes are placed under the front bench. The other four are placed two on each walk. The front bench, four feet wide, is constructed so that it will hold five or six inches in depth of soil; but the middle or main bench, which is thirteen feet wide, requires to be walled up to a height of two feet (see plan) and filled up to the top with soil. The soil best fitted for the growing of Lettuce is five parts good, strong, fresh loam to one part well-rotted cow dung. I will give, as nearly as I can, our manner of operating. The first sowing of Lettuce (which is mainly the Boston Market variety), made in the open ground about the 20 th of August, will be large enough to be set in the greenhouse benches (at six or seven inches apart each way), by the 20th of September, and will without fire heat give fine heads by the first of November. For the second succession, sowings are still made outside about the 20th of September, to replant the space where the first crop has been cut out by the first week in November. As the season is now getting colder the crop planted by the first 
of November will not be fit for market until about the Christmas Holidays, at which time it usually sells well. For the third crop, to be planted in January, the plants made by the sowing on the 20th of September should be used. This crop, which has to be grown in midwinter, will not be ready, if planted the first or second week in January, until about the first of April.

One of the greatest pests in growing Lettuce is the Green Fly or Aphis, and the remedy must be preventive, for if it once gets a foothold on the growing plant, it cannot be destroyed. From its operations being mainly on the under side of the leaves, nothing can reach it; consequently every insect must be destroyed before planting. Tobacco in any form is destructive to it. So before planting let the surface of the soil be sown over with tobacco dust, and also let the young plants be rinsed in water wherein tobacco stems have been steeped long enough to give it the color of strong tea. By using these precautions there is little danger that the Lettuce will be attacked by the insect, although, as a further measure of precaution, it will be well to strew the paths with refuse tobacco stems, which will make a complete antidote against the Aphis. There is another disease often affecting Lettuce, with which, however, it is not so easy to cope. It is first seen by the leaves hardening and spotting brownish red, theu gradually decaying towards the center of the plant until it partly destroys it. The cause seems to be anything that gives the plant a check -any too sudden change of temperature, too much dryness or too much moisture. There is, I think, no remedy after the disease has once started, so our efforts must be for prevention. (See page 68).

Mr. Hudson has used some of his greenhouses for growing the Early Round Dark Red and the SmallTopped Forcing Radish, which he finds better suitable for forcing than any other. These are first sown about the first week in October, succession sowings being 
made on the same ground as each crop is marketed, which, according to the season, is from four to six weeks from the time of sowing, five crops usually being obtained by the middle of May. The seed is sown thinly in rows three or four inches apart, and the radishes thinned out when an inch high to two inches between the plants. After a crop of early Lettuce and Radishes has been marketed (about the middle of March), the benches are often planted with Snowball Cauliflower at twelve or fourteen inches apart each way, which is marketed about the end of May, or two weeks before the outdoor crop is ready. Another, and very often profitable, use is made of these forcing greenhouses by packing large clumps of roots of Rhubarb or Asparagus, lifted so as to leave the soil still adhering to the roots. These clumps can be set as close as they can be packed, about the middle of December, under the front bench, as they require no light, and will be found to be very profitable, the only cost being the roots, which can easily be raised, where ground is plentiful, in the open field, by sowing the seed in rows eighteen inches apart, and thinning out to a foot between the plants. It requires three years, however, to grow roots of Rhubarb large enough to force, and four years for Asparagus. There are often cases where old beds must be removed, where the roots, instead of being thrown away, would give, by being closely jammed together under a greenhouse bench, a product of about fifty cents per square foot, if sold any time before April.

It is not easy to estimate the profits on such an investment in forcing greenhouses for vegetable crops, as so much depends on what the market demands. Of course, all the products in such a market as New York are sold at wholesale, and not infrequently pass through several different hands before reaching the consumer; but even thus sold, it is safe to say that, with fair arerage culture, such crops at wholesale rates will pay a clear net profit of 
thirty per cent. annually; while there is but little doubt that if the consumer could be reached direct, at least twice that amount could be realized.

The business is a particularly pleasant one, and is a great advantage, in all respects, over the hot-bed system, as one has complete control over the greenhouse temperature, both hy night and by day, if the heating and ventilating apparatus have been properly constructed. These greenhouses are also well adapted for raising all kinds of vegetable plants. For the past six years nearly all our Cabbage, Cauliflower, Lettuce and Tomato plants have been raised in such greenhouses at far less expense than in the old-fashioned hot-beds. When the expense of hot water apparatus cannot be entertained, the same style of greenhouse can be heated by the horizontal smoke flue, costing little more than half as much as the hot water apparatus, as the latter is about one-half of the entire cost of the construction of such houses.

\section{FORCING CUCUMBERS.}

The wide greenhouses or forcing-houses, which we have described as being used by Mr. Hudson for forcing Lettuce, Radishes and Cauliflower, can also be made equally available for forcing Cucumbers, either during the entire winter and spring season, or to be used to succeed the last crops of Radishes or Lettuce in spring. If wanted for the forcing of Cucumbers during the fall season, the seed should be sown in the greenhouse about October 1st in small pots, three or four seeds in each, thinning out to one strong plant. These, in thirty days, will have become sufficiently strong to plant out at twenty to twenty-four inches apart on the south side of the bench, one row only. A trellis of galvanized iron wire is made with about a nine-inch mesh, diamond shaped. This, on the middle bench, should be kept two feet from the glass, but on the front bench it can only be kept one 
foot from the glass, owing to its nearness to the sashes. The depth of soil should be, if on raised wooden benches, about five or six inches; if on the solid center bed, eighteen inches to two feet. The soil should be a sandy loam, with one-fifth well-rotted cow manure. The night temperature in the forcing-house for the fall, winter and spring months for cucumbers, should range as near as possible from sixty to sixty-five degrees, with a temperature on bright days of from ten to fifteen degrees higher, giving ventilation at all reasonable times. Cucumbers delight in a moist atmosphere, and whenever the weather is bright and clear, water should be sprinklod on the pipes, walks and under the benches. A dry atmosphere is certain to develop the Red Spider, which is fatal to success. It may also be here stated,-if Cucumbers are to be; forced during the winter months, that to keep up the necessary high temperature eight runs of four-inch pipes will be required in a greenhouse twenty feet wide, instead of six, as recommended for Lettuce and Radishes, though, when grown only to succeed the Lettuce or Radish crop in spring, which is usually the case, the six runs of pipes at that season will be sufficient.

Although there is no necessity for artificial impregnation of the Cucumber flowers when grown in the open air, where the insects and winds do the work, yet, when grown in the forcing-house, it is absolutely necessary, particularly in midwinter. This is best done with a camel's hair pencil, by detaching the pollen, or fertilizing dust, from the stamens and applying it to the stigma. It will also facilitate impregnation on bright days to slightly jar the wire trellis, so as to let the pollen loose, which, in floating through the air, fastens on the stigma. Cucumbers from seed sown in October will give a continuous crop until June- of course, if well handled. When wanted only to succeed crops of Lettuce or Radishes in spring, the seed should not be sown until February or 
March. The variety for forcing which seems to be most favorably received in our markets is "Selected Early White Spine," though, of late years, the beantiful long kinds, such as "Telegraph" and "Rambler," which are almost exclusively used in Europe, are beginning to be farorably received. Forced Cucumbers from December to May average, for best quality in the market of New York, $\$ 6$ per dozen, and, if the forcing is well done, this price will be found to pay very well. Southern competition, of course, seriously interferes with the forcing of cucumbers, as it does with nearly everything else in early vegetables and fruits ; but, like hot-house grapes, the bloom and fine appearance, together with the more delicate flavor, of the forced Cucumber, finds customers in all large cities who are willing to pay for the finer quality.

FORCING STRAWBERRIES.

The wide greenhouses, already described as being suitable for forcing Lettuce and Radishes or Cucumbers, are equally adapted, with slight modification, for the forcing of Strawberries. This modification is in having the benches or tables raised, so as to be as near the glass as it is practicable to have them, as shown by the sketch, figure 13, of end section annexed. It is also necessary that eight runs of four-inch pipe are used instead of six, as are in use for Lettuce and Radishes, as Strawberries require a somewhat higher temperature. The proper preparation of the plants for Strawberry forcing is indispensable to success. This is best done by layering the runners in small pots, as described under the head of Strawberry Culture. The layers may be placed in the pots at any time from the middle of July to September 1st. When the pot is filled with roots (which will be in about two or three weeks from the time the Strawberry runner is placed in it), it is then taken up and shifted into a four-inch pot in soil four-fifths turfy loam to one- 
fifth rotted cow dung, to which may be added a slight sprinkling of pure bone dust-say a handful to every bushel of soil.

When the strawberry plants have been shifted from the pots in which they were layered, into the four-inch size, they should be set in the open sunshine, standing the pots close together, and carefully watered as occasion requires, so as to induce the best possible growth. All runners should be carefully pinched off as they appear, so that the whole force of the roots may go to develop the main plant, or fruiting crown, as it is sometimes called. In four or five weeks the four-inch pots will be filled with roots, and the plants must again be shifted into six-inch pots and treated as before, which will give, by the middle of October, the necessary strong plants for forcing. As the season of growth stops about this date, water should be withheld to some extent, so that the plants may get a season of rest.

When they are placed in the forcing-house they may either be planted out on the benches at six or eight inches apart, in soil five or six inches deep, or they may be forced in the pots, as may be desired, but, in any case, twice as many plants should be prepared as will fill the house, for, if desired, two crops can easily be raised in succession. The first plants should be placed in the forcing-house about November 1st; these will produce marketable fruit by January or February. Plants put in in February will be ready by March or April. Of course, it will be necessary to keep the reserve plants of strawberries in a dormant state, which is best done in cold frames or pits, the pots being plunged up to the rims in dry leaves.

The best rule to follow in forcing any plant, is to keep as near as possible to its natural condition. We know that as the Strawberry plant develops its leaves and flowers throughout May in this latitude in the open ground, 
that the night temperature will average, perhaps, forty degrees for the first two weeks in May and fifty degrees for the last weeks, while for the first two weeks in June it will be about sixty degrees at night, and in all cases from ten to fifteen degrees higher in the day. This, then, is our rule for the forcing-houses: Start slowly, increasing the temperature as the plant develops and ripens its iruit, just as nature does in the field.

Like Cucumbers, artificial impregnation is necessary for the Strawberry in the dull winter months. This is best done by using a camel's hair pencil, twirling it from one flower to another-particularly from the staminate to the pistillate flowers-on clear days if possible, and allowing all possible ventilation. Sometimes hives of bees are kept in Strawberry and Cucumber forcing-houses, to assist in the impregnation.

Some judgment is necessary in watering until there are indications of vigorous growth. Water at the roots sparingly; at the same time, do not allow the soil to get too dry, and be careful not to water the plants overhead when in bloom, as that will destroy the impregnation. When the fruit has "set," give water freely whenever necessary, and throughout the whole season of growth keep the atmosphere of the house well charged with moisture, in order to keep down the Red Spider, the insect which is quickly destructive to both Strawberries and Cucumbers.

The kinds of Strawberries which seem to have been the favorites for forcing are the Champion, a rather dark crimson berry of great beauty and of the largest size, with occasional trials of Jersey Queen, on account of the great size and beauty of the fruit. But the new variety, raised by Mr. Seymour, of Norwalk, Conn., and named in our honor, "The Henderson," from trials made with it, is likely to prove the most valuable variety for forcing purposes. It has what are known as "perfect flowers," and 
hence is certain to "set" fruit. It is of the largest size, of beautiful form ; color, a rich shade of scarlet crimson, the surface looking as if varnished. In flavor it is unsurpassed by any known variety, besides having a rich and powerful aroma ; these peculiarities make it specially attractive-a necessity for forced strawberries when retailed at about fifty cents a berry, for in the winter months, it must be remembered, they sell at wholesale at $\$ 6$ per quart, and it takes only eighteer to twenty large berries to make a quart.

To our rural readers this extraordinary price paid for fruit may seem incredible, but all large cities contain people who are rich enough to afford these prices, not only for fruits but for flowers, for it is no unusual thing for $\$ 1$ and even $\$ 2$ to be paid for single rosebuds of the rarer or finer sorts. At the same date that forced Strawberries are selling in New York at $\$ 6$ per quart, or forced Cucumbers at $\$ 6$ per dozen, both Strawberries and Cucumbers grown in the Sonthern States, are selling at onesixth these prices, but the quality, of course, bears no comparison with the forced commodities. We have never ourselves forced either Strawberries or Cucumbers for market, but quite a number in the vicinity of large cities make it a profitable business. In fact, there is comparatively little difference in the profits of forcing-houses, no matter whether they are devoted to growing vegetables, fruits or flowers; they pay well for the investment in all cases if the work is well done.

\section{HEATING BY FLEES.}

For beginners with small means, when personal attention can be given to the fires, by heating greenhouses with flues a great saving in cost can be made-in fact, nearly half the cost of construction; for we find that the hot water heating apparatus is usually half the cost of ordinary commercial greenhouses, while if heated by flues 
the cost of these would not be mole than ten per cent. of the whole. A new method of constructing flues (or rather a revired method, for it originated in 1822,) has been in use for the past few years, which has such manifest advantages that many now use it who would no doubt otherwise have used lot water heating. Its peculiarity consists in running the flue back to the furnace from which it -starts and into the chimney, which is built on the top of the furnace. As soon as the fire is lighted in the furnace, the brick-work forming the arch gets heated, and at once starts an upward draft, driving out the cold air from the chimney, which puts the smoke flue into immediate action and maintains it ; hence chere is never any trouble about the draft, as in ordinary flues which have the chimney at the most distant point from the furnace.

By this plan, we not only get rid of the violent heat given out by the furnace, but at the same time it insures a complete draft, so that the heated air from the furnace is so rapidly carried through the entire length of the flue that it is ncarly as hot when it enters the chimney as when it left the furmace. This perfect draft also does away with all danger of the escape of gas from the flues into the greenhouse, which often happens when the draft is not active. Although no system of heating by smoke flues is so satisfactory as by hot water, yet there are hundreds who have neither the means nor the inclination to go to the greater expense of hot water heating, and to such this revived method is one that will, to a great extent, simplify and cheapen the erection of greenhouses. Many old-established florists, who have had the old plan of flues in use, have changed them to the one here described, and with great satisfaction. The wonder is that such an important fact has been so long overlooked, for at the time it was discovered, heating greenhouses by flues was almost the only method in use.

Figure 12 (scale, one-eighth of an inch to the foot), 

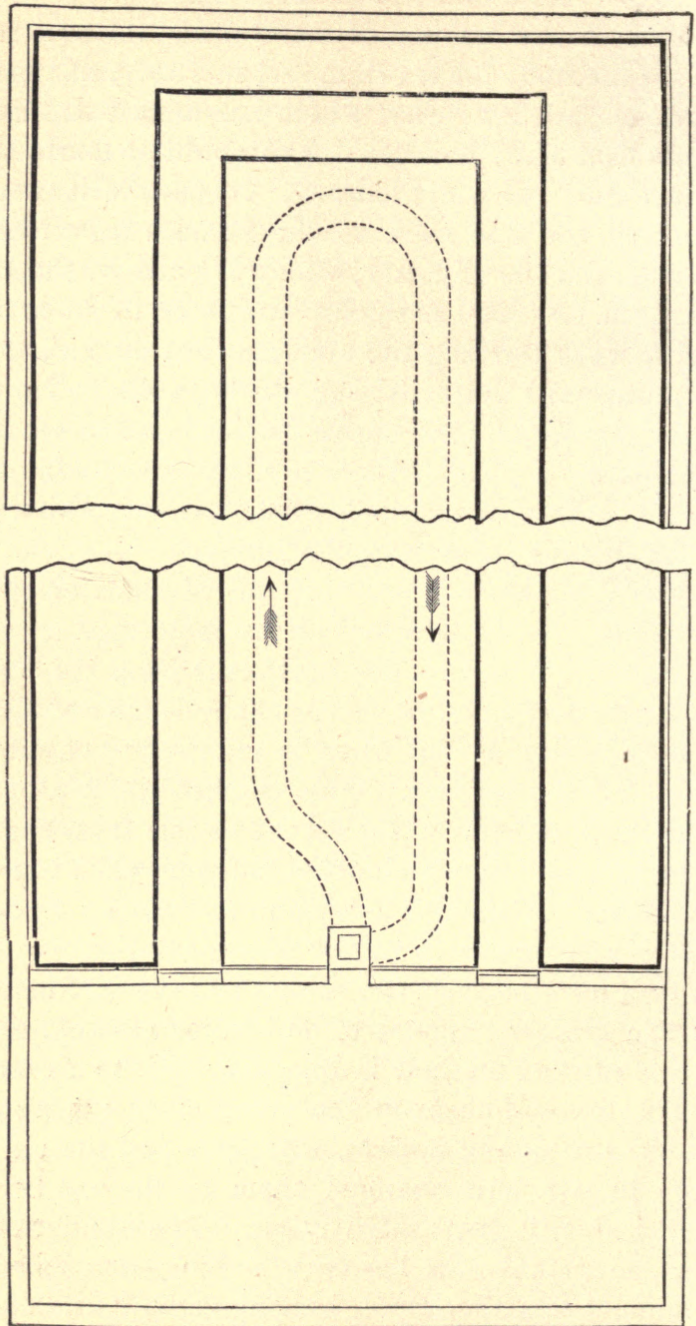

Fig. 12.-HOUse heATED BY FLUE. 
shows a greenhouse twenty feet wide by fifty feet long, with furnace-room, or shed, ten by twenty feet. Here the flues are so disposed as to avoid crossing the walks, being placed under the center bench, but as near as possible to the walk on each side, so that the heat may be evenly diffused throughout. If a difference in temperature is required in a house of this kind, it may be obtained by running a glass partition across the house, say at twenty-five feet from the furnace end, which will, of course, make the latter end the hottest. It will be

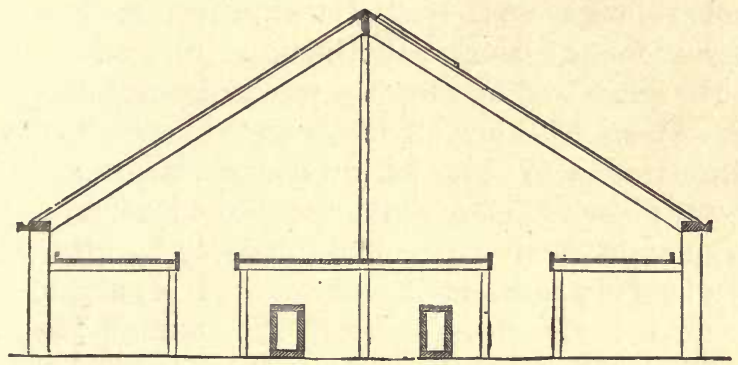

Fig. 13. - END-SECTION.

observed that the plan (figure 12) shows by dotted lines this new or revived plan of flue heating. Figure 13 (the same scale) is a section, showing the arrangement of the benches, etc.

In constructing the furnace for flue heating, the size of the furnace doors should be, for a greenhouse twenty by fifty, about fourteen inches square, and the length of the furnace bars thirty inches; the furnace should be arched over, and the top of the inside of the arch should be about twenty inches from the bars. The flue will always "draw" better if slightly on the ascent throughout its entire length. It should be elevated, in all cases, from the ground on flags or bricks, so that its heat may be given out on all sides. The inside measure of the brick flue should not be less than eight by fourteen 
inches. If tiles can be conveniently procured, they are best to cover with; but, if not, the top of the flue may be contracted to six inches, and covered with bricks.

After the flue has been built of brick to twenty-five or thirty feet from the furnace, cement or vitrified drain pipe, eight or nine inches in diameter, should be used, as they are not only cheaper, but radiate the heat quicker than the bricks; they are also much easier constructed and cleaned. Care should be taken that no wood-work is in contact with the flue at any place. It may be taken as a safe rule that wood-work should in no case be nearer the flue or furnace than eight inches. In constructing do not be influenced by what the mechanics will tell you, as few of them have had any experience in such matters, and are not able to judge of the dangers resulting from wood-work being in close contact with the heated bricks.

The cost of such a greenhouse, twenty by fifty feet, heated by flue, when built alone, would be, at present prices in this vicinity, about $\$ 12$ per running foot, or $\$ 600$; but if three were built together, connected at the gutters, and thus save the outer walls, as shown in the chapter on Forcing Pits and Greenhouses in another part of this book, the cost of construction for three houses heated by smoke flues would not exceed $\$ 10$ per running foot, or $\$ 1,500$ for three houses each twenty by fifty feet. 


\section{H A P T E R X I.}

\section{SEEDS AND SEED RAISING.}

If there is one thing of paramount importance in vegetable gardening it is purity of seed; and for this reason the seed offered by seedsmen should be tested not only for its germinating qualities, but for its genuineness of kind. The test of germination is easy enough, and there is rarely any trouble with that; but to be certain that the variety is true to its kind, is a matter requiring time and a knowledge of varieties.

In our own practice no important seeds, such as Melons, Cucumbers, Cabbages, Cauliflowers, Lettuce, Celery, Radishes or Beets, are ever sold until tested in our 'Trial Grounds, consequently they are never sold until they are a year old, or after we have had an opportunity to prove, beyond any question, that they are genuine or true to their kinds. But as all these seeds are just as good four or five years old-some of them really better-this want of "freshness," as some might term it, is no disad vantage whatever. It is quite a common practice for market gardeners to purchase from $\mathrm{ns}$, when they are pleased with some special strain of seed, as much of it as they will use for three years, so as to be certain beyond doubs that they have the kind they want.

Thirty years ago the market gardeners grew nearly all their own seeds, as in those days we had hardly any seedsmen that knew anything about varieties, and consequently the market gardeners dared not risk their crops in buying from them. I remember on one occasion the seed crop of our indispensable Wakefield Cabbage failed with nearly all of us. There was only one man among us who had had foresight enough to have a two years' supply ; I offered him $\$ 50$ per pound, but could not pro- 
cure an ounce from him, and as no one cared to risk the seed stores in those days for Wakefield Cabbage seed, he had the whole field to himself. He planted nearly ten acres with this variety, which coming in some eight or ten days earlier than anything else, he made a little fortune by his being able to have a monopoly of the seed. That is now over thirty years ago, but I have never known a Jersey gardener to be out of Wakefield Cabbage seed since, and not know where to get it. Before we adopted the system of proving seeds in our Trial Grounds, we often suffered severe losses. I remember once getting from one of my neighbors-a market gardener-a pound of what he honestly thonght was Silesia Lettuce, but which proved to be Curled India. I used it for planting in my forcing-frames, which resulted in nearly an entire loss of the crop. The India Lettuce is a summer variety, maturing in the hottest weather, and consequently almost useless for forcing. This blunder entailed on me a loss of over a thousand dollars. A year or two ago, we imported from England 500 pounds of one of the leading kinds of Celery, from a source that in twenty years had always proved to be correct. Our Trial Ground test showed it to be worthless, as it was lank growing and hollow stemmed; had we not put it through the crucial test of our Trial Grounds, we would have spread serious disaster among hundreds of our market garden customers.

There is but little new to say of the manner of raising seeds; the importance of selecting the purest specimens of each variety, and of keeping plants that are of the same families apart as far distant as the limits of the ground will admit, is now well understood. It is not practicable, however, to raise all the seeds wanted in our vegetable gardens in our climate, and consequently we have to rely on importation for seeds of Broccoli, Cauliflower, some varieties of Cabbage, Radishes, Peas, etc. 
But the great majority of seeds used are raised here, our climate being particularly well adapted for maturing them. In the raising of market vegetables, near large cities, the usual practice is for each grower to grow only a few varieties, and these of the sorts most profitable to his location or soil. For example, we of New Jersey, in the immediate vicinity of New York, grow Beets, Cabbages, Cauliflowers, Cucumbers, Lettuce, Radishes and Turnips as a first crop, followed by Celery, Thyme, Sage, Broccoli and late Cabbage as a second crop; but in the more southern counties of the State, where crops mature ten or twelve days earlier, but the distance greater from market, the bulkier and cheaper articles are not grown, and only the more portable and (when early) valuable kinds are raised, of which Tomatoes, Melons, Peas, Kidney Beans, Early Turnips and Beets are the staple articles.

Seed growing, as practiced by market gardeners, is on much too small a scale to make it profitable; in fact, there is hardly a seed raised, but costs much more than what it can be purchased for from the seedsmen. Seedsmen are supplied by regular seed growers, who make a special business of it; they are located in nearly every State in the Union, as the proper geographical distribution of where seeds are grown, is found to be of the first importance; tropical seedis, such as Melons, Cucumbers, Egg plants, and Tomatoes, doing better in higher temperatures, while Cabbages, Peas, etc., do better in colder latitudes. California is becoming an important seed growing State, its climatic conditions being favorable for nearly all kinds of seeds. Seed growers, as a whole, are a highly responsible class of men, who thoroughly understand the business, and are now successfully competing with the English and French growers, from whom, only a few years ago, nearly all our seeds were imported. By being able to get the seeds grown in our 
own country, we are able to supervise the growing of them, and, consequently, the risk of error in getting spurious or inferior varieties is now very small indeed. Hence there is now no necessity for the market gardeners to grow their own seeds, when they can be confident of getting what they want from the seedsman at half the price at which they can be grown by the market gardener; for while the seedsman contracts for tous, raised with all the appliances for saving seed in the best manner, the market gardener can only grow a few pounds on his usually limited area. As a result of the market gardeners growing their own seeds, may be mentioned the fact that the Chinese gardeners in California, by reason of saving their own seeds, have let varieties so run down as to be hardly recognizable as the best types as now grown by our best Eastern market gardeners. However, no gardener should risk his crop without testing the seed, unless he has implicit confidence in the sourco from whence it has been purchased.

It will be understood that of all annual plants, such as Beans, Corn, Cucumbers, Egg Plants, Lettuce, Melons, Peas, Radishes, Tomatoes, etc., the seed is saved the season of planting, and should be always taken from those first maturing, if earliness is an object. The seeds of biennial vegetables, such as Beets, Carrots, Celery, Cabbages, Onions, Leeks, Parsley, Parsnips, etc., are raised by selecting the best specimens from those preserved over winter, planting them out in good soil on the opening of spring, at distances such as are recommended for their growing.

Duration of Germination in Seeds.-There are very few seeds that will not germinate as freely the second year as the first, if properly kept in a cool place, and not exposed to either a too drying or too damp an atmosphere. With the exception of Parsnips, Onions and Leeks, I would just as confidently sow seed two 
years old as when fresh gathered; but there is a limit to the vitality of seeds, varying much in the different families.

Among those only safe for two years are : Beans and Peas of all kinds, Peppers, Carrot, Corn, Egg Plant, Okra, Salsify, Thyme, Sage, and Rhubarb.

Those safe for three years: Asparagus, Endive, Lettuce, Parsley, Spinach, and Radish.

Those safe for five years: Broccoli, Cauliflower, Cabbage, Celery, and Turnip.

Those possessing the greatest vitality are: Beet, $\mathrm{Cu}$ cumber, Melon, Pumpkin, Squash, and Iomato; the time ranging from six to ten years.

Market gardeners find this knowledge very valuable; for example, in procuring the stock of a seed known to be good, of a variety that does not seed the season it is marketable, such as Broccoli, Cauliflower, Cabbage, or Celery, we procure enough to last at least two seasons. The first season only a little is sown, to test the merit of the variety, for we are never incautious enough to risk a full crop with one experiment. If it proves valuable, we have enough in reserve to sow for a full crop, knowing that it is sure to germinate. This was particularly the case with our New Dwarf Celery. On the recommendation of a friend I imported ten pounds of the seed, but, doubtful of kow it would suit our market, only as much was sown as would furnish a few hundred plants. These showed so much superiority, in all respects, to the tall varieties that we had been growing, that the following season I put in half my crop with the dwarf seed. 'T'he thing was entirely new in our market, and so much superior that it sold for prices that would seem incredible. My ten pound bag was not half exhausted, and the next season I planted my whole crop, fourteen acres, containing nearly half a nillion roots, and made 
one of the best hits I ever made in gardening. But by this time my neighbors began to take an unusual interest in my Celery crop, and I could monopolize the variety no longer. 'The originator of our New White Plume Celery, which will be described elsewhere, made an equally good hit before his neighbors waked up to the importance of its merits.

A frequent source of complaint is the fact of seeds failing to germinate during long continued dry weather, and it is very important that the gardener should always apply common-sense to his work, and not simply follow routine, for what will suit for one condition of soil or atmosphere would be unnecessary, or even wrong, for arother. I will give a case to illustrate. About the fifth of May of 18\%1, I sowed a large patch of open ground with Celery seed, and another with Cabbage seed. The soil was in fine order, and the beds, after sowing, were raked-the Celery with a fine steel rake, the Cabbage with a large wooden rake, which covered the seed of each to the regular depth. The weather was dry, with indications of its continuing so, and after sowing I had both the Cabbage and Celery beds rolled heavily, leaving, however, a strip of each unrolled, so that I could clearly show to some of my young men what the result of this omission would be if dry weather continued. Had a heavy rain fallen within a day or two after sowing, it would have compacted the soil and produced the effect of rolling it. But we had no rain for three or four weeks, and a burning-hot atmosphere, passing through the shallow, lcose covering of the seeds, shriveled and dried them up so that it was impossible they could ever germinate. This little experiment resulted exactly as any one having experience in seed-sowing knew it must; our crop of Celery and Cabbage plants were as fine as need be on the rolled bed, while not one seed in a thousand of the Celery, and not one in 
a hundred of the Cabbage started in the strips where the soil was left loose.

In the sowing of Cauliflower, Cabbage, or Lettuce in September, the same precaution had better be used. But in small beds, such as are usually taken for these, if a roller is not at hand, after raking the beds the soil should be firmly patted with the back of the spade ; this not only produces quicker and more certain germination, but it leares the surface of the bed smooth, so that the plants come up stiaighter than if the beds were left rough. We consider the practice of soaking seeds worse than useless. For fuller instructions on this, one of the most important of all garden operations, see Chapter on the "Use of the Feet in Sowing and Planting." The greater part of this chapter has been already published in my book, entitled "How the Farm Pays," as well as portions of it in some of our seed catalogues. Believing it is of vital importance, I think it cannot be too often repeated. I have been writing on Horticulture for nearly forty years, but I consider that I have benefited the farmers and gardeners of the United States more by the instructions given in the "Use of the Feet in Sowing and Planting," than by any other article I have ever written. 


\section{H A P T E R XII.}

\section{THE USE OF THE FEET IN SOWING AND PLANTING.}

[Read before the National Assuciation of Nurscrymen, held at Cleveland, O., by Peter Henderson.]

It may be useless to throw out any suggestions in relation to horticultural operations to such a body of practical men as is now before me. Yet I candidly admit that, although I have been extensively engaged in gardening operations for over a quarter of a century, I did not fully realize, until a few years ago, the full importance of how indispensable it was to use the feet in the operations of sowing and planting.

For some years past I have, in writing on gardening matters, insisted upon the great importance of " firming" the soil over the seeds after sowing, especially when the soil is dry, or likely to become so. I know of no operation of more importance in either the farm or garden, and I trust that what I am about to say will be read and remembered by every one not yet aware of the vast importance of the practice. I say "vast importance," for the loss to the agricultural and horticultural community from the habit of loosely sowing seeds or setting out plants in hot and dry soils, is of a magnitude which few will believe until they have witnessed it; and it is a loss all the more to be regretted, when we know that by "firming" the soil around the seed or plant, there is, in most cases, a certain preventive.

Particularly in the sowing of seeds, I consider the matter of such great importance that it cannot be too often or too strongly told; for the loss to the agricultural and horticultural community by the neglect of the simple operation of firming the soil around the seed 
must amount to many millions annually. For the mischief done is not confined only to the less important garden operations, but even Corn, Cotton, Wheat, Turnips and other important crops of the farm often fail, in hot and dry soils, by being sown without being firmed sufficiently to prevent the dry air shriveling or drying the seeds. Of course, the use of the feet is impracticable in firming seeds on the farm, but a heavy roller, applied after sowing, is an absolute necessity under certain conditions of the soil, to insure perfect germination. From the middle of April to nearly the end of May of this year, in many sections of the country, there was little or no rain. Such was particularly the case in the vicinity of New York City, where we have hundreds of market gardeners, who cultivate thousands of acres of Cabbage, Cauliflower and Celery, but the "dry spring" has played sad havoc with their seed-beds. Celery is not one-fourth of a crop, and Cabbage and Cauliflower hardly half, and this failure is due to no other cause than that they persist in sowing their seeds without even taking the precaution to firm the soil by rolling.

We sow annually about forr acres of Celery, Cabbage and Cauliflower plants, which produce probably five millions in number, and which we never fail to sell mostly in our immediate neighborhood to the market gardeners, who have, many of them, even better ficilities than we have for raising these plants, if they would only do as we do, firm the seed after sowing, which is done thus :

After plowing, harrowing and leveling the land smoothly, lines are drawn by the "marker," which makes furrows about two inches deep and a foot apart; after the man who sows the seed follows another, who, with the ball of the right foot, presses down his full weight on every inch of soil in the drill where the seed has been sown; the rows are then lightly leveled longi- 
tudinaliy with the rake, a light roller is passed over them, and the operation is done.

By this method our crop has never once failed, and what is true of Celery and Cabbage seed is nearly as true of all other seeds requiring to be sown during the late spring or summer months.

On July $2 \mathrm{~d}$ of $18 \% 4$, as an experiment, I sowed twelve rows of Sweet Corn and twelve rows of Beets, treading in, after sowing, every alternate row of each. In both cases, those trodden in came up in four days, while those unfirmed remained twelve days before starting, and would not then have germinated had not rain fallen, for the soil was as dry as dust when the seed was sown.

The result was that the seeds that had been trodden in grew freely from the start, and matured their crops to a marketable condition by fall; while the rows unfirmed did not mature, as they were not only eight days later in germinating, but the plants were also, to some extent, enfeebled by being partially dried in the loose, dry soil.

This experiment was a most useful one, for it proved that a corn crop, sown in the vicinity of New York as late as July $2 d$, could be made to produce "roasting ears" in October, when they never fail to sell freely at high rates, but the crop would not mature unless the seed germinated at once, and which would never be certain at that dry and hot season, unless by this method.

The same season, in August, I treated seeds of Turnips and Spinach in the same way. Those trodden in germinated at once and made an excellent crop, while those unfirmed germinated feebly, and were eventually nearly all burned out by a continuance of dry, hot air penetrating through the loose soil to the tender rootlets.

I beg to caution the inexperienced, however, by no means to tread or roll in seed if the ground is not dry. The soil may often be in a suitable condition to sow, 
and yet may be too damp to be trodden upon or rolled. In such cases these operations may not be necessary at all. for if rainy weather ensue, the seeds will germinate of course ; but if there is any likelihood of a continued dronth, the treading or rolling may be done a week or more after the seed has been sown, if there is any reason to believe that it may suffer from the dry, hot air. Another very important advantage gained by treading in the seed is, that when we have crops of Beets, Celery, Turnips, Spinach, or anything else that is sown in rows, the seeds to form the crop come up at once; while the seeds of the weeds, that are just as liable to perish by the heat as are those of the crop, are retarded. Such of the weed seeds as lie in the space between the rows where the soil is loose will not germinate as quickly as those of the crop sown; and hence we can cultivate between the rows before the weeds germinate at all.

Of course, this rule of treading in or firming seeds after sowing, must not be blindly followed. Very early in spring or late in fall, when the soil is damp and there is no danger from heated, dry air, there is no necessity for doing so.

Now, if firming the soil around seed, to protect it from the influence of a dry and hot atmosphere, is a necessity, it is obvious that it is more so in the case of plants whose rootlets are even more sensitive to such influence than the dormant seed.

Experienced professional horticulturists, however, are less likely to neglect this than to neglect in the case of seeds, for the damage from such neglect is easier to be seen, and hence better understood, by the practical nurseryman; but with the inexperienced amateur the case is different. When he receives his package of trees or plants from the nurseryman, he handles them as if they were glass, every broken twig or root calls forth a complaint, and he proceeds to plant them, gingerly 
straightening out each root and sifting the soil around them, but he would no more stamp down that soil than he would stamp on the soil of his mother's grave. So the plant, in nine cases out of ten, is left loose and wabbling; the dry air penetrates through the soil to its roots; the winds shake it; it shrivels up and fails to grow; and then come the anathemas on the head of the unfortunate nurseryman, who is charged with selling him dead trees or plants.

About a month ago I sent a package of a dozen roses by mail to a lady in Savanuah. She wrote me a woful story last week, saying that, though the roses had arrived seemingly all right, they had all died but one, and what was very singular, she said, the one that lived was the one that Mr. Jones had stepped on, and which she had thought sure was erushed to death, for $\mathrm{Mr}$. Jones weighs 200 pounds. Now, though I do not advise any gentleman of 200 pounds putting his brogan on the top of a tender rose plant, as a practice conducive to its health, yet, if Mrs. Jones could have allowed her weighty lord to press the soil against the root of each of her dozen roses, I much doubt if she would now have to mourn their loss.

It bas often been a wonder to many of us, who have been workers in the soil for a generation, how some of the simplest methods oi culture have not been practiced until we were nearly done with life's work.

There are few of us but have had such experience; personally, I must say that I never pass throangh a year but I am confounded to find that some operation cannot only be done quicker, but done better, than we have been in the habit of doing it.

These improvements loom up from various eauses, but mainly from suggestions thrown out by our employees in charge of special departments, a system which we do all in our power to encourage. 
As a proof of the value of such improvements which have led to simplifying our operations, I will state the fact that though my area of greenhouse surface is now more than double that which it was in $18 \% 0$, and the land used in our florist's business is one-third more, the number of hands employed is less now than in $18 \%$, and yet, at the sume time, the quality of our stock is vastly better now than then.

Whether it is the higher price of labor in this country that forces us into labor-saving expedients, or the interchange of opinions from the greater number of nationalities centering here, that gives us broader views of culture, I am not prepared to state; but that America is now selling nearly all the products of the greenhouse, garden, nursery and farm lower than is done in Europe, admits of no question ; and if my homely suggestions in this matter of firming the soil around newly planted seeds or plants will in any degree assist us in still holding to the front, I shall be gratified.

In the summer of $1886 \mathrm{I}$ had a visit from one of the market gardeners of Norfolk, Va., who told me that he annually grows fifty acres of Spinach, but that often by dry weather in autumn, only a partial crop was obtained, owing to the failure of the seed to germinate. I asked him if he trod in the seed with the feet; he said no, that it would be quite a big job to tread in rows at one foot apart on an area of fifty acres. A little calculation showed that it could be done for less than $\$ 50$, and when it is known that a good crop of Spinach grown in Norfolk will sell in the markets of New York for at least $\$ 300$ an acre, it will readily be seen that it would hardly be worth while to withhold $\$ 1$ per acre extra labor, if it would, as it undoubtedly would in many cases, secure a crop. Seedsmen have more complaint of Spinach seed failing to germinate than perhaps anything else, as it has usually to be sown in hot, dry weather, but failure would 
rarely occur if after sowing the seed the soil was carefully pressed down with the feet.

It was rather an amusing incident that first brought to the attention of a truck farmer of Charleston, S. C., the importance of firming the soil. It seems that a gentleman of color, having the constitutional weakness for chickens peculiar to some of his race, got into a hen roost and helped himself bountifully. In evading the highroad, he struck a bee-line through a newly-sown Turnip field, where he left tracks that led to his detection. But these tracks did more. 'They showed to Squire Buncombe, whose chickens had suffered, that wherever the foot of the colored citizen had fallen, there he had a "stand" of Turnips and nowhere else (for they had been loosely sown and the weather was dry). The lesson shot home and bas been worth tens of thousmads of dollars to the farmers of South Carolina, who, it seems, were never before sufficiently alive to the importance of firming the soil until the unfortunate negro showed them the way. 'The world has often raised monuments to men who hare done far less to benefit their fellows than this poor negro unconsciously did for the farmers of North Carolina. 


\section{CH A P T E R X I I.}

\section{HOW, WHEN AND WHERE TO SOW SEEDS.}

As seed sowing is the starting point of cropping, a thorough knowledge of the conditions necessary for the germination of the different varieties will go far towards putting the tyro in gardening well on the way to success. The very general want of knowledge in this matter is too often the cause of much undeserved censure upon the seedsman, for in nine cases out of ten the failure is not with the seeds, but results from the time or manner of sowing. When the owner of a garden sends his order for seeds to the seedsman, it is generally a complete list of all he wants for the season. They are received, and the interesting operation of sowing is begun : first in a hot bed, if he has one, often as early as the first week in February (which in the latitude of New York is a month too soon), and in go indiscriminately, at the same date and under the same sash, his seeds of Cabbage, Cauliflower, Lettuce, and Egg Plant, Peppers and Tomatocs. Yet even in the waning heat of this early hot-bed, where a thermometer would possibly not indicate more than fifty degrees, he finds in a week or so his Cabbage, Lettuce, and Cauliflower "coming through" nicely, but as yet no Egg Plants, Peppers, or Tomatoes. He impatiently waits another week, makes an examination, and discovers that instead of his Tomatoes and Egg Plants beginning to vegetate, they are commencing to rot. It is now plain to him that he has been cheated; he has been sold old seed, and if he does nothing worse, he forever after looks upon the seedsman he has patronized as a renal wretch, destitute of principle and honesty. But he must have 
Tomatoes, Peppers, and Egg Plants, and he buys again, but this time from another seedsman, warranted honest. $\mathrm{He}$ renews his hot-bed-it is now a month later, and a bright.March sun, with milder nights, give him the proper temperature in his hot-bed (seventy or eighty degrees) - and his eyes are at last gladdened by the spronting of the troublesome seed. April comes with warm sunshine, inviting him to begin to "make garden" outside. He has yet the balance of the original lot of seeds that he bought in February. But as he is still entirely befogged about the cause of his failure in the first hotbed, he begins his open ground operations with little confidence in his seeds, but as he has got them, they may as well be tried. And aggin he sows, on the same day, his Peas and Lima Beans, Radishes and Pumpkins, Onions and Sweet Corn. Hardy and tender get the same treatment. The result must of necessity be the same as it was in the hot-bed; the hardy seeds duly vegetate, while the tender are of course rotted. This time he is not surprised, for he is already convinced that seedsman No. 1 is a rascal, and only wonders how any of his seeds grew at all, so he isain orders from seedsman No. 2 for the articles that have failed. Here circumstances continue to favor the latter, for by this time the season has advanced in its temperature, and the seeds duly vegetate. Every experienced farmer knows that in this latitude he can sow Oats or Wheat in March or April, but if he sows his Corn or Pumpkins at the same time they will perish; this he knows, but he may not know that what is true of the crops of the farm, is equaliy true of the garden. Hence the importance of a knowledge of the season when to sow regetable seeds or set out plants. A most important case in point occurs just as I write (May 15th, 1886). A would-be farmer to whom we sold ifty bushels of Sweet Corn complains that not a seed of the corn which he had planted has grown. He had 
sowed it about May 1st, in Northern Indiana, and three wceks too early for that section; what made matters even worse, we have had a cold, wet May ; the average temperature at night for the fortnight would probably not exceed forty-five degrees. Under such circumstances the seed corn could no more have germinated than if it had been thrown into the fire. That the seed was good was certain beyond question, as our trials showed that ninety per cent. grew.

A decision was not long ago rendered in one of the Philadelphia courts against the claim for damages made by a market gardener, who brought suit against a wellknown seedsman of that city for having sold him seed of Early York Cabbage that had "run to seed."

'The ventilation of such a matter is exceedingly instructive to those engaged in gardening operations, as was shown by the facts elicited on the trial, the gist of which was, that the prosecutor had sown the Cabbage seed on the 5th of September instead of the 15th, and that error, combined with an unusually mild and growing fall, practically lengthened the season, so that the Cabbage plants became "annuals"-running to secd within the year of sowing-rather than forming heads and acting as "biennials," as was expected of them. Now, just here an excellent lesson comes in with another vegetable. Many of our so-called scientific gardeners are English, Scotch, Irish, or Germans; they come here, most of them, with a thorough contempt for our rougher style of doing things (a practical style born of our necessities in the bigher cost of labor); and it is next to impossible to convince one in a dozen of them that there is anything in horticultural matters here that they need to be informed of. Accordingly, if he wishes to raise Celery, he starts his seed in a hot-bed in February, just as he would have done in England, and is astonished to find in July that instead of forming a thick and solid 
stalk, as it would have done there, it spindles and runs to seed. If his knowledge of the art had been basea on common-sense, instead of the blind routine practice acquired in a colder climate, he would have known that our séason-from April 1st to July 1st-would sum up nearly the same mean of temperature here as it would there, from February 1st to July 1st; and hence it was not only unnecessary here, but dangerous to the welfare of the crop, to sow such biennial plants as Celery in any other place than in the open ground, and that not before April. It was just such an error that the market gardener made who sued the seedsman above alluded to. He had been following, likely, the English or German method, and paid the penalty not oniy of losing his crop, but losing his law-suit, by not adapting his practice to our conditions of temperature. As the matter of sowing the seeds of Cabbage, Cauliflower and Lettuce to make plants to winter over in cold-frames, is one in which there is a wide-spread interest, I may state that the time of sowing in fall, in a country having such an area and difference of latitude as ours, is somewhat difficult to fix upon; but taking the latitude of New York as a basis, the safest time we have found to sow is about the 15 th of September. Of late years we have even sown some kinds as late as September 30th, with excellent success, in warm, well-sheltered positions, in a rich, well-prepared soil.

Each kind of seed has certain limits of temperature, below or above which it cannot well germinate. Below the minimum heat it remains dormant; above its maximum limit, its vitality is destroyed; between these two points is found the temperature most favorable to rapid germination. Practically it suffices to divide our garảen seeds into two classes : natives of temperate and natives of subtropical countries.

The temperature best fitted for the germination of 
seeds of the leading kinds, will be best understood by the tabular form given below :

Vegetable seeds that may be sown, in this latitude, from the middle of March to the end of April. Thermometer in the shade averaging $4 \tilde{5}$ degrees.

$\begin{array}{ll}\text { Beet. } & \text { Lettuce. } \\ \text { Carrot. } & \text { Onions. } \\ \text { Cress. } & \text { Parsnip. } \\ \text { Celery. } & \text { Parsley. } \\ \text { Cabbage. } & \text { Peas. } \\ \text { Cauliflower. } & \text { Radish. } \\ \text { Endive. } & \text { Turnip. } \\ \text { Kale. } & \text { Spinach. }\end{array}$

Vegetable seeds that may be soun in the open ground, in this latitude, from the midale of May to the midale of June. Thermometer in the shade averaging 60 degrees.

Beans, Bush. Melon, Musk.

Beans, Cranberry. Melon, Water.

Beans, Lima. Nasturtium.

Beans, Pols. Okla.

Beans, Scarlet Pumpkin. Runner. Squash.

Corn, Sweet. Tomato.

Cucumber.

It will be understood that these dates refer only to the latitude of New York; farther South operations should be begun earlier; farther North, later. So much for the time of sowing. I will now refer to suitable soil and the manner of sowing.

The Choice of Soll wherein seeds are sown, when choice can be made, is of importance, the best being a light soil, composed of leaf mold, sand, and loum; the best substitute for leaf mold being well-decayed stable manure, or, better yet, decayed refuse hops from the breweries-in short, anything of this nature that will tend to lighten the soil, the point to be avoided being a weight of soil, either from the nature or quantity of it. The nature of the soil is not of so much importance for the germinating of large vigorous seeds, as Peas, Beets, Beans, Corn, etc.; but with the delicate, slow sprouting sorts, as Celery, Parsnip, Egg Plant, or Peppers, it is of much importance. Seeds of nearly every garden regetable should be sown in rows; the distance apart according to the variety, and the depth proportioned to the size of the seed. No better information can be given in this matter than the old rule of covering the seed with 
about twice of thrice its thickness of soil, but this should always be followed up by having the soil pressed closely down. In our market gardens here we invariably tread or have the ground rolled; or in frames or hot-beds, where the roller cannot be used, we pat the soil down evenly with a spade after sowing. This may not be of so much consequence in early spring, when the atmosphere is moist, but as the season advances, it is of great importance. Another advantage in rolling after seed sowing is, that it leaves the surface smooth and lerel, thereby greatly lessening the labor of hoeing. Instead of adopting the questionable practice of soaking seeds, preparatory to sowing in dry, hot weather, we prefer first, if very dry, to thoroughly saturate the bed with water, and after it has dried enough, so that it can be raked without clogging, sow the seed. It is much better to do this than to water the soil after the seed has been sown, as it has a tendency in most soils to cause the surface to bake.

Although directions for sowing in hot-beds have becn already fully given in the Chapter on "Formation and Management of Hot-beds," and also under the head of "Spring-raising of Cabbage, Canliflower and Lettuce," yet at the risk of some repetition I again refer to it here.

Sowing In Hot-Beds. - After the hot-bed has been formed-say the first week in March-let soil of the kind recommended be placed on it six inches deep, into which plunge a thermometer three or four iuches, and when the temperature recedes to seventy-five or eighty degrees, you may then sow, giving air in mild weather as soon as the seeds begin to regetate, covering up warmly at night with straw mats. But many that may read this never saw a hot-bed, and are perhaps never likely to have one; to such I would say that there is an excellent substitute on hand in most dwellings, in the kitchen or basement windows, facing South or East, inside of which is a temperature usually not far from that required for the regeta- 
tion of seeds, and where plants from seeds of the early vegetables, or tender plants for the flower border, may be raised nearly as well, and with far less attention, than in a hot-bed. Instead of hot-beds, we use our greenhouses for the purpose, using shallow boxes in which we sow the seed; these are made from the common soap box, cut into three pieces, the top and bottom forming two, and the middle piece, bottomed, making the third; these form cheap, convenient boxes. Fill these nearly full with the soil recommended, and, after sowing, press nicely down level and make the surface soil moderately ifrm; keep moist in a temperature in the window of from sixty to seventy degrees, and your little trouble will soon be rewarded.

In this way sceds should be sown thickly, and after they have made the first rough leaf, should be again planted out into the same kind of box, from one to three inches apart, aceording to the kind, and placed in the window to receive similar treatment as the seeds; but as the season advances, in mild days the boxes should be set out of doors, care being taken that they are brought in before night, and that the soil in the boxes is never allowed to get dry.

I know what is usually the first thing the novice in gardening does if he gets any choice seed or favorite cutting; he has somehow got the belief that there is some hidden virtue in a flower pot, and he accordingly sows his seed or plants his cutting in a pot, but in nine cases out of ten they are destroyed, or partially so, by the continued drying of the soil in the porous flower pot. If early in the season, let delicate seeds be sown in the kitchen or sitting-room window, in the boxes as recommended, or if late, in the open border ; but seeds should never be sown in pots, as even in experienced hands they are much more troublesome and uncertain than boxes.

Rotation of Crops. - Cultivators of the most limited 
experience soon discover that the same kind of crop cannot be grown on the same ground for many years in succession without deterioration. A great many thecries have been advanced assigning causes for this, but they are as yet far from satisfactory, and as this is not a book of theory but of practice, I will not further allude to them. The following general rules will be found useful as a guide :

1st. Plants of the same family should not be planted to succeed each other.

2d. Plants which occupy the ground for a number of years, such as Rhubarb and Asparagus, should be succeeded by annual plants.

3d. Crops grown for heads, such as Cauliflower, Cabbage, etc., should be succeeded by crops grown for their bulbs or roots.

It is hardly practicable to vary crops according to any set rule, the demand in different localities for certain articles being greater than in others. Generally variety enough is demanded to allow of suflicient rotation. Our system of heavy manuring, deep culture, and taking two crops from the ground each season, seems to do away in a great measure with the necessity for systematic rotation, which would often be found to be very inconvenient. The crops of all others that we find most benefited by change are the Cabbage tribe, together with the allied 'I'urnip, Radish, etc., while, on the other hand, we have grown Onions successively on the same ground for ten years-the last crop just as good as the first; but, as a rule of safety, vary whenever you can.

The best of all rotation for crops is to "rest" the land whenever practicable from its continued manuring and cultivating, by sowing down to grass for one, two or three years; this gives a renewed vigor and vitality that nothing else will impart. The farmers and market gardeners of Long Island, who grow truck to supply the 
great market of New York, are now excelling our Hudson County, New Jersey, market gardeners, whose limited areas and high-priced lands do not permit them to use this system of "resting". their lands by a rotation of grass or clover. I have been so much impressed with the value of this plan, that, as soon as our cold frames have been emptied of Cabbage and Lettuce plants in May, the ground is sown at once with Clover, Millet or Oats-it makes little difference which; this crop is cut off twice or thrice and by September it forms a good sod, which is turned down. It is rotted in thirty days and the land is in the very best possible friable condition for the reception of the cold frame Cabbage, Cauliflower or Lettuce plants, which we begin to plant about the middle of October. Even when only a few weeks can be spared, we find it pays to sow the land with some green crop to be plowed in, rather than it should remain bare.

Quantity of Seeds Per Acre.-The quantities given below are somewhat higher in some kinds than the usual estimates, our experience showing us that in weak vegetating seeds, such as Parsnips, Carrots, etc., it requires numbers, particularly on stiff soils, to force through plants enough to form a crop. More seed is required when sown during the dry, hot months of summer than if sown in the cooler and moist seasons of spring and fall, hence quantities are regulated accordingly:

\section{QUANTITY OF SEED REQUIRED TO SOW AN ACBE.}

Asparagus 4 to 5 pounds.

Beans, Dwarf in drills 2 bushels.

Beans, Pole. in hills 10 to 12 quar's.

Beet in drills . 5 to 6 pounds. Cabbage ....... in beds to transplant

Carrot. in drills. $1 / 2$ pound.

Corn in hills 3 to 4 pounds. Corn (for soiling) 8 to 10 quarts. .3 bushels. in drills 2 to 3 pounds. 2 to 3 pounds. 
Cress, Upland ................. in drills.............. 2 to 3 pounds.

Kale, or Sprouts........................................ 3 to 4 pounds.

Mustard ........................ broadeast.................. $1 / 2$ bushel.

Melcn (Musk) . . . . . . . . . . . . . in hills................. 2 to 3 pounds.

Melon (Water) -................. in hills ............... 4 to 5 pounds.

Onion .............................. 5 to 6 pounds.

Onion, (for sets) ................ in drills ................... 30 pounds.

Onion, (sets) ................... in drills ............ 6 to 12 bushels.

Parsnip ................. 4 to 6 pounds.

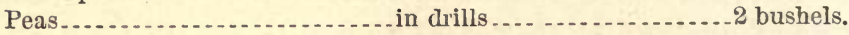

Peas . . . . . . . . . . . . . . . . . . . broadcast. ... . . . . . . . . . 3 bushels.

Potato, (cut tubers) . . ................................

Pumpkin . ................... 4 to 6 pounds.

Radish . . . . . . . . . . . . . . . . in drills .............. 8 to 10 pounds.

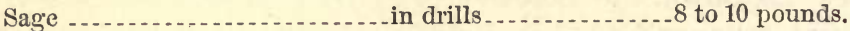

Salsify ...................... in drills . ............. 8 to 10 pounds.

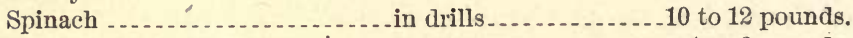

Squash, (bush varieties) ..........in hills................. 4 to 6 pounds.

Squash, (running varieties) ......in hills............... 3 to 4 pounds.

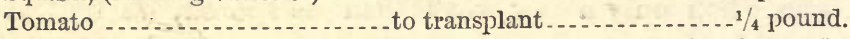

Turnip .....

Turnip ........................ 3 to 4 pounds.

Barley ........................... 2 to 3 bushels.

Broom Corn .................... in hills............. 8 to 10 quarts.

Clover (Red) alone. . . . . . . . . . . . . . . . . . . . . . . . 15 to 20 pounds.

Clover (White) alone .................................. 12 to 15 pounds.

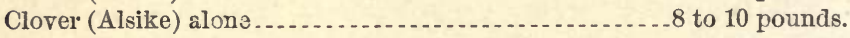

Clover (Lucern) alone . . . . . . . . . . . . .

Grass (Mixed Lawn) ............................... 4 to 5 bushels.

Oats................................... 2 to 3 bushels.

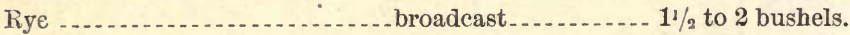

Vetches ...................... broadeast............. 2 to 3 bushels.

Wheat........................ broadeast......... $11 / 2$ to 2 bushels.

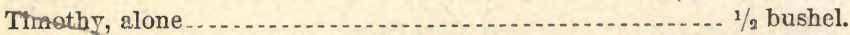

Orchard Grass, mixture............................... 4 to 5 bushels.

Millet........................................................ to 1 bushel.

MIXTU2E FO3 \$SEDING MOWING LANDS.

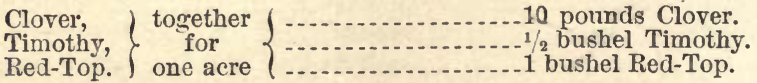

When drills are referred to, the seed should be sown with a seed drill. 
QUANTITY OF SEEDS REQUIRED FOR A GIVEN NUMBER OF PLANTS, NUMBER OF HILLS, OR LENGTH OF DRILL.

Asparagus, $1 \mathrm{oz} . . . .60 \mathrm{ft}$. of drill. Beet, $1 \mathrm{oz} \ldots \ldots \ldots$ ft. of drill. Beans, Dwarf, 1 qt. $100 \mathrm{ft}$. of drill. Beans, Pole, 1 qt......... 150 hills. Carrot, 1 oz $150 \mathrm{ft}$. of drill. Cucumber, $1 \mathrm{oz} . . . . . . . .50$ hills. Corn, 1 qt............. 200 hills. Dandelion, $1 \mathrm{oz}_{\text {.... }} 200 \mathrm{ft}$. of drill. Endive, $1 \mathrm{oz} \ldots \ldots 150 \mathrm{ft}$. of drill. Leek, $1 \mathrm{oz} . \ldots . . . .100 \mathrm{ft}$. of drill. Melon, Water, 1 oz ........ 30 hills. Melon, Musk, $1 \mathrm{oz} . . . . . . .60$ hills. Okra, $1 \mathrm{oz} . \ldots . . . . .40 \mathrm{ft}$. of drill. Onion, $1 \mathrm{oz} . \ldots \ldots . .100 \mathrm{ft}$. of drill. Onion, Sets, $1 \mathrm{qt}$.... $40 \mathrm{ft}$. of drill. Parsley, $1 \mathrm{oz}$. ...... $150 \mathrm{ft}$. of drill. Parsnip, $1 \mathrm{oz} \ldots \ldots \ldots 200 \mathrm{ft}$. of drill. Peas, $1 \mathrm{qt}$..........100 ft. of drill.
Pumpkin, $1 \mathrm{oz} \ldots \ldots . . . .40$ hills. Radish, $1 \mathrm{oz} \ldots \ldots . . .100 \mathrm{ft}$. of drill. Salsify, $1 \mathrm{oz} \ldots \ldots \ldots 70 \mathrm{ft}$. of drill. Spinach, $1 \mathrm{oz} . . . . .100 \mathrm{ft}$. of drill. Squash, Early, 1 oz ....... 50 hills. Squasb, Marrow, $1 \mathrm{oz} \ldots . . .16$ hills. Turnip, $1 \mathrm{oz} \ldots \ldots 150 \mathrm{ft}$. of drill. Asparagus, $1 \mathrm{oz} . . . . . .500$ plants. Cabbage, 1 oz . . . . . . . 2,000 plants. Cauliflower, $1 \mathrm{oz} \ldots \ldots$. . 2,000 plants. Celery, 1 oz . . . . . . . 3,000 plants. Egg Plant, 1 oz ...... 1,000 plants. Lettuce, $1 \mathrm{oz}$. . . . . . . 3,000 plants. Pepper, 1 oz ........ . 1,000 plants. Rhubarb, $1 \mathrm{oz} . \ldots . . .500$ plants. Tomato, $1 \mathrm{oz}$.......... 1,500 plants. Thyme, $1 \mathrm{oz}$........... 3,000 plants. Sage, 1 oz . .......... 1,000 plants.

THE NUMBER OF PLANT, TREeS, ETC., REQUTREd TO SET AN ACRE.

\section{Distance.}

Number.

$1 \mathrm{ft}$. by $1 \mathrm{ft}$ 43,560

$11 / 2 \mathrm{ft}$. by $1 \frac{1}{2} \mathrm{ft}$. 19,360

$2 \mathrm{ft}$. by $2 \mathrm{ft}$ 10,890 $2^{1 / 2} \mathrm{ft}$. by $2^{1 / 2} \mathrm{ft}$ $-6,970$

$3 \mathrm{ft}$. by $1 \mathrm{ft}$ 14,520

$3 \mathrm{ft}$. by $2 \mathrm{ft}$ 7,260

$3 \mathrm{ft}$. by $3 \mathrm{ft}$ 4,840

$4 \mathrm{ft}$. by $4 \mathrm{ft}$ 2,722 $5 \mathrm{ft}$. by $5 \mathrm{ft}$ :

\section{Distance.}

Number.

$6 \mathrm{ft}$. by $6 \mathrm{ft} \ldots \ldots \ldots \ldots$

$9 \mathrm{ft}$. by $9 \mathrm{ft} \ldots \ldots \ldots \ldots$

$12 \mathrm{ft}$. by $12 \mathrm{ft} \ldots \ldots \ldots$

$15 \mathrm{ft}$. by $15 \mathrm{ft} . \ldots \ldots \ldots \ldots$

$18 \mathrm{ft}$. by $18 \mathrm{ft} \ldots \ldots \ldots \ldots$

$20 \mathrm{ft}$. by $20 \mathrm{ft} \ldots \ldots \ldots \ldots . . . . . . . . .103$

$25 \mathrm{ft}$. by $25 \mathrm{ft} \ldots \ldots \ldots$

$30 \mathrm{ft}$. by $30 \mathrm{ft}$.................. 40

$40 \mathrm{ft}$. by $40 \mathrm{ft} \ldots \ldots \ldots \ldots \ldots . . . . . .27$ 


\section{H A P TER XIV.}

\section{TRANSPLANTING.}

Transplanting is an operation of great importance ; the condition of the plant, the state of the soil, and of the atmosphere, have much to do with its success, independently of the simple mechanical operation. It is not very easy to instruct the uninitiated as to what the proper condition of the plant should be; experience in this being, as in everything else, the best teacher. Attention to keeping the seed-bed clear of weeds, the "topping" of plants when they get too tall, and careful digging up of them so as to preserve the root fibres, will all greatly assist. We cannot always get the soil in the proper condition of moisture to receive plants at the time transplanting should be performed, but to make up for the want of moisture, planting should be delayed always until late in the afternoon, unless in cloudy weather. It is also of great importance that the ground be freshly plowed; the moist soil thus brought to the surface will induce the formation of root fibres in one night in warm weather, after which the plants are comparatively safe; but if they be allowed to wilt before the new roots begin to be emitted, and continued dry weather ensues, then nothing will save them but having recourse to watering, which, however, should only be done in ease of dire necessity. In planting, such plants as Cabbage, Lettuce and Celery, each man is provided with a boy, who carries the plants in a basket, and whose duty is to drop the plant on the line at the proper distance before the planter. In planting, a hole is made by the dibber about the depth of the root; the plant being inserted, the soil is then pressed close to the root; the hole thus made by the displacement of the soil is again filled up by one stroke of the dibber. In dry weather we still further 
firm the plant by each planter returning on his row and treading the soil around plants firmly with the feet. I am thus particular in describing a simple matter, knowing well that millions of plants are annually lost by inattention to this firming of the soil. The same rule is applicable to transplanting of all kinds, trees, shrubs, or vegetables. Instead of "puddling" the roots in mud, we prefer to keep the plants dripping wet during the whole time of planting, so that each plant, as it is put in the soil, puddles itself by the particles of soil adhering to the wet root. Besides, the leaves of the plant, being wet, will for some time resist the action of the dry air.

Planting of Vegetable Plants. - A year or two ago, about the middle of April, the snow, after its long acquaintance with us during the past winter, intruded itself again in the spring and covered our newly-planted gardens to the depth of several inches. Veteran tillers of the soil could smile at this assault, knowing it to be harmless. But correspondents, still young in the business, wrote to me fearing their planted crops were ruined.

A snow, after planting in spring, I have never known to injure plants of any kind, unless, indeed, it was heavy enough to break them. The fear of snow, and of the slight late frosts, often prevents the setting of such plants as Cabbage, Lettuce, and even Asparagus, among vegetables, and of Strawberries and other small fruits, until the season is so far advanced that hot weather comes on, starting the tops before the roots have had time to get a foothold. There is rarely danger (when the grouud is sufficiently dry to work, and it never should be worked until it is so), that such hardy or half-hardy plants as we plant in spring will be injured by any frost that may come after they are put out. This opening up for spring work usually begins here by the end of March, and I have never yet seen plants injured by frost after that time. 
To give an idea what amount of cold Cabbage and Lettuce plants will stand without injury, I will relate an experience I had in my early days of market gardening. A particularly mild spell in the latter part of February had led us to believe that spring had come. Ont went the teams, and the ground was manured, plowed, and planted with Cabbage and Lettuce to the extent of two acres, which was all finished up by the 26th of February. It was my second year in the business. I was yet an inexperienced hand, and my neighbors predicted that my venture was a foolhardy one, and would result in total loss, no one having ever before planted such crops in this section at such an early season. But fortune favored me; the weather continued mild long enough to allow the plants to "strike root," and though the thermometer afterward marked as low as fifteen degrees above zero, and the ground was frozen for full ten days, so that it could not be again dug or plowed, yet the wild venture proved a success, and I had the satisfaction of having the first Cabbages from that February planting that were sold in market. I never after had an opportunity of plarting so early, and would not do so if I had, for it was simply favorable conditions that saved the crop. If the cold snap had set in immediately after planting, there is but little doubt the plants would have suffered injury. But the experience was valuable in showing what severity of frost such plants would stand without injury. Much depends on the condition of the plants; if taken from the hot-bed or frame without being previously exposed, they might be in condition to be as easily injured as a Tomato plant.

The past season I had the sashes taken off my entire crop of Cabbage and Lettuce plants on March 1st (they being hardened beforehand by ventilating), and never covered them again. They were twice covered up with snow, and the mercury several times marked only twenty 
degrees above zero. Yet we hardly ever before had finer plants.

The sashes so taken off-nearly 1,000 in number-were used for our flower business, but, had we desired it, they might have been used on temporary frames, and grown a crop of Lettuce which in five weeks from date of planting, March 1st, would have easily given $\$ 2$ per sash. I mention these facts to give confidence to the hundreds now engaged in market gardening, who, from dread of exposing their plants in spring, not only do them an injury, but lose the profit of a second use of their sashes. A third use of sashes may be had in growing T'omato, Sweet Potato, or Egg plants, aiter the crop of Lettuce is sold, or forwarding an early crop of Cucumbers or Melons. (See "Forcing Cucumbers.")

\section{H A P T E R X V.}

\section{VEGETABLES, THEIR VARIETIES AND CULTIVATION.}

In describing the modes of cultivating the different varieties of vegetables, I shall notice at length only those of the most importance, and the most profitable for market purposes, while for those of less value as market crops, the directions for culture will be such as are adapted to private gardens only.

A limited number of kinds will be deseribed, and such only as our experience has shown to possess the greatest earliness and productiveness. Nothing is more perplexing to the beginner than to be bewildered by descriptions of perhaps twenty so-called varieties of a vegetable that in reality does not embrace four distinct kinds. For example, in early Cabbages, there are some hundred or more varieties described; yet we find, after having 
experimented with some scores of kinds in our time, there are two varieties more profitable to grow than any others-viz., the Jersey Wakefield and Early Summer, which are grown in this locality to the exclusion of all others. However, some kinds are found to do better in some localities than in others-hence, as in fruits, no particular variety should be claimed to be universally the best.

\section{ASPARAGUS.-(Asparagus officinalis.)}

Asparagus being a hardy perennial plant, that may be grown on the same ground for twenty years without renewal, special care is required in forming the beds in which it is to grow. This is done sometimes by trenching to the depth of two or three feet, mixing each layer of soil, as turned over, with two or three inches of wellrotted manure ; but for market purposes, on a large scale, trenching is seldom resorted to ; deep and thorough pulverizing by the plow and subsoiler serving instead. The soil best suited for Asparagus is a deep and rather sandy loam, such as is often to be found on the borders of meadows or on the margins of lakes or rivers-land formed by the washings of the higher grounds, and known as alluvial. This land, when clear from under water or from overflow is by far the best suited for the growth of all kinds of vegetables and is, from the nature of the plants, particularly adapted for Asparagus or Celery.

Propagation.-Asparagus is propagated by seed, which is sown in spring, as soon as the soil will admit of working, which should be prepared by being thoroughly pulverized and enriched with well-rotted manure. The seed is sown in rows one foot apart, and if kept carefully hoed and clear from weeds, the plants will be in fine condition to plant out the succeeding spring. Strict attention to this will save a year in time; for if the seed-bed has been neglected, it will take two years to get the plants as large 
as they would be in one year, if they had been properly cared for. In consequence of this very common neglect of proper cultivation of the seed-bed, it is an almost universal impression that the plants must be two or three years old before planting. 'This is undoubtedly an error, for almost all large growers for market purposes, in the neighborhood of New York, invariably plant one-yearold plants, and count on marketing a crop the third spring from the time of sowing. One pound of seed will produce about 3,000 plants ; and to plant an acre of Asparagus requires from 15,000 to 20,000 plants when planted close.

Planting.-The bed being prepared as previously described, planting may be done any time for six or eight weeks from the opening of spring. The plant, from its peculiar succulent roots, is less susceptible of injury from late planting than most other vegetables, although at the sanie time delay should not occur, unless unaroidable, as the sooner it is planted after the ground is in working order, the better will be the result. When there is plenty of ground and the crop is to be extensively grown, perhaps the best mode of planting is in rows three feet apart, the plants nine inches apart in the rows. For private use, or for marketing on a small scale, beds should be formed five feet wide, with three rows planted in each ; one in the middle and one on each side, a foot from the edge; the distance of the plants in the rows, nine inches; the alleys between the beds should be two feet wide. In planting, a line is set and a cut made a little slanting to the depth of six or eight inches, according to the size of the plants. The plants are then laid against the side of the trench, at the distance already named (nine inches), care being taken to properly spread the roots. The crown or top of the plant should be covered about three inches. In a week or so after planting, the beds should be touched over lightly with a sharp steel 
rake, which will destroy the germinating weeds. The raking had better be continued at intervals of a week or so, until the plants start to grow, when the hoe or handcultivator may be applied between the rows and alleys; the weeds that come up close to the plant must of necessity be pulled out by the hand.

In the first edition of this work I gave it as my belief that we had only une .variety of Asparagus, and that all the so-called "Giant" and "Mammoth" varieties were merely the results of superior soil or cultivation, which on being propagated by seeds or otherwise, and placed in ordinary conditions of culture, would fall back to their original or normal condition; in short, that the species had never "broke," as we technically term it.

This belief necessarily made me skeptical to the claims of the "Colossal" when that variety was first introduced, and I invariably replied to all inquirers that past experience in this matter led me to believe that it was no different from the ordinary sort.

I was finally invited to pay a visit to the farm of Abraham Van Siclen, of Jamaica, Long Island, and there to inspect an acre of the Oyster Bay Asparagus (the ordinary kind), and an acre of his "Colossal," which Mr. Van Siclen had planted in the spring of 1868 , each then one year old from seed. A thorough inspection of the roots of each lot proved that they were of the same age when planted. The soil was next examined, and found to be as near the same as it could well be, yet these two beds of Asparagus showed a difference that left me no longer a shadow of a doubt of their being entirely distinct varieties. In the old variety we found no shoot thicker than one inch in diameter and averaging twenty shoots to a hill, while in the "Colossal" many shoots were found an inch and a half in diameter, and averaging thirty-five shoots to a hill-an enormous growth, when it is remembered the plant was only three years from the seed. 
Mr. Van Siclen is well known as one of our best Long Island market gardeners, who has made the growing of Asparagus a specialty for twenty years, and who has probably in that time sold more Asparagus in the markets of New York than any other man. He was exceedingly enthusiastic in praise of this variety, believing that at a low estimate it would yield a profit of at least one-third greater than the ordinary sort, under the same conditions, besides coming to maturity two years sooner.

Mr. Van Siclen's method of growing Asparagus is simple, and in some respects new to me. To begin, he sows his seeds in his rich sandy loam in April, in rows one foot apart and two inches in depth, dropping the seeds so that they may be distributed evenly about half an inch apart; the plants are cultivated by hoeing between the rows and keeping them clear of weeds by hand picking. In the spring following he sets his plants, now one year old, which are in his experience preferable to those two years old. His mode of planting is somewhat different from the usual practice, but for having a lasting Asparagus bed-one that will be as good at the end of twenty years as it is at eight-it is probably the best.

It differs in setting the roots much wider apart than usual ; his stand, six feet between the rows and four feet between the plants, making less than two thousand plants to an acre. In preparing the land to receive the plants, he merely plows to the depth of a foot or so with the ordinary plow; his soft, sandy subsoil rendering the use of the subsoil plow unnecessary, but in soils less favored the use of the subsoil plow would be of decided advantage. In preparing to plant he turns out a furrow with a double mold-board plow, so that at its deepest part it is nearly twelve inches deep ; a good shovelful of thoroughly rotted manure is then placcd in the furrow, at distances of four feet, so spread that it will make a layer of three inches or so ; an inch or two of soil is then 
thrown on the top of the manure, and the Asparagus planted as shown in the engraving, figure 14, and with its crown six or seven inches below the surface level. The plant is now only lightly covered up with the soil, say two or three inches, until it starts to grow, when the furrows are thrown in by the plow so that the whole surface is leveled, which places the crown of the Asparagus some six or seven inches under the surface. This would be, perhaps, four inches too deep in heary soils, but in light, soft soils it answers well. The first and second seasons after planting no Asparagus is cut for

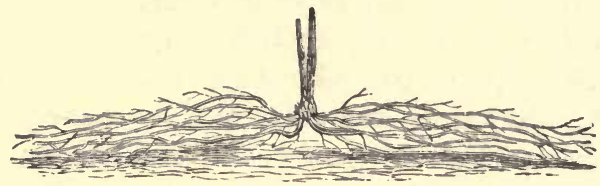

Fix. 14.-MANNER OF Planting asparages.

market, as it weakens the roots, but in the third year a partial crop is taken, although the beds are not considered to be at their best until the sixth or seventh year. Their productiveness may be continued for twenty years by this wide system of planting, recourse being had to manuring freely annually, by digging or plowing it in around the roots before the crop has started to grow, or after it is cut.

Growing Asparagus from Seed, without transplanting, is a method now finding many adrocates. It is not only a much cheaper method, but in my opinion it is the best method if the operator can have patience to wait a year longer for a crop. The plan is very simple, and can be done by any one having even a slight knowledge of farming or gardening work. Prepare the land by manuring, deep plowing and harrowing, making it as level and smooth as possible for the reception of the seed. Strike out lines three feet apart and about 
two to three inches deep, in which sow the seed by hand or seed drill, as is most convenient, using from five to. seven pounds of seed (which costs fifty cents per pound), to each acre. After sowing the seed and before corering tread down the seed in the rows evenly with the feet (see "Use of the Feet in Sowing and Planting") ; then draw the back of a rake lengthwise nver the rows, after which roll the whole surface. As soon as the land is dry and fit to work in Spring, the young plants of Asparagus will start through the ground sufficiently to define the rows in two or three weeks. At once begin to cultivate with hand or horse cultivator, and stir the ground so as to destroy the embryo weeds, breaking the soil in the rows between the plants with the fingers or hand weeder for the same purpose. This must be repeated at intervals of two or three weeks during the summer, as the success of this method is entirely dependent on keeping down the weeds, which, if allowed to grow, would soon smother the Asparagus plants, which for the first season of their growth are weaker than most weeds. In two or three months after sowing, the Asparagus will have attained ten or twelve inches in height. It must now be thinned out so that the plants stand nine inches apart in the rows. By fall they will be from two to three feet high, strong and vigorous, if the directions for culture have been faithfully followed. When the foliage dies (but not before), cut the stems down to the ground and cover the lines for five or six inches on each side with two or three inches in depth of rough manure. As the spring again returns, renew the same process of cultivation to keep down weeds the second year exactly as was done for the first, and so on to the spring of the fourth year, when a crop may be cut that will well reward all the labor that has been expended. Sometimes, if the land is particularly suitable, a crop may be had well worth marketing the third year, but as a rule, it will be 
better to wait until the fourth year without cutting much, as it would tend to weaken the plants. To compensate for the loss of a year in time in thus growing Asparagus from seed, such crops as Cabbage, Lettuce, Onions, Beets, or Spinach-all of which will be marketable before the Asparagus will have grown high enough to interfere with them-can be sown or planted between the rows of Asparagus the first year of its growth with but little injury to it; and as the ground for the Asparagus has been heavily manured and well prepared, such crops will, in a measure, make up for the year's loss in time, provided there is a market near enough for their sale. I had an old friend near Macon, Ga., who grew an acre of Asparagus after this plan. His crop was sold in the New York market and brought him an average of $\$ 1,000$ a year for six years after it came in to bearing, to my certain knowledge, my salesman having sold it for him. He died some ten years ago, and I presume the bed was neglected, or it might still be in full bearing. There is no crop so certain of sale and so easily shipped as Asparagus, from the fact that it has perhaps greater value for its weight than any other vegetable, besides, it is ready at a season when the temperature is low, so that whether shipped from the extreme Southern States to our large cities in the Middle States, or reshipped to still further North, there is never danger from injury in transit. The reason of its being profitable is obrious. The cultivator has to wait three or four years for a crop. The majority of gardeners either cannot or will not wait, and hence it becomes profitable to the few who cultivate it. The variety usually grown is the Colossal, but Mr. John Nix, a well-known commission dealer of New York City, and who is also one of the largest truckers in Sonth Carolina, claims that the new variety of Asparagus, "The Palmetto," is one which excels all other varieties grown at the South, in earliness, yield, quality and even- 
ness of growth. It has not yet been extensively tried at the North, but we have every reason to think that it will do equally well here.

The Application of Salt to Asparagus as a topdressing is claimed to be of benefit in inland districts out of the range of a saline atmosphere, but is of little or no benefit in the vicinity of salt water. When ustd it should be applied in spring only, at the rate of half a pound per square yard, strewed on the surface ; the rains will dissolve it and wash it down to the roots. Besides its beneficial effects upon the plant, it is to some extent destructive to the wire worm and other insects that are often troublesome to the Asparagus.

We have found Asparagus beds very profitably benefited by the application of superphosphate of lime or pure bone dust as a spring top-dressing, applied at the rate of 500 pounds per acre, sown on the beds and hoed in. Experiments with this on alternate rows showed a difference of nearly one foot in height of the stalk in favor of the rows to which the superphosphate had been applied over those which had none; and a difference of nearly double the product when the crop was cut in the succeeding spring.

The fall treatment of the Asparagus beds varies with the locality ; in cold regions, where, if left unprotected, the frost would penetrate below the roots, a covering of three or four inches of rough manure or leares is necessary. Although an entirely hardy plant, it will start earlier and with greater vigor in spring if the root has not been subjected to severe freezing. In milder sections no such precaution is necessary; all that need be done is to clear off the stems as soon as they are withered in the fall, and clean the beds preparatory to giving a dressing of two or three inches of minure, which had better not be applied untıl spring. We believe the common practice of top-dressing Asparagus beds in fall to be a very waste- 
ful one, in districts where it is not necessary to provide against severe freezing, for, as the plant is then dormant, the juices of the manure are either evaporated or else washed down by rains below the roots of the plant. I remember having three small Asparagus beds under my charge many years ago, on one of which I applied in December twenty-five pounds of Peruvian guano, dissolved in fifty gallons of water; in April the same application was made to another bed, and the other was left without anything. There was no perceptible difference between that to which the liquid had been applied in December and that to which none had been given, but on that which received it in April nearly double the weight of crop was produced. Since then, all our practice, corroborated by direct experiment, has convinced me beyond all doubt, that manures, either liquid or solid, are unprofitably employed when applied to plants in the dormant state.

In gathering the crop caution must be used not to injure the plants by continued or excessire cutting; for it must be borne in mind that to reproduce annually its crop of shoots in spring. something must be left to grow to encourage the formation of fresh roots. In our market gardens the practice is to cut off all the shoots as they are ready, until the middle of May or 1st of June, when the shoots begin to show signs of weakness; then all is left to grow and no more cut. In its preparation for market the shoots are tied up in round bunches. The size of the bunch is governed somewhat by the abundance of the crop, and is about four to five inches in diameter and from seven to nine inches in length, in weight from two to three pounds, firmly tied at the butts and tops. The tying material is the matting known as Raffia, as that is soft, pliable, and has the necessary strength. The proper bunching of Asparagus used to be quite an art, but the "Asparagus Buncher" (see implements) has ren- 
dered the operation so simple that any one can do it rapidly with a few minutes practice.

This crop is subject to so many conditions that an average value can hardly be given; some of our growers here yet claim that it pays an annual clear profit of $\$ 500$ per acre, while others say that it does not pay them over $\$ 200$ per acre. During a period of ten years, counting from the time the bed was planted, it is safe to say that, in this vicinity, the average profits per acre will be $\$ 250$. It is a crop that never fails to sell, is always productive if properly treated, and having a great value for its weight - a ton often being worth from $\$ 200$ to $\$ 400$-it is, in all respects, a valuable crop for the market gardener. In packing Asparagus for shipping it is best packed in bóxes of a depth equal to the length of the bunch or perhaps an inch deeper, because in packing, Asparagus is placed on end, and some soft material, as moss, cottnn, or soft paper should be placed on the top, so that should the box be turned upside down, the soft tops will not be bruised. The interstices between the bunches should also be filled in, so that the whole may be firm enough to not be injured by jarring. This is true of packing all vegetables for shipment; unless the box is pacised full and firm, jarring in the handling is sure to injure them.

In some localities, especially on Long Island, New York, the Asparagus Beetle (Crioceris asparagi) has injured the crop to such an extent as to cause whole plantations to be plowed under. When the bectle first appears it may be controlled by picking it off and destroying it ; but if allowed to become established the task is hopeless. The engraving (figure 15) shows the insect in its different stages. The lower figure is a part of a branch, with the small black eggs attached by their ends; these are given of the natural size, and magnified. The larva, or caterpillar, as well as the perfect beetle, is shown at the top of the engraving; the natural size of these is in- 
dicat; d by the lines drawn at the side. Whenever the eggs or the larvæ appear, cut and burn the plants as long
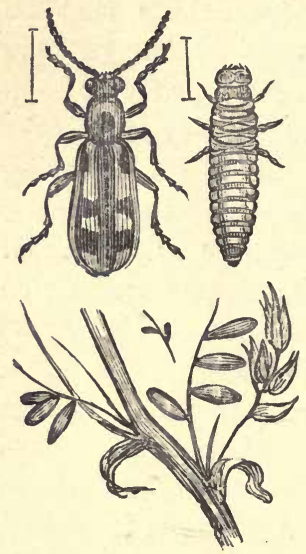

Fig. 15.-ASPARAGUS BEETLE.

as any traces of the insect are to be seen; this must be done if it destroys every vestige of vegetation. A remedy much in use in some sections is to coop up hens in the vicinity of Asparagus beds, and let the chickens out to pick up the larvæ and insects. A certain remedy against the Asparagus beetle, it is claimed, can be made by mixing one pound of Paris green in 100 gallons of water, sprinkling over the plants twice each week on the first appearance of the insect. The varieties of Asparagus now are confined to the "Colossal" and the "New Palmetto," already described. The "Giant," formerly so much grown, is now nearly out of cultivation.

\section{ARTICHOKE.-(Cynara Scolymus.)}

Although a vegetable as yet rarely seen in our markets, it is extensively used in Europe, particularly in France. The portion of the plant most used is the undeveloped flower-head, or rather those portions of the flower-head called the scales of the involucre. They are sometimes boiled and used as a salad, with vinegar, oil, and salt; but more generally in the raw stats.

Another use of the Artichoke is to blanch it, by tying the young side shoots moderately close together, as we tie Endive, flling in between with soil to exclude the air until the shoots are blanched; this is what is known as "Artichoke Salad," or "Artichoke Chard ;" it is used 
in this state in various forms of cookery, besides being used as a salad.

It is a vegetable of easy culture, originally propagated from seeds until a stock is secured, after which it is readily increased by suckers from the root. These are planted out in April or May, in rows from three to four feet apart, and two feet between the plants, care being taken that the plants are well firmed in planting, and if the weather is dry, they must be freely watered until they start to grow. The plantation, the first season, will only give a partial crop; but, as it is a perennial plant, after being once planted the same bed will remain in bearing for years. The plant may be said to be entirely hardy south of Mason and Dixon's Line, but north of that it requires to be protected by covering between the plants

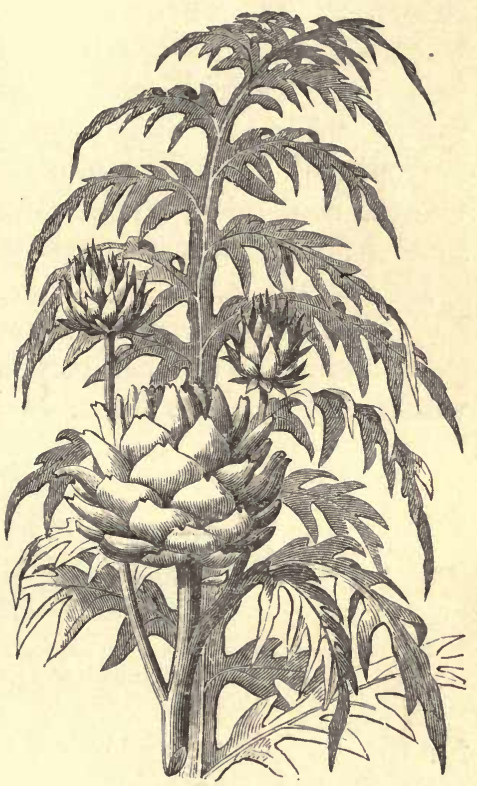

Fig. 16.-GREEN GI.OBE ARTICHOKE. with six or eight inches of leaves or coarse manure.

The Varieties are the Green Globe and Common Green, differing but little, except in the form of the flower-head, the former being globular, the latter conical. It is claimed by some that the Common Green is more hardy and productire, but we have grown them side by side for years and never have observed any difference, except the very trifling one in the shape of the flower-head. 


\section{ARTICHOKE.-JERUSALEM.-(Helianthus tuberosus.)}

This is an entirely different plant from the true Artichoke, though it resembles it somewewhat in flavorhence its name. It is a species of Helianthus, or Sunflower, and the plant has the general appearance of a small Sunflower. The edible part of the plant is its tubers. These are like the potato in appearance, but when cooked, to the taste of most people, are very inferior in flavor. 'Their nutritive value is said, however, to be fully equal to that of the potato. Used in the raw state it is pickled like the cucumber, or sliced and eaten with vinegar as a salad, but as a culinary vegetable it is but little grown, except for variety or novelty.

Its culture is, in all respects, similar to the potato, but it is more productive, always free from disease, will grow almost in any soil or situation, and will stand the winter on light soils wherever a Parsnip crop will stand;

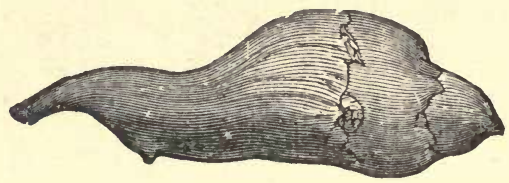

JERUSALEM ARTICHOKE.

for these reasons it is regarded as a valuable food for cattle or pigs, who eat it freely. It is planted largely at the West as food for swine, which do their own harvesting.

There are several varieties, known as Red, Purple, Yellow and White skinned. 


\section{EASIL.-(Ocimum Basilicum.)}

An herb of a highly aromatic odor, and a strong flavor of cloves. It is used for flavoring soups, stews and sances, and is by some used in salads. Its culture is the same as that of other sweet herbs. The seed should be sown in the open ground and not in frames, which is the English practice, and necessary there from their colder climate. Sow in rows one foot apart; when three or four inches high it may be transplanted in rows one foot apart and six inches between plants. If a small quantity only is required, it may be thinned out in the seed rows and left to grow where sown.

There are two species cultivated, namely, the Common Sweet Basil (Ocimum Basilicum), and the Bush Basil (O. minimum).

\section{BALM.-(Melissa officinalis.)}

Another well-known aromatic herb which has a very agreeable lemon-like odor. It is used as a tea for its" soothing effect in irritations of the throat and lungs, and a century ago was used as a specific for coughs and colds. Its young shoots are sometimes used as an ingredient in salads. It is rapidly propagated by divisions of the root, which, planted in Spring at one foot apart each way, will form a solid mass by fall.

Besides the common kind we have now in cultivation a beautiful variegated variety, possessing all the properties of the other.

BEANS.-(Phaseolus vulgaris.)-Bush, Kidney and Pole.

A leading vegetable of our market gardens, and extensively cultivated in every section of the country North 
and South. Although it can be grown on soils that are not enriched by manure, yet, like almost every other vegetable, it is more profitable when grown on highly cultivated land. It is what we term a "tender" plant; that is, one that will be killed by the action of slight frosts, hence it is not planted untıl late enough in the spring to secure it from the risk. As in a country presenting such differences of temperature as ours, no stated date can be given at which to sow, perhaps no safer rule can be adopted for sowing all "tender" vegetables for all parts of the country than the time at which our great staple, Indian Corn, is planted. This rule will be equally intelligible to the inhabitants of Maine and to those of South Carolina, for all plant Corn, and know that our great enemy to early vegetation, "Jack Frost," will, without scruple, smite this "tender" regetable if it be forced to grow before his icy reign is past. In this section we plant Beans for first crop when we plant Corn, from 10th to 20th May. But as the crop of Beans comes rapidly to maturity under favorable circumstances, in five or six weeks, it may be sown any time from these dates until July, August, or September, according to the temperature of the district.

The culture in market gardens is simply to draw drills about three inches deep, and from eighteen inches to two feet apart, according to the richness of the soil; the poorer the soil the closer they can be planted. The seed is dropped in the drills two or three inches apart, and the soil covered in on them with the feet; this we find to be a quicker and better method of covering in seeds of this size than by the hoe or rake. After the plants have grown an inch or two a cultivator is run between the rows, which generally is all that is necessary to be done, until they are large enough to have a little earth thrown to each side of the row by the plow, which completes their cultivation. Beans, like Tomatoes and 
Peas, are easy of cultivation and not particular as to soil, and are, in consequence, rarely a profitable crop in the locality in which they are grown; hence the only way in which they are made profitable is by growing South and shipping North, they being easily transported. Large quantities are grown in early soils in Southern sections of the country and shipped to our large Northern cities, and meet a rapid sale at prices that must pay a large profit, if their manner of growing the crop is as simple as ours. It will be understood that this crop is almost exclusively sold in pod as snap shorts (in the green unripened state) by the hucksters, and rarely as a shell bean.

The varieties are now very numerous, but the following, placed in what we consider the order of their value to the market gardener, will embrace variety enough for all practical purposes.

\section{BEAN,-DWARF.}

Earliest Red Valentine.-This variety is at least ten days earlier than the Early Red Valentine, which is one of the very best market varieties. On account of its great earliness it is largely grown by market gardeners; but except in the characteristic of extreme earliness, it differs in no other way from the Early Red Valentine next described. (See figure 1\%).

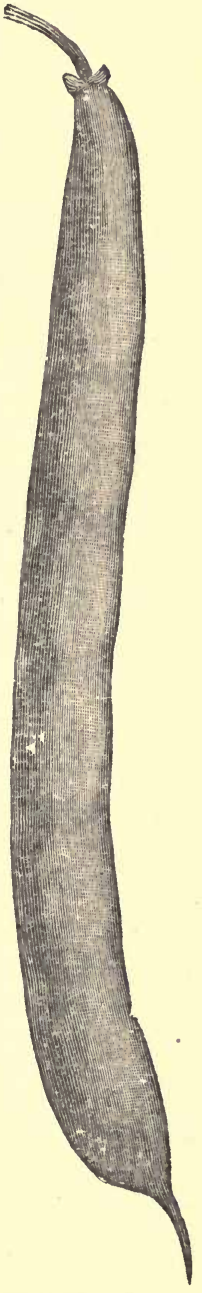

Fig. 17.-EARLIEST RED VALENTINE BEAN. 
Larly Red Valentine.-Equally desirable for either market or family use, being early, productive, tender and of excellent flavor. The pods are round, somewhat curved, and the seeds, when ripe, salmon speckled with purplish rose. This variety is usually ready to pick in six weeks from the time of sowing.

Early Mohawk. - A very productive early variety and one that will stand more cold than most of the bush varieties. Both this and the preceding sort are largely grown in the Southern States for Northern markets. The pods are from five to six inches long; seeds, when ripe, drab with purple spots.

Long Yellow Six Wecks.-Early, very prolific, and of excellent quality. Pods, six to eight inches long; seeds, when ripe, yellow or dun color.

Refugee or Thousand to Onc.-A very productive medium or late variety. The young pods are tender and of fine flavor. This variety is extensively grown for pickling. Seeds, speckled purple.

Gallega or Large Refugec.-This is of recent introduction and is a larger form of the Refugee above described. Both pods and seeds are not only much larger in size than their parent variety, but it is also a much better yielder. Seeds, when ripe, purple, speckled with white.

White Marrowfat.-The variety so often grown for sale in the dry statc. It is also valued as a string bean, but is used to a greater extent as a shelled bean, either green or dry. Seeảs large, ivory white.

\section{BEAN.-WAX.}

Black Wax.-When ripe the pods are yellow, averaging from six to nine inches in length. They are tender, 
and the quality is of the very best. The seeds, when ripe, are glossy black.

Golden Wax. - A strong growing, distinct variety, at least a week earlier than the Black Wax. 'The pods will average six inches long, are brittle and entirely stringless. $\quad$ s a snap bean, it perhaps excels all others in tenderness and richness of flavor. Seeds, when ripe, are purple and white. (See figure 18.)

Flagcolet Wax.-The pods of this are very large size, often a foot in lengtin, exceedingly tender and succulent, and enormonsly productive. It is equally good as a shell bean. I consider this one of the best of the Bush Beans.

\section{BEAN.-(Phaseolus lunetus, etc.)-RonNing OR POLE.}

These are more tender and require rather more eare in eulture than the Bush Beans. The soil best suited is sandy loam, which should be liberally enriched with short manure in the hills, which are formed, according to variety, from three to four feet apart, and provided with a stake from eight to nine feet in height, set in the center of each. This class of beans is particularly tender, and it is perfectly useless to plant the seeds before the weather has become settled and warm in spring, as they are

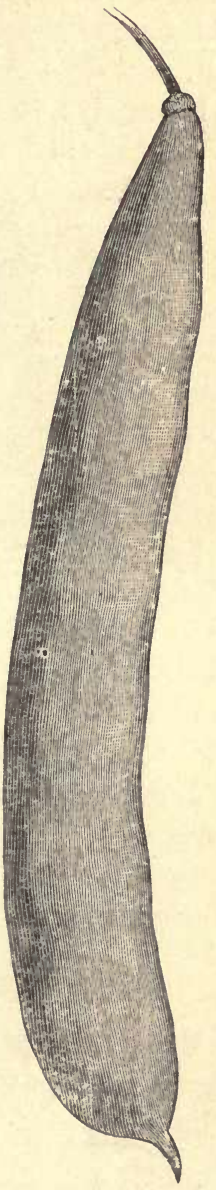

Fig. 18.-GOLDEN WAX BEAN. almost certain to rot, and even should they not, the plant makes no growth, unless in uninterrupted warm weather. 
In this district they should never be planted out until a week or more after the planting of Bush Beans ; if planted at the same time, 10th of May, they are almost certain to fail.

From five to six seeds are planted in each hill about two inches deep. Being a vegetable requiring considerable expense in growing, staking, picking, etc., it brings a correspondingly high price per acre in market; but maturing during the heat of summer, the advantage of earliness in this crop is not so manifest as in many others. The profits per acre average about $\$ 150$, when sold for consumption in the locality in which it is grown. Shipped from earlier sections it, no doubt, would double the above amount. There are many varieties, but only a few of leading merit.

Large White Lima.-With nearly every one the seeds of this variety, either green or lipe, are considered the most tender and delicate of all the varieties of the bean, and it is therefore universally grown, both for market and family use. The ripe seeds are kidney shaped, and of a dull white color.

Jersey Extra Larly Lima.-(See figure 19.) A new variety, said to be ten days earlier than any other sort grown in this vicinity. The pods have been in the New York market as early as July 30th, and sold at the rate of \$3 per bushel (of pods). In size, appearance and quality it is much the same as the Large White Lima.

Dreer's Improved Lima.-The distinctive features of this bean are, early maturity, large yield and extra quality. The bean itself is thick, and in shape more round than oval.

Scarlet Runncr.-A great favorite in European gardens, both as an ornamental plant and a useful vegetab'e. It grows to a height of nine or ten feet, producing dazzling scarlet flowers from July to October. Used both 
as string beans and shelled. Seeds, when ripe, are lilac, mottled with black. A distinct species, Phaseolus multiflorus.

Giant Wax. - Very productive, bearing pods from six

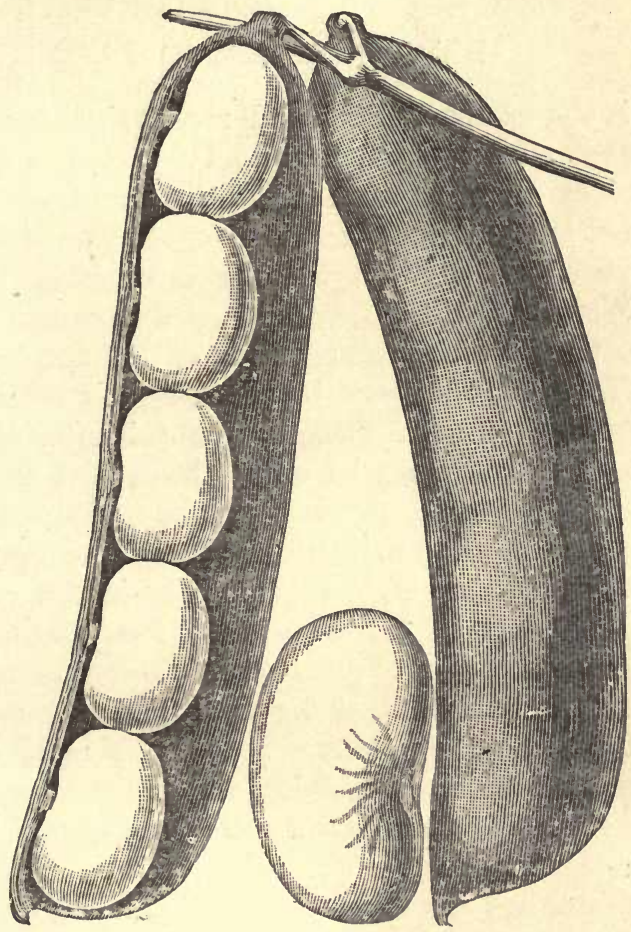

Fig. 19. -JERSEY EXTRA EARLY LIMA BEAN.

to nine inches long, of waxy color, thick and fleshy, tender and of good flavor. The seeds are red when ripe.

German Wax,-One of the best pole varieties, producing large, flat pods.

Horticultural or Speckled Cranberry.-One of the best of the pole sorts for use in pods. It is very produc- 
tive, and of excellent quality, whether served in the green state or shelled. The ripe beans are yellowish white, spotted with pink.

\section{BEET. - (Beta vulgaris.)}

This is one of the leading and most valuable crops of our market gardens, and, next to Cabbages, is perhaps the most extensively grown as an early crop. The soil best suited is that which is rather light than otherwise, always provided that it is thoroughly enriched by manure. We make little difference in the manner of working or manuring the ground for any of our leading early crops. The ground must, in all cases, be thoroughly pulverized by plowing, subsoiling and harrowing, and when stable manure ean be procured, plowed in at the rate of seventy-five to one hundred tons per acre. It must be borne in mind that this large quantity of manure is used where two crops are taken off the land in one season, for Celery always follows crops of Early Beets, Cabbages, Onions, etc. If stable manure cannot be had, the next best substitutes must be used in the quantities specified in Chapter on Manures. As early in spring as the ground becomes fit to work, the Beets are usually sown in rows one foot apart, made by the "marker," about three inches deep. We prefer to sow rather thickly by hand (not less than eight pounds per acre), for the reason that late frosts often kill off a portion of the young plants; but when sown thickly, enough is generally left to make a crop which amply repays the difference of a few pounds of seed. After sowing, the seed is pressed in by the feet (see "Use of the Feet in Sowing and Planting," page 96), and if the weather is dry, the whole surface is also rolled, which firms the soil better around the seed and also leaves the ground level, making it easier 
to be hoed. This firming of Beet seed is very important, as hundreds of acres, particularly of the Sugar Beet, grown on the farm for stock, are anuually lost for want of this precaution. Beets are occasionally planted two feet apart, and the intervening row sown with Radishes. The Radishes mature early, and are used or sold off soon enough to allow more room for the Beet crop. It makes but little difference with us in the profits of the crop which way it is done, the results being nearly the same in each case. But in places where but limited quantities of vegetables can be disposed of, perhaps the latter plan is the best. The young Beets are thinned out to six inches apart when the rows are one foot apart, but when at two feet to only four inches, as they have more space between the rows for air. The thinnings of the Beets are used like Spinach, aud, when carefully handled, they will always sell for more than the cost of the labor of thinning the crop.

In this neighborhood, Beets sown first week in April are begun to be marketed the first week in June and entirely cleared off by July 1st, when the ground is prepared for the second crop. It will be understood that they are, at this early date, sold in an immature state, before the root has reached complete development; but the great point is earliness, the public being well satisfied to pay more.for it half-grown, if early, than when full-grown, if late.

This crop I have always considered a very profitable one, even at the seemingly low price of seventy-five cents per 100 roots, the arerage wholesale price in New York markets. But 80,000 roots are grown per acre when sown at one foot apart, and although the labor of pulling and bunching up is greater than in some crops, yet at seventy-five cents per 100 it will give an easy profit of $\$ 250$ per acre.

Beets are an excellent article to ship, and the price 
paid in New York for the first lots from Savannah and Norfolk, etc., is often as high as $\$ 2$ per 100 roots.

The foregoing all relates to the crop in the green state for an early market, but they are also extensively grown for use in fall, winter and spring. For this they are usually sown later, often in some sections as a second crop, as late as July 1st, although in the Northern States the roots hardly develop enough when sown after June. The manner of saving them in winter will be found under the head of Preserving Vegetables in Winter.

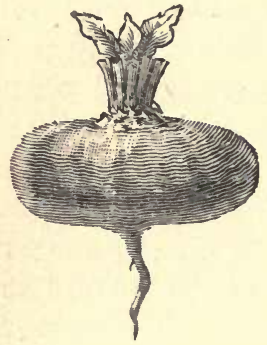

Fig. 20.-EGYPTIAN TURNIP BEET.

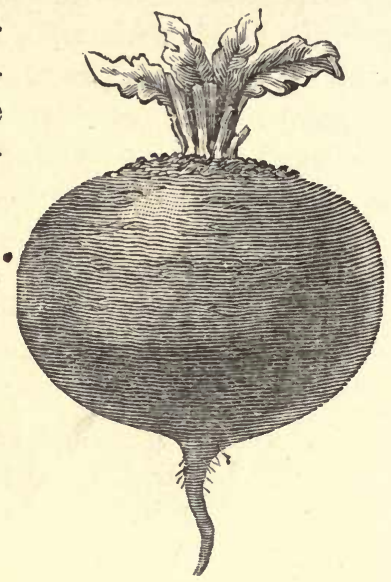

Fig. 21.-ECLIPSE BEET.

The really useful varieties of Beets are very limited in number, and are embraced in the following, arranged as usual, according to their merit as market sorts:

Egyptian Turnip.-(See figure 20.) Now a standard sort, being from ten to twelve days earlier than the old . Blood Turnip. The roots are large in size and of a rich, deep crimson color. From the smallness of the tops at least one-fourth more can be grown on the same space than of any other sort we have been in the habit of raising.

liclipse.-(See figure 21.) A new variety that bids fair to rival the Egyptian as an early market sort. It is just about as early as the Egyptian, but is larger and of very 
much finer quality. It makes a comparatively small top and the roots are of the globe form shown in the illustration. Our market gardeners in the vicinity of New York claim that it is bound to be the leading market sort.

Bastian's Blood Turnip. - After the Egyptian and Eclipse varieties, this is probably the earliest Beet in cultivation. In shape it is very similar to the Early Blood Turnip described below.

Early Blood Turuip. - A well-known variety, following the Egyptian and Eclipse in earliness. It is a deep red color, and of excellent quality.

Dewing's Improved Blood.Turnip.-This is simply an improved variety of the Early Blood 'Iurnip, with the roots of a deep blood-red color, and fine form and flavor. An excellent market sort.

Long, Smooth Blood.-(See figure 22.) A great improvement on the common Blood Beet, being less strong and freer from rootlets, besides being a week earlier. It is now grown here to the entire exclusion of the other. The market demand, however, for early crops requires twice the quantity of round to that of long beets; for late sales of barreled roots exactly the reverse quantities are needed.

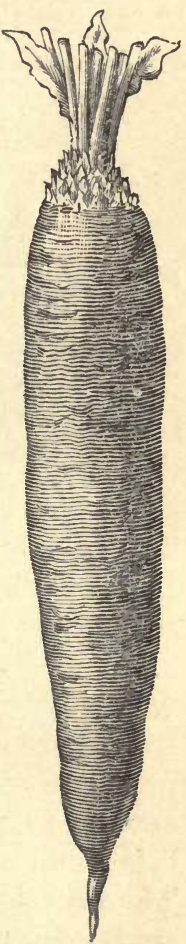

Fig. 22. - LONG, SMOOTI BLOOD BEET.

Swiss Chard.-A distinct species from the common Beet, which is grown for its roots, while the former is cultivated solely for its leaves. The midrib of the leaf is stewed as Asparagus, the other portions of the leaf being used as Spinach. The outer leaves are pulled off as in gathering Rhubarb. It is largely grown in France and Switzerland. In this coun- 
try it is now cultivated to some extent in private gardens only. Its bandsome leaves are as attractive as many of our prized flower garden "foliage plants," and no doubt it would be much valued if we could only regard it without the idea of its being only a Beet.

\section{BORECOLE OR KALE.-(Brassica oleracec. Var.)}

A variety of this, receiving the rather indefinite term of "Sprouts," is extensively grown for the Northern markets, many acres of it being cultivated in the vicinity of New York. It is sown in the month of September in rows one foot apart, treated in every way as Spinach, and is ready for use in early spring. It is difficult to keep in some soils in winter ; those of rather a light nature beng the best. When successfully wintered over, it is a very profitable crop, not unfrequently selling for $\$ 500$ per acre. The variety thus grown is known in the seed stores as Dwarf German Greens. Another class of it is cultivated as we grow late Cabbage ; it is sown in the open ground in May, and planted out at distances, according to the variety, from two to three feet apart. Of all the Cabbage tribe this is the most tender and delicate, and it is st.rprising that it has never yet been wanted in quantity enough to make it a marketable vegetable, not one head being sold to one thousand of the coarse winter Cabbage. The varieties are very numerous; those below described. are all standard sorts.

\section{"Siberian Dwarf Curled Kale," "I)warf German} Greens," or "Sprouts."-(See figure 23.) The leaves are of a bluish green, resembling somewhat the foliage of the Ruta Baga Turnip. It is of delicate flavor and in every way desirable. It is the popular market variety. This is the kind grown exactly as Spinach ; it is cultivated in immense quantities South for Northern markets. 
Very Early Dwarf.-A new rariety that is said to be of special excellence. The leaves are of a yellowish green color, very dwarf and finely curled. It grows very close to the ground.

Dwarf Green Curled Scotch.-A dwarf variety, rarely exceeding eighteen inches in height, but spreading out

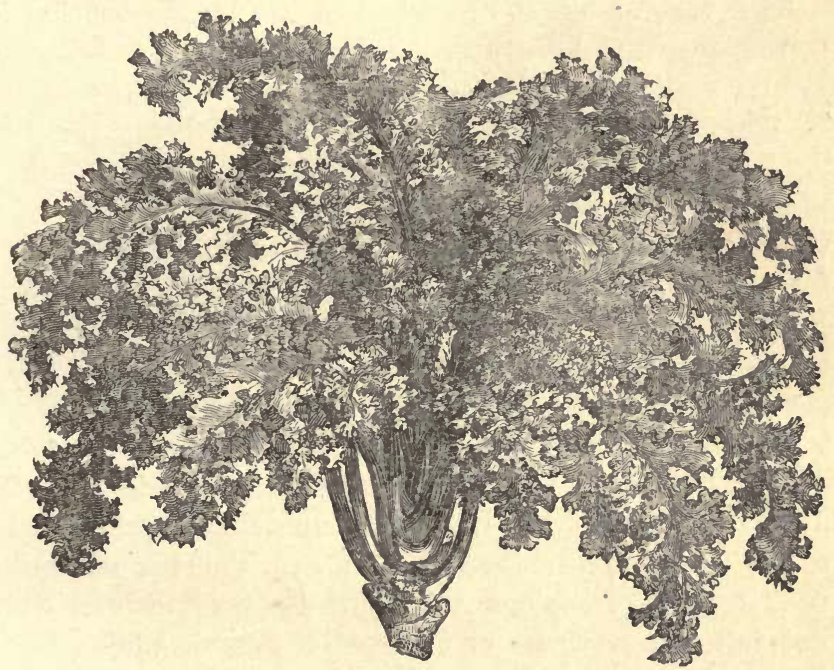

Fig. 23.-GERMAN GREENS.

under good cultivation to three feet in diameter. The leaves are beautifully curled and of a bright green. This variety is very hardy and will remain over winter in any place where the temperature does not fall below zero. It is most tender after being touched by sharp frost. This is the variety used in the famous Scotch dish of "beef and greens."

Purple Borecole.-Similar to the above in all respects except the color, which is a dull purple. 'This is the va- 
riety most esteemed by the Germans. It is very hardy and is often seen in the markets of New York as late as January.

\section{BROCCOLI.-(Brassica oleracea. Var.)}

This vegetable is so closely allied to Cauliflower that it seems absurd to have ever divided them under different heads. Still, we persist in growing them under the names of Broccoli and Cauliflower, the Broccoli being planted for fall use, Cauliflower, on the other hand, being mostly planted for summer use, although it is well known that their seasons might be reversed without any marked difference in the results. Like all of the Cabbage tribe, Broccoli, to grow it in perfection, requires the soil to be in the highest possible degree of fertility. The seed should be sown, in this district, in the early part of May, which will give plants large enough to be transplanted in July. Farther sonth the sowing should be delayed until June or July, and the transplanting delayed accordingly until August, September, or October. There is no doubt that in parts of the country where the thermometer does not fall below twenty or twenty-five degrees above zero, Broccoli may be had in perfection from November until March. A necessary condition of perfect development is a moist and rather cool atmosphere ; for this reason we only get the crop in fine condition, in this district, during the cool and moist months of Uctober and November. Owing often, however, to heat or dryness in the months of Angust and September, the crop becomes an entire failure, and for this reason, for market purposes, it is rather hazardons. When a good crop is made, however, it is very profitable, rarely bringing less than $\$ 8$ per 100 , or about $\$ 800$ per acre; but as the crop in this section falls two seasons out of three, it is not considered a 
desirable one to plant. The plants of most of the varieties are set out two and a half by one and a half feet, or about 10,000 plants per acre.

In this district, for market purposes, we confine ourselves to the first two varieties named below; some others, however, are occasionally grown for family use.

White Cape.-Heads of medium size, close, compact, and of a creamy white color; one of the most certain to head.

Purple Cape.-Nearly similar in all respects to the White Cape, except in color, which is greenish-purple. This variety is rather hardier than the preceding, but its color renders it of less value in market, White Heads of the same quality bringing $\$ 1$ to $\$ 2$ more per 100 . This is a mere matter of fancy in the buyers, however, as, when cooked, there is but little difference in its appearance from the White, and none whatever in the flavor.

Early Walcheren.-This variety seems to produce its heads earlier than the preceding, but they are not usually so heavy or compact. 'This variety so closely resembles a Cauliflower that it is not easy to say in what respect it differs from one. In England, where the Broccoli is much more grown than with us, this variety is sown every few weeks, in order to keep up a constant supply. 'The English catalogues enumerate some thirty or more varieties, and each year adds to the list.

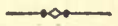

\section{BRUSSELS SPROUTS.-(Brassica oleracea. Var.)}

This vegetable has never come into general use in this country, probably owing to its being too tender to stand the winters of the Northern States. Still, by sorwing in April or May, and planting out in July, it may be had 
in fine condition until December; and, in the Southern States, may be had in use from Norember to March.

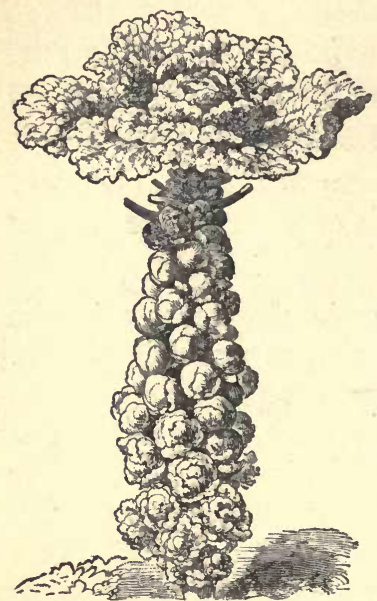

Even in England, where it is very extensively grown, it is not much raised for market, being mainly cultivated for private use. Its cultivation is very simple, and it can be grown on almost any soil. Plant about two feet apart, and cultivate as for Cabbages.

Brussels Sprouts are readily distinguished from all other varieties of the Cabbage tribe by the sprouts or buds, about the size of walnuts, which grow thickly around the stem. 'These Fig. 24. - BRUSSELS SPRouts. sprouts are the parts used, and are equal in tenderness and flaror to Cauliflower or Broccoli.

\section{$\rightarrow \infty$ \\ CABBAGE AND CAULIFLOWER.}

Cabbage is much easier managed than Cauliflower, and is consequently more certain of giving a crop, even under unfarorable conditions. The first condition of success with the Cabbage crop, like that of nearly every other vegetable, is the right kind of soil.

The best soil for Cabbage is a rather sandy loam, not less than ten inches deep, the subsoil under which should be sand or gravel-a clayey or stiff subsoil is uncongenial to almost every crop. It may bo superfluous to say that unless the soil for Cabbage is drained artificially or naturally (by a sand or gravel subsoil), that success is impossible. 'This, of course, is true of nearly every crop grown. The proper pulterizing of the soil is a matter of 
the utmost importance. Although many of the large market gardens in England are yet dug with the spade or digging fork, it is rare that anything else is used with us than the plow and harrow. We ourselves are so satisfied of the superiority of the plow as a pulverizer of the soil over the spade or digging fork, that we would not allow our grounds, for any purpose, to be dug, even if done for nothing, and no digging is ever done on our grounds in any spot where horses can be worked. Experience has shown us that it is always beneficial for the Cabbage crop to plow land in the fall, not only because when thus thrown up in ridges it gets pulverized by the action of the frost, but also that the turning up of the soil exposes the larvæ and eggs of insects also to the frost, which tends greatly to lessen their numbers the succeeding year.

Manure for the early Cabbage crop should always be spread on broadcast, and in quantity not less than 100 cart loads, or seventy-fire tons to the acre, which will leave it, when spread, about two or three inches in thickness. It is not unusual that much choice can be made in stable manure, but when such is the case, equal portions of cow and horse manure are preferable, not that there is much difference in value, weight for weight, but that it is advantageous to have the manure of the cow stable mixed with that of the horse, so as to prevent the violent heating of the horse manure, which, if not repeatedly turned, will generate heat so as to cause it to "fire fang" or burn, which renders it comparatively useless. Always bear in mind that the more thoroughly rotted and disintegrated manure can be had, the better will be the results. When manure is thoroughly rotted and short, it may be turned in by the plow just as it is spread on the land, but if long, it is necessary to draw it into the furrow ahead of the plow, so that it is completely covered in. After plowing in the manure, 
and before the ground is harrowed, our best erowers in the vicinity of New York sow from 400 to 500 pounds of guano or bone dust, and then harrow it in deeply, and smooth over with the back of the harrow, when the bed. is ready to receive the plants.

In the vicinity of New York, and, in fact, now wherever the business of market gardening is intelligently followed, the two best kinds of Cabbage for the early crop are recognized to be the "Early Jersey Wakefield" and "Henderson's Early Summer" for general culture, and to describe others of the scores named would be only confusing. "Jersey Wakefield" is the earliest and a little the smallest, and is planted usually twenty-eight inches between the rows and sixteen inches between the plants, thus requiring from 10,000 to 12,000 plants per acre. "Early Summer" grows a little larger, and should be planted thirty inches apart and eighteen inches between plants, requiring from 8,000 to 10,000 per acre. The reason for placing the rows so wide apart and the plants so close in the rows, is to admit of a row of Lettuce, Spinach or Radishes between the rows of Cabbage. All of these vegetables mature quickly, and can be cut out before the Cabbage grows enough to interfere with them, and it is necessary that this double crop should be taken off the land so as to help pay for the monure that is so lavishly used, but which is absolutely necessary to produce a good crop of Cabbages. Where early Cabbages are grown alone, then it would be better to plant about two or two and a half feet each way, so that cross cultivation can be done; and also in cases where manure in sufficient quantities is not attainable, they are better thus planted when manure has to be applied in the hill. If applied in the hill, a good shovelful of stable manure should be used to each, mixing it well with the soil, but raising the "hill," so-called, no higher than the general surface. 
There has been a want long felt by many of the market gardeners and truckers for a variety of Cabbage which would come in after the Early Summer and before any of the late sorts, but such a sort, with all the characteristics of the Henderson's Early Summer, of standing without bursting, of being later, and consequently larger, is hard to obtain. 'Through the medium, however, of the same good friend who first brought to our notice the Henderson's Early Summer, Mr. Abraham Van Sicklen, of Long Island, we think we will be able, within another year, to present to the public a variety of Cabbage which will exactly supply this long-feit want. That is, of a Cabbage to succeed the Early Summer, being about two weeks later than the average crop of that variety, larger, and with all its good characteristics of standing in the field without bursting and of regularity in habit, close growing and sure heading. I have not yet named this variety, as I wish another season's test of it before deciding to give it to the public; but if it should prove itself during another season as valuable as in the last two it will be a decided acquisition.

The raising of Cabbage, Cauliflower and Lettuce plants will, for "wintered over" plants, be found under the head of "Uses and Management of Cold Frames," and for spring plants under the head of "Spring Raising of Cabbage, Cauliflower and Lettuce Plants."

WHAT DEGREE OF FROST WILL CABBAGE AND CAULIFLOWER STAND IN THE FRAMES BEFORE BEING COVERED WITH THE SASH?

This is often a source of anxiety to beginners. Much depends on the condition of the plants; it sometimes bappens that after the transplanting is finished to October (we usually begin the transplanting in the frames about the 15th), that we have a continuation of com- 
paratively warm weather, which induces a quick and soft growth in the plants, which, of course, renders them very susceptible to injury from frost. When in that condition we have seen them injured when the thermometer only marked twenty-seven above zero, or but five degrees of frost; while if gradually hardened by being exposed to chilly nights, they would receive no injury, even when the thermometer marks ten or twelve above zero. This will be well understood when we remember that in midwinter, when covered with sash alone, they sustiin a cold often for days-together of ten degrees below zero, but then of course they have been gradually inured to it. In sections of the country where the thermometer falls to fifteen or twenty degrees below zero, it will be necessary to use straw mats or shutters over the glass. At all times from the time of putting sashes on in fall until taking them off in spring (which is usually from March 15th to April 1st), abundant ventilation should be given, so as to render them as hardy as possible. The sure indication that they are in the "frost proof" condition is, when the leaves show a bluish color, which they get when they have been gradually hardened off. Although the most of the Jersey market gardeners still use the cold frames for growing the bulk of their early Cabbage crop, of late years the system of spring. sowing and transplanting, and sometimes even without transplanting, is also used to a considerable extent. For full instructions. on this point, see page 51, "Spring Raising of Cabbage, Cauliflower and Lettuce."

In the latitude of New York, Cabbage planting is usuaily begun about the 25th of March and finished by middle of April. It must always be borne in mind that Cabbage, being a very hardy plant, when wanted for an early crop, its setting out in spring should be done in any section as soon as the land is dry enough to work. As a guide, we may say that whenever spring crops of 
Rye, Wheat or Oats can be sown, Cabbage may safely be planted in the open field, for if plants have been properly hardened they will not be injured after being planted out even by eight or ten degrees of frost.

The conditions in the different Southern States are so varied that it is not easy to give directions. It may be taken, however, as a general rule that in any section of the country where the thermometer does not fall lower that fifteen above zero, the seed for Cabbage plants should be sown about October 1st, left (without covering) in the seed-beds all winter, and transplanted to the open ground as soon as it is fit to work in spring, say January or February. In sections where the fall weather continues fine into November, transplanting is done in that month to where the crop is to mature. Great loss is often occasioned in mild seasons in the Southern States, by Cabbages, particularly the favorite variety"Early Summer"-running to seed. As a remedy against this danger I would advise sowing from two to four weeks later than the usual time, in such a way as they could be covered in cold nights only with muslin, or, what is better, the new protecting cloth ; these will answer all the purposes of sashes at one-tenth of their cost. I refer to this cloth more fully in another portion of this work.

After planting in the field, no crop takes so kindly to hoeing or cultivating as the Cabbage, In ten days after the planting is finished, cultivation should begin. If the Cabbages have been set two or two and a half feet apart each way, then the horse cultivator is the best pulverizer, but if a crop has been sown or planted between the rows of Cabbage, then a hand or wheel hoe can only be used-we ourselves now use the Planet Jr. Wheel Hoe exclusively, and find it a saving of three-fourths in labor, with the work better done.

The price at which early Cabbage is now sold varies so much at different dates, and in different parts of the. 
country, that it is impossible to give anything like accurate figures, the range being all the way from $\$ 2$ to $\$ 12$ per 100. Perhaps $\$ 4$ would be a fair average for "Wakefield" and \$5 for "Early Summer," so that counting 11,000 as the average per acre of the former and 9,000 of the latter, we have respectively $\$ 440$ per acre for "Wakefield" and \$450 for " Early Summer." These are the wholesale prices for large markets like New York. In smaller cities, where the product is sold direct to the consumer, one-third more would likely be obtained.

\section{LATE CABBAGES}

are such as mature during the months of September, October and November, the seed for which is sown in open ground in May or June. Perhaps the best date for sowing for main crop is about the 1st of June. We always prefer to sow Cabbage seed for this purpose in rows ten or twelve inches apart, treading in the seed with the feet, after sowing and before covering; we then level with a rake lengthwise with the rows and roll or beat down with the back of a spade, so as to exclude the air from the soil and irom the seed. Sown in this way, Cabbage seed will come up strongly in the driest weather, and is less likely to be afflicted with the black flea than if it made a feeble growth. When the plants get too tall, mow two or three inches off the tops, which will make them stouter and stronger rooted. As the ground used for late Cabbage only yields one crop, unless manure is cheap and abundant, it will not often pay to use it in the profusion required for early Cabbages, so that it is usual to manure in the hill, as is done for early crops, if with stable manure, but when that is not attainable, some concentrated fertilizer, such as bone dust or guano should be used, giving a good handful for each bill, but being careful, of course, to mix it well with the 
soil for about nine or ten inches deep and wide. In this way about 300 pounds per acre will be needed, when 6,000 or 7,000 plants are set on an acre. In our practice we find nothing better than pure bone dust and guano mixed together.

In transplanting Cabbages from the seed-bed to the open field in summer, the work is usually done in a dry and hot season-end of June or July-and here again we give our oft-repeated warning of the absolute necessity of having every piant properly firmed. If the planting is well done with the dibber, it may be enough, but it is often not well done, and as a measure of safety, it is always best to turn back on the rows after planting and press alongside of each plant with the foot. This is quickly done, and it besides rests the planter, so that he can start on the next row with greater vigor. In some sections of the country, particularly in the New England States, six or eight Cabbage seeds are planted in the hills, and when of the height of two or three inches, are thinned ont to one plant in each hill. This we think not only a slower method, but is otherwise objectionable, inasmuch as it compels the manure to be placed for three or four weeks in the ground before the plant can take it up, to say nothing of the three or four weeks' culture necessary to be done before the seedlings in the hill get to the size of the plants when set ont. The cultivation of late Cabbage is, in all respects, similar to that of early, except as it is usually planted alone ; the work of cultivation is done entirely by the horse cultivator, the rows and plants in the rows being, according to the kind, from twenty-four to thirty inches apart. There are a great, number of kinds offered in the different seed lists, but experienced cultivators confine themselves to but very few kinds. These we give in the order in which they are most approved: "Henderson's Selected Flat Dutch," "American Drumhead," and "Marblehead Mammoth." 
In addition to these, the "American Drumhead Savoy" is grown to a considerable extent, and it is really surprising that it is not grown to the exclusion of vearly all other sorts, as it attains to nearly as much weight of erop, is much more tender, and finer in flavor. The "Green Seotch" and "Brown German Kalo" belong to the Cabbage family, but do not form heads. The curled leaves of the whole plant can be used, and are, litio the "Savoy," much finer in flavor than the plain headed cahbages, particularly after having been subjected to frost.

\section{KEEPING CABBAGES IN WINTER.}

It is best to leave late Cabbages out as late as possible, provided they can be lifted before being frozen in. In this latitude they can be safely left out until the third week in November. They are then dug or pulled up, according to the nature of the soil, and turned upside downthe roots up, the heads down-just where they hare been growing, and the heads placed closely together in beds, six or eight feet wide, with alleys of about same width between, care being taken to have the ground leveled, so that the Cabbages will set evenly together. They can be left in this way for three or four weeks, or as long as the ground remains so that it can be dug in the alleys between the beds, the soil from which is thrown in on the beds of Caboage, so that when finished they have a covering of six or seven inches of soil, or sufficient to cover up the roots completely. Sometimes they are covered up immediately on being lifted, by plowing a furrow, shoveling it out wide enough to receive the heads, then plowing so as to cover up, and so on till beds six or eight feet wide are thus formed. This plan is the quickest, but it has the disadvantage, if the season proves mild, of having the Cabbages covered up by the soil too suon, and hence more danger of decay. After the giound is frozen, stable litter, straw or leaves, to the depth of 
three or four inches, should be thrown over the Cabbage bec's, so as to prevent excessive freezing, and to facilitate the getting at the Cabbages in hard weather.

\section{INSECTS ATTACKING THE CABBAGE.}

The insects that attack the Cabbage tribe are various, and for some of them we regret to say that we are almost helpless in arresting their ravages. Young Cabbage plants in fall or in hot-beds in spring, are often troubled with the Aphis, or, as it is popularly known, the "Green fly," or "Green louse." This is easily destroyed by having the plants dusted over once or twice with tobacco dust. This same insect, of a blue color, is often disastrous to the growing crop in the field, and, on its first appearance, tobacco dust should be applied, as, of course, if the Cabbage is headed up, it could not be used; hence, it is always best to apply it as a preventive remedy.

Another insect which attacks them in these stages is a species of slug, or small caterpillar-a green, glutinous insect, about one-fourth or one-half an inch in length. This is not quite so easily destroyed as the other, but will succumb to a mixture of one part white hellebore to four parts lime dust, sprinkled on thick enough as to slightly whiten the plants.

This same remedy we have found to be the most efficacious in preventing the ravages of the "Black Flea," or "Jumping Jack," that is often so destructive to Cabbage plants sown or planted in open ground during May and June, but in this case its application may have to be repeated daily often for two weeks.

Another most troublesome insect is the Cabbage caterpillar, which often attacks the crop when just beginning to liead. This is the larva of a species of small white butterfly, which deposits its eggs on the crop in May or June. When fields of Cabbage are isolated, or where neighbors can be found to act in unison, the best plan is 
to catch the butterflies with an insect-catching net as soon as they show themselves. This is the most effective and quickest way to get rid of them. Howerer, if that has been neglected, the caterpillar can be destroyed by dusting white hellebore on the Cabbages, but, of course, this cannot be done when the heads are matured enough to be ready to use, as the hellebore is to some extent poisonous, though if used when the plants are about half grown, it will do no harm, as the rains will have washed it of sufficiently by the time they head up. The insects here described are not, probably, all that afflict the Cabbage crop. A letter just received from a gentleman in Montgomery, Alabama, says that the young Cabbage plants in that region are often swept off in twenty-four hours by a small green worm - a species of slug or caterpillar, no doubt. The remedy for all such is white hellebore powder, which had better be dusted on the plants once a week, as a preventive, before the insect makes its appearance. In fact, all remedies against insects are best used as preventives, or, at least, on their first appearance.

But the insect enemies that attack the roots of the Cabbage are not so easy to destroy. In fact, with the Wire Worm and Cabbage Maggot we are almost helpless, as far as my experience lias gone. For the latter, which is the worst enemy, a remedy has recently been recommended to me which as yet I have not tested. It is to make a hole with the dibber fire or six inches deep, close to each root, and drop into it nine or ten drops of bisulphide of carbon, closing up the hole again.

Last year the Cabbage and Cauliflower in our "trial grounds" were attacked by the Cabbage maggot at the roots early in May. A small handful of Peruvian guano was at once strewn around each plant and hoed in around the roots; this at once started an unusual vigor of growth, which sustained the plants until they matured excellent heads. Understand, the guano did not injure 
the insect; it only enabled the Cabbage to outgrow its attack.

This season (1886), after plowing our Cabbage ground, we gave it a heavy dressing of lime, thick enough to almost completely whiten the ground. This was thoroughly harrowed in, and to further help against the attack of the maggot, after the plants had been set out three or four weeks, we removed the earth around the stem, and again sprinkled a little lime around it. This has completely stopped the attack of the maggots, for, in a portion of a neighbor's field adjoining, the maggots have nearly destroyed the crop.

But one of the best preventives against the maggot is to plant early, so that the plants get strong enough to overcome their attack. Our market gardeners here rarely have trouble with their main early crops, which are planted last of March or first week in April. In our own trial grounds, having to wait until our samples come in, we do not get our seeds of early Cabbage and Cauliflower sown until first week in March, which is a month too late, hence the liability of the too tender plants to the attack of the maggot. One of the most common mistakes of the inexperienced market gardener is, to delay the planting of early Cabbage too late. Many of them in this latitude delay planting until May, which, if the ground is dry enough to work, had far better be done in April.

For the destruction of the insect which causes the excrescence known as "club root" in Cabbage, a heavy dressing of lime in fall and spring will check it to a great extent. In fact, on lands adjacent to the shores of New York Bay, where the soil is mixed with oyster shells, "club root" is rarely seen, Cabbage having been grown on some fields, successively, for fifty years, without a trace of it being seen, showing that the insect which causes the "club root" cannot exist in contact with lime; for it is 
found on lands where there is no oyster shell deposit, a quarter of a mile distant, where Cabbages cannot be grown two years in succession on the same land, unless heavily dressed with lime, and even then, it is always deemed safest never to plant Cabbages two years in succession on the same ground; for, while such crops as onions show but little benefit by rotation with other crops, Cabbages perhaps more than anything else, are benefited by such alternation, and when it can be done, nothing is better than to let the Cabbage crop be alternated with a green crop, such as German Millet, Timothy or Clover, or else a crop of Oats or Rye.

This is the method pursued by many of the Long Island market gardeners, who grow for the New York market, where their lands are cheap enough to allow them to do so. But the gardeners of Hudson County, New Jersey, which is in sight of New York City, whose lands now are limited in area, and for which an arerage of $\$ 50$ per acre rent is paid per annum, cannot well afford to let their lands lay thus comparatively idle, and, in consequence, do not now raise as fine crops as the lands thus "rested" by the grass or grain crops.

If the land for the Cabbage crop is of a kind suitable to grow a good crop of Curn or Potatoes, and is tilled or fertilized in the manner advised, it is rare indeed that a crop will fail to head, if the plants are in good condition and have been properly planted, unless they are attacked by the maggot or "club root." In our trial ground, where over a hundred different sorts of Cabbage are tested each year, we have found that every kind of Cabbage tested, early or late, has produced solid heads, showing that when the conditions are right, all kinds of Cabbages will head up and produce a crop, though, of course, some are earlier, larger and heavier than others -hence, the value of known sclected kinds.

A circumstance came under our notice in the summer 
of 1882, which well illustrates the necessity for care in planting. We had sold, some time in February, a large lot of our "Early Summer" Cabbage seed to two market gardeners in Rochester, N. Y. The orders were filled from the same bag of seed. Some time about the end of June one of the market gardeners wrote, saying that he had eridently got some spurious kind of Cabbage from us, as his neighbor was marketing his crop, while in his own field of ten acres, he had not a head fit to cut, nor was there any appearance of their ever being so, he thought. Investigation showed that no Maggot, "club root," or other insect was affecting the roots; the land was nearly identical with that which had made a successful crop, and had been equally well manured and cultivated. So the only probable solution of the matter was, that the plants in the case of failure had been loosely planted and had failed to make a prompt start, as in the other case where the planting had been properly done, so that while the one lot advanced without a check, the grow th of the other lot was arrested. This was undoubtedly the case, for there could be no cause for the difference unless on some such hypothesis. But there was a fortmuate sequel. to the case. It luckily happened that a heavy rainstorm occurred while the Cabbages were yet in this unheaded condition. This started, as it were, a second growth, which resulted in their forming splendid heads by August 1st, at a time when Cabbages were scarce, which, lnckily for the owner, brought a much higher price than if they had matured at the proper season in June or July. The result was fortunate for us who had sold the seed, for had it not rained so opportunely, the crop might never have headed up, and it would then hare been hard to convince the man that he had not been furnished with a spurious kind of seed. What has been advised for Cabbage crops, either early or late, is exactly the culture necessary for a crop of Cauliflower, except that Cauli- 
flower, being a plant of more delicate constitution, it requires to be more carefully handled; for, where the Cabbage plants in the cold frames will safely keep over winter in this latitude with no corering but the glass sash, Cauliflower plants require the use of straw mats over the sashes, as the plant is much more easily hurt by frost. In fact, in our increased experience, we find that it is better not to keep the plants through the winter; those sown in February and transplanted into cold frames in March, and planted in the open ground in April, as recommended in the Chapter headed "Spring Raising of Cabbage, Cauliflower and Lettuce," doing rather better and costing much less in labor. The plants, however, must be started early enough, so that they can be set out not later than middle of April, for if not rooted well before warm weather sets in, they will either "button"- that is, form small stunted flowers-or else fail entirely to head up. Cauliflower delights in a cool atmosphere, and never doès well when the season is hot and dry, unless complete irrigation can be given when the plant is about half grown. If this can be done the crop is certain. We ourselves grew in this manner nearly an acre for many years, the crop selling for an average of $\$ 1,200$ per acre annually, and that was before we had introduced the now famous variety known as "Henderson's Early Snowball," which is ahead of all other kinds in its certainty to make a crop. T'he next in succession to this, is the "Early Erfurt," which is again succeeded by the "Early Paris," but neither of these in any respect is equal to the "Snowball." For late crop, the varieties known as "Algiers" and "Erfurt" are the kinds usually grown. The plants are obtained by sowing at the same dates as for late Cabbages. It is planted three feet each way and cultivated exactly as late Cabbages and often sells as high as $\$ 25$ per 100 in November and December. We are of 
the opinion, however, that the "Snowball," of which twice the number can be grown per acre, will prove a more profitable crop even for late, than the "Algiers," as it is assuredly more certain to form heads. It is not once in twenty years that a variety of vegetables or fruit makes such an advance in earliness and quality as this "Snowball" Cauliflower, and we have much satisfaction in the knowledge that we were the first to bring it into cultivation about five years ago. It is now grown to almost the entire exclusion of all other early kinds of Cauliflower in this country, and hundreds have succeeded, both North and South, in raising a crop from this variety, who had previously completely failed with all other kinds. In Cauliflowers, as in Cabbages, it is folly to attempt the experiment of many kinds. Long experience has tanght us that two or three of each for early and second early is all sufficient. Although our seed catalogues enumerate scores of kinds, gardeners who know what they are about, fight shy of all except those whose merit, has been proved beyond any question of a doubt. For this reason we only give the names of such as we know to be the best.

As yet nearly all Cauliflower seed is imported, as we have not yet been successful in raising it here so as to give satisfactory results, our climate seeming to be unsuited for the growth of the seed. But Cabbage seed is almost exclusirely grown here. Though the imported seed costs less than half the price, we rarely have found it safe enough to risk it for market garden crops; the American grown Cabbage seeds should be exclusively used. 


\section{VARIETIES OF CABBAGE.-EARLY.}

Early Jersey Wakefield. - The first notoriety that this variety attained was when we first wrote "Gardening for" Profit." That was nearly twenty years ago, and sinee then it has deservedly taken the-first place as an early market variety. "To most growers the merits and characteristics of the variety are so well known as to hardly need repeating here, but for the benefit of those who may not be familiar with it, we would say that it is univers-

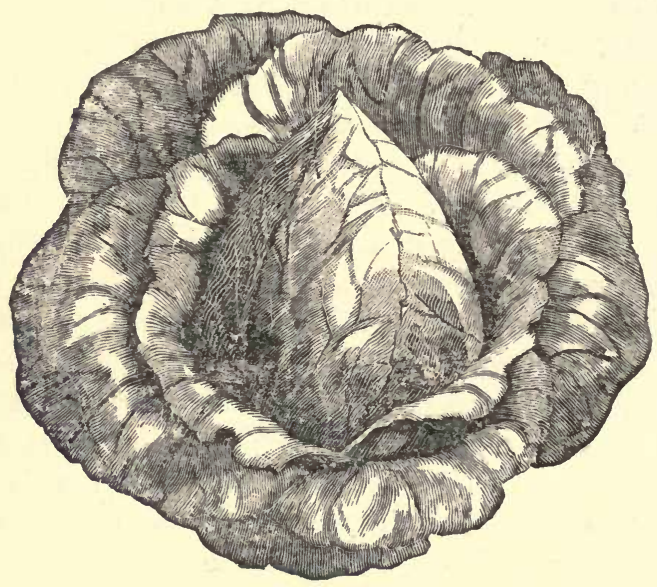

Fig. 25.-Early jersey wakefield cabbage.

ally considered the best early Cabbage in cultivation. Among its merits may be mentioned its large size of head, small outside foliage, and its uniformity in producing a crop. The heads are pyramidal in shape, having a blunted or rounded peak.

A few years after the introduction of the Wakefield Cabbage, we found that it broke into over a dozen subvarieties, of varying size of leaf and shape of head, and, worse than all, of varying earliness. No matter how 
carefully we selected the heads that we used for seed, the same difficulty occurred. A few miles inland, somewhere near the Orange Mountain, New Jersey, we found that an old German was always ahead of us in having the first Wakefields in New York market, and these, too, of a uniformity in shape that none of us nearer the city could produce. All inducements to get him to sell seed were disregarded, and year after year he kept the lead. Several plans were laid to circumvent him, such as ordering a hundred of his Cabbages with roots on. But old Carl was not to be caught so. He filled the order to the letter, making the buyer pay roundly for the roots, but took the liberty of first dipping them in boiling water ! But one day he invited a friend and countryman to see his wonderful Cabbages as they grew. This was a fatal day for Carl's monopoly, for his friend had his eyes about him. and observed that several of the stumps from which the earliest heads had been cut, were marked with a stake, as were a few of the choicest shape, as yet uncut. The secret was out. Carl's success had been gained by persistently, year after year, selecting the earliest and finest heads; taking up the stumps from which they were cut, he planted them carefully, and, removing the young shoots produced from the stumps, he treated them exactly as we treat cuttings of a flower; that is, by planting the slip in the soil, watering it freely, and shading it until it rooted. After these cuttings or shoots of the Cabbage were rooted, they were planted in the usual Cabbage-frame, covered with glass in winter, set out in spring, like a plant from the seed, and next July ripened seed. This process is too expensive and slow to follow for raising Cabbage seed in quantity, but it is now used by careful growers to produce pure and improved stock from which to raise seed. 
IIenderson's Early Summer.-This peerless variety originated with Mr. Abraham Van Sicklen, of Jamaica, Long Island, N. Y., (to whom I paid $\$ 600$ for twenty pounds of the seed), but was named and first introduced by me in 1874. The Early Summer heads about ten days later than the Jersey Wakefield, but being of over double the size, it may be classed as the best large early Cabbage. In weight it is equal to most of the late vari-

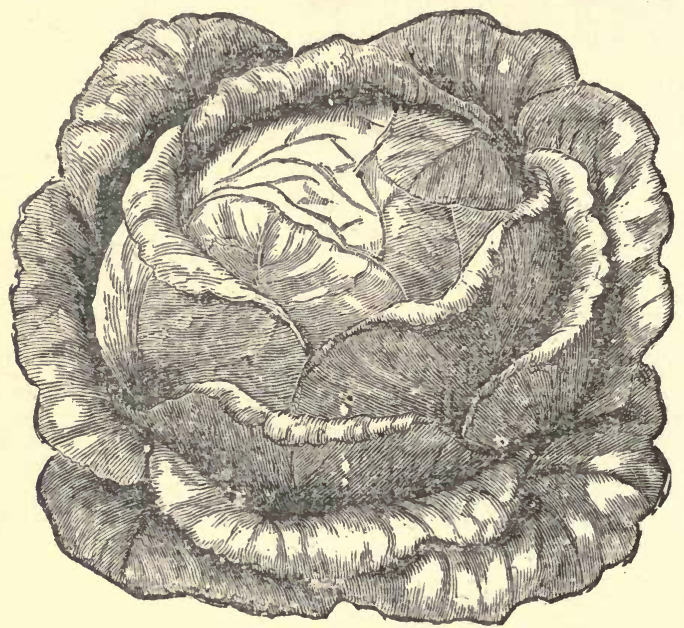

Fig. 26.-HENDERSON'S EARLY SUMMER CABBAGE.

eties, and its short outer leaves enable it to be planted as close as the Wakefield, or at the rate of about 10,000 to 12,000 to the acre, while the Early Flat Dutch, Winningstadt, etc., producing no larger heads, can only be grown at the rate of 8,000 to the acre. It is equally valuable to use as a late sort, as, when sown and planted at the proper time for late Cabbage to be used in winter, we consider it has no superior.

Premicr.-A variety of quite recent introduction, exceedingly early, and much valued as a market sort. 
The heads are somewhat smaller than the Wakefield, but, as it forms very small outer leaves, it can be planted onethird closer-fifteen or eighteen inches apart each way, or from 14,000 to 16,000 to the acre.

Early Winningstadt.-This is really a second early variety, coming in about three weeks later than any of the above. It is an excellent sort, however, where first earliness is not the object, as it heads uniformly and is of large size, often weighing twenty pounds. It is a distinct variety; head pyramidal, the outer leares spiral and spreading. It requires to be planted wider than the eariy sorts. For this reason, together with its comparative lateness, it is not a favorite in gardens where two crops are grown in one season.

Early Flat Dutch.-A very dwarf variety, having large round heads, almost flat on top. It is a very excellent varisty for a succession crop, being two or three weeks behind the earliest sorts, but is now almost supplanted by the Early Summer.

\section{CABBAGE.-LATE.}

Selected Late Flat Dutch.-(See figure 2\%) An excellent standard variety, making large flat heads, very solid, and an excellent keeper for late winter use. Although it grows larger than the "Early Summer," yet as it has to be planted nne-third wider apart, it gives no more weight per acre. It is very largely grown as an early fall sort. It is very tender and of excellent flavor, and is largely used for Sauer Kraut.

Fottler's Improved Brunswick.-A second early and late variety, used originally by the Boston gardeners, but which is now cultivated quite generally all orer the country. It produces large heads of excellent quality. 
Marblehead Mammoth Brumhead. - Probably the largest variety of Cabbage in cultivation, specimens often growing to weigh sixty pounds. In good soil and with proper culture it will average thirty pounds. The heads are round and somewhat irregular in shape. It should be cultivated with the plants four feet apart each way.

Filder Kraut.-This resembles the Winningstadt, but

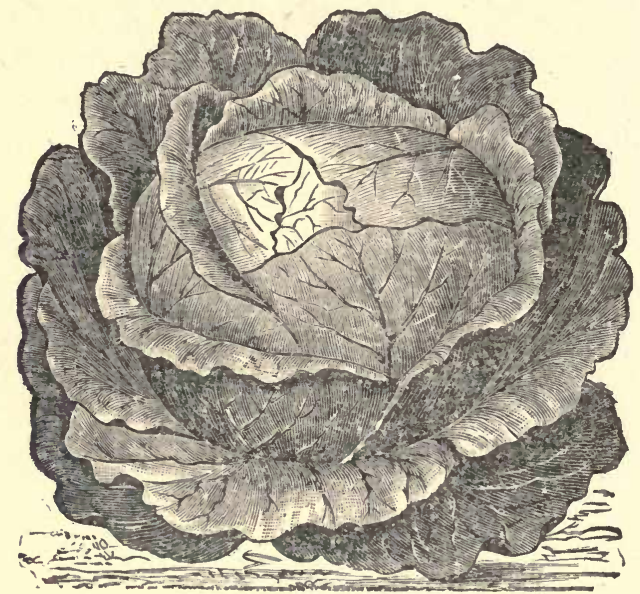

- Fig. 27. - selected j.ATE flat dutch cabbage.

is larger and more pointed. Also largely grown for Sauer Kraut.

American Drumhead Savoy.-This is the largest of the Savoy class, and is the sort most generally cultivated for market. The head is large, spherical, very solid, compact and of a yellowish-green color, and, like all of the Savoy varieties, is of excellent fiavor, far surpassing that of any other late Cabbage. Still, such is the force of habit, that the public do not purchase one Savoy for every thousand of the coarse Drumhead Cabbages, al- 
though the difference in quality between the two is as great as between the fox grape of the woods and the cultivated Delaware. Grown in fall and allowed to be touched by frost, it is one of the most delicious of all vegetables. figure 28.)

Red Dutch,-This is used almost exclusively for pickling. It is one of the hardiest of all Cabbages, and when preserved as directed for the others, will keep later in the

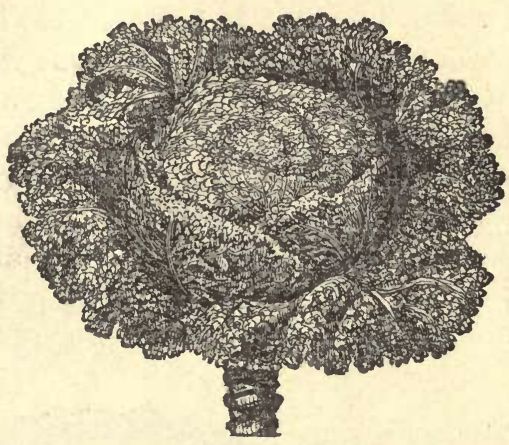

Fig. 28. - american DRUMHeAd Savot CABBAGE. season than any of them. It is slow to mature, howerer, and requires a richer soil for its perfeet development.

Mammoth Rock Red.-A new large-growing selected strain of the old Red Cabbage, the heads of which will average twelve pounds each.

\section{CAULIFLOWER.}

As the cultivation of Cauliflower is almost identical with that of Cabbage, and as these are two of the most important of all crops to the market gardener, very full instructions are given under "How to grow Cabbage and Cauliflower," on page 51.

Ilenderson's Early Snowball.-(See figure 29). This variety, introduced six years ago by me, is now the leading early variety. We have found it to be not only the 
earliest of all Cauliflowers, but it is more certain to make a head than any other variety we have erer grown. Sown March 1st in our trial grounds in Jersey City (which, however, is a month too late), at the same time and under the same conditions with other kinds, heads of the Early Snowball measuring nine inches in diameter have been ready to market by June 10 th, one week before any other sort. From its dwarf growth and short outer leaves, this variety has been found to be peculiarly well adapted for forcing under glass, and for this purpose no other variety is now so largely grown. It is also beginning to be used for the fall crop of Cauliflower, for which

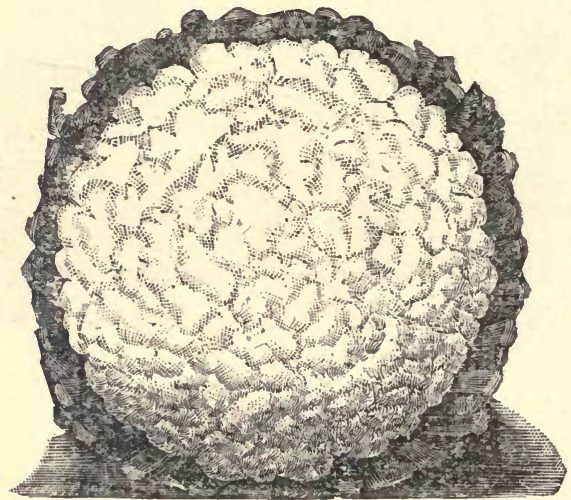

Fig. 29.- HENDERSON'S EARLY SNOWBaLy CAULIFLOWER.

it is equally well adanted as for the early crop. From 12,000 to 13,000 are planted on an acre. This variety is a very shy seed-bearer, and the consequent high price of the seed has induced unprincipled dealers in many sections of the country to substitute spurious sorts. In our trial grounds we found that in a test of ten of these samples purporting to be the true "Snowball," not one was correct, and nearly all were worthless. 
Extra Early Dwarf Erfurt.-This fine sort is a dwarf, compact, growing kiud, producing uniformly large heads. The leaves grow larger and not so close as the Snowball, besides it is not so early.

Extra Early Paris.-This well-known variety is equally meritorious in all respects with the Erfurt, except that it requires more space to grow in, as it forms larger heads.

IIalf Larly Paris or Nonpareil.-A useful variety for succession crop. The difficulty with Cauliflowers for market is, that the whole crop comes in and must be sold in a space of two or three weeks, unless we have a succession of varieties.

Le Normand's Short Stemmed.-A large late vasiety, producing well-formed heads of excellent quality.

Large Late Algiers. - An excellent late variety, now coming into very general favor on Long Island, New York, and other Cauliflower-growing districts. Enormous quantities of this variety are annually grown for market and pickling, with varying results, sometimes selling as high as $\$ 25$ per 100 , and again as low as $\$ 3$. It is usually planted quite wide-three by three feet each way-and worked by horse cultivation. It is a good plan to break and turn down the leaves of Cauliflower over the head as it is developed. This not only keeps it whiter, but prevents its spreading.

\section{CARD00N.-(Cynara Cardunculus.)}

A regetable that is but little grown, and grown oftener as a novelty than for use. It belongs to the same family as the Artichoke, which it much resembles. The leaf stems, after blanching, are used in soups or in salads. It is cultivated by sowing the seeds in early spring, 
thinly, in rows three feet apart, and thiuning out to eighteen inches between the plants. The plant attains its growth in early fall, when it is blanched by tying the leaves together so as to cause an erect growth, after which it is earthed up, and preserved exactly as we do Celery.

\section{CARROT.-(Daucus Carota).}

This may be classed more as a crop of the farm than of the garden, as a far larger area is grown for the food of horses and cattle than for culinary purposes. Yet it is a salable vegetable in our markets, and by no means an unprofitable one to grow on lands not too valuable. It is not necessary that the land for this crop should be highly enriched. I have grown on sod land (which had been turned over in fall), 300 barrels per acre, without a particle of manure, and three years after, and on the same land, which had been brought up to our market garden standard of fertility, a very inferior crop; the land being too rich, induced a growth of tops rather than roots. In our market gardens, we sow in rows fourteen inches apart, thinning out to three or four inches between the plants ; but on farm lands, where space is not so valuable, they shoula be planted eighteen or twenty-four inches between the rows, and worked with the cultivator. For early crops, we sow at the beginning of our first operations in spring, in the same manner as we sow Beets, as soon as the ground is thoroughly dry; but for later crops, they may be sown any time in this latitude until the middle of June. This is one of the regetables that requires a close watching to see that it does not get enveloped with weels, as, in its eariy stage, it is of comparatively feeble growth, and unless it is kept clean from the start, it is apt to be irrevocably injured. 
The usually preseribed quantity of seed per acre is five pounds, bat I have always considered it safer to sow nearly double that quantity. In "dry weather it germinates feebly, and not infrequently, when seed comes up thinly, it is scorched off by the hot sun, and the saving of a few pounds of seed may entail the loss of half the crop. We prefer to sow all such crops by hand, though for field culture on a large scale, the seed drill should be used. In all cases tread in the seed--see "Use of the Feet in Sowing and Planting," Chapter 12-to which, even at the risk of repetition, I again beg to call attention.

The Carrot, like all other root crops, delights in a sandy loam, deeply tilled. Considerable quantities of the early varieties are sold in our markets in bunches, in a half-grown state, at prices equal to early Beets sold in the same manner. Sold in this state, they are highly profitable at the prices received, but only limited quantities can be disposed of. In the dry state, during fall and winter, they range from $\$ 1.50$ to $\$ 2$ per barrel, according to quality, and at these prices will yield double the profit of Potatoes as a farm crop.

The varietes in general cultivation are limited. The favorite variety for all purposes is the

Early French Forcing.-The earliest variety, and one largely grown for forcing purposes. It makes a small, almost globe-shaped root, of an orange-red color.

Early Scarlet IIorn.-An old and favorite sort for an early crop, but not large enough to be suitable for general culture. It is one of the varieties that is bunched and sold in our markets in a green state. It matures eight to ten days earlier than the Long Orange, and is sometimes used for forcing.

Ilalf Long Red (Stump Rooted). - (See figure 30.) At this time this variety is more largely grown for the New 
York market than any other, and is the finest of the early sorts. It is intermediate in size and time of maturity between the Early Scarlet Horn and the Long Orange.

Varly Haif Long Scarlet (Pointed Rooted).-The only difference between this and the preceding variety is that it has a pointed instead of a stump or blunt root.

\section{Early Ilalf Long Scarlet} ('arentan.-A distinct variety, almost cylindrical, with few and very small roots. The skin is smooth, flesh red, and without any core or heart. It is excellent for forcing, and for fine quality and perfect shape can hardly be surpassed.

\section{Long 0range Im-} proved.-(See figure 31.) This is equally adapted for market and family use. It is of large size, fair specimens LONG RED STUMP- ORANGE IM-

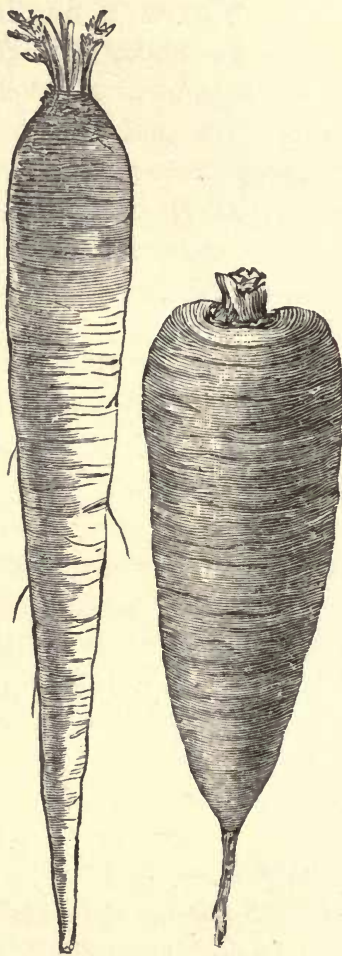

Fig. 32. DANVERS CARROT. averaging twelve inches in length, with a diameter of three inches at the top; color, orange red, varying in depth of shade in diferent soils.

Danvers.-(See figure 32.) The color of this valuable sort, which is of comparatively recent introduction, 
is a rich shade of orange. In shape it is midway between the Early Scarlet Horn and the Long Orange. Under the best cultivation, it is said to have yielded from twenty-five to thirty tons of roots per acre.

Large White Belgian.-The most productive of all varieties. The root is white; that part. growing above ground, and exposed to the air, green. It is exclusively grown for stock, bearing nearly twice as much in weight per acre as the Long Orange. Horses do not eat it quite so readily, however, and it is said to be less nutritious than the red or orange sorts.

Yellow Belgian.-Similar to above; color, yellow.

CHERVIL.-TURNIP-ROOTED.-(Choerophyllum bulbosum.)

A vegetable of recent introduction, closely allied to the Parsnip, which it resembles in shape. It is of a grayish color; the flesh is white and mealy, tasting something like the Sweet Potato. It is equally as hardy as the Parsnip, and in France, where it has been cultivated to a considerable extent, is said to heve yielded six tons per acre. It is one of the many plants that were experinented with in Europe as a substitute for the Potato, when it was feared that that tuber would be lost to us by disease. Its culture is in all respects similar to the Parsnip or Carrot; it is entirely hardy in any latitude, and is rather improved by the action of the frost. It must be sown as early in spring as the soil is fit to work, it being slow to germinate if the weather becnmes hot and dry. 


\section{CELERY.-(Apium graveolens.)}

I know of no vegetable upon which so much unnecessary labor is expended with such unsatisfactory results as Celery. Many private cultivators still think it necessary to dig out trenches, from six to twelve inches deep, involving great labor and expense, and giving a crop very inferior to that planted on the level surface, in the manner practiced on hundreds of acres by the market gardeners in the vicinity of New York.

Our manner of treating the Celery crop is now very simple. Instead of sowing the seed in a hot-bed or cold frame, which is the European plan, but not practicable here (unless when on such soils as the muck deposits at Kalamazoo, Michigan), owing to the tendency of plants thus sown to run to seed, the seed is sown in the open ground as soon as that is fit to work in spring-here about first week in April-on a level piece of rich mellow soil, that has been specially prepared by thorough pulverizing and mixing with short stable manure.

I have had large experience in growing Celery plants, as our demand for the plants often reaches $2,000,000$ of plants in a season, and we never fail in getting a crop by rigidly adhering to the following simple method.

The bed being fined down by raking, so that it is clear of stones and all inequalities, lines are drawn out by the " marker" eight or nine inches apart, in beds of eight rows in each, rubbing out every ninth mark for an alley, on which to walk when weeding, etc. The seed should be sown rather thinly, one ounce being sufficient for twenty feet in length of such a bed, or about 150 feet of row.

The seed is sown by hand in the rows; after the sower follows a man who evenly presses down the seed in the drill with the feet. That done, the back of a rake is drawn lightly lengthwise of the bed, which slightly cov- 
ers the seed to the average depth of something less than half an inch. After this, the bed is still further firmed and levelled by being rolled, or in small areas evenly patted down with the back of a spade.

As soon as the seeds of Celery begin to germinate, so that the rows can be traced, hoe lightly between the rows, and begin to pull ont the weeds as soon as they can be seen. One day's work, at the proper time, will be better than a dozen after the secd-bed gets enveloped with weeds, besides insuring much finer plants.

As the plants advance in growth, the tops are shorn off, generally twice before the time of setting out, so as to induce a stooky growth ; plants thus treated suffer less on being transplanted. This plan of shearing off the tops we practice with Cabbage, Cauliflower and many other kinds of plants to induce stocky growth.

The time of planting out in the Northern States may run from June 15th to the end of July, and in the Southern States from August 15th to the end of September. In this section, we prefer to plant in July, as there is but little gained by attempting it early. In fact, I have often seen plants raised in hot-beds and planted out in June, far surpassed both in size and quality by those raised in the open ground and planted a month later. The great difficulty experienced in the Southern States is, in raising the plants ; for, if sown in March or April, as we do here, the high temperature and dry atmosphere either kill the plants outright, or so shrivel them up that they never start to make a free growth.

By sowing about the middle of August in extreme Southern States, shading with the protecting cloth sashes, already referred to, in hot days from 9 A. M. to 4 P. M., and planting out the end of September, a fair crop of Celery may be obtained in the late fall and early winter months. The plants are sometimes specially grown at the North for planting at the South, but 
in all such cases they must be plants grown from sowings made in June or July, for if grown at the North at the usual season, they would not answer, as they would become so large that they would require to be planted out before the end of July, and in most of the Southern States, if planted then, they conld not stand the longcontinued high temperature and dry atmosphere of August and September.

It is doubtful if this special growing oi plants is likely to be done, and our friends at the South must submit to paying us for our Celery already grown, just as we must submit to have the cream of our profits taken off by their early supply of spring vegetables. It is a geographical condition of culture that both sections must accept. In almost all the early vegetables, the first supplies come from Southern gardens, thus anticipating our crops by some weeks; while Celery is one of the very few things with which we can compete with our Southern friends in their own markets.

Celery is a plant requiring a cool, moist atmosphere, and it is nonsense to attempt to grow it early in our hot and dry climate, unless under climate and soil specially adapted, which is found in the vicinity of Kalamazoo, Michigan, Horse Heads, New York, and some other similar localities, where there is a rich regetable deposit on level bottom lands.

But even when grown, it is not a vegetable that is ever very palatable until cool weather. This our market experience well proves, for, although we always have a few bunches exposed for sale in July and August, there is not one root sold at that time for a thousand that are sold in October and November.

(elery is always grown by us as a "second crop;" that is, it follows after the spring crop of Beets, Onions, Cabbage, Cauliflower, Peas or early Potatoes, which are cleared off and marketed, at latest, by the middle of July. 
The ground is then thoroughly plowed and harrowed. No additional manure is used, as enough remains in the ground from the heary coat it has received in the spring, to carry through the crop of Celery.

After the ground has been nicely prepared, lines are struck out on the level surface three feet apart, and the plants set six inches apart in the rows. If the weather is dry at the time of planting, great care should be taken that the roots are properly "firmed." Our custom is to turn back on the row, and press by the side of each plant

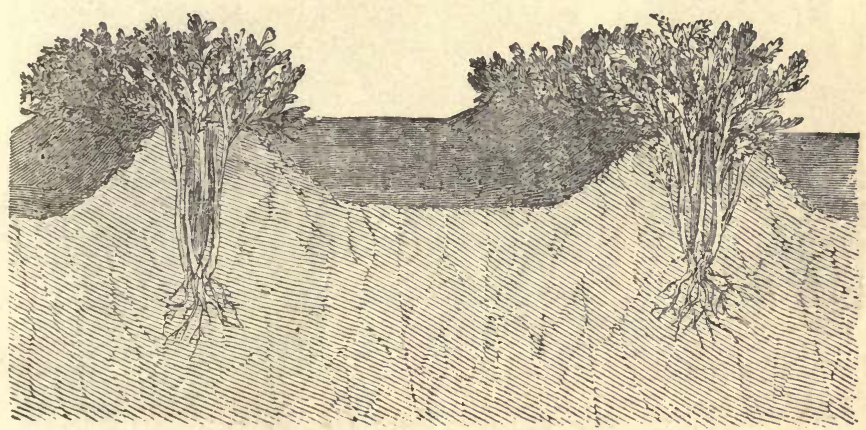

Fig. 33.-CELERY AFTER "HANDi.ing."

gently with the foot. This compacts the soil and partially excludes the air from the root until new rootlets are formed, which will usually be in forty-eight hours, after which all danger is over. This practice of pressing the soil closely around the roots is essential in planting of all kinds, and millions of plants are annually destroyed by its omission. After the planting of the Celery is completed, nothing further is to be done for six or seven weeks, except running through between the rows with the cultivator or hoe, and freeing the plants of weeds until they get strong enough to crowd them down. This will bring us to about the middle of August, by which 
time we usually hare, especially at night, that moist and cool atmosphere essential to the growth of Celery.

Then we begin the "earthing up" necessary for blanching or whitening that which is wanted for use during the months of September, October and Norember. 'The first operation is that of " handling," as we term it ; that is, after the soil has been drawn up against the plant with the hoe, it is further drawn close around each plant by the hand, firm enough to keep the leaves in an upright

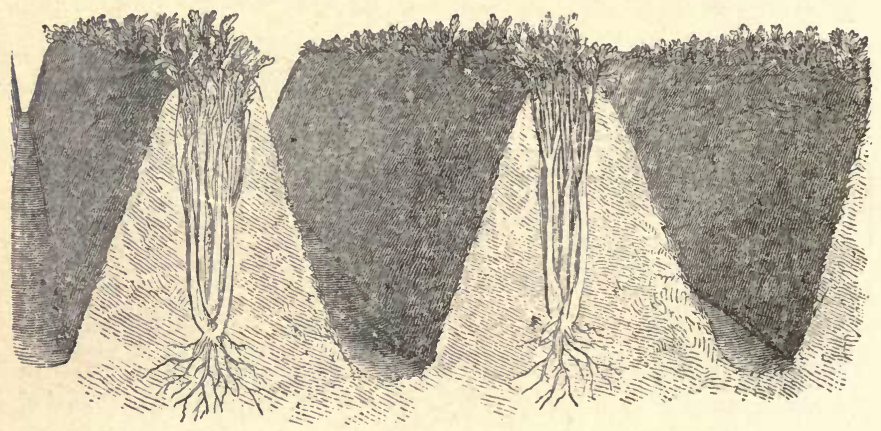

Fig. 34.-CELERY EARTHED UP.

position, and prevent them from spreading, which will leave them as shown in figure 33.

This being done, more soil is drawn against the row, either by the plow or hoe, as circumstances require, so as to keep the plant in this upright position. The blanching process must, however, be finished by the spade, which is done by digging the soil from between the rows and banking it up clear to the top on each side of the row of Celery, as in figure 34.

Three feet is ample distance between the dwarf varieties, but when "Seymour's Superb," “Giant White Solid," or other large sorts are used, though they are now rarely grown, the width between the rows must be 
at least four and a half or five feet, which entails much more labor and loss of ground. For the past fifteen years no Celery but the dwarf rarieties is grown in our vicinity, which saves in consequence at least one-half in labor and one-third in ground, while the average price per root in market has been always equal to, and occasionally higher, than for the tall growing sorts.

Nearly all market gardeners have at last got their eyes opened to the value of the dwarf sorts, and I think that a few years more will suffice to throw the large and coarse-flavored sorts, such as "Seymour's Superb" and " (riant White Solid," out of our markets.

The preparation of the soil and planting of Celery for winter use is the same in all respects, except that what is intended for winter need never be "banked up" with the spade. It merely requires to be put through the handling process to bring it into a compact and upright position preparatory to being stowed away in winter quarters. This should not be done before the middle of September, or. just long enough before the Celery is dug up to keep it in the upright position.

We have, howerer, another method which we have found to answer very well for the late crop, and it is one by which more roots can be grown on the same space and with less labor than by any other. It is simply to plant the Celery one foot apart, each way, nothing farther being required after planting, except twice or thrice hoeing to clear the crop of weeds until it grows enough to cover the ground. No handling or earthing up is required by this method, for, as the plants struggle for light, they naturally assume an upright position, the leares all assuming the perpendicular instead of the horizontal, which is the condition essential before it is put into winter quarters. This method is not quite so general with us as planting in rows, and it is, perhaps, better adapted for private gardens than for market. As the plant is 
more excluded from the air, the root hardly attains as much thiciness as by the other plan.

We are often asked for the cause of and remedy for Celery rusting or burning. The cause, we think, is the condition of the weather, which destroys the tender fibers or what are called the "working roots" of the plant, for we find it usually worse in seasons of extreme drouth or moisture, particularly in warm weather.

We know of no remedy, nor do we believe there is any. We may say, however, that it is less liable to appear on new fresh soils, that are free from acids or sourness, than on old soils that have been surfeited with manure and have had no rest.

Althongh, under ordinary conditions, if proper varieties of Celery are used, the crop should never be pithy or hollow, yet we have found that now and then even the most solid kinds of Celery have become more or less hollow when planted in soft loose soils, such as reclaimcd peat bogs, where the soil is mostly composed of leaf mould. In fact, on heavy or clayey soils, the Celery will be specifically heavier than on lighter soils.

Our manner of preserving Celery during the winter is now very simple, but as the knowledge of the process is not yet universally known to market gardeners in all sections of the country, I will endeavor to put it plain enough, so that my readers "may go and do likewise." In this locality we begin to dig up that which we intend for winter use about the end of October, and continue the work (always on dry days) until the 20th or 25th of Norember, which is as late as we dare risk it out for fear of frost. Let it be understood that Celery will stand quite a sharp frost, say ten or even fifteen degrees, while twenty or twenty-five degrees will destroy it. Hence, experience has taught us that the sharp frosts that we usually have during the early part of November rarely hurt it (unless in rare cases where we have had an unusual 
warm spell succeeded by sharp frost), though often causing it to droop flat on the ground, until thawed out by the sun. It must, however, never be touched when in the frozen state, or it is almost certain to decay. The ground in which it is placed for winter use should be as dry as possible, or if not dry, so arranged that no water will remain in the trench. The trench shonld be dug as narrow as possible, not more than ten or twelve inches wide, and of the depth exactly of the height of the Celery; that is, if the plant of the Celery be two feet in length, the depth of the drain or trench should be two

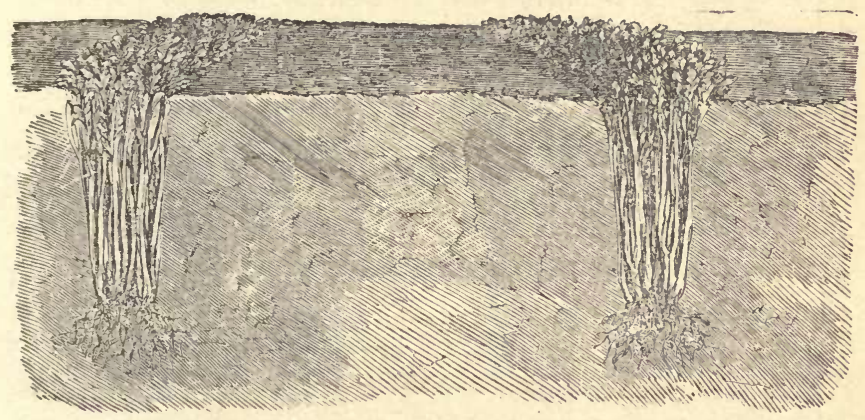

Fig 35.-CELERY STORED FOR WINTER.

feet also. The Celery is now placed in the trench as nearly perpendicular as possible, so as to fill it up entirely, its green tops being on a level with the top of the trench. Figure 35 represents a section across trenches filled with Celery in the manner just described. No earth whatever is put to the roots other than what may adhere to them after being dug up. It being closely packed together, there is moisture enough always at the bottom of the trench to keep this plant, at the cool season of the year, from wilting, and also to induce it to form new white roots, which must be formed before the Celery will blanch. That which is put in trenches about the 25th 
of October is usually ready to be taken up for use about the 1st of December ; that a couple of weeks later, by 1st of January ; and the last (which we try always to defer to the 15th or 20th of November), may be used during the winter and until the 1st of April. For the first lot no covering is required, but that for use during the winter months must be gradually covered up until the middle of December, or until the 1st of January, when it will require at least a foot of covering of some light, dry material-hay, straw, or leaves-the latter perhaps the best. I have said the covering up should be gradual. This is very important; for if the full weight of covering is put on at once it prevents the passing off of the heat generated by the closely packed mass of Celery, and in consequence it to some extent "heats," and decay takes place. Covered up in this manner, it can be got out with ease during the coldest weather in winter, and with perfect safety. 'These dates of operations, like all others named throughout this work, are for this latitude; the cultivator must use his judgment carefully in this matter, to suit the section in which he is located.

For market gardeners, and others who have large quantities, this is the best method of storing ; but for smaller growers, either for sale or for private use, quite a quantity may be preserved in any cellar where there is no furnace or other fire heat. When a few hundred roots only are to be stored it can be placed in narrow boxes, say nine inches wide, four or six feet in length, and of a depth a little less than the height of the Celery. A few inches of sand or soil is placed on the bottom of the box, but none must be put between the stalks of the Celery, and the Celery is packed in the box upright, the roots being placed on the sand at the bottom; the Celery must be packed in as tight as possible, but without bruising. Boxes thus packed and stood on the cool floor of the cellar, if put away in Novem- 
ber, will be "blanched" fit for use auring January, February, and March. If put in sooner than November it will blanch earlier, and if stored later it will keep later. If larger quantities are to be kept in the cellar, the cheapest practicable way to do so is to begin at one side next tine wall, furthest from the entrance, and erect boards across the cellar, nine inches from the wall, and of a height a little less than the length of the Celery-that is, if the Celery is twenty-four inches in length, the boarding may be eighteen or twenty inches high. In this narrow division the Celery is packed in upright, as above described for packing in boses. As soon as the first tier is filled, erect another board trench or division at nine inches distant from the first, and so on until the whole space to be used is flled up. It will be understood that no soil or sand is packed between the stalks of Celery, only two or three inches being strewn on the floor, on which the roots are placed. Simultaneously with the formation of the white rootlets the blanching process begins, which is simply the plant making an effort to grow in the dark, and thus becoming blanched or whitened. We have sometimes complaints that Celery fails to blanch or whiten. In all such cases the roots must have been in some way injured by being frozen or dried too much while being lifted from the field, but this should never happen with ordinary care. A cellar or root-house twenty by twenty feet, so packed, will hold from 3,000 to 5,000 roots of Celery, according to their size. Care must be taken not to get the board partitions forming the trenches, or divisions between the tiers of Celery, more than nine or ten inches apart, for if at much greater distance the stems and leaves would be in too large masses and would generate heat and rot.

As the cellar or root-house is usually a damp and dark apartment, there will generally be no necessity to water the Celery after it is packed. Every means of rentilation 
should be used, even in cold weather, for it must always be borne in mind that Celery is a vegetable that will stand quite a sharp frost without injury, so if the temperature of the cellar falls five or six degrees below the freezing point, no injury will be done. When Celery or other vegetables are packed away for preservation in cellars or in the open field, it is indispensable that no water be allowed to lodge in the pit or trench; so that in the event of using a cellar or root-house for this purpose, a matter of first importance is thorough drainage, in soils where drainage is necessary.

Regarding the profits of this crop I can speak from a very extensive experience in its culture, having cultivated at one time, an arerage of ten acres for eighteen years. For many years, in the early part of that time, it was by no means what we would now call a profitable crop. By persisting in raising the large growing sorts, and the awkward and expensive mode we had then of working it, we were satisfied if it gave us a profit of $\$ 50$ or $\$ 75$ per acre. But for the last twenty years, by adopting the flat culture, and the drain or trench system for winter storage, it has done much better, and is now a very profitable "second crop," averaging a clear profit of \$2:50 per acre, though it rarely brings here over $\$ 2.50$ per 100 roots. No doubt, in many parts of the country, it is much more profitable than in the crowded markets of New York. It is shipped from here in all directions-to Philadelphia (largely), Baltimore and Washington (South), and to Newport, Providence, Hartford and New Haven (East). It is a bulky and expensive article to ship, and the dealer must realize more than double on the purchase, or it will not pay his risk. It must thus cost the consumer, in those towns to which we send it, seven or eight cents per head, a price at which it would pay a clear profit of $\$ 1,000$ or $\$ 1,500$ per acre.

If the arkward and laborious systems of cultivation 
still persisted in for the growing of Celery are a mistake, the continued use of the tall growing and coarse varieties we believe to be even a far greater one. The kinds that are offered in European catalogues are many, but in the whole list there are but few that are desirable for the market gardener or for private gardens. The climate of England is much more favorable to the growth of Celery than that of our country, and every year new varieties are offered there, of which only now and then one proves of permanent value, but with the majority the differences are mainly in the name The following kinds, some of them of rery recent introduction, are great improvements on the sorts grown a dozen years ago:

\section{Ienderson's Golden} Dwarf.-(See figure 36.) This is now the

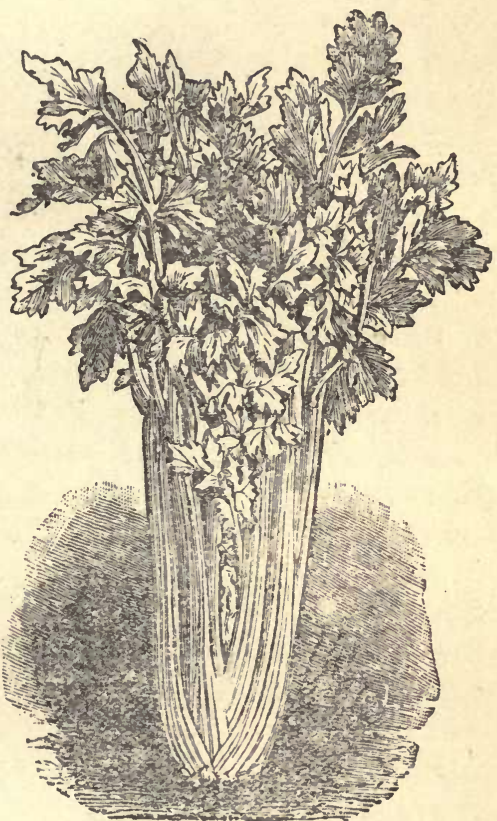

Fig. 36. - HENDERSON's GOLDEN DWAKF CELERY. leading variety, not only around New York, but in nearly all parts of the country. In the great Celery-growing district of Kalamazoo, Michigan, it is the variety that is planted almost exclusively. In size and habit of growth it is much the same as the Half Dwarf and Dwarf White kinds, except that when blanched, the heart is of a waxy 
golden yellow, rendering it a most attractive and showy variety for either market or private use. It is entirely solid, of excellent flavor, and one of the best keepers during winter. It originated with us from a chance seedling, about fifteen years ago.

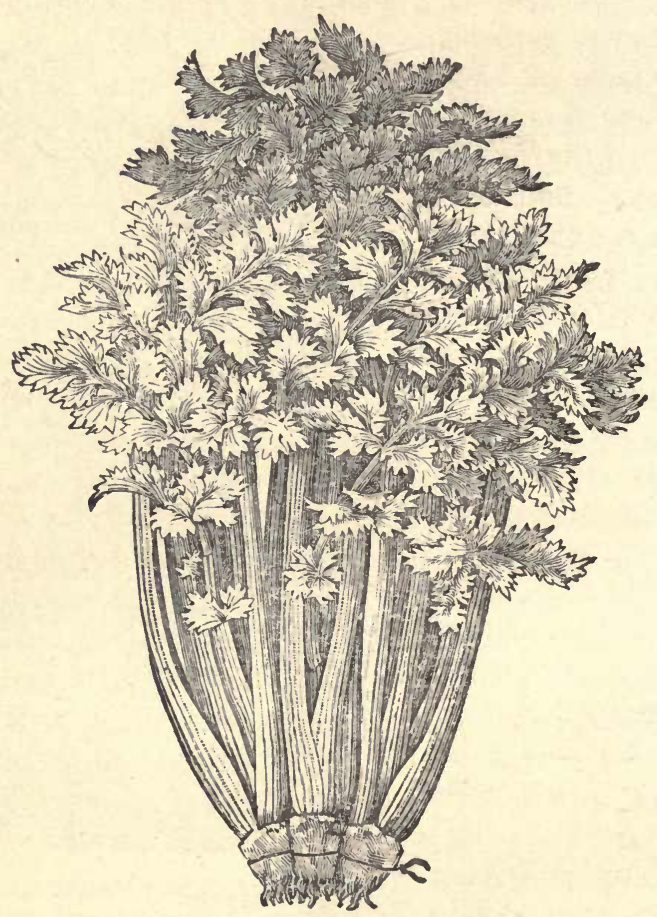

Fig. 37. - WHITE PLUME CELERT, AS PUT UP FOR THE NEW YORK MARKET.

White Plume.-(See figure 3\%) This variety presents characteristics so different from what we have been accustomed to find in Celery that it merits the rather extended description which follows. The peculiarity of the variety is, that its stalk and portions of its inner leaves and. 
heart are naturally white, so that by closing the stalks, either by tying them up with matting or by simply drawing the soil up against the plant and pressing it together with the hands, and again drawing up the soil with the hoe or plow, so as to keep the soil that has been squeezed against the Celery in its place, the work of blanching is completed; while it is well known that in all other varieties of Celery, in addition to this, the slow and troublesome proeess of "banking" or " earthing up" with a spade is necessary. Another merit of this variety is that it far excels any known'vegetable as an ornament for the table, the inner leaves being disposed somerhat like an ostrich feather, which suggested its name. It is also, we think, the earliest Celery in eultivation, and when to all these valuable characteristies is added that its eating qualities are equal to the very best of the older sorts, being erisp, solid and possessing a rich, nutty flavor, it is but little wonder that the White Plume should have secured in so short a time a permanent place in eultivation. It should be stated, how ever, that this variety never whitens in a young state, and usually only begins to show its self blanching character when the growth begins in the cool weather. When I first sent out the White Plume Celery in 1884, I imagined from its having the stems and leaves white, that it would not keep in winter, and so stated, but. further trial has shown that it keeps nearly as well as any of the other kinds.

IIenderson's IIalf Dwarf.-(See figure 38). Except the Golden Dwarf, this variety is now grown more extensively than any other by the market gardeners who supply the New York markets, and is now found on the tables of all first-class hotels. When blanched it is a yellowish white, making it very ornamental for the table. It is entirely solid and possesses a rich, nutty flavor, while it has much vigor of growth, surnassing 
most of the large growing sorts in weight of bunch when grown under the same conditions.

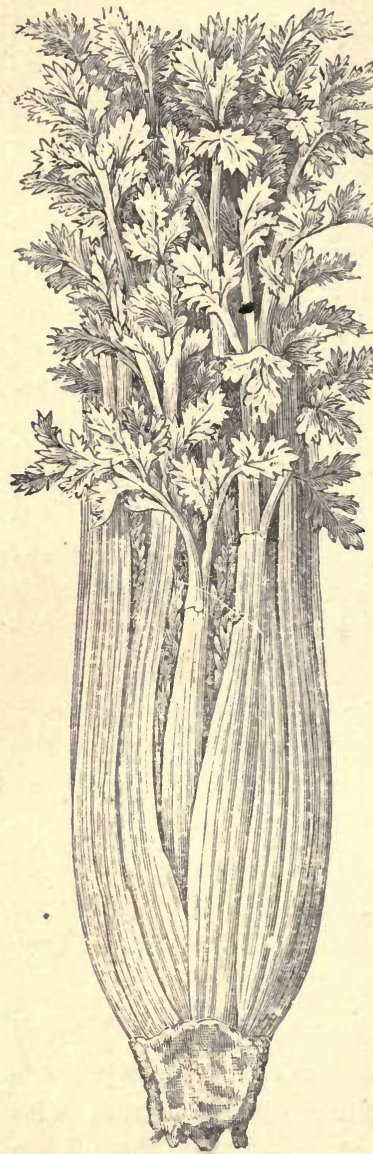

Fig. 38.-HENDERSON'S HALF DWARF CELERY.
Sanỏringham.-Under good cultivation this variety attains a height of two feet and a circumference of twelve inches. It is perfectly solid, the stalks half round, the leaves and stems being rather light green. When blanched it is a yellowish white, crisp, tender and of very fine flavor. The great advantage of this, as weil as the other dwarf sorts, over the large kinds, is that nearly every part of the plant is fit to eat when blanched. For instance, if in the dwarf varieties the length is only two feet and in the large sorts three feet, the extra length of the large sort is unfit for use, being usually only an elongation of the outer leares, the heart or edible part rarely rising more than eighteen inches in the large sorts, while the dwarf sorts may be said to be all heart. This variety in this section seems to have more tendency to blight or rust than any other kinds; but where it can be grown without this difficulty, as it can be in such soils as at Kalamazoo,

Michigan, I think it has no equal.

Boston Market.-A great favorite around Boston and 
similar to the Dwarf White, but rather more robust. 'The leaves are a darker green, the stalks when blanched are nearly white. It is an excellent variety, solid, crisp and tender.

Giant White Solid.-The best of the large growing corts, attaining a height, under good cultivation, of three

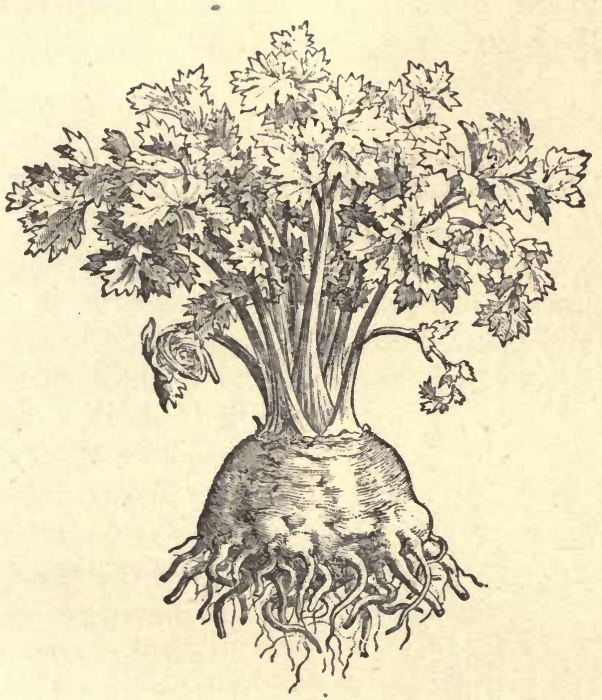

Fig. 39.-Celeriac.

feet. It should never be planted closer than four feet between the rows, or it cannot be properly worked. For southern sections of the country this variety is more suitable than the dwarf sorts, as it grows freer in a hot and dry atmosphere.

Irenderson's Rose.-The superiority in flavor, as a rule, of the red or rose Celeries over the white sorts, is much better understood in England (where the majority of Celery grown is red), than with us. For some unexplained reason, the red Celeries have not sold 
well in our markets. This cannot long be, however, as when once grown they will never be given up, not only for their superior flavor and crispness, but for their far better keeping qualities. 'This variety is one of the best I have ever seen.

Major Clark's Pink. - Another excellent variety among the red sorts. It is of medium growth, stiff, close habit, large heart, solid, crisp and of fine walnut flavor.

\section{CELERIAC, OR TURNIP-ROOTED CELERY.}

(Apium graveolens. Var.)

This, figure 39, is grown from seeds sown in the same manner, and planted out at the same times as directed for Celery; but as it requires but a slight earthing up,

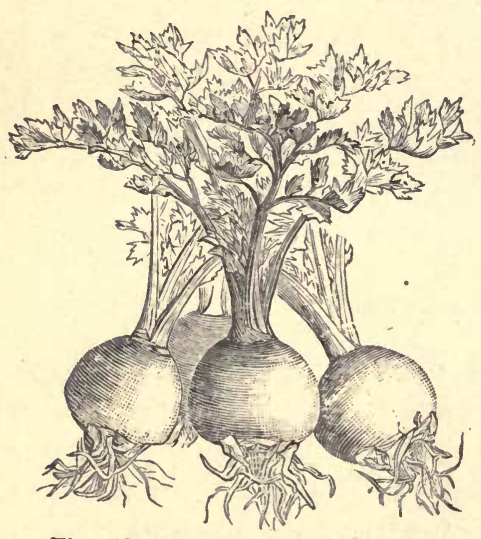

Fig. 40.-DWARF APPLE-SHAPED Celerio.

it is planted closer than ordinary Celery ; eighteen inches between the rows and six inches between the plants. It is preserved for winter use in shallow trenches, and covered up as the season advances, as directed for Celery. It is as yet grown to but a limited extent here, being used only by the French and Germans. The turniplike root is cooked, or it is sliced and used with vinegar, making a most excellent salad.

Dwarf Apple Shaped.-(See figure 40). This comparatively new variety is now the main kind grown. 


\section{CHIVES.-(Allium Sch.cenoprasum.)}

A small bulbous-rooted plant of the Onion tribe, entirely hardy and of the easiest culture, as it will grow on almost any soil for many years without renewal. It is propagated by division of the root, and may be planted at nine or ten inches apart; the leaves are the parts used, which may be repeatedly shorn off during the early summer months. They are sometimes used in soups, but more generally in the raw state.

\section{CORN SALAD, OR FETTICUS.-(Fedia olitoria.)}

A vegetable used as a salad and sold to a considerable extent in our markets. It is sown on the first opening of spring in rows one foot apart, and is fit for use in six or eight weeks from time of sowing. If wanted to come in early in spring it is sown in September, covered up with straw or hay as soon as cold weather sets in, and is wintered over exactly as Spinach. The covering is removed in March or April when it starts to grow, and is one of our first green vegetables in spring. It is also grown to a large extent by the German gardeners on New York Island in cold frames.

\section{CRESS, OR PEPPER GRASS.-(Lepidium sativum.)}

Another early spring vegetable, used as a salad, and of easy culture. It is sown in early spring in rows one foot apart; as it runs quickly to seed, succession sowings should be made every eight or ten days. There are several varieties, but the kind in general use is the Curled, which is used for garnishing as well as for salads. 


\section{CRESS-WATER.-(Nasturtium officinale.)}

This is a well-known hardy perennial aquatic plant, growing abundantly along the margins of runining streams, ditehes and ponds, and sold in immense quantities in our markets in spring. Where it does not grow naturally, it is easily introduced by planting along the margins of ponds or streams, where it quickly increases, both by spreading of the root and by seeding. Many a farmer in the vicinity of New York realizes more profit from the Water Cresses, cut from the margin of a brook running through his farm in two or three weeks in spring, than from his whole year's hard labor in growing Corn, Hay or Potatoes.

Water Cress ean be best cultivated in places where the streams run through a level tract. Supposing the stream to be a foot deep on an average, and six or eight feet wide, running through a meadow, a good plan for cultivation is to make excavations laterally, say in beds five feet wide (with five foot alleys between), to a depth of about eight inches, or deep enough to be flooded by the stream when it is of average height, or when shallow, by damming it up so as to flood the beds.

The advantage of having the beds exeavated at right angles to the stream rather than parallel with it is, that in the event of freshets the crop is less liable to be washed away. The length and number of the beds excavated must, of course, be determined by cireumstances.

Water Cress seeds germinate freely in earth when kept saturated; hence the beds, when properly levelled and pulverized by digging and raking, should be slightly flooded-enough to only saturate the soil until the seeds germinate, for, of course, if the beds were filled up with water, the seeds would be washed off. After the seedlings have started so as to show green, the water may be gradually let on as they develop.

The best time of sowing the seed for the latitude of 
New York, for spring, is about the middle of April ; for fall, about the middle of August. I adrocate that seeds of all plants of this description should be sown in rows a foot or so apart, as the seed is small and germinates freely, so that three or four pounds will be enough for an acre. It should be cultivated exactly as Spinach is.

When Water Cress is found growing naturally, the beds can be made by setting the plants six or twelve inches apart each way. When the cultivation is once fairly begun, there is no difficulty about forming new beds, as few plants grow more rapidly when proper conditions are present.

After the crop is planted or sown, in two months it will have spread all over the beds. The streams being full in autumn, the beds will be fully flooded so as to protect the plants during winter. It is always found growing best wild, in clear, shallow, slowly-running water, with a sandy or gravelly bottom; and as nature is always the surest guide to successful cultivation, the nearer it can be imitated the better the success.

I find it is one of. the plants the culture of which is not very easy to give by writing, as so much must be de-. termined by the circumstances of locality. Wherever a suitable stream is at command, the experiment of growing Water Cress is worthy of trial, especially when we know that it in many cases pays, for a given area, six or eight times more than any other vegetable cultivated, provided it can be sold in the markets of New York or Philadelphia.

It is usually sold in baskets containing about three quarts, which sell, when first in market, at fifty cents each ; 200 or 300 such are carried in an ordinary wagon, so that from a single load of this simple regetable, $\$ 100$ to $\$ 200$ are realized. The Water Cress has a particularly pleasant pungent taste, agreeable to most people in eariy spring. 
It is said that when Sir Joseph Banks first arrived in England after his vovage around the world, among the first things he asked for were Water Cresses, well knowing their value as a purifier of the blood; and that he afterwards presented one of the largest Water Cress growers for the London market, a Banksian Medal, for energy shown in the business, believing that while he had benefited himself he had benefited the community.

I have no doubt whaterer that in situations where irrigation could be used at pleasure, and regular plantations made, as for Cranberries, that, grown in this way, judging from the enormous price it sells at, picked up as it is in the present hap-hazard way, at present prices, an acre would sell for $\$ 1,000$ to $\$ 2,000$.

To give some idea of the immense quantities of Water Cress sold about some of the cities in Europe, we may state that a recent number of "Covent Garden Gazette" states that Water Cresses to the value of $£ 60,000$ are annually consumed in Paris, and in London to the extent of $£ 30,000$ annually.

\section{UPLAND CRESS.-(Barbarea vulgaris.)}

This has recently been introduced as a new regetable by a Mr. Beyer, of Iowa, and Mr. Beyer may be well pardoned for believing it to be new, for he says that he is informed by the largest seed firm in Paris in a letter written in 1885, that in their belief it is "new in France."

Now, it is not " new," but a very old plant, as I well remember it in my 'prentice days, when it was grown as Spinach, and used exactly as Water Cress. In fact, it so much resembles Water Cress in taste that the difference is scarcely discernible, and the wonder is that its use has not become more general, as it is of as easy 
culture as Spinach; indeed, easier, for it is a perennial plant, and can be grown easily for two years without resowing, and it yields enormous crops. The seed should be sown in April, in rows twelve to fifteen inches apart, and Mr. Beyer, who has been experimenting with it in the climate of Iowa, says it has stood a temperature of five degrees below zero, and still keeping green. He believes that its great value as a salad will soon be appreciated here, and, besides, as cattle eat it greedily, it may, in some sections, prove a valuable forage plant.

\section{COLLARDS (SOUTHERN).-(Brassica oleracea. Var.)}

Most of the Collards, as grown in this section, are nothing more than sowings of any early variety of Cabbage in rows about one foot apart, which are ent off for use when six or eight inches high. The Southern Collard is a distinct variety of vigorous growth, attaining a height of five or six feet, and grown in portions of the South where the ordinary kinds of Cabbage fail to head. Spring sowings may be made every two weeks at two feet apart from February to May ; and in fall from September as late as the season will admit.

\section{CORN.-(Zea Mays.)}

The varieties known as "Sweet" are the sorts most cultivated for culinary use in the green state. It may be either sown in rows four and a half feet apart, and the seeds planted at eight or nine inches in the rows, or planted in hills at distances of three or four feet each way, according to the variety grown or the richness of the soil in which it is planted. The taller the variety or richer the soil, the greater should be the distance apart. 
The soil best suited for Corn for an early crop is a wall enriched sandy loam. The planting should never be done until the weather is settled and warm, as heat is indispensable to the healthy growth of Corn. We make our first plantings in this ricinity about the middle of May, and continue succession plantings every two or three weeks until the first week in July, which date, in this latitude, is the latest at which we ean plant and be sure of a crop of "roasting ears." In more southerly latitudes planting is begun a month earlier and continued a month later. The crop is hardly profitable enough for the market gardener where land is high in price, but the farmers realize double the price for Sweet Corn when sold in the green state in our markets, that they do for Ripe Corn, besides, as the ground can be cleared when the ears are thus sold in August, it can be used afterwards for Turnips.

About twenty years ago I came into possession, about the 1st of May, of a four-acre plot that had lain for many years in sod. It was then too late to be able to break it up for planting any of the finer kinds of regetables, so I decided to plant it with Sweet Corn. Accordingly, I had the sod plowed over flat in such a manner as would best rot it. I was careful to have the furrows straight, and at every five feet where they lapped together I dropped Sweet Corn at four or five inches apart, so that when it started to grow it stood in regular lines five feet distant. The Corn was planted about May 20 th, and hoed around the line as it grew, the space between being run over by the harrow cultivator. By the middle of June, from the action of the cultivator, the space between the rows of Corn was in fine friable condition, and Celery was planted in double rows, ten inches apart. The shade given by the Corn was of no injury to the Celery at this early stage of its growth, and as the Corn crop was sold and the stalks were cleared off 
by the middle of August, the growth of the Celery was not in the slightest impaired. The whole transaction was quite satisfactory; the Corn crop sold (green), for about $\$ 600$, or $\$ 150$ per acre ; the Celery at about $\$ 400$ per acre, which was exceedingly low, not much more than one cent per root for every root planted; in some subsequent years the price would have doubled that for the same quantity. No fertilizer. was used, except a slight sprinkling of bone dust for the Celery. A profit now of from $\$ 50$ to $\$ 75$ is usually realized per acre from Sweet Corn. The best valrieties now are :

Narly Marblehead.-(See figure 41.) Certainly as early, if not a little earlier, than any of the other sorts of Sweet Corn. In appearance it resembles the better known Early Narragansett. The stalk is dwarf and it sets its ears very low down, which are of fair marketable size.

Cory.-Equally early as the preceding, and said to be larger in size.

Early Minnesota.-(See figure 42.) Very early and desirable alike in the market and family garden. Height of stalk, four and a half feet; ears of fair size and good quality.

Crosby's Early Sugar.-Early, and a great favorite in the markets of all large cities. Ears rather small but productive, and of excellent quality.

Henderson.-This variety is of medium earliness and is valued alike in the market and family garden, or for canning purposes, for which latter use enormous areas of it are now grown. The ears are twelve rowed, straight and handsome; quality of the very best.

Squantum Sugar.-One of the sweetest and most valued varieties I know of. It is rather early and wonderfully productive. Rows irregular, but setting four and five cars on a stalk. 
Egyptian.-The ears of this variety are of large size, the flavor peculiarly rich and sweet. It is grown in equally large quantities for both canning and for selling in the green state. Like all the other large varieties, it matures late-perhaps the best late sort.

Stowell's Evergrecn.-(See figure 43.) Now recognized

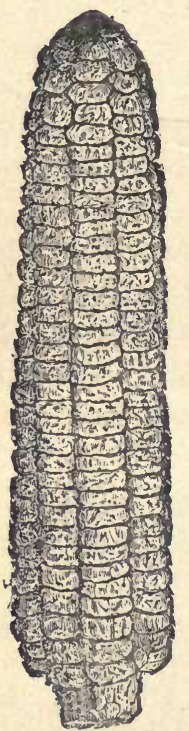

Fig. 41.-MARBLe- Fig. 43.-minnesota HEAD CORN.

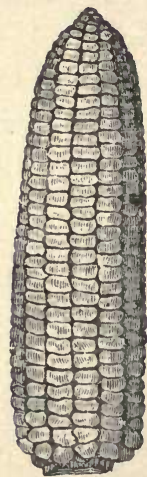

CORN.

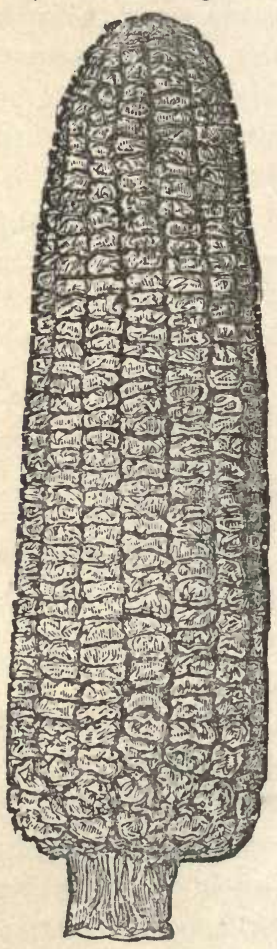

Fig. 43. - STOWELL's

EVERGREEN CORN.

everywhere as the standard late variety, and having the peculiarity of remaining longer in the green state than most other sorts.

Mammoth Sugar.-A late variety and a sort that pro- 
duces ears of very large size and fine flavor. It is unusually productive, and is the variety almost exclusively grown by New York market gardeners for their late crop.

\section{CUCUMBER.-(Cucumis sativus.)}

The growing of the Cucumber out-of-doors is, in most places, attended with a great deal of annoyance and loss, occasioned by the attacks of the "Striped Bug." When the seed is sown in the open ground, repeated sowings are often utterly destroyed by this pest, despite all remedies. To avoid this, and at the same time to forward the crop at least a week, we have long adopted the following method with the greatest suecess : About the middle of May (for this section), we cut from a pasture lot, sods two to three inches thick; these are placed with the grassy side down, either on the benches of our forcing-house, in an exhausted hot-bed, or inside of a cold frame; at that season of the year any one of these will do as well as another. The sods being fitted together neatly so that all crevices are filled up, they are then cut into squares about three or four inches in length and breadth; on each of these are planted two or three seeds of Cucumber, and over the whole is sifted about half an inch of covering of some fine rich mold. They are then sprinkled thoronghly from a rose wateringpot, and the sashes put on and kept closed until the seeds begin to germinate, which will be in three or four days. As soon as they are up, the sashes must be raised to admit air, else the sun's rays, acting on the glass, would raise the temperature too high ; at that season of the year the sashes, as a rule, may be tilted up at eight or nine o'clock in the morming, and shut down by three or four o'clock in the afternoon. By the time the $\mathrm{Cu}$ - 
cumber plants have attained two or three of their rough leares, which will be in about three weeks from the time of sowing, they are planted out in the open ground in hills three feet apart each way. The hills should have been previously prepared, by mixing thoroughly with the soil in each, a shovelful of well-rotted manure.

It is always better to plant in the afternoon rather than during the early part of the day, as the coolness and moisture at night enable the plants to recuperate from the effects of removal. If the weather is hot and dry, it is safer to give each hill a thorough watering onc, immediately after planting. I have recommended sods in preference to flower-pots for starting the Cueumbers, inasmuch as they are not only procurable in all places, but our experience shows that the sod is even better than the flower-pot; it better retains moisture, and there is a freshness about sod in which the roots of all plants love to revel, and which no composts we can prepare can ever equal.

It will be seen that the expense of growing Cucumbers in this manner is considerable; to grow enough for an acre-about 5,000 hills-it will require the use of twenty three by six foot sashes, and the preparation of the sods and attention in airing, ete., until they are fit to plant, will involve ten times more expense than simply sowing the seed in the hills; but all such expenditures are well returned, for it is safe to say that the profits would always be at least three times more by this plan than by the other. The average receipts are $\$ 500$ per acre, working expenses probably $\$ 250$, and the erop is off in time for Turnips or Spinach as a second crop.

The Cucumber is a regetable perhaps better fitted than any other for Southern market gardeners. There is no doubt that by the forwarding process above described, it could be had in marketable condition in the neighborhood of Charleston or Savannah, at least a month before it 
could in New York, and as it is one of the easiest things we have to ship, a profitable business could be made of growing it to send North. The profits un an acre of $\mathrm{Cu}$ cumbers grown by this method in Charleston, and sold in New York in June, would, I think, exeeed the average profits of twenty-five acres of Cotton. For forwarding under glass see "Foreing Cucumbers," on page 79.

Cucumbers are also extensively raised for pickling, hundreds of acres being grown for this purpose in the vicinity of New York, especially in Westchester County. Sod or stubble land, plowed in early fall, and again turned over twice or thrice in spring, is the condition of soil usually chosen.

'The ground is marked out as for Corn, four feet each way, and a good shovelful of well-rotted manure, dug in at the angle which forms the hill; the seed is sownabout a dozen in each hill-usually about the 20th of June, but equally good crops can be obtained by sowings made as late as the middle of July.

The average price of late years has been $\$ 1.50$ per 1,000 , and the number grown per acre on properly cultirated lands is 150,000 , which is $\$ 225$ gross receipts per acre. The expense of raising is said to be about one-half. These profits would not satisfy the market gardener on his few valuable acres near the city, but, no doubt, are remunerative enough to the farmers with large quantities of cheap land.

The varieties are numerous and embrace many very well marked kinds. The large growing kinds that attain two feet or more in length have never become favorites in our American markets.

Improved White Spine.-(See figure 44.) This, a favorite market variety, belongs to the section of short Cucumbers, producing fruit of medium size, from six to eight inches in length, and two to three inches in diameter. It is a handsomo friit, deep green in flesh, crisp, and of 
fine flavor. This is one of the varieties grown for forcing.

Nichol's Medium Green.-This new variety is excellent as a pickle sort, and for forcing there is none better. It is very productive, of medium size, and always straight and smooth. Color, dark green ; flesh, crisp and tender.

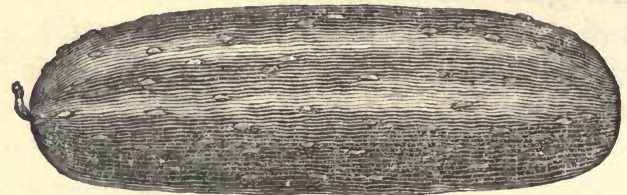

Fig. 44.-IMPROVED WHITE SPINE CUCUMBER.

Early Cluster.-A much esteemed early variety, growing in clusters and extremely productive. Its color is bluish green, shading lighter at the extremities.

Early Russian.-(See figure 45.) This is the earliest variety, coming into use about ten days before the Early

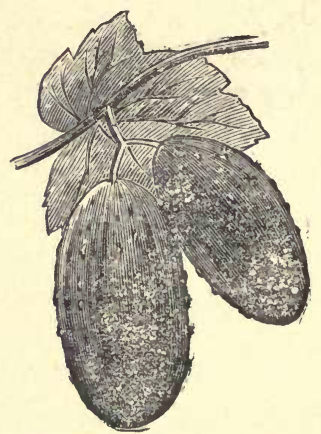

Fig. 45.-EARLY RUSSIAN cuccmber.

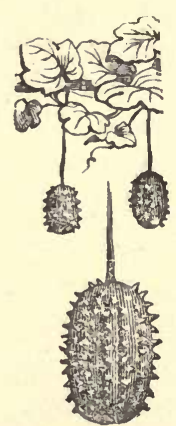

Fig. 46.--WEST INDIAN GHERKIN OR BURR CUCUMBER.

Cluster, which it resembles in some respects, but is smaller and shorter. The fruit is generally produced in pairs, and is from three to four inches long, hardy, productive and fine flavored. One of the best varieties for private gardens. 
Green Prolific.-As a pickle variety it is unsurpassed. Its characteristics are its very uniform growth, hardly ever yielding Cucumbers too large for pickling, and its immense productiveness.

Tailby's Hybrid.-Dark green and glossy in color, good yielder and fine flavor; resembles the English forcing varieties, with one of which it is a cross.

West India Gherkin or Burr.-(See figure 46.) This variety, which is exclusively grown for pickling, is a species distinct from the common Cucumber (Cucumis Anguria). It is very small, length from two to three inches, a strong growing sort, and should be planted fire feet apart.

\section{EGG PLANT.-(Solanum Melongena.)}

The cultivation of the Egg Plant, from its extreme tenderness, is, in its early stage, attended perhaps with more trouble than any vegetable of our gardens. A native of Tropical America, it at all times requires a high temperature. For this reason, in this latitude, the seeds should not be sown in the hot-bed until the first week in April ; even then a steady bottom heat is necessary to a healthy development, and there should be a warm covering at night over the sashes. I have always found that with tender plants of this kind, notlning was gained by starting early, even though by great care the plants are carried through the cold season. By the time they can be planted in the open ground, about June 1st, those started the 1st of March would be no larger than those started 1st of April, besides being harder both in roots and leares, in which condition they are far inferior to the younger plants that have been raised with less than half the labor.

A correspondent from an inland town writes that, for the first time, the Egg Plant has been grown in his sec- 
tion this season, and that it has been a wonder to the good people of that place, and they wish for more light on its culture and uses. This gentleman says that the earliest and best fruit is produced on the plants last set out (June 10th), and seems to wonder that such should be the case.

His experience here teaches a forcible lesson on the subject that we so often $d$ well upon, cautioning against the sowing or planting of tender kinds, such as Tomato, Egg Plant, Cucumber or Melon, too early. In the latitude of New York, Egg Plants should never be sown in hot-beds sooner than April 20th, the temperature of the hot-bed to be not less than seventy degrees at night. The plant at no season of its growth should be kept for any length of time at a lower average temperature than seventy degrees.

The experiment of my correspondent demonstrated that his plants, planted in open air on May 19th, were inferior to those set out on June 10th. Egg Plants, when they first germinate, are very sensitive to damp and to being chilled, and the amateur often fails to raise them, even with his hot-bed. But as they are now grown in all large towns, those wishing to try them, and not having the proper means of raising the plants, can procure them at trifling expense from the market gardeners or florists of their nearest town. The soil in which they fruit best is a light, sandy loam, well enriched by decayed stable manure.

The Egg Fruit is fit for use from the time it is the size of a turkey's egg until it is full grown, say five inches in diameter; but it is not so good when the seeds become hard, and indicate an appearance of ripening.

'I'he soil in which Egg Plants are to be grown can hardly be too rich, for it is a plant that will generally repay good treatment. They are planted from two to three feet apart, according to the degree of richness of 
soil ; in the fertile market gardens never less than three feet. Although their sale is comparatively limited, yet, from the difficulties often experienced in raising the plants, all that are offered are sold at good prices; the average is about $\$ 1$ per dozen, each plant producing six to nine full-sized fruit. It is more important with this vegetable to select the proper variety for growing than with any other that I know; for that reason we are

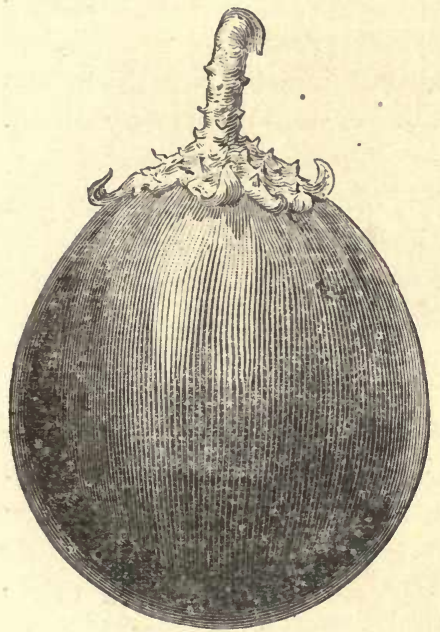

Fig. 47.-NEW YORK IMPROVED EGG PLANT.

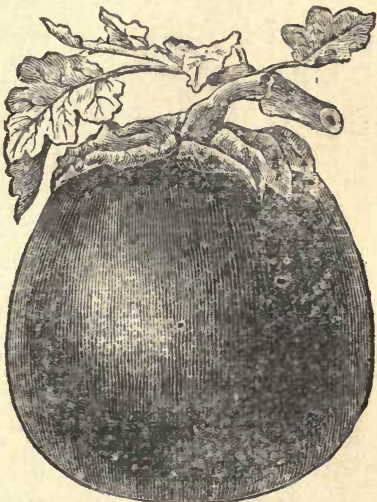

Fig. 48. - BLACK PEKIX EGG PLANT.

chary of touching any other sorts for market purposes than the "New York Improved" and "Black Pekin."

New York Improved.-(See figure 4\%) This is our leading market variety, and is readily distinguishable from either the Large Round or Long Purple varieties in the plant being more robust in all its parts, the leaves and stems also being thickly studded with spines, which are not found to any great extent on the other varieties. A productive and excellent rariety. 
Long Purple.-Different in shape from the foregoing; sometimes deep purple, and again pale, with white or yellowish stripes. Early, productive, and of easy culture.

Black Pekin. - (See figure 48.) A comparatively new variety of superior excellence; fruit glossy, deep purple, almost black, of globular form and very solid. It is earlier and more productive than the New York Improved, and much superior in flavor, and is now selling rather better in our New York markets.

White-fruited Igg Plant.-Similar in growth to the Long Purple, but the fruit is larger, and of an ivory whiteness. It is good when cooked, but much less productive, and, like the Scarlet, which is almost identical except in color, is grown more for curiosity and ornament.

\section{ENDIVE-(Cichorium Endivia.)}

The cultivation of this regetable for market purposes is not yet extensive, it being used by few except our German and French population. It is, however, offered now by the wagon load, where a few years ago a few basketfuls would have supplied all the demand. Like all other vegetables that are grown in limited quantities, it commands a high price, and the few who do raise it find it very profitable.

Like Lettuce, it may be sown at any time, from early spring until August, and perfect its crop the season of sowing. As it is used almost exclusively in the fall months, the main sowings are made in June and July, from which plantations are formed, at one foot apart each way, in August and September. It requires no special soil or manure, and, after planting, it is kept clear of weeds by hoeing and weeding, until the plant has attained its full size, when the process of blanching begins ; for it 
is never used except when blanched, as it is harsh and bitter in the green state.

Blauching is effected by gathering up the leaves, and tying them up by their tips in a conical form, with bass matting. This excludes the light and air from the inner leaves, which, in the course of three to six weeks, according to the temperature at the time, become blanched.

Another method of blanching is much simpler and quicker, and is the one mostly practiced by those who grow Endive for market; it consists simply in covering

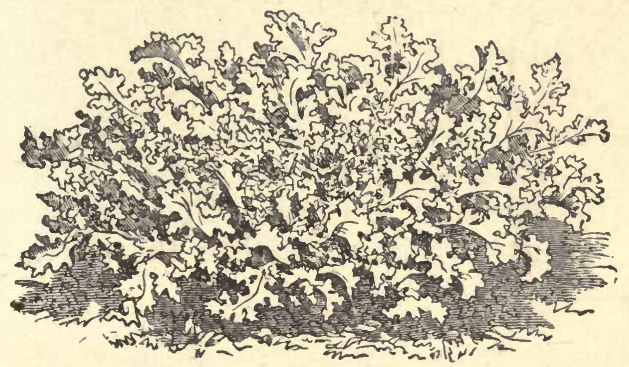

Fig. 4\%.-GREen CLRLED ENdive.

up the plants as they grow, with slates or boards, which serves the same purpose, by excluding the light, as the tying up. The average price during the months of October, November and December is fifty cents per dozen.

The best sorts are the following :

Green Curled.-(See figure 49.) This is not only one of the most useful as a salad, but is highly ornamental from its delicately cut and curled leaves ; it is much used for garnishing.

Moss Curled.-This variety is now common, and is being extensively cultivated. From the density of the foliage, the plant is heavier than the Green Curled, is 
equally agreeable as a salad, and its appearance, either green or blanched, is particularly handsome, and is now being much used for garnishing in our best hotels.

Broad-leaved Batavian.-A loose growing variety, forming but little heart. As with this blanching ean only be aceomplished by tying $\mathrm{np}$, it is not so desirable as either of the preceding.

\section{GARIIC.--(Allium sativum.)}

Another regetable used mostly by foreigners. It is of the easiest culture, growing freely on any soil suitable for onions. It is propagated by divisions of the bulb, ealled "cloves" or "sets." These are planted in early spring, in rows one foot apart, and from four to six inches between the plants in the rows. The erop matures in Angust, when it is harvested like the Onion. It is always sold in the dry state.

\section{HORSERADISH.-(Nasturtium Armoracia.)}

This root is an important erop, upwards of five hundred acres of it being grown in the vicinity of New York alone, and for the last twenty years there has been nothing grown from which we have realized more profit as a second erop. It is always grown as a second crop in the following manner :

In preparing the roots for market during winter, all the small rootlets are broken off and reserred for planting, leaving nothıng but the main root, which is usually from twelve to fifteen inches long, and weighing about three-quarters of a pound. The rootlets, or sets, are cut into pieces of from four to six inches in length, from 
one-quarter to one-half an inch in diameter; these are tied in bundles of from fifty to sixty, the top end being cut square and the bottom end slanting (see figure 50), so that in planting there will be no danger of setting the root upside down; for although it would grow if planted thus, it would not make a handsome root.

'The sets, when prepared, are stowed away in boxes of sand, care being taken that a sufficiency of sand is put between each layer of bundles

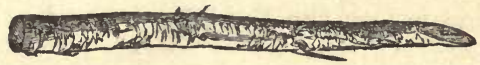

Fig. 50.-HORSERADISH SET. to prevent their heating. They may either be kept in the boxes in a cool cellar, or fitted in the open ground, as may be most convenient. We prefer the open ground, when the weather will permit.

I have said that Horseradish is always cultivated as a second crop. With us, it usually succeeds our Early Cabbage, Canliflower or Beets. Thus we plant Early Cabbage, lining out the ground with the one-foot marker ; on every alternate line are first planted Early Cabbages, which stand, when planted, at two feet between the rows and sixteen or eighteen inches between the plants. We always finish our entire planting before we put in the Horseradish, which delays it generally to about 1st of May. It is then planted between the rows of Cabbage, and at about the same distance as the Cabbage is in the rows, giving about 12,000 or 13,000 plants per acre.

The planting is performed by making a hole abont cight or ten inches deep with a long planting stick or light crowbar, into which is dropped the Horseradish set, so that its top will be two or three inches under the surface; if the sets should be longer the hole should be made proportionally deep, so that the top of the set is not nearer the surface. than two or three inches; the earth is pressed in alongside the set, so as to fill up the hole, as in ordinary planting. 
The main reason for planting the set so far under the surface is to delay its coming up until the crop of Cabbage be cleared off. The Horseradish makes its main growth in the fall, so that it is no injury to it to keep it from growing until July; in fact, it often happens that by being planted too near the surface, or too early, it starts to grow so as to interfere with the Cabbage crop; in such cases, we have often to cut the tops off twice with the hoe before the Cabbage is ready, but this does not injure it in the least.

It is a crop with which there is very little labor during summer ; after the Cabbage has been cut off, the Horseradish is allowed to grow at will, and as it quickly covers the ground, one good deep stirring by hoe or cultivator is all that is required after digging out the Cabbage stumps.

When grown between Eariy Beets the culture is, in all respects, the same, only it is more profitable to have the rows of Beets only eighteen inches apart; this, of course, throws the Horseradish nearer, so that when grown between Beets it should be planted at the distance of two feet between the plants in the rows, making about the same number of plants per acre as when planted between early Cabbages.

As it is an entirely hardy plant, it is one of the last roots we dig up in fall, it keing usually delayed until December. After digging, the small roots are usually broken off in the field and stowed away in boxes, so that they can be trimmed under cover at leisure. 'The inain root is then put away in the pits, as recommended in Winter Preservation of Vegetables, so that it can be got at as required during winter. The preparation for market is very simple, being merely to cut off the green tops and small rootlets, leaving the main root only, as represented, in reduced size, by figure 51. It is sold by weight, and is generally washed, which is done suffi- 
ciently by rinsing a quantity of it together in a large tub.

Our manner of growing Horseradish in this district, we claim to be a great advance on the methods generally practised. All American writers on the subject that I have seen, follow in the same track, and recommend planting the crowns. This would not only destroy the most salable part of the root, but when planted thus, the crowns will produce only a sprawling lot of rootlets that are utterly unsalable in the market. They also tell us that "after two seasons growth the roots will be fit for use." Now, my experience in growing this root has most emphatically told me that, after two seasons growth, it is entirely unfit for use, or at least unfit for sale, which I suppose is about the same thing. Twenty years ago, one of my neighbors had a patch of about two acres, whish from some cause or other he had neglected to have dug until Jate in spring, and concluded, as it was then rather late to sell it, he would leave it to

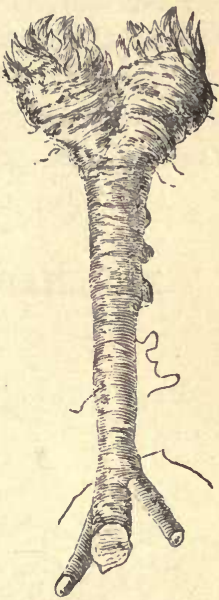

Fig. 51.-HonseRADISH. grow over until next season. On commencing to dig it the next fall, he found that the main root, instead of being solid, as it is at one one year old, had become partially hollow and of a woody, stringy nature, and when offered to manufacturers it was refused at any ${ }^{\circ}$ price. So there was no help for it but to dig up and throw away his entirely worthless crop at a most unusual expense, as its two year's growth had massed the whole soil with roots. This experiment of my neighbor was a loss to him of certainly not less than $\$ 1,500$, as the price then was higher than now.

Grown in the deep rich soil of our market gardens, 
Horseradish has been for the past thirty years, one of our most profitable second crops, and as an encouragement to beginners, I will state that the price has still kept sufficiently high to make it a fairly profitable crop. Our average weight per acre is five tons, or a little over three-quarters of a pound per root for 12,000 planted. Its arerage price is now about $\$ 100$ per ton. But there is one thing to be remembered: these heavy crops are only obtained in our gardens that are in the highest state of culture; no ordinary farm land, the first season, manure it as you might, will produce such results.

\section{KOHIRABI, OR TURNIP-ROOTED CABBAGE.}

\section{(Brassica oleracea. Var.)}

In general appearance, this vegetable more resembles a Ruta Baga Turnip than a Cabbage, though it is more

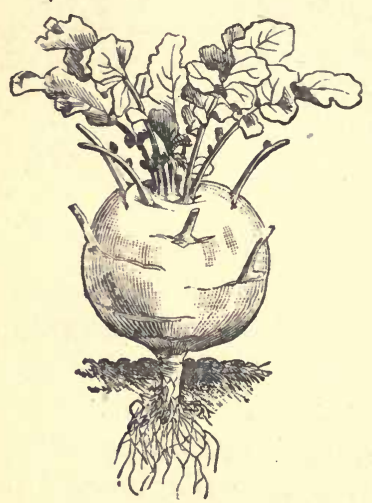

Fig. 52.--KOHLRABI. generally classed with the latter. It is best cultivated by sowing the seeds in rows in May, June, or July, according to latitnde. In this district we sow throughout June, for succession in rows eighteen inches apart, thinning out to about eight or ten inches between the plants. It is rather difficult to transplant, and we generally prefer to sow the whole crop from seed, and thin out where it stands; although when the weather is suitable, the thinnings may be planted at the distances above named. It is sold in our markets in fall in the green state in bunches containing three roots, at an average price of 
seventy-five cents per dozen bunches. As it is not in general use, its sale is limited. The varieties mostly cultivated are :

Early White Vienua.-This is greenish-white ontside; flesh white and tender while young. 'The best condition for use is when the root is from three to four inches in diameter; if younger it partakes too much of the taste of the Cabbage, and when older it is dry and stringy. 'I'he best market sort.

Early Purple Vienna.-Almost identical with the preceding, except in color, which is a bluish-purple.

\section{LEEK.-(Allium Porrum.)}

The Leek is another regetable that is exclusively grown as a second crop. The seed is sown in April in rows one foot apart in ground well prepared, as recommended for the Celery seed-bed; and, like all seed-beds, it is kept scrupulously clear of weeds. The best time of planting is the same as that for all our second cropsduring July, or as soon as the first or spring crop can be cleared off. The ground can hardly be too rich for Leeks, and, when time will allow, we always contrive to get in a slight adcitional coat of manure for this crop; the spring dressing, large as it always is, hardly being sufficient. The ground being well prepared by plowing and harrowing, lines are marked out by the marker at one foot apart, and the Leeks planted on each line at five or six inches apart; we do not earth up, but instead plant rather deeply. As it is a plant the foliage of which is but little spreading, great care must be taken that weeds are never allowed to get ahead, for if they do, they may soon entirely envelop the crop to its total destruction. 
It is a regetable used mostly in winter and spring, and requires to be dug up, in this vicinity, in November, as otherwise it would be injured by our severe winters, but in milder sections, it is better left standing where it grew.

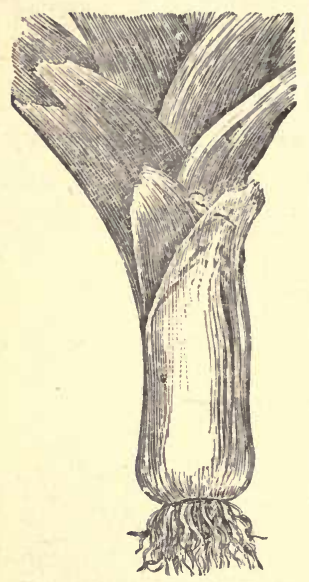

Fig. 53.-MUSSELBURGH I.EEK.

It is quite a hardy vegetable, so that twenty or twenty-five degrees below freezing will not injure it. It is preserved by the market gardeners here in trenches, exactly as Celery is preserved (see Chapter on Celery.) Large quantities are sold in our Northern markets at fairly remunerative rates, althongh, from the nature of the plant, it requires perhaps more labor than any other vegetable to prepare it for market. Figure 53 represents the Musselburgh Leek, trimmed previous to being bunched up for market. From six to eight roots are tied in each bunch, which bring in the market upon an average, throughout the season, about fifty cents per dozen bunches. We plant about 85,000 plants on an acre.

The two varieties used are known as Musselburgh and London Flag. The former is rather preferred in market, being usually larger, but there is but little choice between them.

\section{LETTUCE-(Lactuca sativa.)}

Perhaps there is no plant of the garden that we could so ill afford to dispense with as Lettuce. Its cultivation is universal by all classes, and from its tractable nature and freedom from nearly all insects and diseases, it is manageable in the hands of every one. In a well-ap- 
pointed market garden it is the most important vegetable cultivated, engaging our attention throughout the entrre year, either in the open ground in summer, in forcing houses or hot-beds in winter, or in cold frames in spring. As our mode of growing it under glass is sufficiently described in treating of pits, frames, etc., I will in this place confine myself to our system of cultivating it out of doors.

For our main early crop, that is sold from the open ground in the latter part of May or first of June, the seed is sown the previous season in the open ground, from the 15th to 25th of September. These plants are usually large enongh to be planted in frames four or five weeks later, as recommended for Cabbage plants; about 600 or 700 are planted under a three by six sash. Occasionally we sow seed thinly in the frame in fall and do not transplant them, as it saves a great amount of labor, but they are not quite so good plants as those transplanted, as it is difficult to sow them so that they come up at the regular degree of thickness. The winter treatment of Lettuce plants in every way similar to that described for Cabbage plants. In dry, well-sheltered spots, by covering up with leaves or litter, late in the season, say middle of December, Lettuce plants, particularly of the more hardy kinds, such as Boston Mar. ket and Butter, may be saved over winter without glass covering, in southern parts of the country without difficulty. Like most plants that we term hardy, twenty degrees of frost will not injure them. The plants for setting out in spring are also sown in cold frames in February, and in hot-beds in March. (See Chapter on "Spring Raising of Cabbage, Cauliflower and Lettuce.") To economize not only in space, but in manure, we make every foot of our gardens available, so that when we come to plant out our Lettuce in March or April, instead of setting it in a bed exclusively for 
itself, it is planted at the same time and between the rows of Eurly Cabbage or Cauliflower, which are set at two feet apart. The Lettuce matures its crop in half the time that it takes for the Cabbage, and is consequentiy all cut off and marketed before the Cabbage is half grown. If it were not so, they could not be both grown at once on the same ground, for, when the Cabbage crop attains its growth, it requires the full space allowed-two feet-for its development.

This early crop of Lettuce from the open ground is considered rather an auxiliary than a main one ; it meets with a rapid sale at an average of $\$ 1.50$ per 100 heads. Rather a low price, it may be thought; but growers having only ten acres of ground iot unfrequently plant over 100,000 heads. It is planted somewhat closer than Cubbage, usually about 15,000 per acre.

For succession crops of Lettuce, sowings may be made in the open ground as early as spring opens until July. When not planted between Cabbage, they are set at one foot apart each way. They are sold to some extent throughout the whole summer, but the great weight of the crop is sold about the first week of June in New York markets. The summer price of Lettuce is very variable, as the supply is often irregul:rr ; it may arerage $\$ 2$ per 100.

The passenger in Elevated Railroad cars going from Sixtieth Street to Harlem, on New York Island, may yet see, any day from June to October, little patches of vegetation of different shades of green, ranged in uniform and regular lines. These are the "salad patches," cultivated mainly by German market gardeners; they range from two acres down to a quarter of an acre in area. It seems a wonder that the cultivation of such a small plot of earth should give an able-bodied man a living; but a living it does give in nearly all cases, and some have quite a respectable surplus for a "rainy day." 
The manner of growing the Lettuce for the first or early crop, is the same as that practiced by the market gardeners of New Jersey or Long Island, namely, using plants from seed sown in fall that have been wintered over under sashes, and planted out as early as the ground is fit to work, which, in these warm nooks (in most cases at the base of rocky elevations), is often as early as the first week in March. In some particularly favored spots the Lettuce is planted out in the first week of October, and, if it remains unscathed during winter, comes in in such fine condition for market in May as to well repay the risk. The variety used for this purpose is the "Brown Dutch."

In any section of the country where the thermometer never falls lower than ten degrees above zero, Lettuce sown the first week in September and planted out the first week of October in sheltered spots in dry soils, will be almost certain to "winter over," and give a erop in spring earlier than if treated by any other method.

A plan of recent introduction for the summer growing of Lettuce, is to mark out lines one foot each way across the bed, and at the intersection of the lines six or eight seeds are planted, pressed down and slightly covered. These in the summer months germinate in a few days. When the plants are an inch or so high, they are all taken out but one plant. This is a quicker and better plan than planting in hot summer weather, as the Lettuce plant at that season is somewhat difficult to transplant. Succession sowings should be made erery two or three weeks.

To return to the New York City growers. The rarieties grown under glass and first planted out in spring are usually the "Butter" and "Curled Simpson," both white and black seeded. As soon as the crop is planted out, sowings are made for a succession; this time of the "Salamander" and the "New York," the "Simpson" 
being unfitted for the warm weather at which this sowing would mature.

The crop planted out in March, matures by the end of May or 1st of June, and as soon as it is cut off, the ground is plowed or aug over, and the plants from the March sowings are set. Another sowing is made for plants to suceeed these again, and so on during the entire season, the rule being to sow seed at each time of planting. Four crops of Lettuce are usually taken from June to October, or nearly a crop each month.

The plants are set about a foot apart each way, and will average one cent per head, so that the four crops give a return of nearly $\$ 2,000$ per acre. This seems like an immense return for an acre, but though the net profits are respectable, there are some serious disadvantages attending the cultivation. Few, or none, of these men are owners of the land in New York City, nor in hardly any instance have they a lease. They are tenants at will, and pay a yearly rental, in some instances, of $\$ 250$ per acre. Many of our country readers may think that an extra cipher has boen added to the amount, but they must recollect that the value of some of these "salad patches," as they are called, is $\$ 8,000$ per city lot, or over $\$ 100,000$ per acre, so that the paltry rental of $\$ 250$ per acre hardly pays the interest on the amount of taxes. The following figures were given me by one of the best and largest growers, whose patch was two acres :

Rent . . . . . .

Manure

Labor of three men for six months

Horse keep and incidentals..................... 450

$\$ 1,850$

Four crops Lettuce, estimated at .................. $\$ 4,000$

Expenditures .................................. 1,850

Annual profits for two acres.................. $\overline{\$ 2,150}$

This was in 1874 ; it is probable that now the profits would be quite one-third less. 
A pretty good profit, but deservedly earned, for to attain this result the grower works early and late. It must not be supposed that five acres could be cultivated by one man with the above profit. The loss from inadequate hired labor, and the difficulties of selling large quantities of a quickly perishable crop, would be likely to make the attempt to largely increase the area cultivated a failure. Besides, Lettuce is only used to a limited extent in the summer and fall months, and if grown in the quantities that it is in spring, could not be sold, yet in all large cities it is used more or less at all seasons, and commands, for limited quantities, usually a higher price than in spring, the season of its greatest consumption. No doubt the system of our New York City Lettuce growers might be successfully and profitably followed in the neighborhood of many other cities and large towns.

The varieties of Lettuce used for the different purposes of. forwarding and forcing, and for out-door culture in spring and summer, are of more importance than with most vegetables. I once lost almost my entire crop of Frame Lettuce, from planting the Curled India, a summer variety, instead of the Curled Simpson, which I had got from

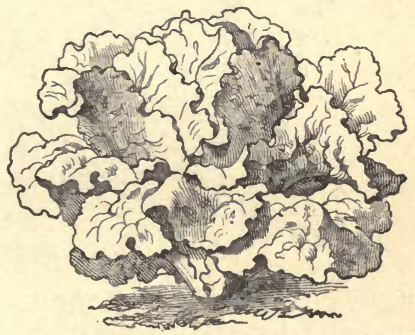

Fig. 54.-EARLY C:: RLED SIMPSON LETTUCE.

a well-meaning but not very learned friend, whose hieroglyphics had got transposed.

Early Curled Simpson.-(See figure 54). This is still the most generally useful variety for all purposes, and so I place it at the head of the list. Properly speaking, it does not head, but forms a close, compact mass of leaves, which are of a yellowish shade of green and much curled. 
'I'his peculiarity allows it to mature quicker than varieties that form firm heads, and gives it its great desideratum-earliness. It is the kind that is largely planted in cold frames, although not so largely as the Boston Market; it is also largely grown as an early open air variety between the rows of the Cabbage crop.

Black Seeded Simpson.-(See figure 55.) Like the Curled Simpson, this variety does not form a head proper, but it differs from the preceding in being much lighter colored, the leaves being creamy yellow; it attains a size

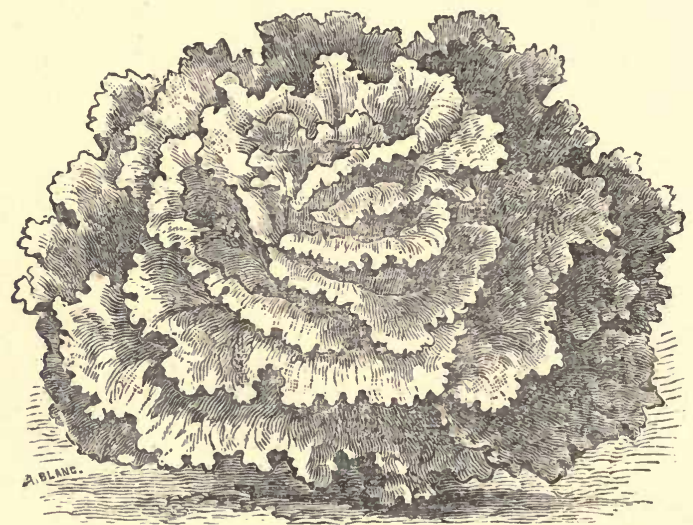

Fig. 55.-BLACK SEEDED gINPSON LETTUCE.

nearly double that of the Curled Simpson. It stands the summer heat well, while it is equally suited for forcing. On account of its large size, however, it might not, under some circumstances, prove so profitable as a strictly forcing sort, such as the Boston Market.

Black Seeded Tennis Ball.-A favorite forcing rarety, and, as the name indicates, forming a hard head. It makes few outer leaves, and for this reason can be planted quite closely under glass-irom six to seven inches apart. It is the variety so largely used in our hotbeds and forcing-pits in greenhouses. 
Boston Market, or White Seeded Tennis Ball.-This is an improved variety of the 'Iennis Ball which attains a larger size. It grows very compact, is beautifully white and crisp, and is one of the very best varieties for forcing ; in our opinion it is preferable to Black Seeded Tennis Ball.

Salamander.-(See figure 56.) A grand Lettuce for summer use, forming good - sized, compact heads; in color it is light green outside and white on the inside. Its great merit is that it will withstand drouth and heat, and remain longer in head without bursting, than any other

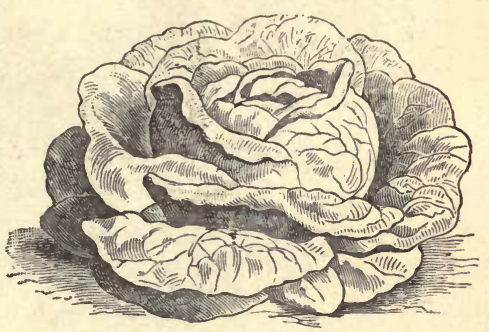

Fig. 56.-SALAMANDER LETTUCE.

variety except the "New York." Is largely grown for Philadelphia and New York markets.

Yellow Seeded Butter.-Like the Salamander, this stands the summer's heat well. It is a very distinct sort, making a large, dense, yellow head, very crisp and tender, and of excellent flavor. Its beautiful yellow heart gives it a very handsome appearanee.

Large White Summer C'abbage.-One of the very best late varleties for summer; heads of good. size, close, and well formed. It is a splendid market variety.

New York.-(See figure 5\%) This is a remarkable summer Lettuce introduced in the spring of 1886 ; the size and solidity of its head are unusual. We have seen it eighteen inches in diameter and weighing nearly four pounds, with heads almost as solid as an Early Summer Cabbage, which in form it somewhat resembles. It blanches itself naturally, is crisp, tender, and ot excel- 
lent flavor. It will not do for forcing, but is almost certain to prove one of the best summer varieties, as the

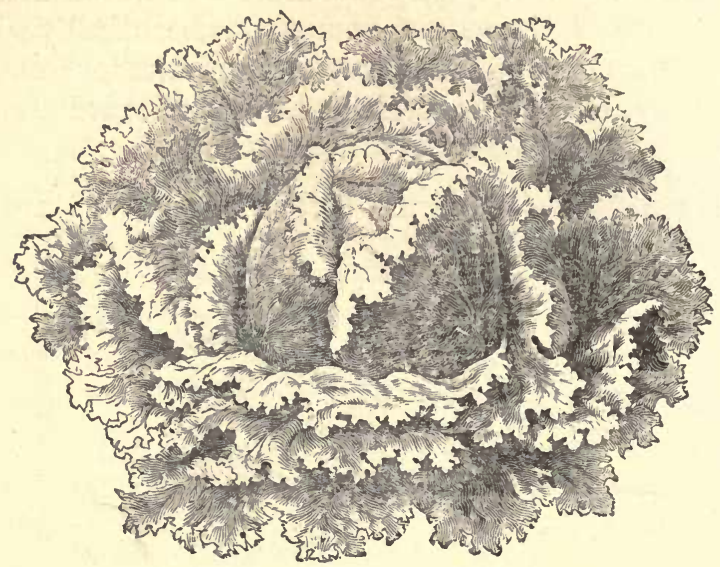

Fig. 57.-NEW YORK LETTUCE.

trials in my Experimental Grounds for the past two years show it to be the last of fifty kinds to run to seed.

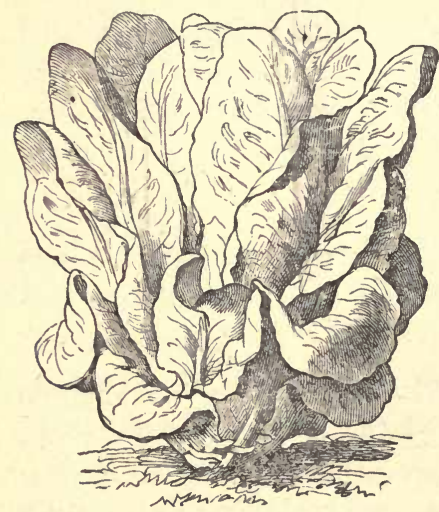

All the Year Round,As its name implies, it is one of the best for general crop. Heads of medium size, solid, of dark green color.

\section{Paris White Cos.-(See} figure 58.) Although the Cos varieties of Lettuce are not so suitable for our climate (as they tend too quickly to run to seed), as the varieties previously Fig.58.-PARIS WHITE COS LETTUCE. mentioned, yet they are sometimes grown in the early spring and fall for private use, though I have never seen them in our markets. In 
shape they differ materially from the other varieties, the head being elongated and of conical form, eight or nine inches in height, and five or six inches in diameter. The color of this variety is yellowish-green. To be had in perfection, it requires to be tied up to ensure blanching. Millions of this variety are annually grown to supply the markets of London alone, where it is preferred to all others.

\section{MARJORAM.-SWEET.-(Origanum Marjoram.)}

A well-known aromatic herb, grown to a considerable extent for market purposes; but as it is of less importance than 'Thyme, which is grown very largely for sale, the reader is referred to that head for all information regarding its culture, price, etc., as in these particulars they are entirely identical.

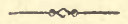 \\ MELON.-MUsk-(Cucumis Melo.)}

The Melon is not cultivated in the vicinity of New York in the market gardens proper, but to a large extent in what may be called the farm gardens of long Island and New Jersey. There it is grown almost in the same manner as they grow Corn, planting about the same time and cultivating in the same manner, and often with but very little more profit per acre than a crop of Corn. But the Melon is a fruit easily shipped, and when grown by the forwarding process we detail for Cucumbers-by planting the seeds on sods under glass-there is no question but that it can be made equally profitable in all respects with the Cucumber, when grown in southorn latitudes for our northern markets; although, like many other fruits and regetables so easily raised, it can 
never be expected to be very profitable if sold in the district in which it is grown. It is a plant not at all particular as to soil, provided it be not wet or heavy. Moderately enriched, light soils, are those most congenial to it.

For open field culture, Melons should be planted in hills six feet each way, incorporating well with the soil in each hill a couple of shovelfuls of thoroughly rotted manure. Sow four or five seeds in each hill,* and cultivate afterward as for Corn.

A clover sod is especially farorable for Melons. The main point is to push the crop forward as rapidly as possible, so as to catch the high prices which usually rule for an early crop. One of the Melon growers of Hackensack, New Jersey, admitted to me that he had lost the whole of his late crop by withholding the expenditure of $\$ 25$ or $\$ 30$ for guano on his fieia of twelve acres, which, if used at the planting, wonld have pushed the crop forward six.or eight days, and would thus have saved it from an early fall frost. For this reason, a dressing of guano or bone-meal, well mixed with the soil, should always be used if we would attain the most profitable results. It is a crop that can be as easily raised as a crop of Corn, and when sold at wholesale, it is safe to say, will always pay $a$ profit of at least $\$ 100$ per acre. The variety most preferred for this section is that known as Hackensack, which is grown by the hundreds of acres for the New York market. The most successful growers greatly increase the yield of this crop by a system of

* The term "hill," when used here and elsewhere, means but a slight elevation of the surface, and is used only as a convenient term to denote where the seed or plant is to be planted. But from the signification of the word, it naturally leads the novice in gardening into very serious error, by causing him to think he must literally raise a hill on which to sow or plant, and in consequence we too frequently see plants elevated on little knolls a foot or more above the general surface from which the rain slides, and on which the sun beats to their utter destruction. 
pinching the main vine, so as to encourage the lateral shoots upon which the fruit is borne. A large grower in the vicinity of Hackensack, New Jereey, a noted locality in this respect, gives the following details of the culture :

Melons are a special crop which needs particular care and culture. In some localities they are grown for market in great quantities. It is said that, on one evening in 1885, 160 two-horse wagon loads, each of about 1,000 Melons, crossed by one ferry from a suburb of New York City. And this was by no means an extra occasion. The Melon season lasts from July into October, so that some idea may be gained from this of the magnitude of this business. The crop is a very profitable one when skilfully cultivated, and often realizes $\$ 500$ to $\$ 1,000$ an acre, and more rarely even as high as $\$ 1,500$, when the Melons are the first in the market and bring the highest price of the season. But as with other products, these large profits are only realized by those growers whose long experience and skill give them more than usual advantages. The methods, however, are no secret, and any one who will follow them may just as easily meet with the same success.

The most suitable soil for Melons is a rich, warm, deep, sandy loam, having a southern or southwestern exposure. The latter is preferable, as it gets the last rays of the sum and the soil is thus warmed up for the night, and, being sheltered from eastern and northern winds, retains this warmth until the moruing. This may make several days' difference in the ripening of the crop, which may be equivalent to $\$ 300$ or $\$ 400$ an acre in the value of the fruit. The manner of culture is as follows: The soil is plowed in the fall or early in the spring and is cross-plowed the first days of May, about twenty loads per acre of manure being plowed under, in addition to the special manuring for each hill: The ground is then well harrowed and furrowed out six feet 
apart each way. A good shovelful of mixed fine manure and night soil, together with a small handful of guano, is used in each hill, being mixed with the soil, for nine inches deep and twenty-four inches wide; six or eight seeds are planted in each hill. The first planting is early in May ; other plantings may be continued through June. The hill is raised two or three inches above the surface, and is made about two feet broad and quite flat. When the plants appear above the surface they require protection from cut worms, which would otherwise cut the stems and destroy them; and as the rough leares appear, the weaker plants are thinned out and only thiree left. A good method of protecting the plants arainst the cut worms is to make a ring of thick paper, about a foot in diameter and three inches broad, and place this around them, so as to form an obstacle over which they cannot climb. The after cultivation consists of deep plowing at intervals, at least twice, and frequent cultivation, until the vines begin to run, when the terminal buds are pinched off to cause the growth of the lateral branches. The main vine produces chicfly male or barren flowers, and if this is left to run, the laterals would not push out and there would be little or no fruit. The lateral shoots bear the female or perfect flowers, and to encourage the growth of these, is one of the secrets of Melon culture upon which the profits depend. The same peculiarity of growth is found in all the gourd tribe, and applies to Squashes, Cucumbers and Water Melons, as well as to Musk Melons, careful attention to which, other things being right, makes success certain.

The pests of the Melon are lice, the striped beetle, and the squash bug. The lice appear on the under side of the leaves and are difficult to get at, so that the simplest and most effective remedy is to pirch off the affected leaves or the part of the vine and carry it away and burn it. If left undisturbed, the lice from one hill will quickly 
spread over several square rods and completely destroy the crop. A sure preventive against the lice or Aphis is tobacco, which, if either in the form of refuse stems or dust, is strewn on the hill, the lice will never appear ; it will also act as a preventive against the striped bug. The striped beetle is the worst enemy to deal with. It lays its eggs on the stem at the ground, and the small grubs work their way to the root and feed upon it. The first indication of their presence is the wilting of the leaves - "going down" of the vines, the growers call it - and vine after vine thus goes down, until at times the larger part of the crop may be destroyed when the Melons are half grown. The remedy for this pest is to apply strong tobacco water around the stem on the first appearance of the small striped beetle and repeat it in a few days, and to repeat it again as soon as the wilting of the first leaf is noticed. The fruit begins to "net" abont two weeks before it ripens, and the indications of ripeness are the fragrant scent, the softness of the blossom end of the melon, and the cracking and easy parting of the stem.

Too much care cannot be used in sowing the seeds of all plants of this class, as they cross very readily; for this reason, when seeds are to be saved from any particular variety, care must be taken that it is widely removed from any other--not less than 300 yards. If seed is not wanted, improper crossing will make no difference to the fruit that season, but the seed-the product of that crop-will be affected thereby, and its impurity developed in the fruit raised from it.

From the facility with which the Melon intermixes, it follows that the varieties are very numerous, and for the same reason it is difficult to retain varieties pure. The following seem to be the most fixed in character, and are the varieties in general use:

Larly Ilackensack.-This is an improvement of recent 
introduction on the well-known "Hackensack," described below, in being from five to six days earlier. This earliness gave a grower in Albany, New York, last summer (1886), over $\$ 100$ more per acre in using this variety, above all other kinds tried. In size it is some-

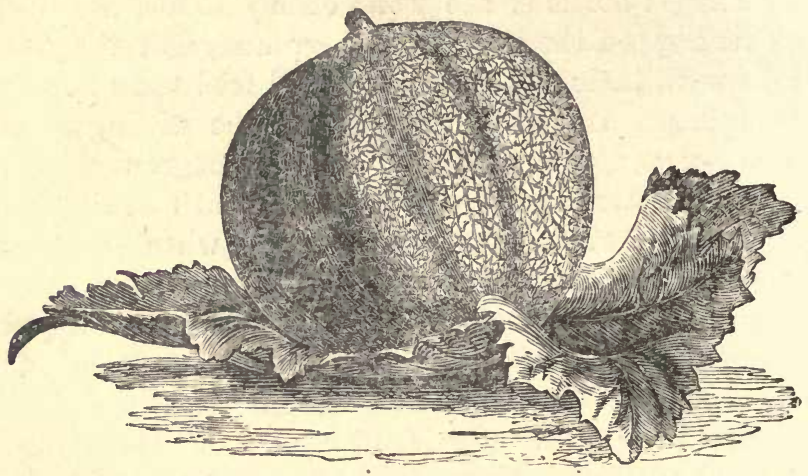

Fig. 59.-HACKENSACK MUSK MELON.

what smaller, but it is similar in other respects to the large Hackensack.

Hackensack.-(See figure 59.) This is now one of the most popular varieties grown for market by the gardeners of this vicinity. It attains a large size, is round in shape and flattened at the ends; skin green and thickly netted. The flesh also is green, and rich and sugary in flaror. It is wonderfully productive.

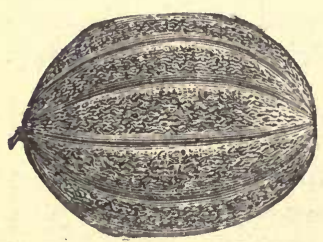

Fig. 60.-GOLDEN NETTED GEM MUSK MELON.

Golden Netted Gem.-(See figure 60.) This is one of the earliest, and no doubt the best small Melon grown. The fruit is globe-shaped, uniform in size, weighing from one and a quarter to one pound and a half each. The flesh is lightgreen, and of fine flavor.

Baltimore.-(See figure 61.) This is a productive and 
excellent shipping Melon, that can always be found in its season in the best hotels and restaurants of New York,

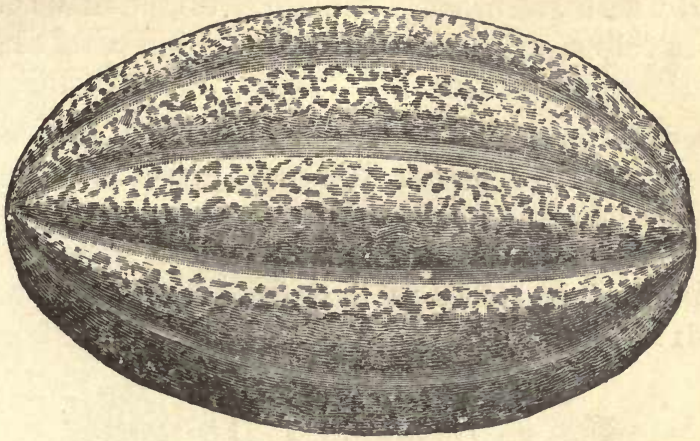

Fig. 61.-BALTIMORE MUSK MEI.ON.

Philadelphia and Baltimore. It is a thick, green-fleshed variety of oblong form, and of excellert flavor. In Baltimore and farther south this class of Melon is known as Cantaloupe.

IIontreal Market.-(See figure 62.) The Melons of

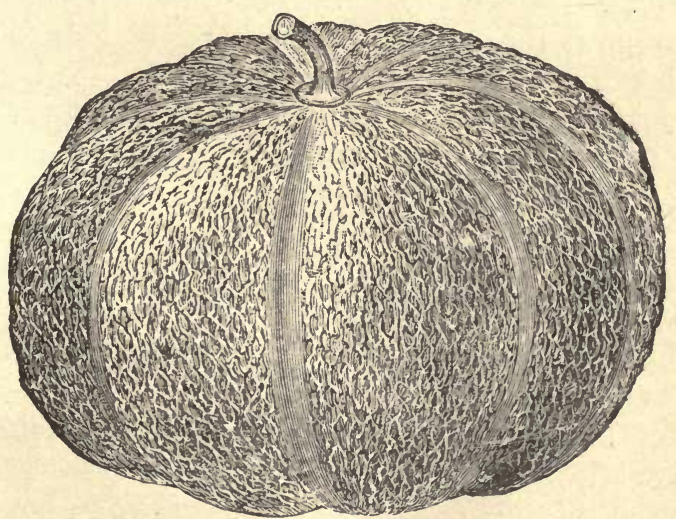

Fig. 62.-MONTREAL MAI:KET MOSK MELON.

this excellent variety are of the largest size. We have 
had them weighing over twenty pounds. In form it is almost round and deeply ribbed. The skin is green and netted; flesh green, very thick and of the finest flavor. It is largely raised for the markets of Montreal, where it is justly highly esteemed.

Green Citron.-This excellent Melon was formerly the leading variety in our New York markets, but of late years it has been superseded by the Hackensack. 'The fruit is of medium size, deeply netted, of globular shape and six to eight inches in diameter. Flesh green and of fine flavor.

\section{MEION.-WATER.-(Citrullus vulgaris.)}

Like the Musk Melon, when cultivated for sale, this is essentially a plant more suited for the furm than the garden, as it requires even more space in which to grow. The soil best suited to it is a rather sandy loam, hearier soils being apt to induce a too strong growth of leaves. It should be planted about the same time and cultivated in all respects the same as the Musk Melon, only that the hills should not be less than eight feet apart. It is grown in immense quantities on the light sandy soils of New Jersey for the New York and Philadelphia markets, in which it is said to give a profit of from $\$ 50$ to $\$ 100$ per acre. But it is in the vicinity of our Southern citiesCharleston, Savannah, and also many points in Florida, etc., where we have regular stcamboat communication, that these tropical fruits can be grown at a high rate of profit to the cultivator.

Water Melons grown in the vicinity of Charleston in July are sold by the tens of thousands in New York to the consumer at $\$ 1$ each, while those grown in Southern Jersey in August and September, are a drug at fifteen and twenty-ive cents. The leading varieties are: 
Phinney's Early. - Very early, productive, of medium size and quality.

Ice Cream.-The White Seeded Ice Cream or Peerless is of medium size, skin pale green, flesh scarlet, of the best quality.

Mountain Sweet.-An old favorite. It is of large size, oblong shape, skin very dark green, flesh red, solid and very sweet.

Rattlesnake or Gypsy.-(See figure 63.) Now perhaps the leading market variety. The Melons are ohlong

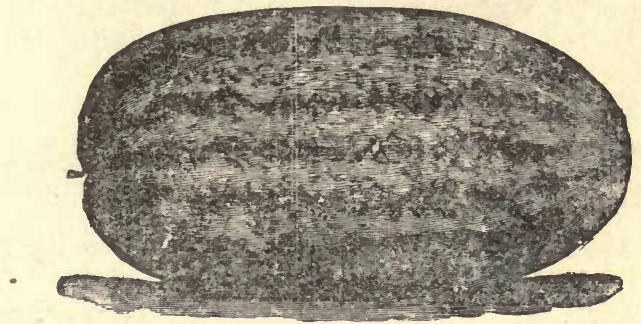

Fig. 63.-STRIPED GYPSY WATERMELON.

in shape, the rind is light green in color, with wavy stripes of dark green ; flesh bright red and of fine flavor. One of the very best Melons for shipping.

Kolb's Cem.-A new and early variety that is already largely grown, particularly in the South, for shipment to the Northern markets. Commission dealers say that as a shipping variety it is hardly equaled. The fruit is nearly round, rind dark green, somewhat marbled with lighter shades. The Melons will vary from twenty-five to fifty pounds each in weight.

Mammoth Ironclad.-This variety is of mammoth size, specimens often weighing eighty pounds and upwards. The rind is marked with regular stripes of light and dark green. It is a very showy variety of fair quality. Shape oblong. 
Icing or Ice Rind.- -(See figure 64.) There are two types of this Melon-dark and light, both of excellent

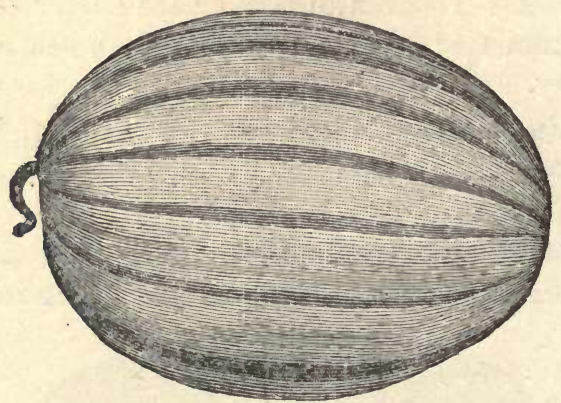

Fig. 64. - ICTNG OR ICE RIND WATERMELON.

flavor. This is the favorite variety of the market gardeners of South New Jersey.

Black Spanish.-Fruit medium size, almost round; skin dark green; flesh red, sweet and delicious.

Scaly Bark.-(See figure 6a.) The rind of this is very thin, and yet so tough and strong that it will bear any

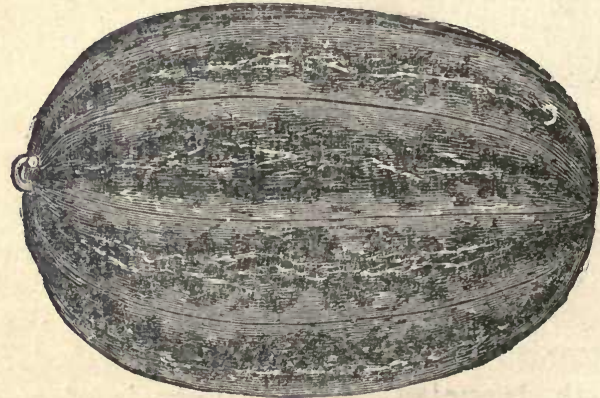

Fig. 65. - SCALY BARK WATERMELON.

amount of handling before bursting or crucking open. This characteristic gives to the variety special value for shipping purposes. The flesh is light scarlet in color, and 
of excellent flavor. To give some idea of what pressure this variety will bear, we state the fact that, in 1884, a specimen of this variety left at our office stood a pressure of 1,250 pounds before breaking. There are numerous other varieties constantly being offered by seedsmen, a few of which are meritorious, although the majority of them are worthless. Besides the sorts already given, the variety known as Pride of Georgia is worthy of mention.

Citron.-Outwardly a very handsome Melon. The fruit is of small size, but not worth growing as a ripened fruit. It is used to some extent for making sweetmeats, for which purpose it is alone cultirated.

\section{MINT.-(Mentha viridis.)}

A hardy perennial plant, found growing in abundance along the roadsides in many places. It is often grow $\mathrm{n}$ in gardens, however, and is used in soups, sauces, salads, etc., very generally. It is of the easiest culture. It is increased by divisions of the root, and planted at distances of a foot apart. It quickly forms a mass, which may be cut from for many years without renewal. It is grown to a considerable extent in hot-beds and forcingpits, in the same way as Letiuce, and sold in the markets in early spring.

Its treatment there is very simple, being merely to lift up the roots in solid mass, placing them on the three or four inches of earth in the hot-bed or bench of the forcinghouse, and water freely as soon as it begins to grow. The sale is not large, but growers realize about $\$ 10$ per sash (three by six), for what is thus grown throughout winter and spring. 


\section{MARTYNIA.-(Martynia proboscidea.)}

A vegetable used to a considerable extent for pickling, the pods or fruit of which are produced in the greatest abundance. It is cultivated by sowing in open ground in April or May, and transplanting to two feet each way in June; it is fit for use in July and August.

\section{MUSTARD.-(Sinapis alba, and S. nigra.)}

Is used for culinary purposes as a salad, usually in conjunction with Cress. For this purpose it may be had throughout the entire season, by sowing during winter in hot-beds or forcing-pits, and, on the opening of spring, in the open ground, where, by sowing at interrals of two or three weeks, it may be had in proper condition for nse thronghout the year. Sow thickly in rows, one foot apart, on any soil.

White Mustard.-This is the variety mostly used as a salad; the seeds are bright yellow, and are used in the manufacture of the Mustard of commerce.

Black Mustard.- This variety is hardly distinguishable from the preceding, except in the color of its seeds, which are dark-brown; they are used for medicinal purposes, and also in manufacture of Mustard.

\section{MUSHR00M.-(Agaricus campestris.)}

I know of no vegetable which has such a novelty and interest to the beginner as the cultivation of the Mushroom. In all other vegetables he sees something tangible to start with-seeds, plants or roots; but here we may almost say he sees neither, for the seeds cannot be seen 
with the naked eye, and it requires an unusual effort of the imagination to believe the white moldy substance we call spawn to be either plants or roots. There are so many different systems of growing the Mushroom, detailed in most of the works on gardening, that the reader is too often bewildered in choosing a guide. In this I will only detail one method, which I have practiced for many years with unfailing success.

To make the enltiration of the Mushroom profitable, it must be done in a building, either specially erected for the purpose, or in some shed, stable or cellar already on the premises, and which can be converted to that use. The most suitable place, in establishments having greenhouses, vineries or forcing pits, are the bas!. sheds, usually erected over the boiler pits, such as are shown in the plans of forcing-pits in this work. But such a structure is not indispensable. Any

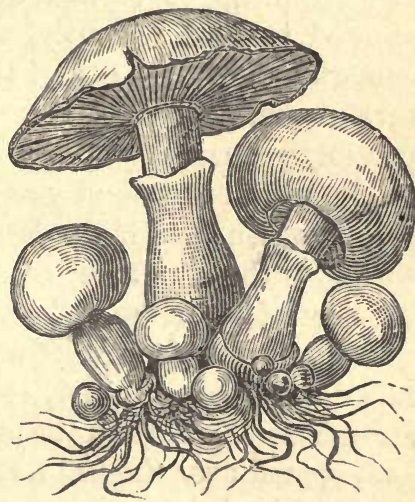

Fig. 66.-musirroums. place where a temperature of from fifty to sixty degrees can be sustained during winter will suit. We have also grown them under the stages of our greenhouses, but our "modern improvements" of late years allow us no longer room for the operation there. The time of beginning may be any time during winter. We have usually begun our preparations about December 1st, which brought our beds into bearing about February 1st, at the season that Mushrooms begin to be most wanted.

Our method of growing Mushrooms is very simple, and can be accomplished to a certainty by any one conforming 
strictly to the following directions. Let fresh horse droppings be procured from the stables each day, in quantity not less, perhaps, than a good barrow load ; to every barrow load of droppings add about the same weight of fresh loam from a pasture or sod land, or soil of any kind, in fact, that has not been manured-the danger of old manured soil being that it may contain spurious fungi. Let the droppings and soil be mixed together, day by day, as the droppings can be procured; if they can be had all at once, in quantity enough, so much the better. Let the heap be turned every day, so that it is not allowed to heat violently, until you have got quantity enough to form the bed of the dimensions required. Be careful that your heap is under corer, so that it cannot possibly get wet.

The most convenient size for a bed is from four to fire feet in width, and if the Mushrooms are wanted in quautity, it is the plan most economical of space to start on the floor of the house with the first bed, the additional ones to be formed of shelving, four feet wide by ten inches deep, raised one above another, something like the berths in a steamboat. Now, from the prepared heap of droppings and soil, spread over the bed a thin layer; pound this firmly down with a brick ; then another layer, pounded down as before, and so on until it reaches a depth of eight inches. Be careful that it be no more nor less than eight inches; more would cause the mass to heat too violently, while less is hardly enough. Into this bed plunge a thermometer; in a day or two the bed will heat so that it will run up to 100 degrees or over, and as soon as it declines to ninetyfive or nincty, take a dibber or sharp stick and make holes all over the bed, at the distance of about twelve inches each way, to about half the depth of the bed. Into each hole put a piece of spawn of the size of a hen's egg or so, covering up the hole again with the compost, so that it will present the same level, firm surface as before the spawn was 
put in. Let it remain in this condition for about ten or twelve days, by which time the spawn will have "run" through the whole bed. This is the method when "brick spawn" is used. When "French Flake" or loose spawn is used, make holes with the hand all over the bed four or five inches deep and wide, in which place a handful of the loose spawn, and again beat it down to its original firmness. Now spread evenly over the surface of the bed nearly two inches of fresh loam, firm it down moderately with the back of a spade, and cover up the bed with three or four inches of hay or straw; this completes the whole operation of "planting the crop." Nothing now remains to be done but to give attention to the proper degrees of heat and moisture.

If you can control the means of heating so that the place can be kept uniformly at a temperature of sixty degrees, all the better, but if not, it may range from fifty to sixty degrees. It should never get much below fifty degrees, else the bed will become cold too quickly, and delay the crop until too late in the season to be profitable. Unless the air of the house has been unusually dry, the Mushrooms will appear before any water is required. But examination should be made, and if the surface of the bed appears dry, a gentle sprinkling of water, heated to about 100 degrees, must be given. With this treatment, beginning in December, our first crop is ready for use in February, and as the Mushrooms do not come up all at once, it takes about three weeks to gather the crop, which is fit to gather when the Mushrooms have got to be an average of about three inches in diameter, the under side having a delicate pink color. In gathering the crop, it is best to give the Mushrooms a slight twist, so as to disturb as little as possible the young ones which usually come up in dense clusters, as shown in the engraving. After the first crop has been gathered, a slight dressing of fresh soil, of about half an inch in 
depth, is spread over the bed, and again beaten down with the spade. This is gently watered with tepid water when dry, and a second crop of Mushrooms (often better than the first), is gathered in March.

T'o show how a simple oversight in our operations may defeat the whole work, I will state that, in my first attempt at Mushroom growing, I labored for two years without being able to produce a single Mushroom. In my apprentice days we had known no such word as fail in so simple a matter, but here, on my first attempt on my own responsibility, I was met by total failure. Every authority was consulted, all the various methods tried, but with no better success. In all such cases something must be blamed, and I pronounced the spawn as worthless; but my good-natured employer quietly suggested that this could not well be, as a friend of his had abundant crops growing from spawn received from the same source. Driven into a corner by this information, I made another exploration of my "authorities," and was fortunate to find in one of them a single sentence that at once showed where my error had been. It was to " be careful to delay the covering with mold until ten or twelve days aiter the bed had been spawned."

Now, in all the different methods I had tried, I had in each invariably put in the spawn, and at once put on the two-inch covering of soil, which had the effect to shut dəwn the steam, thereby raising the temperature in the bed to a degree to destroy the spawn, and consequently to defeat my whole operations. My excuse for this digression is to show the importance of what might otherwise be thought unnecessary details.

The plan of one of our most successful Mushroom growers in the neighborhood of New York is practically that of my own just given, except that he makes a difference in covering. Instead of using the two inches of loose soil, as was my method, he uses old compact sod, 
cut two inches thick, placing the grassy side downward. This he has found in his experience to be the best method, which his extraordinary success seems to well attest.

Although spawn is procurable at cheap rates in all horticultural stores, yet to such as desire to make it themselves 1 give the following brief directions. Take equal portions of horse droppings, cow dung and fresh loam; mix the whole thoroughly together, as you would make mortar; then form it into cakes about the size of large bricks; place these on edge, under cover, until they become half dry; then insert into each a piece of spawn half an inch or so square; let the bricks remain until they are quite dry. Then spread about eight inches of horse dung over the floor of the shed, on which build the bricks in a pile three feet wide by three feet high, keeping the side in which the spawn has been put uppermost; then cover them over with sufficient stable manure, so as to give a gentle heat through the whole. In two or three weeks the spawn will have spread itself through the whole mass of each brick. 'They are then removed to a dry place, and will retain their vital properties for many years. There is not the least question that the cultivation of Mushrooms for market, forced in the manner detailed, will give a larger profit for the libor and capital invested than that from any other vegetable. The supply has never yet been half enough, and sellers have had prices almost pretty much as they pleased.

I know of no house in this vicinity-there are some, I believe, in Canada--that have been especially erected for the purpose, and the markets have been supplied from beds formed in out-of-the-way cornors, giving only an uncertain and irregular supply, very discouraging to buyers. I have no doubt whatever that Mushroom houses, roughly built, but exclusively devoted to that purpose, would, in the vicinity of any of our large cities, pay a profit of thirty per cent. per annum on cost of construc- 
tion. I am often asked if it will pay to raise Mushrooms outside during summer. I do not think it would, unless under special contract, as, besides being less appreciated in hot weather, they come in competition with those grown in the fields. If, however, it is desired to raise the crop in summer, adopt exactly the plan above advised; all that is necessary to see to is, that the beds are made in the shade and protected against rain.

\section{NASTURTIUE,--INDIAN CRESS.-(Tropceolum.)}

A plant at once highly ornamental and nseful. The shoots and flower buds are sometimes used as a salad, but it is grown for its seed-pods, which are pickled in vinegar and used as a substitute for capers. It can be grown in almost any soil or situation, entwining itseli around strings, brush or trellis work, that may be given for its support. It may be sown thinly in drills an inch or so deep, in April or May. There are many beautiful varieties, but the following are only those in use in our regetable gardens.

Tall Nasturtium (T. majus), attains a height of eight or nine feet; the flowers are yellow, blotched with crimson. This variety makes an excellent screen or corering for unsightly places in the garden.

Dwarf Nasturtium ( $T$. minus.)-This, in growth, is quite distinct from the preceding, never attaining more than three feet; it should be sown thinly in drills, three feet wide, and staked up with brush like Peas. Its flowers are handsome, bright yellow, blotched with scarlet. 


\section{OKRA 0R GUMBO.-(Abelmoschus esculentus.)}

This vegetable is extensively grown in the Southern States. Its long pods, when young, are used in soups, stews, etc., and are belicved to be very nutritious. It is of the easiest culture, and grows freely, bearing abundantly on any ordinary garden soil. It is sown at the usual time of all tender vegetables-in this district in May-in drills two inches deep, and from eighteen to twenty-four inches apart in the rows for the dwarf sorts; for the tall, nearly double that width. There are now the following sorts: New Dwarf Prolific, Dwarf White, Dwarf Green and 'Tall Green.

\section{ONION.-(Allium Cepa.)}

Next to Cabbages, perhaps Onions are the most profitable crop of our market gardens, in which they are grown from sets, and nearly all sold in bunches in the green or unripened state. Grown from seed, they are cultivated almost exclusively by farmers or men who devote farm land to this purpose alone. Thus grown they are soid in the dry state, and form an important article of commerce.

I will first describe the manner of cultivating in our market gardens. To produce the "sets," or small bulbs, that are planted to give early Onions to be sold green, a poor piece of ground is chosen as early as it is fit to work in spring. It is brought into a thorough state of pulverization by plowing, harrowing and raking, so that the surface is level and free of stones. A line is then stretched, and lines are marked out by the nine-inch side of the marker. In these the seed is sown in beds of six rows wide, rubbing ont every seventh row marked, so that it forms an alley eighteen inches wide. For this purpose 
the seed is sown quite thickly, and on poor soil, so as to produce the "sets" as small as possible, for we find that whenever they much exceed half an inch in diameter, they will run to seed. It matters not how small the bulb is ; even when of the size of the smallest Peas, they make an equally good if not a better crop than if of a larger size. The sets are taken up in August, well dried, placed with the chaff among them in a loft of a stable or barn, about four inches deep, covered up by six inches of hay on the approach of hard frost, and left thus until wanted for setting out in spring. This is the usual method of raising Onion sets.

But few market gardeners can grow them in the ordinary manier, unless at a cost greater than they can be purchased for from those who make a business of growing them. But the price paid for sets the past six or eight years has been so high that many market gardeners have abandoned growing Onions from them.

For Onion sets the best soil of the garden is chosen, manured with short, well-rotted manure, plowed in at the rate of seventy-five tons to the acre. When only concentrated manures can be obtained, crushed bone is preferable to guano (for quantity see Chapter on Manures). The ground is further deeply harrowed, finishing with the smoothing harrow (see Implements), or, if on a small scale, smoothed fine with the rake. The line is now stretched along the bed, and the nine-inch marker again makes the drills, six in each bed, with the seventh rubbed out for an alley. The sets are now planted in the drills at a distance of two to three inches apart, pressing each bulb down firmly, so that it will keep right side up. The row is then closed in by the feet or a rake, so that the set is entirely covered up. The ground is then rolled over, so as to render it still more compact around the bulbs; as soon as the lines can be traced, by the Onions starting to grow, the hoe is applied between the rows, 
and the soil broken between the plants by the fingers, where the hoe cannot reach, so as to destroy the germs of the weeds. If attended to in time, twice going over with hoeing and weeding is sufficient until the crop is fit for market, which it begins to be about the first week in June, and is usually all gathered by the first week in July, so as to give us time for second crops.

When we first begin to send them to market, they are usually not more than half grown, and are washed and tied in bunches containing from nine to twelve Onions ; later, when full grown, from six to seven. This erop is one requiring considerable labor and expense to get it in shape to sell, taking cost of sets, labor, manure, etc., probably not less than $\$ 300$ per acre, for the past fifteen years; but the receipts have been eorrespondingly ligh, averaging in that time quite $\$ 500$ per acre.

Onions, planted from sets, rarely fail to give a crop on any kind of soil, provided it has been well manured; and although they are sold by the market gardeners in the green state, they are equally good, ripened and dried, when raised from sets as from seed. The quantity of sets required per acre is from six to tan bushels, according to size. At present prices, they cost $\$ 6$ per bushel.

Another plan to get early Onions to sell green, is to sow the seed in fall in rows from nine to twelve inches apart. The time of sowing is of great importance, and varies, of course, with the locality. In the latitude of New York they may be sown from 5th to 20th September ; they do not always stand the winter well here, but it is well worth the risk, as the cost of seed is trifling. compared to cost of setting, and when they stand well the crop is usually better than from sets. A dry, well sheltered soil in this location is a necessity to enable the crop to stand the winter.

The following instructions are given for raising Onions as a farm crop to be sold when mature: 
It is the generally received opinion that Onions grow best in old ground. This we think is an error ; it is not because the ground is "old," or has been long cultivated, that the Onions do better there, but because such lands, from their long culture, are usually better pulverized; and experience has shown us repeatedily that when new soil has been equally well pulverized and fertilized with the old, an equally good crop is obtained and usually a crop more exempt from rust. As a matter of fact, the finest erop of Onions we ever beheld was on sandy swamp land, which had been first thoroughly drained and broken up. In fact, new soils, particularly when broken up from pasture land-turned over early enough in the fill so that the sod is completely rotted-make excellent land for Onion crops, as they are usually free from weedis. Soils of this kind, however, must be well pulverized by the use of the plow, Acme and smoothing harrow, or good results may not follow. Much depends on the quality of such soil. If rather sandy loam, it will, of course, be much easier to pulverize than if stiff or clayey loam, and such soil, in our experience, is always preferable for most crops. Such soils, also, are nearly always free from under water, rarely requiring artificial drainage if the land is level, and it always should be selected as level as possible for the Onion crop, as when land slopes to any great extent, much damage is often done by washing out, the Onicn roots being near the surface, consequently cannot so well resist floods, as crops. that root deeper.

Many Onion growers who make a specialty of the business, find it is economical to alternate the Onion crop with a green one, such as German Millet, which can be cut for hay in July, the "stubble" plowed down in August, giving a fresh fibrous soil clear of weeds for the Onion crop to be sown next spring. It is not claimed that the alternation of a green crop with the Onions is a 
necessity, as it is well known that the Onion is one of the very few crops that do not seem benefited by alternating; but it is claimed that it gives almost entire freedom from weeds, as after a crop of Millet, which has been cut before its seed is ripe, few troublesome weeds will come up the next year.

\section{MANURES.}

I have always held the opinion that when well-rotted stable manure, whether from horses or cows, can be procured at a cost not exceeding $\$ 3$ per ton, delivered on the ground, it is cheaper and better than any kind of concentrated fertilizer. It should be plowed in at the rate of thirty tons to the acre. The concentrated fertilizers in the market are now so numerous that it would be invidious to specify particular brands. We ourselves, except in using occasionally the "blood and bone fertilizer," which we have proved to be excellent, use only pure ground bone and Perurian guano, which, for Onions, we prefer to mix in equal parts, sowing it on the land, after plowing, at the rate of at least one ton per acre of the mixture (when no stable manure has been used), after sowing to be harrowed in, as described in "Preparing the Ground."

One of the most valuable manures for the Onion crop are the droppings from the chicken or pigeon-house, which, when mixed with twice their weight of lime, coal or wood ashes, so as to disintegrate and pulverize, may be sown on the land after plowing, to be harrowed in at the rate of three or four tons per acre of the mixture. Night soil, when mixed with dry muck, coal ashes, charcoal dust, lime, or lime rubbish, as absorbents, and spread on after plowing, at the rate of six or eight tons por acre, and harrowed deeply in, the mixture will nerer fail to produce a heavy crop of Onions in any suitable soil.

There are many other manures that will answer the 
purpose, often to be had in special localities, such as the refuse hops and "grains" from breweries, which should be used in the same manner and in similar quantities as stable manure; while fish guano, whalebone shavings, or shavings from horn, when pulverized so as to be in proper condition for plant food, are nearly equal in value to ground bone. Wood ashes alone, spread on at the rate of five or six tons per acre, will usually give excellent results.

It is well to keep the fact in mind that it will always be more profitable to fertilize one acre of Onions well, than two acres imperfectly. If thirty tous of stable mauure or one ton and a half of concentrated fertilizer are used to an acre, the net profits are almost certain to be larger, than if that quantity had been spread orer two acres; for in all probability nearly as much weight of crop would be produced upon the one well-manured acre as upon the two that had been imperfoctly manured, besides the saving of seed and labor in cultivating oue acre instead of two.

\section{FREPARING THE GROUND.}

In preparing the ground for the reception of the seed (if it has been plowed the fall previous), plowing should be begun as soon as the land is dry enough to work, first having spread over the land well-rotted stable manure, at the rate of thirty tons to the acre. This should be lightly turned under, plowing not more than five or six inches deep, and covering the manure so that it will be three or four inches under the surface. For this reason the manure must be well rotted, otherwise it cannot be well covered by the plow. If concentrated fertilizers are to be used, it is best to plow the land up roughly, sow the fertilizer at the rate of one to two tons per acre, according to its fertilizing properties ; then harrow thoroughly, 
so that it is thoroughly incorporated with the soil. After harrowing with an ordinary toothed harrow, the surface should be further leveled with a Smoothing or Dise harrow. The revolving dises pulverize the soil to a depth of three inches much better than it can be done by raking, and the smoothing board, which follows in the wake of the revolving wheels, makes the surface, if free from stones, as smooth as a board-far better than it can be done by raking.

'The ground being thus prepared, the next thing is the sowing of the seed, about six pounds being used per acre. This, of course, now-a-days, is always done by the seeddrilling machine, of which there are many in the market; we ourselves give preference to the Planet Jr. In sowing the first row, a line must be tightly stretched so as to have that row straight, after which the marker can readily regulate the other rows. The farorite distance apart for Onion rows is fifteen inches, though they are sometimes sown as close as twelve inches, leaving out every ninth row for an alley, thus forming beds of eight rows each. Where there is reason to believe that weeds may be troublesome, this plan of forming into beds has the advantage of the alley (twenty-four inches wide), into which to throw the weeds.

We so fixedly believe in the value of firming in the seeds after sowing, that we advise, in addition to the closing and firming of the sceds by the drill, to use a roller besides, particularly if the land is light, or where the soil has not been sufficiently firmed down.

There is no other crop where the adage of a "stitch in time" 1s so applicable as in the Onıon crop, therefore, just as soon as the lines can be seen, which will be in ten or twelve days after sowing, anply the scuffle hoe between the rows. There are a great many styles of hand cultrvators, many of which are exceedingly useful when the Onions get strong enough after weeding; for the first 
hoeing, after the seed shows the lines, we prefer the Planet Jr. Double Wheel Hoe.

The distance at which Onions should stand in the rows is from one to two inches, and if the crop is sown evenly and thinly, few require to be taken out, but whether it is weeds or onions that are to be removed, one thing should never be lost sight of-that when this operation is done, every inch of the surface should be broken. 'This is best done after hoeing, by using a wooden lawn rake all over the land, raking lightly across the rows. It is one of the most common mistakes in a laborer when weeding or hoeing, if he sees no weeds, to pass orer such portions without breaking the crust. By this neglect, not only is it most likely that he passes another crop of weeds in embryo under the unbroken crust, but the portion unbroken loses the stirring so necessary for the wellbeing of the crop.

In our long experience in garden operations, we have had more trouble to keep our workmen up to the mark in this matter than in any other ; and I never fail, when I discover a man guilty of such negligence, to set him back over his work until he does it properly, and if he again fails to do so, promptly dismiss him.

The Onion crop is usually fit to harvest, in this section, from 5th to 20th of August; that is, when the seed has been sown in early spring, which should be not later than May 1st, if possible, and if by April 1st all the better. If the seed is sown too late, it may delay the time of ripening, which may result in a complete loss of the crop, for, if the bulbs are not ripened by August, there is danger, if September is wet, that they will not ripen at all, hence the great necessity of early seeding in spring.

If the Onion crop is growng very strong, it will facilitate the ripening process if we bend do:wn the leaves with the back of a wooden rake, or some such rimplement, 
so as to "knee" them, as it is called, at the neck of the bulb; this checks the flow of sap, and tends to ripen the bulb.

After the tops of the Onions become yellow and wither up, they should then be pulled without unnecessary delay, for if there is continued wet weather, and we delay the pulling too long, a secondary growth of the bulbs may be developed, which would seriously injure the crop. After pulling, lay the bulbs in convenient rows, so as to cover the ground, but not to lie on each other. By turning them every day or two, in six or eight days they will usually be dry enough to be carted to their storage quarters, where the shriveled tops are cut off, and the Onions stored on slatted shelves to the depth of six or eight inches, in some dry and airy place. It is of importance to have the bottom of the shelves slatted, so as to leare spaces an inch or so apart, that air ean be admitted at the bottom as well as the top of the hesp. The shelres, when all the space at hand is to be made available, may be eonstructed one abore another. But if to be kept through the winter, the Onions must be protected in some building eapable of resisting severe frost, or they must. be eovered with hay or straw as a protection against extreme cold. For, although the Onion will stand a moderate degree of frost, any long continuation of a zero temperature would injure them. When frozen, they should never be handled, as in that condition they are easily blemished, and would rot. When kept in barrels, holes should be bored in the sides for ventilation, and they should be left unheaded until shipping time, to permit the escape of any moisture that may be generated.

For the insects and other enemies that attack the Onion crop, I am much afraid there are few if any effective remedies. Every year's experience with the enemies that attack plants in the open field convinces me that we can suceessfully cope with very few of them. The rem- 
edy, if remedy it is, for rust, smut or other mildew parasites, must, in my opinion, be a preventive one; that is, whenever practicable, use new land, or rentw the old land, by a green crop, such as Rye, 'limothy or Millet, in all sections subject to these diseases. The same plan had better be adopted in all places where the Onion maggot or other insects attack the crop. 'The theory for' this practice is, that it is believed that nearly all plants affected by insects or diseases, have such peculiar to ihemselves, and that the germs or eggs lie in the soil ready to fasten on the same crop, if planted without intermission on the same ground, while if a season intervene, the larva or germ has nothing congenial to feed on, and is, in consequence, destroyed. In practice we usually find that cultivated land "rested" for a season by a grass erop gives a cleaner and healthier crop of whatever vegetable may follow it.

\section{THE PRODUC'T.}

The product of the average Onion crop varies very much, ranging from 300 to 900 bushels per acre, the mean being about 600 bushels per acre. 'The price, like that of all perishable commodities, is variable, ranging from 50 cents per bushel, the price at which they usually wholesale in the New York market in fall, to $\$ 1$ or $\$ 1.50$ per bushel for winter and spring prices. The estimate, then, of profit per acre may be given about as follows :

Manure, per acre

Plowing, weeding and harvesting crop, per acre ....... 100

Six pounds seed, average $\$ 2$ per pound ............. 12

Rent or interest on land, per acre ................. 9

Marketing crop, per acre ....................... 7

Cost ... . . . .

Six hundred bushels per acre, at 50 cents ............ 300

Profit . . . . . . 
This estimate is a moderate one, for if the crop is sold in spring, the chances are that the profit may be two or three times as great.

The leading kinds of Onions are:

Lxtra Early Flat led.-(See figure 6\%) A thin, rather light-colored Onion, a good keeper, and the earliest of all.

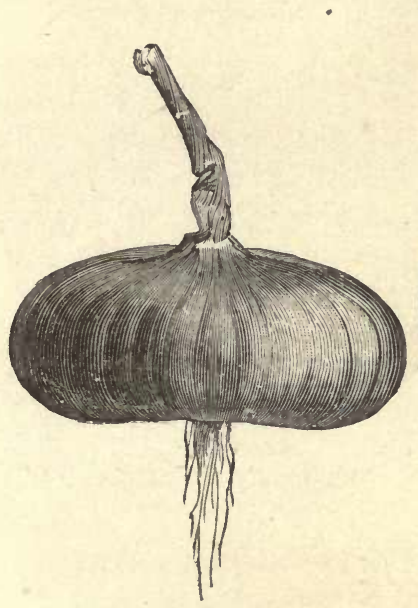

Fig. 67 .

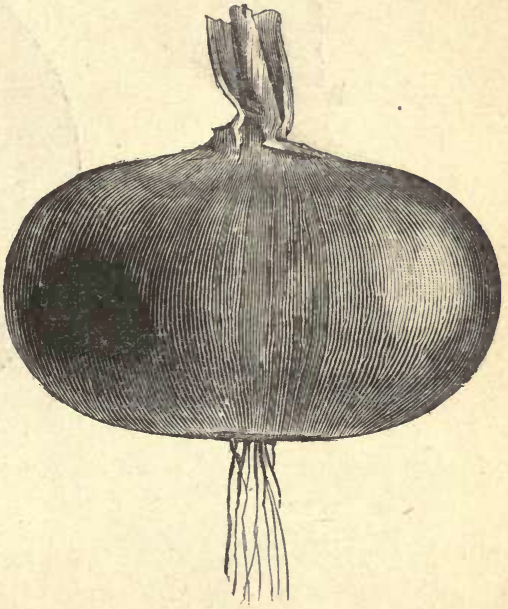

Fig, 68.

LARGE RED WETHERSEIELD CNION.

EXTRA FARIY FLAT RED ONION.

These cuts, which are bardly half the average natural size, are given to show the shape and relative size of the different kinds.

Large Red Wethersfield.-(See figure 68.) This is a favorite sort for general crop. A large yielder and good keeper.

Yellow Globe Danvers.-(See figure 09.) A fine globe-shaped variety, one of the best yielders and a splendid keeper.

Southport Large Yellow Globe.-(See figure 70.) This is perfectly globular in form. It is a good yielder and fine keeper. The Large Red Globe and the South- 
port Large White Globe possess the same characteristics as the variety just described, and vary only in the color.

Southport White Globe.-One of the finest appearing

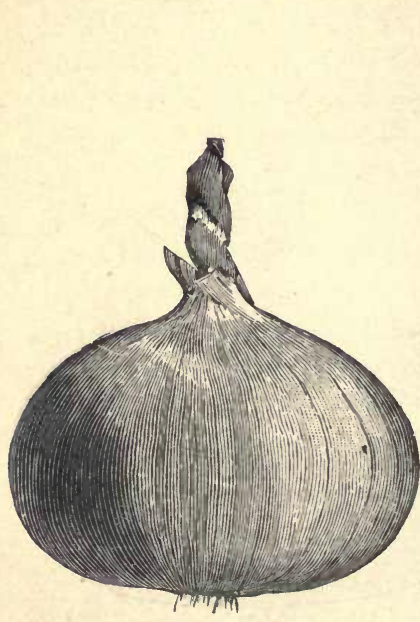

Fig. C9.-YBLLOW GLOBE DANVERS ONION.

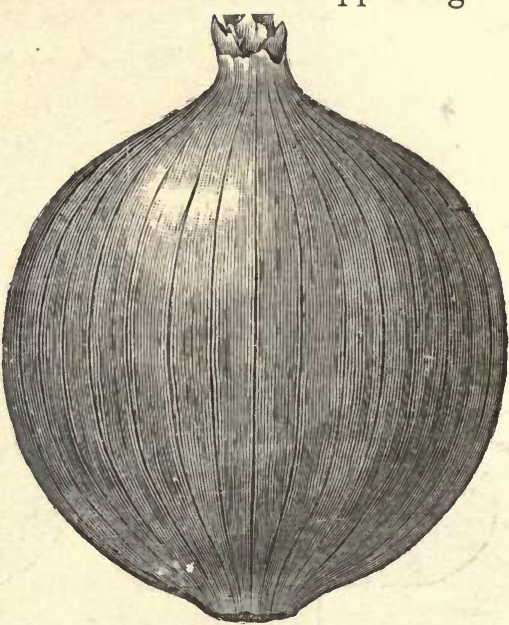

Fig. 70.-SOUthPort L.1RGE YzLlOW GLOBE ONION.

and most saleable sorts we have; pure white, fine flavor and in every way desirable. It is not quite as good a keeper as some of the colored sorts, but it is a great farorite in the New York market.

Southport Red Globe.-Similar to the above in share; color, a deep red; a good keeper.

Bermuda 0nion.-A distinct sort, principally grown in the Island of Bermuda, although the seed cannot be grown there. 'There are two varieties of it, the II lite and the Pale Red. They are both very early, and are the varieties from which as high as 200,000 bags of Onions have been shipped from Bermuda in one season. It is now being extensively inquired for by the truckers in the South, for the reason that it car be grown there as profitably as in Bermuda, which has had 
ior thirty years a complete monopoly of its culture. Great care should be taken in getting the seed genuine.

Yellow Dutch.-A flat, yellow Onion. A good yielder, but not so desirable as other yellow sorts, on account of its color and shape. This and the Flat Yellow Danvers are very similar. It is one of the heaviest croppers.

White Portugal or Silver Skin.-(See figure 71.) One of the leading sorts of white, flat Onions. A most excellent keeper and good yielder.

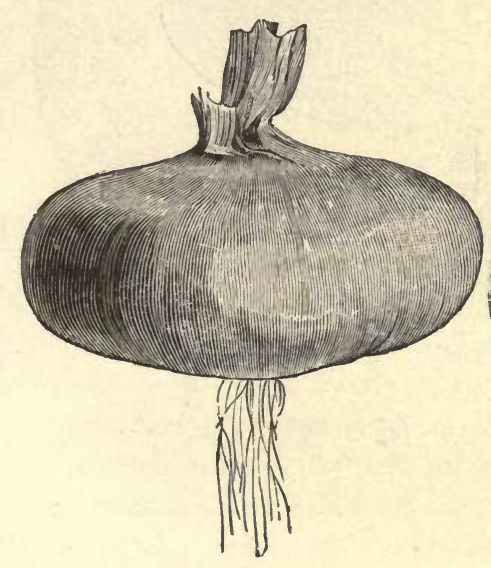

Fig. 71.-WMITE PORTUGAL ONION.

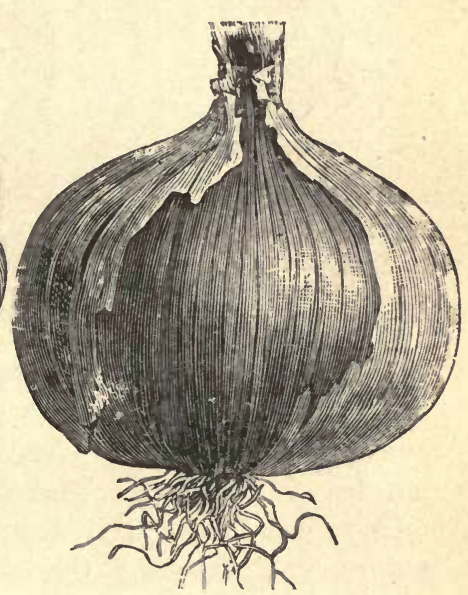

Fig. 72. $\rightarrow$ GIANT ROCCA ONION.

The following sorts are Italian varieties, and are well adapted for growing in the Southern States:

Queen.-This is the earliest of the Italian sorts, small, flat, white and mild-flavored.

Neapolitan Marzajola.-An early, white, flat Onion, of fine flavor.

Giant Rocca.-(See figure 7\%.) A very large-growing globe-shaped variety, of a reddish-brown color; flavor mild and sweet. 


\section{Large White Italian Tripoli and Large Red Italian} Tripoli.-(See figure 73.) These grow to a large size, and are later than either of the preceding.

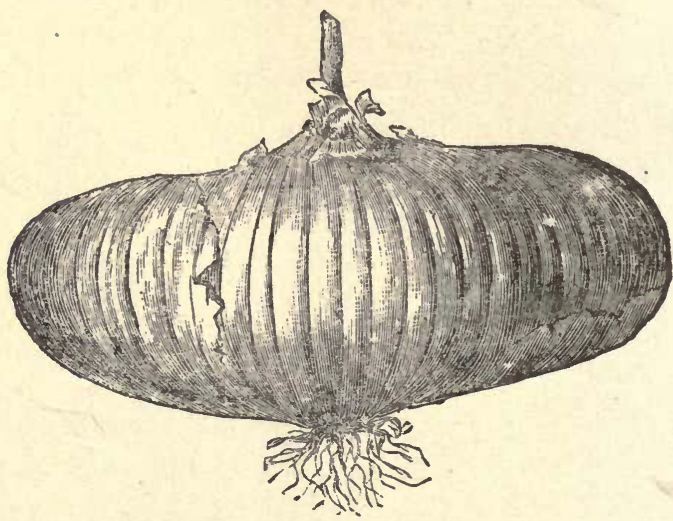

Fig. 73.-WHITE TRIPOL: ONION.

Potato Onions are increased by the bulbs as it grows, splitting into six, eight or ten sections, which form the crop from which the "set," or root for next season's planting is obtained. These are planted in early spring, in rows one foot apart, three or four inches between the onions, and, like the Onions raised from sets, are generally sold green, as in that state they are very tender, while in the dry state they are less desirable than the ordinary Onion.

Top Onions, so-called, are propagated by the peculiar growth of this variety, which produces a cluster of small bulblets on the Onion stalk, a cluster of bulblets being formed instead of flowers and seeds. In all respects its culture is the same as the Potato Onion, only that, as the bulbs are smaller, they can be planted closer. 


\section{PARSLEY.-(Petroselinum sativum.)}

A vegetable in more general use for garnishing than any other plant of our gardens; it is also extensively used in soups, stews, etc. Its cultivation forms quite an important item in market gardens, particularly under glass. The manner of eultivating it thus is by sowing it between the rows of a growing crop of Lettuce in our cold frames in April. As it is slow to germinate, it only appears at the time the Lettuce is cut off in May. It is then cleared from weeds, hoed, and forms a growth fit to eut a month before that sown in the open ground. After the first eutting has been made in June, it is generally so low in price as not to be worth marketing, so it is allowed to grow through the summer until the first week in September, when it is cut off close to the ground and thrown away, as it is rarely wanted at this season. It is again hoed, and as at this time it makes a short, healthy growth, suitable for keeping well in winter, it is stowed away in narrow, shallow trenches, exactly in the same manner in which we preserve Celery.

This way of growing Parsley is, I believe, mainly confined to the vicinity of New York, but as the consumption of such an article is necessarily limited, this market has been oversupplied of late year's. Formerly it has frequently paid twice the value of the sash that eovered it in one season- $\$ 6$ for a three by six sash. No doubt, in many places, this system of growing would be as profitable as it used to be with us. When not grown under glass, it should be sown thickly in rows a foot apart in early spring in the open ground. Where greenhouses are used for forcing vegetables, Parsley can be nicely grown under the benches, at least as far under as there is partial light. This is best done by sowing the seed in boxes (three or four inches deep, eighteen inches wide, and two feet in lengtb), in August, keeping them out-of-doors until cold 
weather in November, and then placing them under the benches of the greenhouse, but close to the walk, where they will get the most light, as this space cannot be utilized for anything else, except for forcing Rhubarb and Asparagus or Parsley. (See Chapter 10, "Greenhouses for Foreing Vegetable Crops.") If Pareley is wanted in winter, it will be found to do nearly as well in this position as in the full light.

The varieties are :

Henderson's Lmerall.-(See figure 74.) The finest variety for market, decidedly lighter in color than the

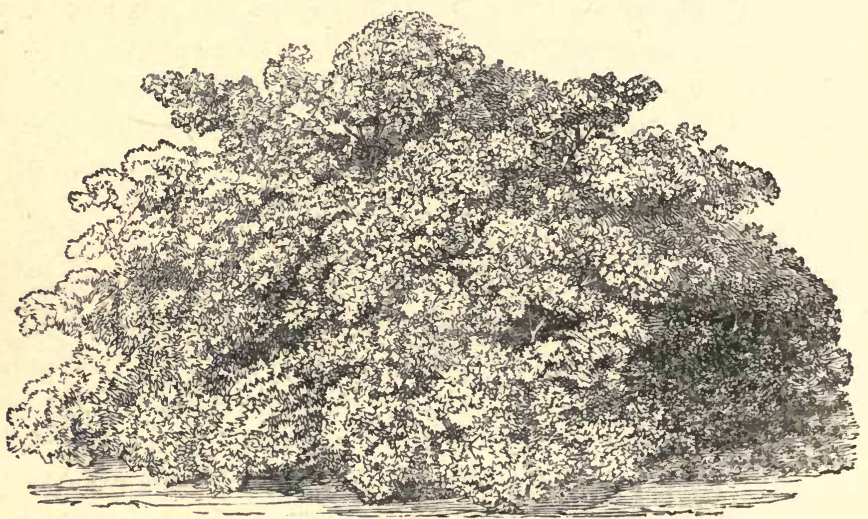

Fig. 74 - EMERALD PARSLEY.

Double and Moss Curled rarieties. Is particularly adapted for garnishing, which is one of the main uses to which Parsley is put. It is now the main sort grown by the market gardeners of New York.

Double Curled.-A dwarf growing variety, beantifully carled. The kind most largely grown by market gardeners, until the introduction of the "Emerald."

Fern Leaved.-Distinct and beautiful. Very useful for table decoration, as it appears more like a crested Fern or Moss than like Parslcy. 
Plain.-Of this variety the leaves are plain. It is hardier, however, than any of the curled sorts.

Ilamburg, or Turnip-Rooted.-A fleshy-rooted kind, the roots of which are used for flavoring soups.

\section{PARSNIP.-(Pastinaca sativa.)}

Of late years our market garden grounds have become too valuable to be used in growing this vegetable, the competition from well cultivated farm lands having brought it down below our paying level. Its cultivation is, in all respects, similar to the Carrot. The soil most suitable is a deep and sandy loam, moderately enriched. It is sown rather thickly in our gardens in early spring, III rows which are about twelve or fourteen inches apart; on farm lands at eighteen or twenty inches, or wide enough for the rows to be worked between by the horse cultivator. Like all vegetables of this nature, it must be thinned out to a distance of about three or four inches between the plants, and our oft-repeated caution about weeds is here again enjoined. Parsnips are used almost exclusively in winter, but in our Northern States what is wanted for winter use must be dug up in fall, and packed away in the manner described under the head of "Preserving Vegetables in Winter." What are wanted for sale or use in spring, are best left in the bed where they grew, being entirely hardy in our coldest districts. About one-half is usually dug up and pitted in fall for sale in winter, and the other half left over for spring. But it sometimes happens that the winter supply is exhausted before the frost is out of the ground in spring sufficiently to permit of their being dug, and when procurable at such times, they command almost fabulous 
prices. However, the average price is just about that of Carrots.

The varieties are confined to the

Hollow Crowned.-Mostly used by market gardeners.

The Student.-Grows a little smaller, but has a more delicate flavor.

Early Round.-A small round early sort.

\section{PEA.-(Pisum sativum.)}

The Pea is grown largely for market purposes in nearly every State in the Union, the time at which it is sown and matures being at widely different dates in Northern and Southern sections. In any district its highest degree of perfection is attained under a comparatively low temperature, hence it is one of the many vegetables described as best to be sown in "early spring." True, it is sown for a succession crop throughout the summer months, even as late as August, but the first sowings everywhere always produce the best results, and it is from the first sowings only that it is mostly offered in market. For market purposes it is more a crop of the farm than of the garden, and many hundred acres are cultivated in Southern Jersey and Long Island for the New York market.

Warm, light soils, moderately enriched by stable manure or bone dust, are best adapted to its culture, but if the ground has been manured the previons year, no manure is needed. The whole crop is marketed by July, and is usually followed by a second crop of Late Cabbages or Turnips. The two crops together arerage a profit of from $\$ 100$ to $\$ 200$ per acre, according to earliness, condition of soll, etc. There is an important matter con- 
nected with growing Peas, that confines their culture to the vicinity of a town or village-it is the necessity of being able to get a large number of hands to pick at the time they are marketable. The variation in one day in the market is not unusually from $\$ 2$ to 50 cents per bushel, which shows the great importance of an early crop. From the soft condition in which it is required to be gathered, it is a vegetable not very manageable to ship, and the packages, which should be latticed boxes or baskets, should nerer exceed the capacity of a bushel, when shipped from distances requiring from two to three days in the transit. But even this expense and care are well repaid by the high rates for which the first lots are sold. When grown as a market crop, Peas are rarely ever staked. They are sown in single rows about two inches deep, the rows two to three feet apart, according to the variety or the strength of the soil. When grown in small quantities for private use, they are generally sown in double rows, six or eight inches apart, and staked up by biush, for the taller growing kinds.

The varieties are very numerous, but are in a great state of confusion, the same kind being often sent out under a dozen names. The following varieties are welldefined, arranged as our experience gives the order of merit for this locality.

\section{PEAS-EXTRA EARLY.}

First of All.-(See figure \%5.) One of the best types of the Extra Early Class, and unsurpassed as a market variety. The pods are of good size and well-filled. A very heavy bearer, and can be picked clean in two pickings, thus making it the best sort for early planting in market gardens. It is also very hardy, and when planted in the fall or early spring, as is done in some parts of the South, usually stands the cold better than 
-

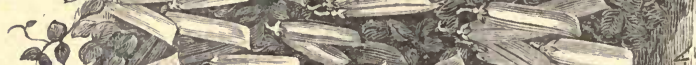

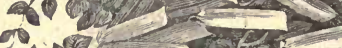

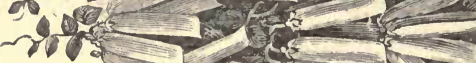

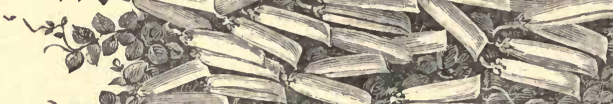

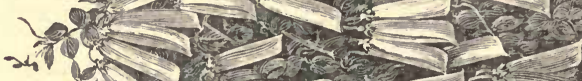

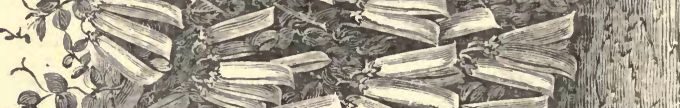

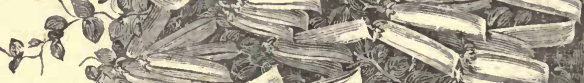

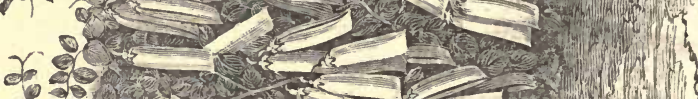

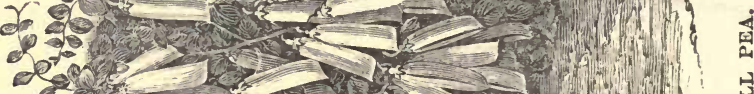

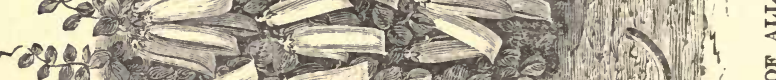

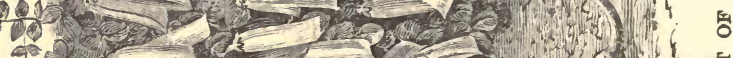

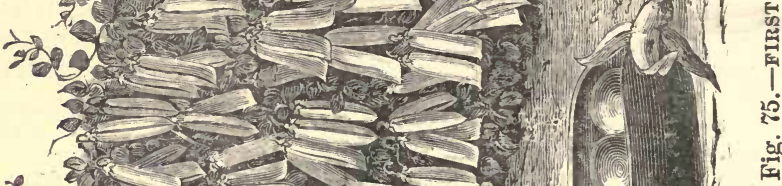

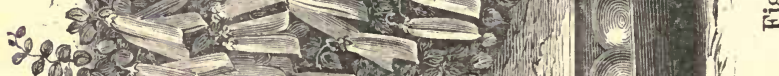

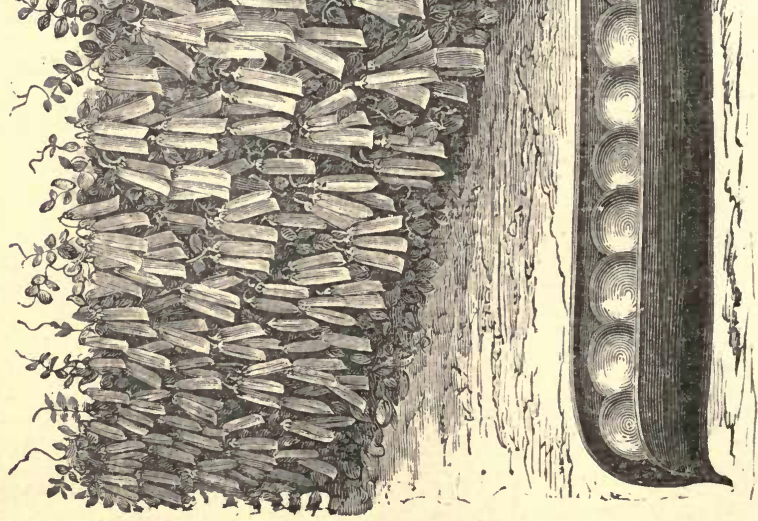


any other sort. One bushel and a half of seed is required per acre.

Improved Daniel 0'Rourke and Extra Early._These are excellent early varieties and great favorites in all parts of the country, but are not so regular in habit as the First of All. These, as well as the First of All, should be sown for a field crop in rows of from two to two and a half feet apart, about one and a half bushel of seed being required for an acre.

American Wonder.-(See figure \%6.) One of the best acquisitions of this generation, but a variety perhaps better suited for private use than to the market gardener. It is early and very productive. The peas are wrinkled, and its distinctiveness consists in its extremely dwarf growth, which rarely exceeeds ten inches in height. Can be sown at eighteen inches apart ; two bushels of seed is required for an acre. Like all wrinkled peas, the flavor is much superior to the round, or first early kinds.

Mlaska.-Very distinct and first. early; foliage very light green, vines slender. In our trials this year (1886), it was shown to be very productive.

Premium Gem.-A green, wrinkled marrow, that comes into use just a few days later than the First of All or Improved Daniel O'Rourke. It grows from twelve to eighteen inches high, is very productive, and of excellent flavor.

Kentish Invicta.-About five days later than the First. of All and Daniel O'Rourke. Very productive, and possesses fine flavor. Although it is one of the best for canning purposes, it is also largely grown for market.

McLean's Advancer, - A second early variety, and now a great favorite with market growers in this neighborhood, among whom it is often known as the Early 


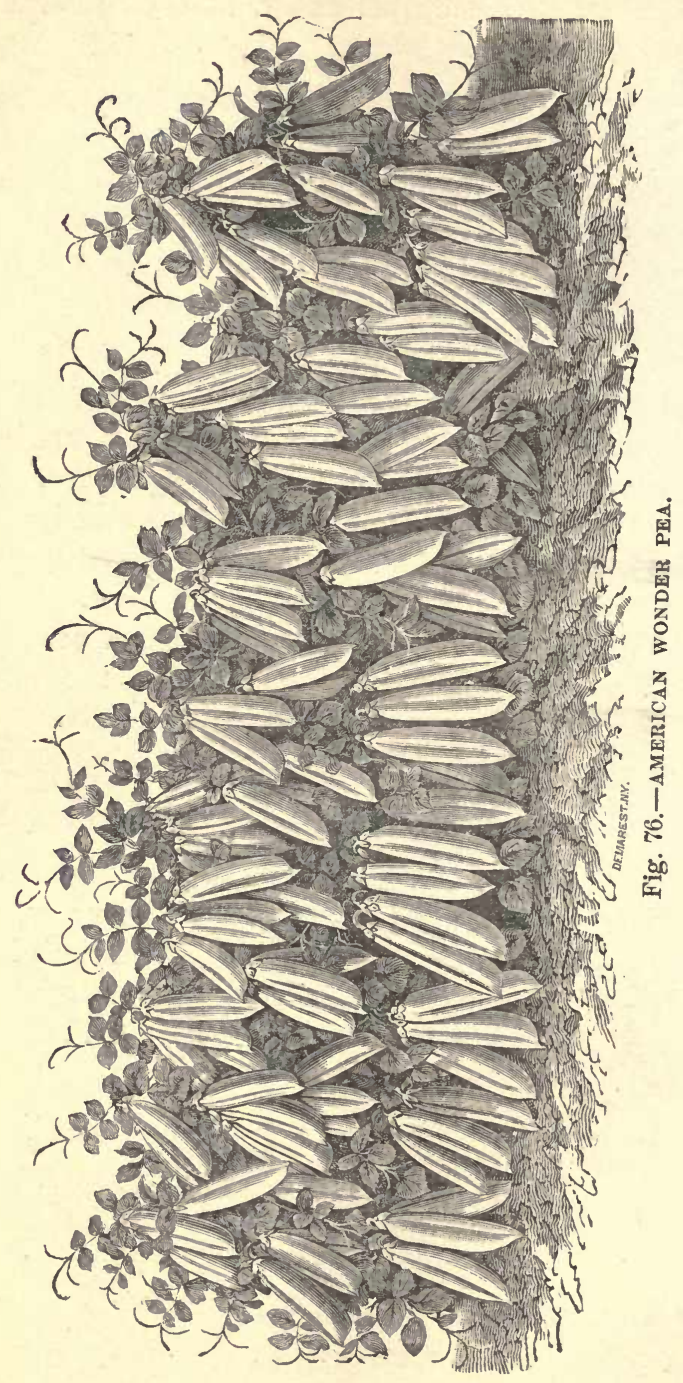


Champion. It is a green wrinkled variety, of delicious flavor.

FOR THE GENERAL CROP.

Champion of England.-This is still, by general consent, acknowledged to be the best of the late sorts. It is a tall-growing kind, attaining a height of four feet or more, and requires to be staked. The pods and peas are of the largest size.

Stratagem.-(See figure 7\%.) Is a newer variety, and by good judges considered one of the best Peas raised in recent years. It is a dwarf-growing, wrinkled, blue marrow, and produces large, well-filled pods.

Yorkshire IIero.-A splendid wrinkled green marrow Pea, of a branching habit, and an abundant bearer. Seedsmen on both sides of the Atlantic find their sales for this variety constantly on the increase.

Telephone.-A newer tall, wrinkled marrow, with enormous pods, which are not always well-filled. In spite of this, it is becoming a favorite market garden sort.

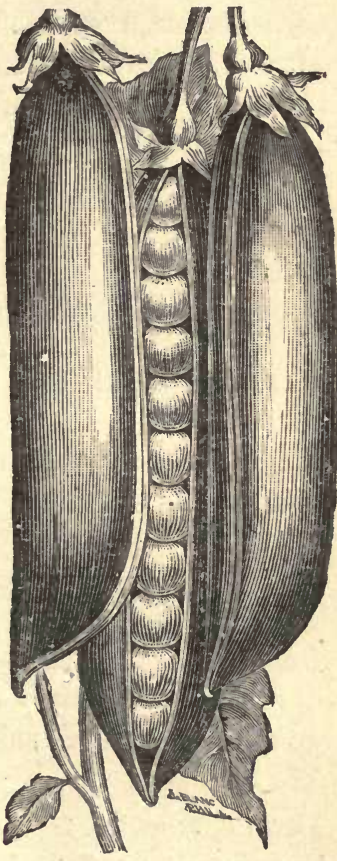

Fig.77. - stratageM PEA.

Bliss' Abundance--Remarkably productive; grows from twenty-four to thirty inches high.

Bliss' Everbearing.-Also very productive; grows 
from eighteen to twenty-four inches high. Should be planted thinly, and is noted for a continuance of bearing.

Pride of the Market.-Also a new sort, strong growing, and a wonderful bearer. It grows only from eighteen to twenty-four inches high, producing large pods of Peas of exceptionally fine flavor.

Black-Eyed and White Marrowfat.-These are both productive and hardy varieties, extensively grown as field Peas, to be used dry. They are also, from their great productiveness, grown largely in both private and market gardens, but they are not of so fine flavor as most other varieties.

\section{PEPPER.-(Capsicum annuum.)}

A tropical plant, that requires to be started in hot-beds or forcing-pits in the Northern States. The most common method is to sow in hot-beds in March, and treat in all respects as directed for the cultivation of the Egg Plant. Light sandy soils are rather best suited for its growth, but it will grow tolerably well on any soil. When cultivated for market they are planted in rows two feet apart and fifteen inches between the plants. The crop is only moderately profitable, but it is not grown in large quantities, the main consumption of it being by the pickle factories.

The varieties are:

Large Bell or Bull Nose.-An early variety, of mild flavor, and a favorite sort both for pickling and for use in the natural state.

Sweet Mountain or Mammoth.-Similar to the Bull Nose, but larger and milder in flavor. Used to make stuffed pickles. 
Ruby King.-Introduced two years ago, and a decided acquisition. The peppers grow from four and a half to six inches long by three and a half to four inches thick, are bright-red in color, and are mild and pleasant to the taste.

Squash or Tomato-Shapad.-Gencrally grown for piekling, hardly so early as the Bull Nose, but very productive, and the lealing market variety.

Golden Dawn.-Of the same shope and size as the Large Bell, but of more delicate flavor, while the color, as the name indicates, is a beautiful golden yellow.

Cranberry.-One of the best for pickling. The fruit closely resembles trie Crimberry in appearance.

Long Red Cayenne.-The variety of commerce. Pods small, cone-shaped, scarlet when ripe. It is quite a late variety, but the pods are as frequently used for pickling green as when ripe.

\section{POTAT0.--(Solanum tuberosum.)}

The soil acknowledged to be best suited for the Potato is sandy loam; in all heavy soils it is more subject to disease, and the flavor is also much inferior; this, however, is true of nearly all vegetables, heavy land inducing a watery insipidity of flavor. Like all robust-growing vegetables, Pototoes can be grown with varying success on soils of all kinds and in all conditions of fertility, but it is every way most profitable to use an abundance of manure when it is at all attainable. In breaking up good pasture land, the decaying sod answers sufficiently well for the first year in lieu of manure. Manure is applied either in the rows or hills, or broadcast over the surface, and plowed in ; the latter plan being in all cases pre- 
ferable, when manure can be obtained in sufficient quantities.

Potatoes, when grown for market at the North, are always a farm crop, the receipts per acre being much too low for the regular market garden. The large quantities that are planted usually prevent the use of manure in any other way except in the rows. When thus applied, furrows are plowed out in spring, after the ground has become dry and warm, usually three feet apart, and from four to five inches deep. The manure is spread in the furrow, the "sets" or " seed" planted thereon from eight to ten inches apart, and the furrow again covered in by the plow. As soon as the shoots are seen above ground the ridge should be at once hoed, and the eultivator run between the rows. As they advance in growth, the soil should be laid up on each side against the row, so as to form a slight ridge.

The Potato disease, which has frequently been so disastrous in Ireland and parts of Scotland, has never been very devastating here. It is now well known to be a parasitical fungus, Peronospora infestens, for which all remedies are useless when the crop is attacked. Like all diseases of this kind, the only help we have is prevention. As far as experiments have gone, they have shown that Potatoes are always less liable to attacks of disease or rot if planted in new land, broken up from the sod, or at least that which has not been long in eultivation. Another enemy to this crop is the well-known Colorado Potato beetle. Fortunately, for this pest we have a certain remedy in Paris green, mixed with twenty parts of flour, applied by dusting while the dew is on the leaves in the morning, or after a rain, or else in a liquid form of one ounce of Paris green to ten gallons of water. But whichever way it is applied, it should be begun at the very first appearance of the beetles. If they once get a foothold, they increase so rapidly that the crop is often destroyed 
before the remedy can be of any avail. Paris green being a deadly poison, it is absolutely necessary that fields on which Potatoes are growirg should be protected from cattle. It is sometimes supposed that danger might arise from the use of the Paris green affecting the Potato tubers. There need be no fear of this, as the tubers do not in any way absorb it.

The Long Island farmers, in the neighborhood of New York, have their crops of Early Potatoes sold off - early enough in July to get the ground leveled and Late Cabbages planted on the ridge on which the Potatoes hare been growing, sufficient manure being left in the ground to carry through the crop of Cabbage. The two crops together give an average profit of $\$ 150$ an acre. Potatoes may be preserved during winter by the section pit system recommended for the general preservation of vegetables, or in a frost-proof cellar.

The varieties of the Potato are rery numerous, many of them having only a local reputation, so that it is somewhat difficult to name the best for such an extensive territory as ours. But few of the varieties named below were grown twenty years ago, but these are such as are now in very general demand, which indicates that they are the best for general cultivation.

Early Rose.-A standard variety everywhere. It is still one of the best for earliness, quality and productiveness yet introduced.

Vanguard.-Extremely early, perhaps the earliest of all. Quality unsurpassed, but not quite so heavy a yielder as some others.

Pearl of Savoy.-A good yielder and a very excellent variety. The tubers are large and oblong; flesh, white and mealy.

Beauty of IIebron.-One of the best early sorts, being very productive and of fine quality. 
Empire State-(See figure 78.) This is a new main crop variety, very productive, and in the estimation of the originator, Mr. Coy (to whom we are indebted for

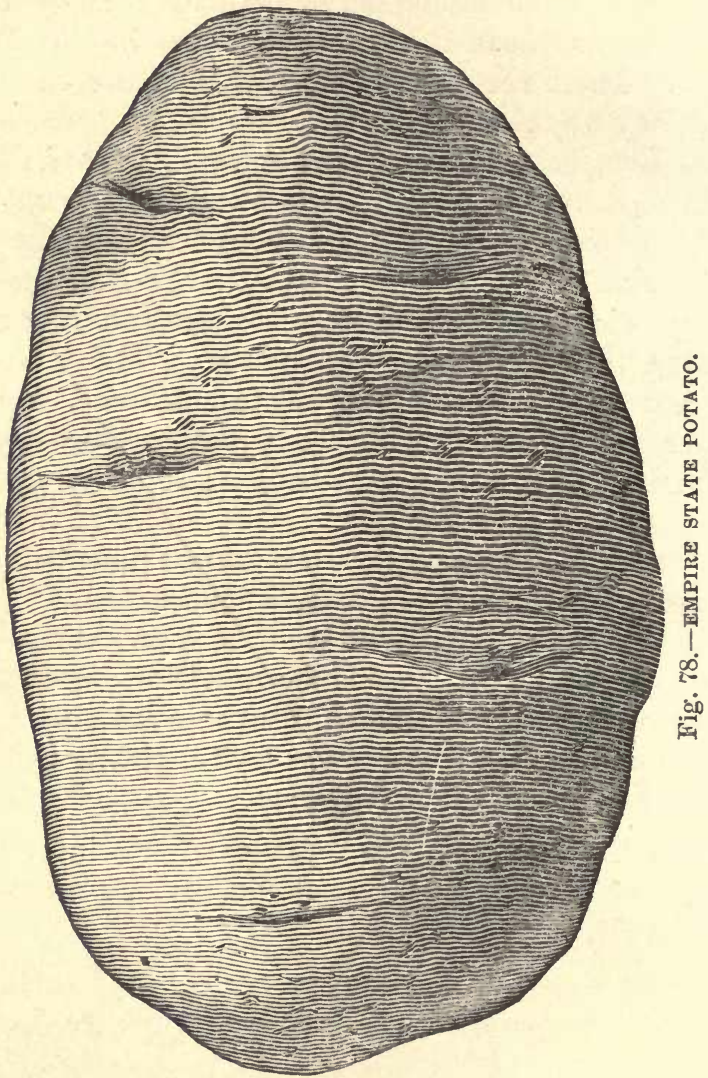

the Beauty of Hebron), a perfect Potato for general purposes. It is of excellent quality, and a rough and vigorous grower.

White Llephant.-Is late, large, of good quality, and enormously productive. 
Clark's No. 1.-(See figure 79.) This is said to be earlier than the Early Rose, and it is certainly very productive. The flavor is excellent, and it cooks dry and

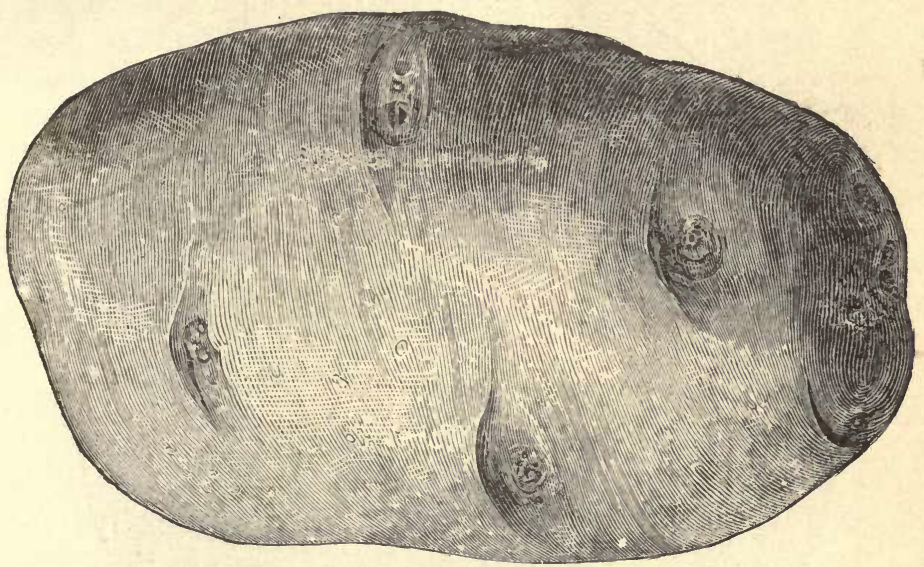

Fig. "99.-CLARK"s No. 1 ротато.

mealy. A great farorite abcut Charleston, S. C., where it is grown for the Northern markets.

St. Patrick.-One of the handsomest varieties in cultivation. The tubers are smooth, with very few and shallow eyes. A good yielder, and of the best quality.

Rural Blush.-Spoken of very highly, both as to yield and quality.

Rochester Favorite.-A late sort, tubers white and oblong. It is an excellent market Potato, as it is an immense yielder.

Triumph.-An early variety, that has given great satisfaction, particularly in the South. Very productive, and of good quality.

Perfect Peachblow.-(See figure 80.) A most promising new variety, resembling somewhat the old Peach- 
blow in general appearance, but ripening earlier and cooking through very quickly and evenly, a characteristic

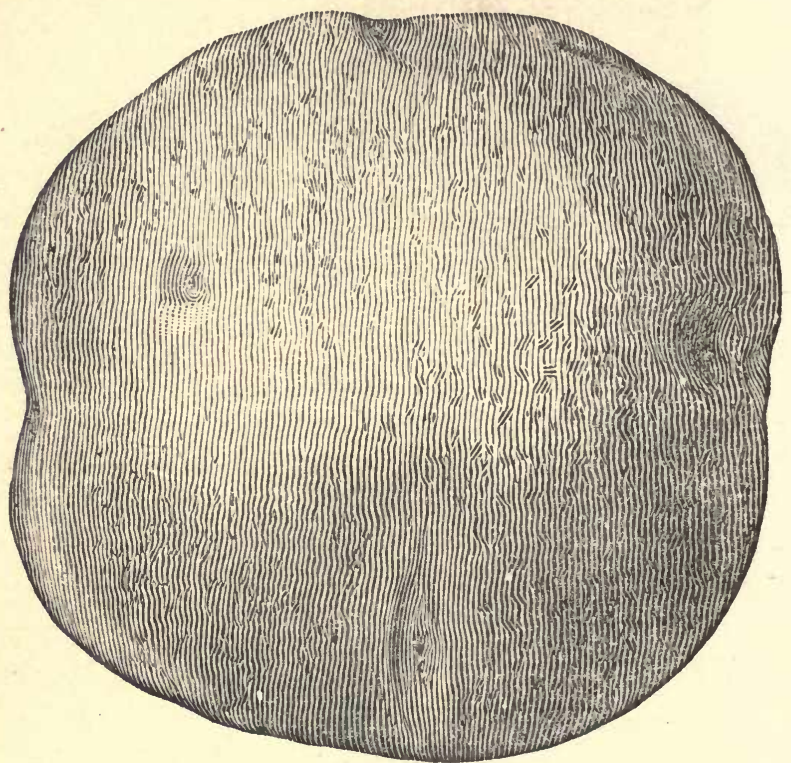

Fig. 80.-PERFECT PEAChBLow potato.

that was wanting in the older Peachblow. The flesh is pure white and the quality excellent.

Considerable discussion has at various times occurred concerning the relative merits of planting cut or whole tubers, but is yet undecided, each method having its advocates; a fact which goes far to prove that it is of little consequence which way is followed. The best rule, in our expcrience is, to plant the whole small tubers if fully matured, and cut the larger ones, but in either case leaving enough in bulk of the potato to give sufficient sustenance to the plant.

The superintendent of one of the State Experimental 
Stations, in a recent report on experiments made with Potatoes, gave it as his opinion that by continually selecting the best tubers, a variety could be permanently improved. Believing this to be an error which should not go forth unchallenged from such an authority, I take the liberty, at the risk of a slight digression, to give a few facts which argue against the belief, published by me in an agricultural journal in 1885 , under the head of "Do Plints Vary when Propagated by Cuttings?" On reading what is said about "sced" Potatoes, I notice the assertion is made that "seed" taken from the most productive hills gave a larger yield of tubers than that taken from the least productive. I sm inclined to believe that further experiments will show that this increased productiveness will not continue to hold, because the reason for the greater or less yield was probably only an accident of circumstances-specially farorable conditions of the set made to form the hill, or by being highly fertilized, or some such cause that gave it this temporary advantage-and that the chances are all against any permanent improvement being made by such sélections.

The Potato is said to have been introduced into Europe in 1584. If the original tubers had had the highest cultivation that the skill of man could give, it is exceedingly doubtful if 300 years of culture would have changed them in the slightest degree, if propagation had been solely from the tubers, and not from seed proper.

I base this opinion on a very extended experience in the cultivation of plants from cuttings. Strawberry plants taken from any well known kind, such as Sharpless, for example, from strong, vigorous growing plants, will certainly give better results than from weak plants of the same kind planted in the same soil. But if the progeny of the strong and the weak plants are again taken and replanted, the difference between the two would hardly be perceptible after thcy had been growing to- 
gether under the some conditions. Every now and then we hear of varieties of fruits or flowers, said to be degenerating, that are propagated from cuttings, grafts or roots. I believe there is no such thing as permanent degeneration of any fruit, flower or vegetable that is raised from cuttings, grafts or roots. The Jargonelle Pear, the Ribston Pippin Apple, the Hamburg Grape or the Keen Seedling Strawberry of the English gardens, are found to look just as good and as bad, under different conditions of culture, as they were fifty or 100 years ago, and that any change, either for better or worse, is only an accident of circ imstances, and temporary. For, be it remembered, that when a plant is raised from cuttings, as in the grape-vine, grafts as in a Pear, or layers as in a Strawberry, or pieces of the tuber as in a Potato, such parts are not seed proper, but are merely parts of the same individual that was first called into existence. The Early Rose Potato, introduced nearly a quarter of a century ago, is just as good to-day, under proper cultivation, as when first introduced, bnt it is certainly no better. It is often to be found under unfavorable cireumstances, and then may be supposed to have degenerated; but when it is shown, under other circumstances, to be as fine as when first introduced, how can the assertion of permanent degeneracy be admitted?

Permanent improvement, in my opinion, in varieties, can only be made by the selection of the fittest specimens that have been raised from seed proper. Here we have, as in the Early Rose Potato, the Sharpless Strawberry and the Concord Grape, rarieties that have shot ahead of their fellows, having merits that the general public recognize, but all the art of man cannot further improve these, so that their "progeny" (to use a convenient, though, perhaps, not a strictly correct term), when increased by "sets," "layers" and "cuttings," will be permanently better or worse than when first 
called into existence. It is a very common error, when a luxuriant crop of anything is seen growing under specially good culture, to imagine that cuttings, roots or grafts from such plants must necessarily give similar results when the same conditions to grow such crops well are not present. Not long ago Boston was famed for its Rosebuds, and even experienced florists paid double price for stock from such plants, only to find that in their hands these plants would not produce Boston Rosebuds. Now the case is changed. Madison, New Jersey, as a whole, beats Boston in Rose culture, and the demand has changed from Boston to Madison, and, of course, with the same results, for, if the purchasers of Madison Roses cannot give Madison culture, there will be no Madison Rosebuds. While we admit the advantage of a healthy stock, and even, perhaps, the value of a change of stock, what I claim is, that no culture will permanently change the variety from its normal condition, and that the only advance that can be made is by selecting the best specimens, hybridizing these from their seed, again selecting, and so on forward.

To be sure, we have in rare instances what are known to gardeners as "sports," or what Darwin has called "bud variation," which may he improvements on the original variety or the reverse ; but culture, good or bad, has nothing to do with such anomalous cases.

We often see it asserted as a matter for wonder, that the wild Celery of English marshes, or the wild Carrot of the hedge rows, have attuined their present high condition by "cultivation." If cultivation means that man has through generations "selected the fittest" of these again and again, taking always the "flower of the flock," so as to have attained the present perfection, then that is true ; but if by "cultivation" is meant that "domestication" by high culture, manuring, etc., in a garden or a field has caused such results, then, in my humble opinion, it is not true. 


\section{PUMPKIN.-1Cucurbita Pepo.)}

The Pumpkin is yet offered in large quantities for sale in our markets, but it ought to be banished from them as it has for some time been from our gardens. But the good people of our cities are suspicious of all innovations in what is offered them to eat, and it will be many years yet before the masses will understand that the modest, and sometimes uncouth looking, Squash is immeasurably superior, for ail cuinary purposes, to the mammoth, rotund Pumpkin. The Pumpkin is an excellent agricultural plant, of great value for cattle, but I only allude to it here, to denounce its cultivation or use as a garden vegetable.

\section{RADISH.-(Raphanus sativus.)}

Radishes are consumed in immense quantities, and are one of the regetables which we deem of no little importance as a market crop. To have them early, a light rich soil is the best; heavy or clayey soils not only delay their maturing, but produce crops much inferior, both in appearance and flavor. They are grown by us by various methods; the most common is, after sowing a crop of Beets in rows fourteen or fifteen inches apart, to sow Radishes between. The Radishes come up quickly, and are gathered and sold usually in six weeks from the time of sowing. The Beets at this time have only become large enough to be thinned, and will not be ready for at least a month later, so that the Radish crop is taken from same ground with little or no injury to the Beet crop. Another method is, to sow them between the rows of Early Cabbages or Cauliflowers, where they also are gathered off so soon as not to interfere with these crops. 
These are the methods practiced in our gardens here, where land is so valuable that we must make it always carry double, and often treble, crops in a season. Radishes are also grown in some places very extensively, on land devoted exclusively to that purpose in spring. Their culture thus is exceedingly simple. The ground being plowed and harrowed well, the seed is sown, and the harrow again run over, which places the seed at the proper depth. But though the field cultivation of this vegetable is simple, the labor of gathering, tying up, and washing, preparatory for market, is great, which detracts largely from the profits. Perhaps the average receipts are $\$ 300$ per acre, but the expense, before this is realized, is probably one-lialf that amount. It must be remembered that, in many eases, it is an auxiliary crop, interfering but little with our main spring crops. It is one of the regetables convenient to ship, and the early samples from Norfolk, Virginia, average $\$ 7.50$ per barrel, of 200 bunches; or about $\$ 750$.per acre, which should be a great inducement to southern cultivators, as there is but little danger of glutting the markets with fresh vegetables shipped from a southern to a northern port. For forcing Radishes under glass, see Chapter

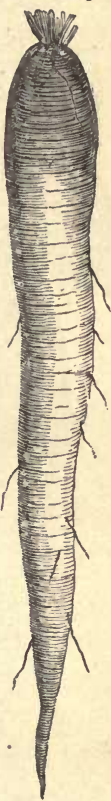

Fig. 81. LONG SCARLET SHORTTOP. 10, on "Greenhouses for Forcing Vegetable Crops."

Wood's Eariy Frame.-This is a farorite with market gardeners, as it is at least ten days earlier than the Long Searlet Radish, which it very much resembles, although it is not hardly as long.

Long Scarlet Short-Top.-This variety is grown the country over in rather the largest quantity, as from its shape (when tied up in flat bunches), it is best suited to 
shipping. In rich, light soils its average length is about nine inches. (See figure 81.)

Beckert's Chartier Radish.-This, shown in figure 82, is decidedly distinct in appearance from any other Radish in cultivation. Its form is well shown by our

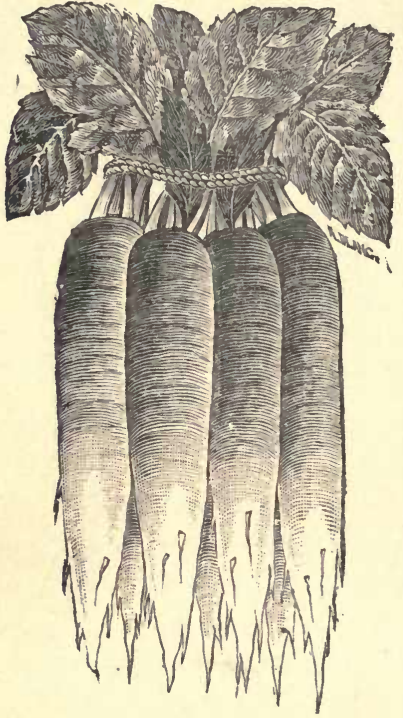

Fig. 82.-BECKERT'S CHARTIER RADISH. engraving, the color at the top being crimson, running into pink about the middle, and from thence downward it is a pure waxy white. It will attain a very large size before it becomes unfit for the table. In fact, at nearly all stages of its growth the quality is excellent. It sold rapidly in market during the past season.

\section{Early Scarlet Turnip.-} More delicate in flavor than the above, and for this reason more in demand for home consumption. By allowing it sufficient time to grow, it attains a size of three inches in diameter,

but it is always gathered at half this size.

Early Round Dark Red.-The shape is the same as that of the Early Scarlet Turnip, and it differs only in the skin, being darker in color, and in making much smaller tops. On this account it is now very largely used for forcing in both frames and greenhouses. This and the preceding varieties are the sorts that are grown most largely for early marketing. (See figure 8\%.)

Red Forcing Turnip.-The tops of this variety are the smallest of any of the early Radishes, which, with 
its extreme earliness, make it especially valuable for strictly forcing purposes.

White Tipped Scarlet Turnip.-(See figure 84.) An

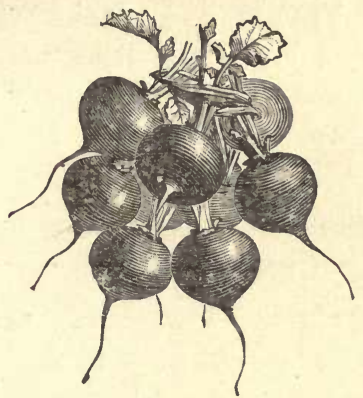

Fig. 83.-EARLY ROUND DARK RED RADISH.

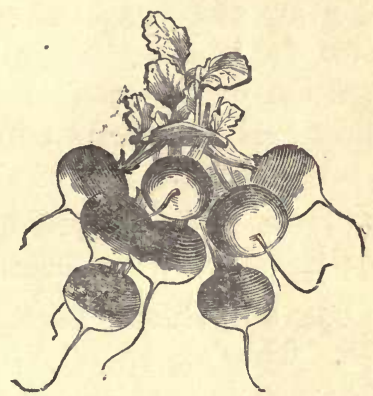

Fig. 81.-WHITE TIPPED TURNIP RADISH.

early variety of medium size, very handsome in appearance, and of excellent flavor.

French Breakfast.-(See figure 85.) A variety of quick growth, very mild and tender, and one of the best

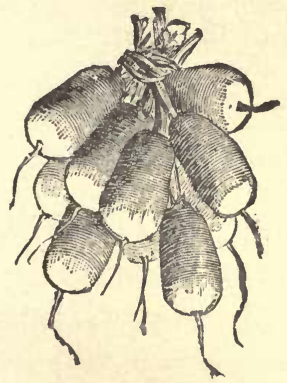

Fig. 85.-FRENCH BREAKFAST RADISH.

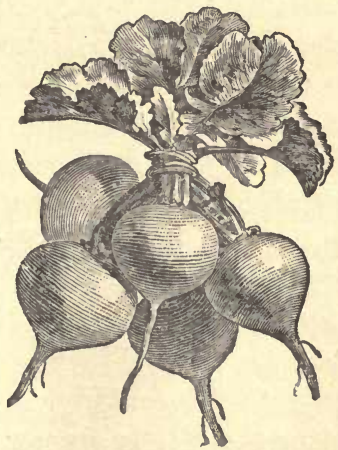

Fig. 86.-TELLOW SUMMER TURNIP RADISH.

for forcing. Of oval form ; color, scarlet, tipped with white. 
Olive-Shaped Scarlet.-Of oblong shape ; flesh, rosecolor, and a good summer variety.

Later varieties, grown for fall and winter use :

Yellow and Gray Summer Turnip. - Varieties well suited for summer use, as they stand the heat better than the early sorts. Both are mild in flavor. The yellow variety is shown in figure 86 ; the other is like it, save in color.

Chinese Rose-colored Winter.-Excellent for winter use ; flesh, firm; skin of a bright rose color.

Long and Round Black Spanish.-Very hardy varieties. They are often preserved, keeping as well as any other root, in sand, until mid-winter, in a cellar or roothouse. 'They are of large size, but rather harsh in flavor. Color, grayish-black.

\section{RHUBARB.-(Rheum Rhaponticum).}

Rhubarb is now cultivated largely for market purposes in the vicinity of all large cities, and few private gardens are without it. Its culture is of the simplest kind. It is a plant that adapts itself to almost any soil, provided it is well drained, artificially or otherwise. The preferable soil for Rhubarb, as for most vegetables, is a deep, sandy loam. Whatever the soil, it should be plowed from ten to twelve inches deep, the subsoil plow following in the wake of the other, stirring to the depth of ten or twelve inches more; after plowing, harrow deeply and thoroughly.

After the soil is prepared, lines are struck out by the plow four feet apart from each side of the field or plot, so that they will intersect at right angles. At these points the plants are set, first mixing with the soil three or four shovelfuls of well-rotted manure for each plant. 
The time of planting in the Northern or Western States may be either in the fall or spring; at the South the fall is preferable.

Rhubarb is usually propagated by division of the old roots; each eye or bud, when broken apart with a root attached, forming a plant. But making a plantation of any great extent in this way is expensive to the beginner ; as the roots are rarely to be purchased under $\$ 50$ per 1,000 eyes, and as about 3,000 plants are required for an acre, quite an outlay is necessary.

This expense may be obviated by increasing the plants by seeds, instead of by division of the roots. In the Northern Statez, the best time to sow the seed is about the middle of April, in the open ground, in rows a foot apart, if the plants are to be again transplanted; if to be left where sown, the rows must be three feet apart, and the plants thinned out in the rows to one foot apart. But as this latter plan requires the occupation of the land too long, the usual way is to sow closely and transplant. Care must be taken that the seed is well trodden in with the feet, as it is very light and rather slow to germinate. The soil best suited is a rich sandy loam, which should be thoroughly pulverized, and the surface made completely level before sowing.

The plants may be transplanted from the seed-bed either in fall or spring.

The first season after planting, no stalks should be pulled, but the next year a full return may be expected if proper attention has been given to cultivation.

It is exceedingly difficult to name the annual profits from an acre of Rhubarb in full bearing, as everything depends upon earliness. Even here, in the vicinity of New York, growers vary in their statements from $\$ 100$ to $\$ 300$ per acre. The difference of a week in earliness often makes a difference of $\$ 150$ and $\$ 200$.

It may be safe to say, however, that it will average, in 
this vicinity, a profit of $\$ 250$ per acre annually from the date of planting; in many places where there is less competition, no doubt double or treble that amount may be realized. Rhubarb is a most simple and convenient plant for forcing, which may be done in the following manner: 'The roots are dug from the open ground in fall, put close together in a box or barrel, and soil sifted in to fill the interstices between the roots; they are then placed in a situation where the temperature will range from fifty-five to about seventy-five degrees, with a moderate amount of moisture. By this treatment Rhubarb may be had from January to April. 'The roots may be placed wherever there is the necessary temperature. Light is not at all necessary ; in fact, the stalks of Rhubarb are much more crisp and tender when forced without exposure to direct light; hence the roots may be placed in the furnace room of a cellar, under the staging of a greenhouse, or in an early forcing grapery. A florist in Boston told me a few years ago, that he had sold enough Rhubarb, grown under his greenhouse stages, to pay his coal bill (over $\$ 100$ ), besides having all he wanted for his family use. Rhubarb is forced quite extensively by some of our market gardeners; the method pursued by them is to lift the roots from the open ground in the fall, place them as closely together as possible in such pits or frames as are used for hot-beds, but about two feet deep, sifting in soil so as to fill the spaces between the roots. On the approach of cold weather, the whole is covered over with a foot or so of dry leaves, and so remains until about February first, when the leaves are removed and sashes placed on the frames. Sometimes this is not done until March, the sashes being then used which have been eovering Cabbage plants through the winter. But little rentilation is given to the frames at this cold season, as it is necessary to raise the temperature of the frame by the action of the sun's 
rays, so as to forward the crop. It greatly aids the forwarding if the sashes are covered up at night by straw mats or shutters. Rhubarb so forced matures about one month before it is marketable from the open ground, and averages about $\$ 10$ for each three by six foot sash. It must be borne in mind, however, that forcing com-

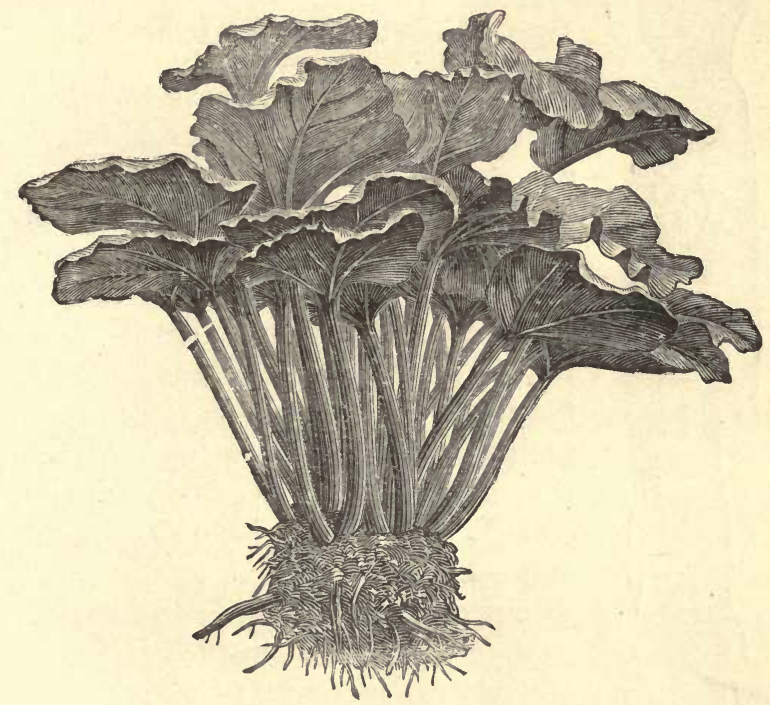

Fig. 87.-ST. MARTIN's RHUBARB.

pletely destroys the roots, and for that reason it is only practiced by those who have a surplus that they would otherwise throw away.

The principal varieties in cultivation are:

St. Martin's.-(See figure 8\%.) A new London variety, which is by far the best, being of rich spicy flavor, enormously productive, and of the largest size of stalk.

The other two well-known kinds are "Linnæus" for early, and "Victoria" for late crops. 


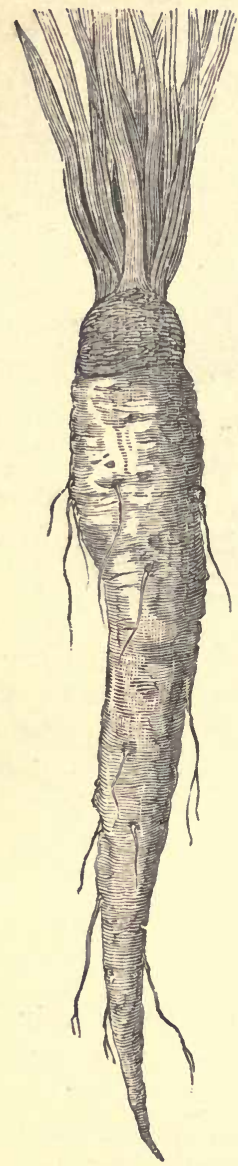

SAGE-(Salvia officinalis).

See Thyme, and other Sweet Herbs.

\section{SALSIEY, OR OYSTER PLANT.}

(Tragopogon porrifolius).

This vegetable is coming rapidly into general use ; patches of arr acre in extent are seen in some of the more extensive gardens here, that a few years ago grew only a few rows. It should be sown in early spring. Its culture is in all respects similar to that of Carrots, and although its consumption is as yet limited, for what is grown of it, the prices are high and very remunerative. It is moreover a safe root to cultivate, for, being entirely hardy, there is no risk whatever of its being injured by frost, should it so happen that the digging up is neglected in the hurry of fall work. It is generally better, however, to dig it up and put it away as we do Parsnips or Carrots, so that it can be had at any time during winter. It usually sells at higher rates in spring than in fall or winter ; but even with the advance in price is less profitable to the grower when sold Fig. 88.-SALSIFY. in spring, as that being a busy season, the labor expended in digging it up and getting it ready, is then of much more value.

As this vegetable will be unknown to many, I will state that it is used in various ways, but generally boiled or stewed, like Parsnips or Carrots. It is also used to 
make a soup, which has a decided flavor of the oyster. It is also eaten as a salad, sliced and dressed with vinegar, salt and pepper. There are no varieties.

\section{SCORZONERA-BLACK SALSIFY.}

(Scorzonera Hispanica).

Very similar to the above in general character, and of the same culture and use. It is not, however, so generally esteemed as the Oyster Plant, and is not grown except for private use, and even for that purpose sparingly.

\section{SEA KALE.-(Crambe maritima).}

This vegetable is much esteemed and grown largely for market purposes, both in England and France, and no private garden of any extent in either country is considered complete without it. Here, however, even yet we seem to make but little headway in its cultivation. I have rarely seen it offered for sale in our markets, and its culture is practiced in but few private gardens.

There is an impression that it is difficult of culture in our climate; this is not so by any means; it is equally as easy to grow it here as it is in England, only that, like all vegetables requiring artificial heat for its perfection, its cultivation is attended with more expense than that of regetables that we plant in the open ground, without other care than to keep them clear of weeds.

It is increased either by roots or by seed; when roots can be obtained to start with, they are quicker. The manner of operating with them is as follows: In fall, a few old plants of Sea Kale are dug up, and the roots cut in pieces of from two to three inches in length; these are placed in boxes of sand in a dry cellar until 
February or March ; they are then strewn on the surface of a hot-bed, where, in a week or two they will emit roots and tops; they are then potted or planted in shallow boxes two or three inches apart, hardened off for a few weeks, and as soon as the weather is settled, planted out in rows three feet

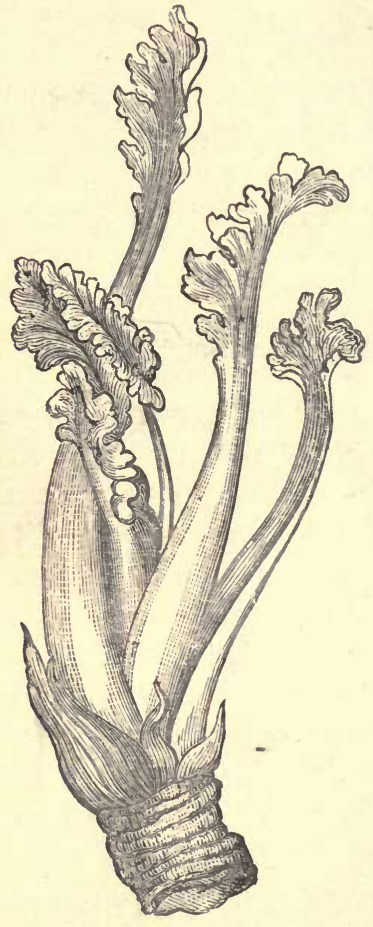

Fig. 89.-SEA Kale. apart, and two feet between the plants. If the ground is in the condition that it should be, Sea Kale, thus treated, will produce crowns strong enough to give a crop the next season after planting. When grown from seed, the seed should be sown in hills at the above distances apart, in the early spring, each hill being thinned out to three or four plants. In our colder latitudes, the crowns should be covered by four or six inches of manure or leares as a protection from frost.

Sea Kale is only fit for use in the blanched state, consequently on the approach of spring, the "cromns" should be covered with some light material, such as sand or leaf mold, to the depth of twelve or fifteen inches, so that the young shoot, being thus excluded from the light, will become blanched in growing through this covering; or sometimes cans, made for the purpose, or inverted flower pots are used, the only object being to 
exclude light. In England it is forced extensively by covering over the whole beds with leaves, manure or some heating material. The young shoots, when cooked, have a flavor something between Asparagus and Cauliflower, but is much preferred to either. The engraving (fig. 89) shows a young shoot when ready for the table. The fully dereloped leaves are large and robust.

\section{SHALLOTS.-(Allium Ascalonicum.)}

This regetable, which is used in the green state in early spring as a substitute for Onions, is planted by dividing the bulbs in September, and planting in rows one foot apart and six inches between the plants; it makes a slight growth and forms its roots in the fall. On the opening of spring it develops rapidly, and the single bulb, planted in September, will have increased by May a dozen fold. From its hardy nature, coming in at least three weeks earlier than the Onion, large quantities are sold at rates corresponding with those of Onions raised from sets. It, with us, has ever been a profitable vegetable to raise, and I have rarely found the profits on an acre to have been less than $\$ 200$. It is generally cleared off by the last week in May, giving sufficient time to follow with second crops of Early Cabbage, Beets, Turnips, etc.

\section{SORREL.-(Rumex Acetos $\alpha)$.}

A well-known perennial plant, cultivated to some extent with us. It is used in soups and sauces, mostly by the Germans and French. In the French markets it is nearly as abundant as Spinach is in ours, and is highly recommended as a wholesome vegetable. Its.cultivation is very simple. Seeds, sown thinly in rows in early 
spring, will give a heavy crop of leaves in June and July; when the flower-stalk of the Sorrel starts to grow, it should be cut out, which will add greatly to the development of the leaves. The crop may be left two seasons, but is more tender when annually raised from seed.

\section{SPINACH.-(Spinacia oleracea.)}

This is a very important crop in our market gardens, hundreds of acres of it being cultivated in the neighborhood of New York. It is one of the most manageable of all vegetables, requiring but little culture, and may be had fit for use the entire season.

In our market gardens it is sown in early spring as an auxiliary crop, between the rows of Early Cabbage; it comes to perfection usually in four or five weeks after sowing. At this season, it sells at a low price, usually about fifty cents per barrel; but it requires but little labor, and generally pays about $\$ \tilde{0} 0$ per acre of profit. The main and important crop is sown in drills one foot apart, in this section from 1st to 15th September, or late enough in fall to get about half grown before cold weather sets in. It is sometimes covered up in exposed places with straw or salt hay during winter, which prevents it being cut with the frost; but in sheltered fields here there is no necessity for covering.

Any soil that will grow a good Corn crop will grow Spinach, though, as is the case with all other vegetables in which the leaf or stem is the part used, the land can hardly be made too rich. Our practice is to grow it on our best soils, applying not less than fifty tons of wellrotted stable manure to the acre, or in lieu of stable manure, one ton of bone dust; or about 1,200 pounds of guano sown after plowing, and deeply harrowed in. The rows are made with the ordinary garden "' marker," 
at the distance of twelve or fifteen inches apart. The seed is sown rather thickly; we prefer to do it always by hand, using from ten to fifteen pounds per acre; when thickly sown the plants can be thinned out, so that a much larger yield will be given. We sow here from the 5 th to the 15th of September, and quite frequently sell, by thinning out, fifty or seventy-five barrels from an acre, which usually in October and November sells for $\$ 1$ per barrel. This thinning out, which is done by cutting out the plants where thickest with a knife, if carefully performed, does not at all injure the main crop, which is to stand over winter until spring. I may here caution the inexperienced of the necessity of treading aown the soil on the seed, if the land is dry ; the crop is often ruined by the want of this precantion, in continued hot, dry spells that are frequent with us during September. If the soil is left loose, the hot air shrivels up the seed so that it will never germinate. The best way is to tread in each row with the feet, and in addition to use a roller. Probably one-half of all Spinach seed sown in fall fails to germinate, and from no other cause than the failure to thus firm the seed. The same precantion is necessary in the sowing for Cabbage and Lettuce plants; at this season these are often lost from the same cause.

Fair crops give a yield of 200 barrels per acre (average price, $\$ 2$ per barrel); at a high estimate the expenses will not exceed $\$ 250$ per acre, so that it is safe to claim a net profit of $\$ 150$, althongh extraordinary crops often do much more than this. The ground can be cleared early enough in May to follow the Spinach with a crop of Flat Dutch or Early Summer Cabbage. Spinach is hardy enough to grow in almost any part of the country ; but in districts where the thermometer falls below zero, it is necessary to cover it up about Christmas with hay, straw, or leaves, to the depth of two or three inches; it 
is best done just as a snow storm is setting in, as the snow settles down the covering and keeps it from blowing off. Spinach is now largely grown at Norfolk, Virginia, and other sections of the South, which has, of late years, seriously interfered with the Northern grown crop.

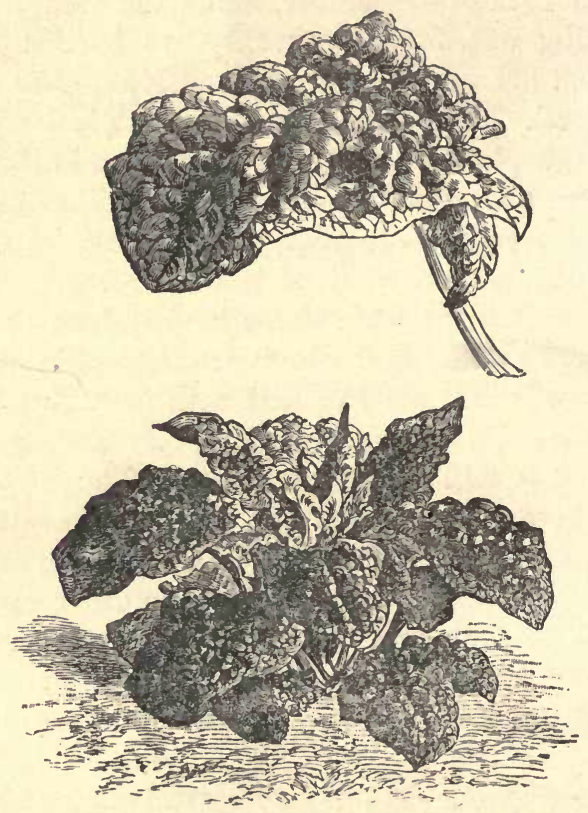

Fig. 90.-NORFOLR SAVOY-LIANED SPINACH.

The quantity of seed per acre is from eight to twelve pounds, according to the distance between rows.

Since the early editions of this book appeared, our list has been increased by two or three varieties of Spinach that are not only distinct in appearance, but which, in many sections of the country, are now grown to the exclusion of the older varieties. The "Savoy-Leaved" and the "Thick-Leaved" sorts, are both varieties that hare secured this popularity. 
Norfolk Savoy-Leaved.-(See figure 90.) This produces nearly twice the weight of crop of the older varie-

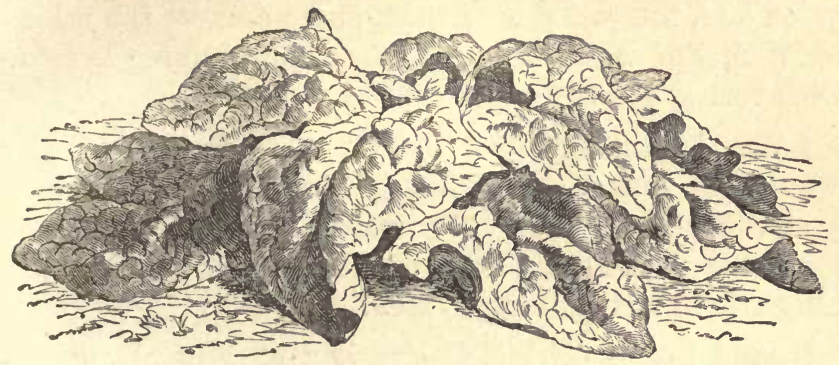

Fig. 91.-THICK-LEAVED SPINACH.

ties, and has a further value in the fact that it is the hardiest of all varieties of Spinach. In appearance the leaf is wrinkled in the same manner as the Savoy Cab-

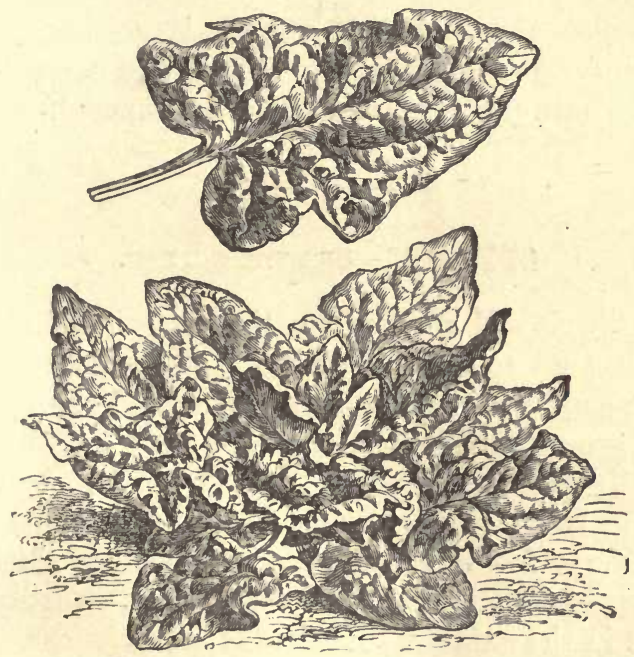

Fig. 92.-LONG STANDING SPINACH.

bage, hence the name. From the tendency of this sort to run to seed, it should never be sown in spring. 
Thick-Leaved.-(See figure 91). This is one of the best market sorts. It produces a large, thick, strong, green leaf, somewhat crumpled, and possesses the valuable quality of standing a long time before running to seed. This variety is equally good for spring or fall.

Lang Standing.-(See figure 92). Except in the peculiarity that it stands a long time before running to seed, this variety, in all other respects, closely approaches the well-known Round Leaf, but it certainly has the characteristic of not running to seed.

Round Leaf-CThis is the variety so generally cultivated for winter use, being very hardy, standing our severest winters with little injury.

Large Round Leaf Viroflay, - A heavy growing sort, resembling the Thick-Leaved; hardy.

Prickly.-Although this variety is usually sown in the spring and summer, it also stands well in winter, but gives less bulk per acre than the other's named.

\section{SPINACH. -SUBSTITUTES FOR.}

As Spinach will not endure the hot suns of summer, it running up to seed at once if sown in hot weather, several plants are used as substitutes, and though these are not grown for market, they are very convenient in the family garden.

One of these is the Swiss Chard, mentioned under Beet, several forms of which are sold as Spinach Beet and Perpetual Spinach. Perhaps the best substitute for Spinach in the summer months is the

New Zealand Spinach.-(Tetragonia expansa).-A plant of the same character and uses, but of a different genus, and used only in private gardens. It is a remark- 
able plant, of low branching habit, growing with wonderful luxuriance during hot weather, single plants often measuring six feet in diameter. The leaves are used exactly as common Spinach; it is best grown by sowing the seeds after the soil is well warmed, and transplanting to three feet apart in very rich, warm soil.

Orach.-(Atriplex hortensis.)-Another plant of the same family, and its leaves are used in the same manner as Spinach. It succeeds best if sown where it is to grow -in rich, moist soil.

\section{"Sprouts," Kale or Borecole.-(Brassica oleracea.} Var. Sabellica.) A form of the Cabbage grown in all respects like Spinach. It is equally hardy and affords similar profits under like conditions. Like Spinach, it is now largely grown at Norfolk, Virginia, and in other places farther South. It is also grown in the Northern States, but not to the same extent with Spinach, probably in the proportion of one to ten only; about half the quantity of seed is required for Sprouts as for Spinach, or about four to six pounds per acré. The kinds used for market are the Dwarf Curled or German "Sprouts," the Early Dwarf Curled, and Dwarf Green Curled Scotch, the first-named being that used to lransplant the others, being grown like Spinach.

\section{SQUASH.-(Cucurbita Pepo, and C. maxima.)}

A class of vegetables embracing more marked distinctions in sorts, fitted for more varied uses, and to be found, during the extremes of the season, in a better state of perfection, than, perhaps, any other product of our gardens. Being of tropical origin, their growth is all consummated during summer; yet the fruit of the "winter varieties" may be kept, with a little care, until May. They are all of luxuriant and vigorous growth, 
and although they will grow readily on almost any soil, yet there is hardly anything cultivated that will so well repay generous treatment. Like all plants of this class, it is useless to sow until the weather has become settled and warm; next to Lima Beans, Squashes should be the last vegetable planted. Light soils are best suited for their growth, and it is most economical of manure to prepare hills for the seeds in the ordinary manner, by incorporating two or three shovelfuls of well-rotted manure with the soil for each hill; for the bush varieties, the hills should be from three to four feet each way, and for the running sorts from six to eight feet. Eight or ten seeds should be sown in each hill, thinning out after they have attained their rough leaves, leaving three or four of the strongest plants.

They are extensively grown for market, but are not sufficiently profitable for our highly cultivated gardens, and are therefore grown rather as a farm-garden. crop. They vary in profit, in our vicinity, of from $\$ 100$ to $\$ 25$ per acre. The early varieties are grown quite extensively in the vicinity of Norfolk, Charleston and Savannah, and shipped North, from two to four weeks earlier than they can be had here, and, like all such commodities, bring three or four times the price of those grown in this vicinity, in quantities that glut the market.

The varieties are very numerous, and from the facility with which they will cross, it is very difficult to retain the different kinds pure.

\section{SUMMER VARIETIES.}

Yellow and White Bush Scalloped.-(See figure 93.) These varieties are the two kinds that are considered the earliest, and are grown almost exclusively for market for first crop. From the hard texture of the rind, they are well fitted for shipping, and are grown exclusively at 
the South for that purpose. Plant three to four feet apart in hills.

Bush Summer Crook-Neck.-A much esteemed variety in private gordens. Somewhat similar to the preceding in growth, but rather more dwarf. The fruit is orange yellow, covered with warty excrescences. It is considered the best yielder of the summer varieties.

Boston Marrow.-This variety may be termed second early, coming in about ten days after the bush and crook-

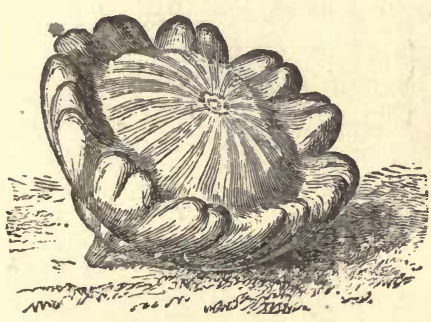

Fig. 93.

WHITE BUSH SCALLOPED SQUASH.

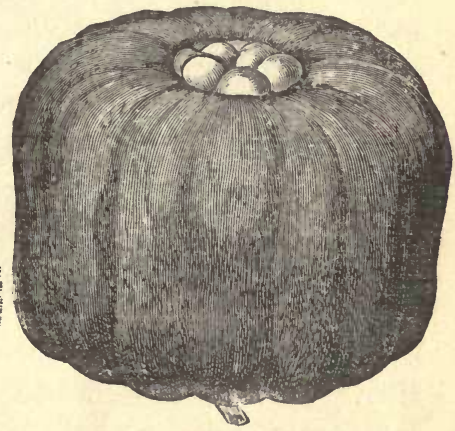

Fig. 94.

ESSEX HYBRID SQUASH.

neck sorts. The skin, which is of an orange-yellow color, is very thin, the flesh being dry, fine-grained, and of unsurpassed flavor.

FALL AND WINTER VARIETIES.

Essex IIybrid.-(See figure 94.) Very fine-grained, rich and sweet, and a splendid keeper. The flesh is very thick and solid. As a Squash for winter keeping it is unsurpassed.

IIubbard.-(See figure 95.) A general favorite, and. more largely grown as a late sort than any other. It is of large size, often weighıng from nine to ten pounds. 
Color, bluish-green, occasionally marked with brownishorange or yellow. Flesh, finc-grained, dry, and of excel-

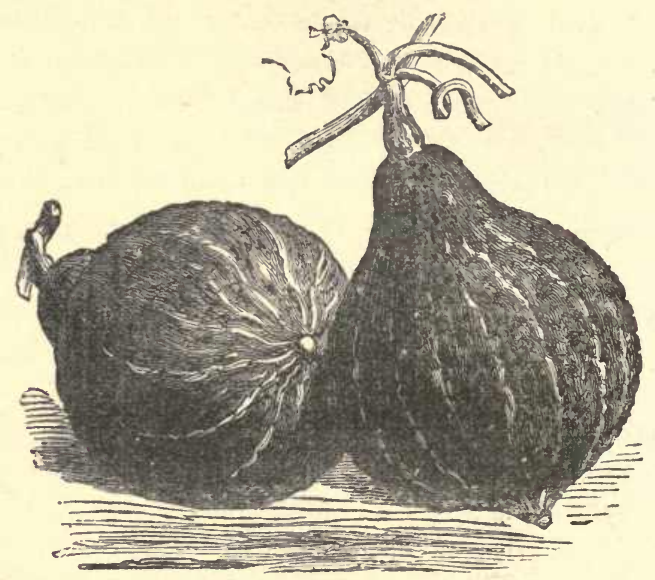

Fig. 95.-HUBBALD SQUASH.

lent flavor. It can be had in use from September to May. Plant in hills eight feet apart.

Marblehead.-An excellent variety, introduced by Mr. Gregory. 'The flesh is rather lighter in color than that of the Hubbard, but it resembles that variety in shape, although it has a harder shell. It is productive, of rich and excellent flavor, and a fine keeper. Plant eight feet apart.

Hammoth Chili._Grows to an immense size, often weighing 200 pounds. Excellent for all purposes. Plant nine feet apart.

Winter Crook-Neck.-A rariety largely grown in some of the Eastern States, where it is often kept the entire winter. Skin, reddish-pink when matured ; flesh, closegrained and sweet. Plant in hills nine feet apart.

Vegetable Marrow.-A favorite English sort. The fruit is very variable in size, ranging from nine to eighteen 
inches in length by from four to six inches in diameter. The skin is greenish-yellow ; flesh, white, soft and of rich flavor. It is entirely distinct from all of the preceding. Plant eight feet apart.

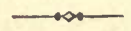

\section{SWEET POTATO-(Ipomoca Batatas.)}

The Sweet Potato requires a rich, light, warm soil. It is more generally grown in the Southern States than the common Potato, as there the soil and climate are more congenial to it. We have often difficulty, in this district, in saving the tubers sound enough until spring, to start for sprouting to produce young plants. The great essentials to their good preservation are a dry and rather warm atmosphere; the cellar, suitable to preserve the common Potato, being usually much too cold and damp for this. Where there is no place of the necessary high temperature, it is best to get them in spring direct from some Southern market, where they can always be had in good condition ; or they can be kept by packing in barrels in dry sand and keeping them in a warm room. In this district we luegin to start the potatoes in lot-beds or forcing-pits about the middle of April, laying them thickly together on a two-inch layer of sand and leaf mold composted together, or sand alone will suit if leaf mold cannot be had. As soon as the buds or eyes show signs of starting, cover the roots completely over to the thickness of an inch with the same material. Treat as for other tender plants in the hot-bed or forcing-pit, and the sprouts or slips will be ready for planting out by the first of June.

Market gardeners often make the sale of Sweet Potato plants a very profitable operation, immense quantities of 
them being sold to private growers at the planting season. As the spronts from the potatoes come up very thickly, repeated thinnings are made, which is not only profitable to the grower, but of great advantage to the remaining plants, by giving them the necessary room to grow. One grower in this vicinity informed me that last season he sold upwards of $\$ 1,000$ worth of plants from 150 sashes, which were sold at an average of $\$ 1.25$ per 1,000. The profit from the cultivation of the plant in the field is something less than that from Tomatoes, but more than from the common Potato.

In Southern New Jersey and further south, these beds are not eovered with glass, but with a light covering of straw or coarse hay, to retain the warmth, but the beds must not be thus made before the first week in May, in New Jersey. This is removed when the plants appear. In sections of the country where Sweet Potatoes are grown even to a small extent, there are generally men who make a business of growing the plants, which are often to be bought as low as $\$ 1$ per 1,000 , and it will be found better for the grower to purchase than to raise them himself, if he has not the proper convenience of sashes and hot-beds. The plants are set out in rows three or four feet distant, and about two feet apart in the rows, using a good shovelful of well-rotted manure, mixed in, for each hill. They are always planted in light, sandy soil, heavy soils being entirely uncongenial to the nature of the root. As they advance in growth the rows are hilled up with the plow in the same manner as ordinary Potatoes, care being taken, however, to prevent the vines, as they hang over, from rooting in the sand. This is done by running along the vines, occasionally under them, with the hand to break the young roots and keep them from striking into the soil. If this were not done it would divert the growth from the main root, and the potatoes would be small and nearly 
worthless. In the Northern States, Sweet Potatoes must always be used previous to December, unless they can be kept in a warm place.

In the Southern States they are kept in pits in the open ground in much the same way as we keep ordinary Potatoes at the North ; but the temperature of the soil is of course much higher in Florida and other extreme Southern States than at the North. Most of the Sweet Potatoes that find their way to our Northern markets in the winter and spring months, are grown in Georgia, South Carolina and other Southern States. They are preserved in the South by storing them in houses specially built for that purpose. The Potatoes are packed in boxes not more than eighteen inches deep, which are placed in tiers one above the other, leaving spaces between for ventilation. But in extremely cold weather it is necessary that the apartment should be heated in some way so that the temperature at no time is allowed to fall below fifty degrees. There is no necessity for packing anything around them; if the heat in the apartment is sufficient, they will keep by the air circulating around them among the shelves or boxes in which they are placed. Probably the best temperature at which Sweet Potatoes can be kept in winter is sixty degrees. The following are the sorts mostly grown:

Nansemond.-This is the earliest sort; tubers large, from three to four inches in diameter at the thickest part, tapering to each end, and from five to eight inches long; flesh dry, sweet and well flavored.

Red Skinned.-This variety is claimed to be hardier than the preceding, but it is doubtful if this is the case. It is a long, slender variety, mostly grown in private gardens, and is thought to be of a richer flavor than the yellow or white sorts.

Yellow Skinned.-This sort is mainly cultivated in the 
Southern States, where it attains nearly the weight of the Nansemond ; it requires a longer season than that variety, and is not so suitable for the North. It is of excellent flavor and more free from stringiness than any other sort.

\section{TOMAT0.-(Lycopersicum esculentum.)}

This regetable is one of the most important of all garden products; hundred of acres are now planted with it in the vicinity of all large cities, and the facility with which it is managed, places it readily under the control of the least experienced. It is now grown here almost entirely by those who grow Peas, Potatoes, Melons, and other crops of the "farm gardens," as our market gardens proper are too highly enriched and much too limited in extent to render the cultivation of the Tomato profitable. 'To produce early crops, the seed must be sown in hot-beds or forcing-pits, about ten weeks before the plants may be safely put in the open ground. Thus, in this district, we sow in the hot-bed about the first week in March; in April the plants are fit to be set out, at a distance of four or five inches apart, in another hot-bed. They are grown there (proper attention being given to the hot-beds, as directed under that head) until the middle of May, when it is safe to place them in the open ground. They are planted, for early crops, on light sandy soil, at a distance of three feet apart, in hills, in which a good shovelful of rotted manure has been mixed. On heary soils, which are not suited for an early crop, they should be planted four feet apart. Some attach great importance to topping the leading shoot of the Tomato, so that it will branch, arguing that by this means we get au earlier 
and heavier crop; all our experience shows that little benefit is derived from the practice. Like all vegetables grown on so large a scale, and in such varying soil and climate, the Tomato sells in our markeis at prices varying widely, from $\$ 6$ down to 25 cents per bushel, the average price for those raised in the district, being about 75 cents per bushel. 'The quantity raised per acre is about 400 bushels. This may seem at first glance to be quite a profitable crop for a farmer; but every acre necessitates the use of at least 100 sashes, for, on the second transplanting, only about fifty p?ants can be grown to a sash, and about 5,000 plants are required for an acre. On one occasion, having a very suitable soil, I grew about four acres of 'Tomatoes for three years, which realized me from $\$ 1,500$ to $\$ 2,000$ annually in receipts; but I discovered that the operation was a losing one, as, to raise 20,000 plants for my four acres, I had to make use of 400 sashes, in which, in rather less time and with far less labor than it took to grow the Tomato plants, Lettuce conld have been grown that would have sold for at least $\$ 2$ per sash. Thus I lost annually, in preparing for the Tomato plants, half the receipts of the crop even before they were planted out. But there are many parts of the country where Lettuce, thus forwarded, could not be sold, while 'Tomatoes could, which would materially change the aspect of the operation. In the sonthern sections of the country, convenient to shipping, Tomatoes are largely grown for the northern markets, and sold there at prices highly remunerative to the grower. In many instances, in the Southern States, the cultivation of Tomatoes for market is carelessly done, the seed being sown in the open ground and the plants transplanted, as we do Cabbages. No doubt, by starting in January or February with the hot-beds, or even cold frames, and planting ouc in March or April, they could be had at least two weeks earlier than they are now sent to us. In some localities thousands of acres of Tomatoes 
are now grown by farmers, under contract for canning purposes, often as low as 30 cents per bushel, and, on suitable land, even this low price will pay better than most farm crops, as there is usually no necessity for having the crop early for canning.

There are always some one or more varieties, said to be earlier than others, sent out every spring, but it must be confessed that the varieties that we cultivated twenty years ago are not a day behind in earliness those issued as "vastly superior" in 1886 . To test them thoroughly, I planted twenty-five plants each of the four most popular sorts, under circumstances exactly similar in all respects; there was no difierence whatever in earliness, and but little perceptible difierence in productiveness.

In my opinion, the extreme point of earliness in Tomatoes has been reached years ago, and now all further improvements must be in point of size, smoothness and solidity; and that any one laying claim to having good varieties a specified number of days or weeks earlier than those we already have, does so without having a knowledge of the subject, or with the desire to impose on the public. The Tomato is a plant requiring at all times a certain high temperature to ripen its fruit; and though it may ripen in Georgia in May, in Virginia in June, in Delaware in July, or in New Jersey in August, it requires the same aggregate amount of heat to do the work. The same is true of most fruits and regetables; we reach a certain point of earliness with a given variety in a given locality, when the temperature tells us we must stop. If improvement in earliness were progressive, we might have reason to expect that the Radish or Lettuce, which matures with us in the open ground here in May, would yet mature in April.

I believe that our ordinary methods of saving 'Tomato and all other seeds, in fact, do much to prevent us from making any advance in procuring choice varieties; if 
we would only take the trouble to always select the first matured fruits, and the best specimens only, for seed, and so continue, there is no question whatever but it would amply repay the trouble. But the grower for market grudges to give up his first basket of fruit, that may realize him $\$ 5$ or $\$ 6$, for a few ounces of seed, knowing that he can get plenty when his crop in not worth the gathering for market. But, depend upon it, he makes a mistake, for the seed from his first fruits would, perhaps, pay him a hundred times better, if used for sowing the next year, than any price he night get for it in the market.

In private gardens, where space is often limited, a greater quantity of fruit will be obtained by elevating the branches of the Tomato from the ground with brush, such as is used for sticking Peas, or by tying to laths nailed against a board fence; or, what is neater yet, the hoop training system as practised in France. But for market purposes, on a large scale, it would require too much labor.

The following, at this date, are the leading kinds :

Mikado.-(See figure 96.) This is the second season that we have grown this variety, and I predict that it will be certain to become a standard sort. It is one of the earliest of the large Tomatoes ; in color purplish-red ; fruit produced in immense clusters, single fruits often weighing one pound and a half each. 'The Mikado is entirely distinct in foliage from any other Tomato, which allows it to always be distinguished.

Acme.-Very early and handsome, fruit of medium size, perfectly smooth and regular, very solid, and a good keeper. Color distinct, being crimson with a pinkish tinge. In some markets the color would be a detriment; in others, again, it would be considered no disadvantage.

Paragon.-The description of the Acme will answer for this, except that in the Paragon the color is of a 


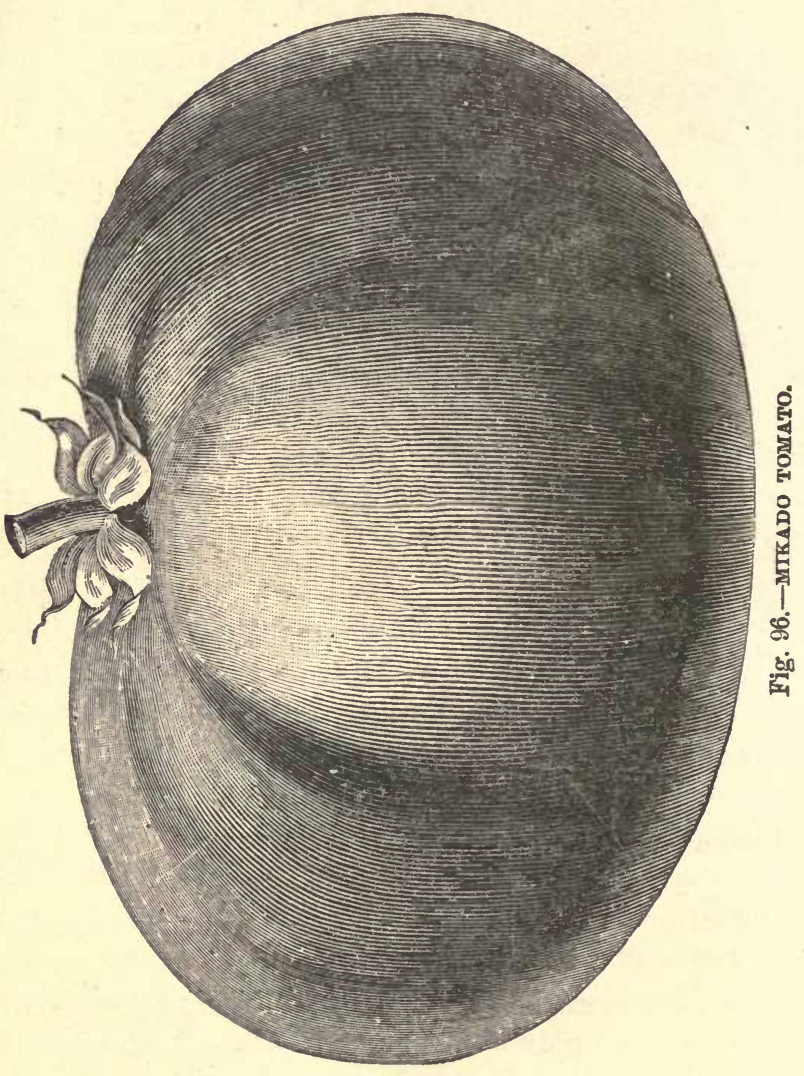


bright, glossy crimson, and entirely free from the pinkish tinge that characterizes the Acme.

Perfection.-(See figure 9\%.) Color blood red. It is as early as the Canada Victor (one of the first to ripen),

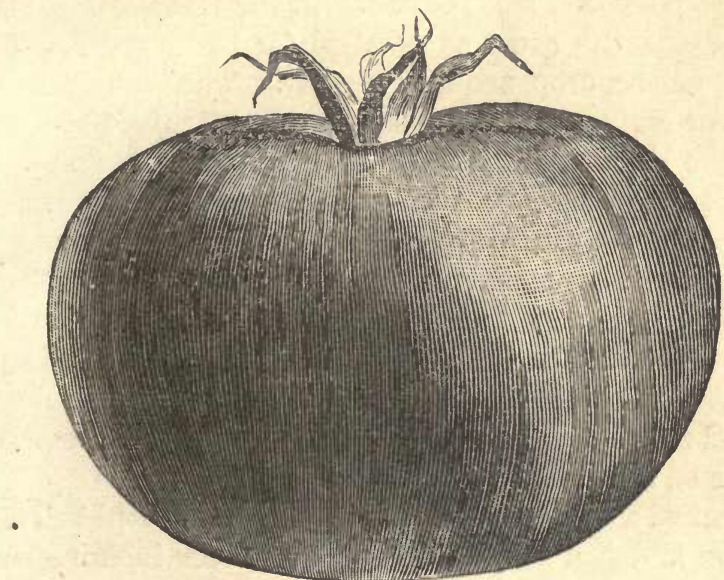

Fig. 97.-PER̈FECTION TOMATO.

almost round in shape, perfectly smooth, and very solid. Of the best quality and enormously productive.

Canada Victor.-One of the earliest, of medium size, bright red, and very symmetrical in shape.

Trophy, - No Tomato ever introduced created the furore that this did when it was first bronght out. It is unsurpassed in size, flavor, and productiveness, but is now superseded by others in earliness and smoothness.

Ceneral Grant.-The fruit of this is large and of good quality, and ripens evenly and thoroughly.

Hathaway's Excelsior.-An early variety, of medium size, smooth, very solid, and of excellent quality.

Red and Yellow Plum Tomato.-Beautiful varieties, never exceeding two inches in length by one inch in diameter. Mainly used for pickling and preserving. 


\section{TURNIP.-(Brassica campestris.)}

The cultivation of the Turnip as an early crop for market purposes, sold bunched in the green state, is in all respects the same as detailed for Early Beets. The profits of the crop are also similar. The Turnip, however, for early crops, is rather more particular about soil than the Beet, and can bast be produced early on light sandy or gravelly soils, highly enriched with manure.

For late crops, sowings may be made, for Ruta Bagas, from May to September, in the different sections of the country; here, the finest roots are obtained by sowing about first week in June. For white and yellow varieties, as they como quicker to maturity, sowing should be delayed four or five weeks later. Here, we sow from the middle of July to the middle of August.

Turnips, whether for early or late crops, should always be sown in drills, about fourteen or eighteen inches apart. In large quantities, they are sown by the machine, when one pound of seed will be enough for an acre. In the Northern States it is necessary to take them up on the approach of severe weather, when they are best preserved during winter by being pitted, as recommended for other roots. The late crops of Turnips are by no means so profitable as the early, rarely realizing to the grower more than $\$ 75$ per acre; but like most other late crops of the garden or farm, they can be grown with less manure, are less perishable if not immediately sold, and are consequently grown by the farmer on his less valuable but more extensive grounds. Again let me reiterate the necessity for firming the soil around the seeds of the Turnip crop, sown in the dry, hot weather in August. Thousands of acres fail to germinate from no other cause, while in England in 1885 fully, one-half of the crop seemed to me was lost, solely from lack of this pre- 
caution. There had been no rain, even to lay the dust, for a period of eight weeks in summer-an experience almost unprecedented there, and no provision had been made for firming the soil over the seed, and as a consequence it was shriveled and dried, and failed to grow. We here hive nearly always such hot, dry weather when

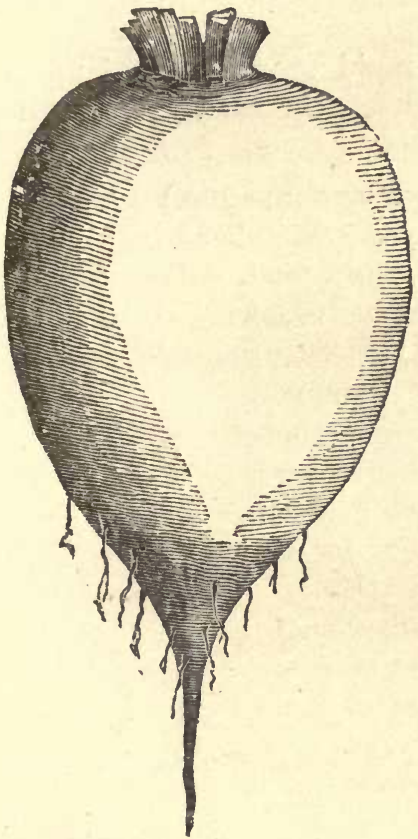

Fig. 98.-

WHITE EGG TURNIP.

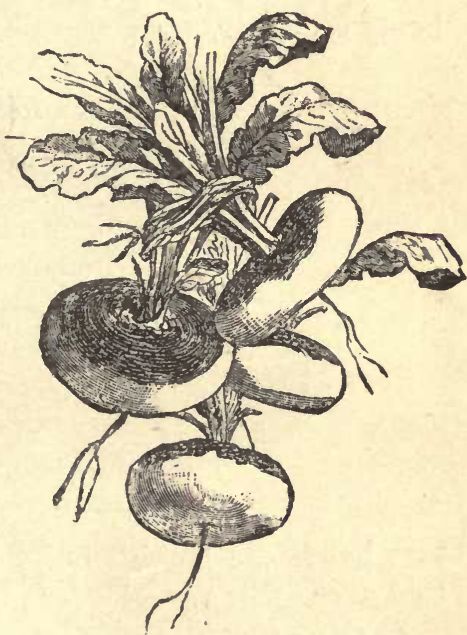

Fig. 99.-

Turnips are sown for late crops, and hence the necessity of always firming the soil.

The following are the leading varieties grown:

White Egg.-(See figure 98.) This in shape, is nearly oval or egg, its flesh is firm and fine-grained, skin thin and smooth. The flavor is mild and sweet, rendering it 
very desirable for table use, while its attractive appearance makes it a most saleable variety for market purposes.

Extra Larly Milan.-(See figure 99.) This is an early strap-leaved variety, coming into use a week or ten days before any of the ordinary early sorts. The bulbs are white, with a purple top, round and solid; flesh pure white, sweet and crisp.

Red-Top Strap-Leaf.-A rapid grower and of mild flavor. The most popular variety for early use, grown either for the table or for stock.

Purple-Top White Globe.-(See figure 100.) A very heavy cropping, early rariety, of globe shape. It has a

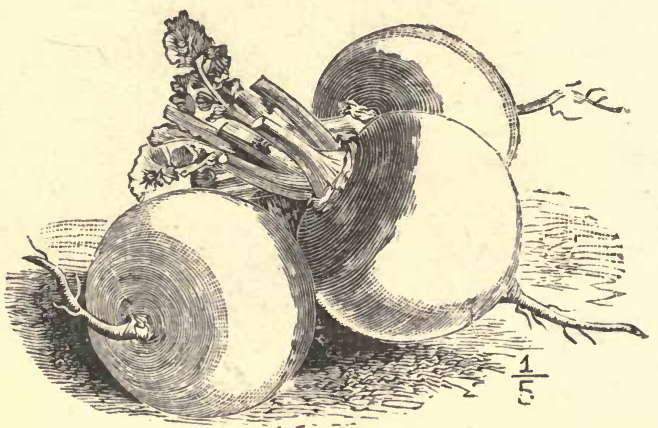

Fig. 100.-PURPLE-TOP WHITE GLOBE TURNIP.

very handsome looking bulb, and is rapidly taking the lead over other varieties for market garden purposes.

Amber Globe.-In great favor in the South. Attains a large size, flesh solid and sweet, hardy, and a good keeper.

Golden Ball.-This has no superior for table use, being of excellent flavor, globe-shaped, and of a beautiful yellow color. It is a very rapid grower.

Snowball.-A round, pure white variety, of superior flavor ; excellent for market. 
Snow-White.-Olive-shaped, very hardy, quality the best.

Seven-Top.-This is the variety so largely grown in the Southern States for Turnip salad or greens.

TURNIP.-RUTA BAGA OR SWEDIST.

Improved American (Purple-Top).-(See figure 101.) This is the leading variety; very hardy and productive;

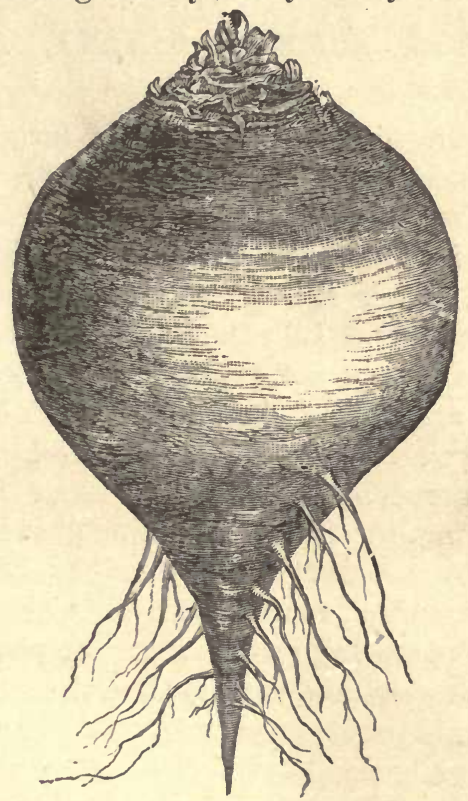

Fig. 101.-IMPROVED AMERICAN PUBLLE-TOP RUTA BAGA.

flesh yellow, solid, sweet, and fine flavored; equally good for stock or table use; the principal variety raised by market gardeners on Long Island, and the best of all yellow Turnips. In our trial grounds we find American-grown seed, of this variety, to yield bettershaped and cleancr Turnips than does imported seed. 
Shamrock.-One of the finest purple-top varieties in cultivation; forms a handsome bulb, with small top and very few leaves; an excellent keeper and good for stock or table use.

Large White French.-A superior variety for table or stock; flesh firm, white and solid ; attains a large size, and has a very rich and sweet flavor; a very popular variety.

\section{THYME, SAGE, SUMMER SAVORY, AND MAR- JORAM.}

I beliere even yet the cultivation of Sweet Herbs, for market purposes, is but little known in this country, except in the regetable gardeus in the vicinity of New York; there it is practised to an extent of perhaps 100 to 150 acres, a fair average profit of which would be about $\$ 250$ per acre. Like the crops of Celery, Spinach, or Horseradish, they are grown only as second crops, that is, they are planted in July, after an early crop of Peas, Cabbages, Beets, or Onions has been sold off. 'The kinds are Thyme, Sage, Summer Savory, and Sweet Marjoram, the former two being grown in the ratio of ten acres to one of the others.

The seed is sown in rows in April in rich mellow soil, carefully kept clean from weeds until the plants are fit to set out, which may be done any time that the ground is ready from middle of June until end of July. As the plants are usually small and delicate, it is necessary that the ground be well fined down by harrowing with the disc harrow, or raking before planting. The distance apart, for all the kinds, is about the same, namely, twelve inches between the rows, and eight or ten inches between the plants; the lines are marked out by the "marker." This is the "marker" used for many other purposes; in lining out the rows for Early Cab- 
bages, for instance, every alternate line is planted, thus leaving them two feet apart, their proper distance. (See Implements.) In eight or ten days after the herb crop has been planted, the ground is "hoed" lightly over by a steel rake, which disturbs the surface sufficiently to destroy the crop of weeds that are just beginning to germinate ; it is done in one-third of the time that it could be done by a hoe, and answers the purpose quite as well, as deep hoeing at this early stage of planting is perfectly useless. In ten or twelve days more, the same operation is repeated with the steel rake, which usually effectually destroys all weeds, the seeds of which are near enough to the surface to germinate. We use the steel rake in lieu of a hoe on all our crops, immediately after planting, for, as before said, deep hoeing on plants of any kind when newly planted, is quite unnecessary , and by the steady application of the rake weeds are easily kept down, and it is great economy of labor never to allow them to start. By the middle of September the herb crop usually covers the ground completely, looking like a field of clover. Allow this mass to grow for another month as it is, and you would not increase the weight of leares; the plants would grow taller, keeping the green and marketable leaves on the top, but only yellow and withered ones and plenty of woody stems below. But by cutting out every alternate row (each plant making about two bunches), the remaining rows are allowed light and air, and in three or four weeks will have spread so as again to cover up the entire surface, from which half the crop has already been gathered. We treat Sage in all respects the same as Thyme; and I have seen both these herbs on rich soil not only meet when left two feet apart, but when every other row at two feet apart was cut out, almost meet again at four feet apart.

By this method of cutting out every other row, fully a 
double crop is taken, and of a quality superior to what it would be were it allowed to grow without being thus thinned out. About thirty years ago I was lncky enough to discover the importance of this plan of doubling our crops of herbs, and as I had not, in those days, begun to tell "what I know about gardening," I kept my own counsel for some years before my neighbors discorered the plan. Herbs are regarded as a safe crop for the murket gardener ; they are less perishable than anything else grown, for, if there be any interruption to their sale in a green state, they can, if necessary, be dried and boxed up and sold in the dry state, months after. The price now is from $\$ 6$ to $\$ 10$ per 1,000 bunches, and we always prefer to dry them rather than sell lower than $\$ 6$ per 1,000 , experience telling us that the market will usually so regulate itself as to handsomely pay for holding back the sale. The cost of getting the crop raised and marketed will arerage about $\$ 150$ per acre, one-half of the expense being in tying it in bunches. But with many of our industrious German gardeners it does not cost half that, as the tying up is usually done by their wives and children.

There are but few varieties among Herbs, but of Thyme there are sereral, and it is very important to plant only what is known as the "spreading variety ;" an upright sort, sometimes sold, is worthless as a market crop. The Sage, known as the Broad-leared, is the best.

I am often asked, by correspondents at a distance, in relation to the best way of selling herbs in New York City. I will here say, that there is no certain sale that I know of, unless they are in a green state. The season for selling is October, Norember and December; and if shipped in open crates, so arranged by divisions of slats that not more than eight or nine inches of a layer would be together, they could be shipped at that cool season to distances requiring fifty or sixty hours in the transit. The arerage receipts per acre is now about $\$ 400$. 


\section{CH A P T E R X I.}

\section{WHEN TO SOW AND PLANT IN THE SOUTHERN STATES.}

We have hundreds of letters each season making inquiries on this subject. From the great variation in latitude, soils, shelter, etc., it is impossible to give accurate information on the subject, for the date that would answer for Charleston, South Carolina, or Jacksonville, Fla., would not do for Norfolk, Va., or Knoxville, Tenn., but at the risk, in some few cases, of repeating instructions already given, I will endearor to approximate as nearly as possible to the dates at which regetables should be sown and planted in the Southern States. The instructions for culture vary but little from what is practised at the North, so the reader is referred to each article under its proper head for cultural instructions.

Asparagus. - Whether raised from seed or from plants, had better be started in the fall months, varying, according to latitude, from the 1st of October to the 1st of December, earlier, as at Norfolk, Virginia, to the latest date in South Carolina, Florida, Louisiana, and Texas. The plant is hardy, and consequently will have made roots enough to sustain itself through the cool season, if sown at these dates, and be ready for vigorous growth as soon as regetation starts in spring.

Beans; Bush or Pole.-Are of tropical origin, and consequently belong to what are classed as "tender" vegetables, and when wanted for eurly crop, as nearly all Southern vegetables are, should not be sown until all danger from chilly weather is past-not before the night temperature will average fifty-five degrees. Perhaps one of the best rules is to delay sowing or planting in the open ground until such date as corn can be safely planted. 
Beets.-Are of intermediate hardiness ; not sufficiently hardy to be sown and wintered over like Asparagus or Spinach, yet hardy enough to be sown three or four weeks earlier than Beans or Corn. For example, if the Corn-planting season is March in extreme Southern points, Beets may be sown at the same place in February.

Cabbage.-Is perhaps the most important of all Southern crops raised for the Northern market, and muchvery much - of the success of the crop depends upon when sown and the quality of seed used. 'Taking the latitude of Charleston, South Carolina, or Savannah, Georgia, as a basis, the usual time of sowing there, in the open ground, is from October 5th to 15th, but even at the later date, the favorite variety, "Early Summer," may run to seed if the season is mild; so we strongly advise to sow, at least a portion of the crop, ten days later-say from October 20th to 30 th-and so shape the seed-beds that they can be covered up by "sashes" made of muslin, or the protecting cloth already alluded to, on cold nights-exposing them, of course, to the light, on warm, bright days.

\section{Cauliflower.-Same as for Cabbage.}

Celery.-Being a winter vegetable, is never shipped from South to North, as it can be grown much cheaper North; but there is a growing local demand for Celery at many Southern points. The seed, to produce plants, cannot safely be sown South in the spring for Celerygrowing, as in most instances, from the longer season, it would run to seed, even if it could be carried through the hot weather. My advice would be to sow at different periods, say from the middle of June to the middle of August, using the protecting cloth "sashes" already described, during the hot sunshine, say from 9 A. M. to 4 P. M., watering them, when dry, in the afternoon after taking off the sashes. As several thousand Celery plants 
can be grown under a three by six feet sash, it will repay the labor in such places as this, where protection against the sun is a necessity.

Collards.- Require to be sown about the same date as Spinach, which see.

Corn.-Sweet Corn is a valuable crop in some sections South, to be sold in our Northern markets. It is one of the most tender plants. Thousands of acres are sacrificed every season by impatient cultivators, who, deluded by a few warm days in spring, plant too early. No date can be given with safety, only, as a rule, one will be safer to be a little behind his neighbor than before him. If the usual date is the 1st of the month, you will be certain to catch up if you wait until the 4 th or 5th, as it is a crop easily checked even by a slight chill. It may be forwarded six or eight days by sowing in pieces of sod under sashes, as recommended for Cucumbers.

Cucumbers.-Another "tender" plant, requiring the same conditions for vigorous growth as Sweet Corn. It may be sown on pieces of inverted sod, cut in sections of three or four inches; these, if placed in frames and covered with the protecting cloth, or better still for this purpose, glass sashes, may be started two weeks sooner than they can be sown outside. In about a month after sowing (if not begun before the temperature would average fifty-five degrees at night), they will have grown two or three inches and have matted the pieces of sod full of roots; the temperature now should be ten degrees higher, and they may then be set in the open field and will give a crop at least a week earlier, which will well repay the extra labor.

Egg Plant.-The same rules may be applied to this, remembering, however, that this is an extra "tender" plant, and at least five degrees higher will be necessary. 
Greens, German or Sprouts.-Same as Spinach, which see.

Lettuce.-The same rules as for Cabbage and Cauliflower will apply nearly as well to Lettuces.

Melon, Musk and Water.-Same as for Cucumbers.

Okra, or Gumbo.-Another " tender" vegetable ; ảate of sowing the same as for Beans.

Onion.-One of the hardiest of vegetables, and, whether grown from seeds or from sets for early crop, should be sown in the fall, about the dates advised for Asparagus, though if wanted for a later spring crop, or for drying, may be sown in spring, at the date advised for Beets.

Peas.-Again taking the latitude of South Carolina or Southern Georgia as a basis, the Marrowfat varieties of Peas may be begun to be sown about the end of November, following with the early kinds for succession crops every week or ten days to January 1 st.

Potato.-(Solanum tuberosum.) We give the botanical name to distinguish it from the Sweet Potato; though indigenous to high Southern latitudes, it is impatient of heat, and should be planted as early in the various Southern States as the ground is in condition to work; in parts of Florida as early as January 1st, while February 1st will be proper at Charleston or Savannah, and nearly a month later in Southern Virginia.

Potato, Sweet.-(Ipomcoa batatas.) This is mainly a crop of the Southern States. The roots are usually started in Florida or South Carolina about February 1st, in cold frames covered with glass, or in warm borders in the open air. The "sets" or "draws" will nsually be large enough to be set out the first week in March in Florida or first of April in South Carolina, and corres. pondingly later as we move north ward.

Radish.-Dame dates as for beets. 
Rhubarb. - Same date as for Asparagus.

Turnips.-For fall sowing, the Sweet or Strap-leaved kinds of Turnip should be sown from September to October, while the Ruta Bagas, requiring a longer time to mature, should be sown a month earlier. For "spring sowing," January to February for the extreme Southern States.

Spinach.-A hardy vegetable, and a valuable crop in many sections of the South. May be sown from September to October at Norfolk, Virginia, and from November to December at Charleston or Savannah ; but as it is slow to germinate in dry weather, see what is said in relation to it at page 101, under the head of the "Use of the Feet in Sowing and Planting." At the extreme South Spinach is not much grown, as it does better in such latitudes as Virginia or Delaware.

Squash.-Same as for Cucumber.

Tomato.-A most important vegetable grown at the South for the Northern markets. It is usually set out by first raising the plants under glass, often in hot-beds, when great earliness is desired. The reader is referred to "Construction of Hot-beds," which will be necessary in most sections for the first sowing for the seedling plants. An ordinary three by six feet sash will raise from 1,500 to 2,000 seedling plants. - These if sown, say, February 1st, will be large enough to transplant at three or four inches apart, again under the protection of sashes or of "sashes" of the protecting cloth, until fit to set out in the open field. As it is also a most tender plant, easily hurt by chill, the same rules apply here as for Cucumbers. 


\section{H A P T E R X II.}

\section{PACKING OF VEGETABLES FOR SHIPPING.}

This is a matter for which it is not very easy to give directions, as the distance, season, and articles to bc packed will greatly determine the manner in which it is to be done; but a few general directions may assist the inexperienced.

The mode of packing during spring and summer is almost entirely the reverse of that practised during autumn or winter, for the reason that, when the temperature is high, provision must be made in the package for the admission of air to prevent the articles from heating; while in cold weather, when there is but little danger from heating, but more to be apprehended from frost, close packages must be used accordingly.

As early vegetables are always shipped from a warm climate to a colder one, at a season which, of course, must be warm to mature them, open work baskets or slatted boxes must be used. If barrels are used, care must be taken that openings be made plentifully in the sides, so that air may be admitted. For distances requiring a delay of more than forty-eight hours in the transit, for most articles, barrels are too large ; boxes or baskets, one-third the capacity of a flour barrel (one bashel), being safer. The articles shipped in this manner from Southern ports to Northern markets, are: Asparagus, Beans, Cucumbers, Lettuce, Melons, Peas, Radishes, Tomatoes, and other summer crops. Bulky articles, such as Cabbages, Beets, Sweet Corn, Water Melons, Turnips, are often shipped loose on the decks of steamers, sloops, etc. ; but even then care must be taken that the heaps are not too large, else they may be injured by heating. The judgmeut of the shipper must be exercised in respect to the article to be shipped. Articles that lie 
close will require to be shipped in smaller packages than those that lie so loosely that the air can pass among them; for example, Melons may be safely packed in a barrel, while if Tomatoes were so packed, they would be utterly destroyed.

The winter or fall shipping of vegetables is the reverse of the summer, for then we send from the North to the South, our colder and damper atmosphere being more congenial to the growth of late crops. Close packages are now used, but still not too large; barrels being best suited to such articles as Beets, Carrots, Celery, Onions, Parsnips, Potatoes, or Turnips, while Cabbages and Cauliflowers may be shipped in crates or in bulk.

\section{H A P T E R X III.}

\section{PRESERVATION OF VEGETABLES IN WINTER.}

Our manner of preserving vegetable roots in winter is, I think, peculiar to this district, and is very simple and effective.

After taking up such crops as Beets, Carrots, Horseradish, Parsnips, Turnips, Potatoes, etc., in fall, they are put in temporary oblong heaps, on the surface of the ground on which they have been growing, and covered up with five or six inches of soil, which will keep off such slight frosts as are likely to occur, until time can be spared to store them in permanent winter quarters; this is done in this section, usually, during the first part of December, in the following manner: A piece of ground as dry as possible is chosen; if not naturally dry, provision must be made to carry off the water, lower than the bottom of the pit. The pit is dug out from three to four feet deep, about six feet wide, and of the length required; the roots 
are then packed in, in sections of about two feet wide across the pit, and only to the height of the ground level. Between the sections, a space of half a foot is left, which is filled up with the soil level to the top; this leaves the pit filled up in sections of two feet long, with roots, and half a foot of soil, and so on, until the whole is finished. 'The advantage of this plan is, that it is merely a series of small pits, holding from three to five barrels of roots, which can be taken out for market without exposing the next section, as it is closed off by the six inches of soil between. Also, we find that roots of all kinds keep more safely when in small bulk than when large numbers are thrown into one pit together. In corering, the top is rounded so as to throw off the water, with a layer of from eighteen inches to two feet of soil. 'This way of preserving roots, with perhaps the exception of Potatoes, is much preferable to keeping them in a cellar or root-honse, as they not only keep fresher, retaining more of their natural flavor and color, but far fewer of them are lost by decay than when exposed to the air and rarying temperature of a cellar. Unmatured heads of Cauliflower, or Broccoli, however, are best matured in a light cellar or cold frame, by being planted in close together; in this way, good heads may be had to January. For the keeping of Cabbages, Celery, and Onions, see instructions in the chapter describing their culture. Mr. William Crozier, of Northport, L. I., who is co-author with me in the work "How the Farm Pays," has adopted this method of keeping potatoes with great success. It is the method almost exclusively in use in England and Scotlanō. 


\section{H A P T E R X I X.}

\section{INSECTS.}

We have but little trouble with insects in our highly cultivated grounds; what with continued moving of the soil by plowing and harrowing every fost, from three to four times each season, incessant hoeing, and the digging up of the crops, we give these pests but little chance for a foot-hold. We are, however, occasionally troubled with Aphides, the "Green-fly," in our forcing-houses of Lettuce. Another kind of aphis, closely allied to the green, assumes a bluish color when it attacks the Cabbage crop, either in frames or ontside. A complete remedy for either pest, in its early stages, is tobacco stems steeped in water to give it about the color of strong tea, and applied with a syringe or watering-pot, or tobacco dust, or, in fact, tobacco in any form that it can be applied. "Jumping Jack," or the Turnip-fly, occasions some trouble with late sowings of Cabbages, Turnips, and Radishes, but we find an excellent preventive in dusting lime over the beds as soon as the seeds begin to germinate. It is of the utmost importance to use preventives in the case of insects, for if once they get a lodgment, it is almost useless to attempt their destruction. The striped Cucumber-bug, which, with us, attacks late sowings only, we have found to yield readily to a few applications of bone dust, which serves the double purpose of disturbing the insect and encouraging the growth of the crop. But our most formidable enemy of the insect tribe is that which attacks the roots of the Cabbage family, causing the descructive disease known as the "clubroot." There is a general misconception of the cause of this disease; happily our peculiar location here gives me the means, I believe, of thoronghly disproving some 
of these absurd dogmas, that club-root is caused by "hog manure," "heavy soil," "light soil," etc. I do not doubt that it has appeared thousands of times under just such conditions; yet, within three miles from the City Hall of New York, I can show to-day, on the classic shores of Communipaw, scores of acres that have been just so manured, both light soils and heavy soils, that have grown cabbages for twenty consecutive years, while the first appearance of club-root is yet to be seen. On the other hand, I can show, on soils not more than a mile distant from those on the Communipaw shore, where the ground is cultivated in the very best possible manner, and where every variety of manure has been tried, and yet it is imposssble to get a crop of Cauliflower or Cabbage clear from club-root for two years in succession. Now, the reason of the immunity from the pest on the one variety of soil and not on the other, does not, to us, admit of the slightest particle of doubt. On the shore side, and for nearly a mile inland, there are regular deposits of oyster shell, mixed with the land almost as we find pebbles in a gravelly soil ; our theory is, that the insect which occasions the club-root cannot exist in contact with the lime, which, of course, is present in large amount in a soil containing such abundance of oyster shell. Reasoning from this, we have endeavored to bring up soils deficient in shell, by heavy dressings of lime; this answered, however, only temporarily, and we found it too expensive to continue it. The increasing demand for manures in the vicinity of New York has rendered them of late years scarce and high in price, so that we were necessitated to begin the use of guano and other concentrated manures, and as this was rather new with us in our market gardens, we have had the pleasure of some very interesting experiments. In my grounds at Jersey City, where we have never been able to get two crops of Cabbages successively without having them in- 
jured by club-root, my foreman suggested to me to experiment with a bed of about half an acre, to be planted with early Wakefield Cabbage. One-half of this he proposed to manure at the rate of seventy-five tons per acre with stable manure, the other half with flour of bone, at the rate of 2,000 pounds per acre; this was accordingly done in the usual way, by sowing the bone dust on the ground after plowing, and then thoroughly harrowing in. During the month of May, we could see no perceptible difference in the beds; but just as soon as our first hot days in June came, down wilted the portion that had been dressed with stable manure, showing a well-defined line the whole length of the bed, and, on pulling up the plants, we found that our enemy was at work, while in that portion that had been dressed by the bone dust, hardly a wilted plant could be seen, but, on the contrary, the crop had most unusual vigor. This experiment has been to me one of the most satisfactory I ever tried; it still further proves that this destructive insect cannot exist, to an injurious extent, in a soil impregnated with lime, and also proves that we have a most effective remedy in this valuable and portable manure. The experiment was, however, to me rather a costly one; onr past experience told us that there was no reason to expect that the portion on which the stable manure was used would not be attacked by club-root, as it had borne a crop of Cabbage the previous year, and nearly twenty years' working of that soil had shown that this crop could never be grown two years successively ; but experiments to be satisfactory must be done on a scale of some magnitude, and although I lost some $\$ 200$ by the difference in the crop, I believe it to have been a profitable investment.

I have incidentally stated that the Cabbage crop, treated in the usual manner, can only be grown every alternate year, the reason of which we infer to be that 
the insect is harmless to the plant when in the perfect state the first season, but that it is attracted by the plant, deposits its eggs in the soil, and that in the larvæ condition, in which it appears the second year, it attacks the root. Whether this crude theory be correct or not, I will not presume to say, but if not, how ean we account for the fact of our being able to grow this plant free from its ravages every alternate year, while if we attempt to do so successively without the use of lime or bone dust, it is certain to be attacked?

All anthorities on gardening to which I hare had access seem to be unaware of the fact that club-root is never seen in soils impregnated with shells. This variety of soil is not common. I have never seen it anywhere except here, and, as I have said, this peculiarity of location, most fortunately, gives a certain clue to the facts, and directly points out the remedy, which, I think, we have found to be in the copious use of bone dust as manure.

Another enemy of the Cabbage plant, and one that is sometimes even more destructive than the club-root, is the Cabbage Caterpillar. This insect is comparatively a new-comer, having been imported from Europe by way of Canada. It is produced by the small white butterfly that is seen hovering over the Cabbage patches in spring. It attacks the leaves of the plant, and is such a voracious feeder that it will quickly destroy a whole plantation. I am frequently applied to for a remedy for this pest and others attacking Cabbages ; the best I know of are given in the chapters on "Cabbage Culture." Nothing is more difficult and unsatisfactory than the attempt to defeat the ravages of insects in the open field, and I have yet to know of any being continuously successful, unless perhaps, the application of Paris Green for the destruction of the Potato Bug. In the long-cultivated gardens of New Jersey and Long Island we do not suffer much from the ravages of either of the above pests. The soil is so re- 
peatedly turned over and disturbed that I presume the maggot is not left long enough at rest to develop itself in sufficient numbers to produce any great injury; and the luxurious growth resulting from the continued and heavy manuring, seems to be less inviting to the butterfly to deposit her eggs than the feebler growth of less fertile soils. Or, it may be that the increase of English sparrows is helping us in both these cases, by destroying the fly that produces the maggot, or the small white butterfly that produces the caterpillar, or it may be that they feed on the caterpillar itself, as I know they do upon the rose-slug. At all events, the farmer will gain by encouraging and caring for the sparrows. A few years ago the street trees of New York, Brooklyn and Jersey City were festooned by myriads of the " measuring worm ;" now, since the advent of the sparrows, they are scarcely ever seen. The sparrows will live in any section of the country if properly housed and fed in winter, and if such care were general we should hear fewer complaints of insect ravages. True, the birds might exact wages for their services, in requiring a little grain, but of the two evils, better submit to that done by the birds than by the insects.

I will relate an experiment to destroy the Cabbage Caterpillar, which occurred during this month in my immediate neighborhood. One of my neighbors found that the pest was attacking his Cabbages; he came to me and asked what I thought of his using slaked lime to dust over them. I told him I had but little faith in it. But he was resolved to try it, and put it on at the rate of four or five barrels to the acre, carefully dusting it on each plant. This was about the 1st of June. On the 17th he came to me in triumph, saying that the remedy had been effectual, and that there was hardly a caterpillar to be seen. Unfortunately for the experiment, but fortunately for truth, another neighbor, whose Cabbage patch 
had been attacked at the same time, but had received no lime, was also entirely clear of the caterpillar! The cure was traceable to another cause. We had had a deluging rain that swept off the caterpillars, and started the Cabbages into luxuriant growth at the same time. Had the insect come in the legions it does in some places, had there been no rain, and had the dry, hot weather continued, the lime dust would probably have failed.

Last summer, I had with great care nursed.along in my greenhouses, for many weeks, a collection of rare varieties of German Stock Gillyflowers, a plant belonging to the same natural orjer (Cruciferæ), as the Cabbage. Upwards of two thonsand plants were set out in June, on rather poor soil; by the middle of July they had made splendid plants, one foot across, and just as they were bursting into bloom we observed the little white butterfly moving amongst them, and knew what might be expected to follow. Lime dust, solutions of carbolic soap, whale oil soap, and sundry other things were used, all to no effect, and by middle of August, the plants were literally eaten up by the caterpillar. There is nothing more unpleasant than to tell any one suffering under a calamity that there is no effective remedy; but it is infinitely better to do so than to delude them with a false one. I have been a worker of the soil since my boyhood, and every year's experience convinces me of the almost. helplessness of remedies against insects or other blight. ing plagues that attack regetation in the open field. It is true that the amateur gardener may save his dozen or two of Cabbages or Roses by daily picking off or destroying the insects; but when it comes to broad acres, I much doubt if ever any remedy will be found to be prasticable, unless in rare instances, such as Paris Green, as as an antidote against the Potato Bug. We have one consolation, in knowing that these pests are only periodical, and never continue so as to permanently destroy. 


\section{H A P T E R X X.}

CULTURE OF SMALL FRUITS.

Complaint has been made that in the former editions of this work, no allusion was made to the culture of small fruits, which, in many sections, is as much a matter of interest to the market gardener as is the culture of regetables, as, in many places the two have to be combined so as to supply the local demand. The most important of all the small fruits is

\section{THE STRAWBERRY.}

The same general rules for soils, drainage, manuring, etc., are generally applicable for Strawberry or other small fruit culture as for vegetable crops. Our method of obtaining a full crop of Strawberries by "pot layering," which we here give in detail, we have practised for the past fifteen years with unvarying success, and if we were growing Strawberries for market, no matter on how large a scale, we would follow no other method. To obtain a crop in June from the plants that were planted out the previous August, or in ten months from date of planting, the plants must be such as are layered in pots, and the sooner they are planted out after the 15th of July the better, although, if not then convenient, they will produce a crop the next season, even if planted as late as the middle of September; but the sooner they are planted, the larger will be the crop. They may be set from pot layers either in beds of four rows each, twelve inches apart, and twelve inches between the plants, leaving two feet between the beds for a pathway; or be set out in rows two feet apart, the plants in the rows twelve inches apart; and if the plants are properly set out (care being taken to firm the soil around the plants, which is best done by pressing the soil against each plant with the foot), not 
one in a thousand of Strawberry plants that have been struck in pots, will fail to grow. For the first three or four weeks after planting, nothing need be done except to hoe the beds, so that all weeds are kept down. Be careful to do this once in every ten days; for if the weeds once get a start it will treble the labor of keeping the ground clean. In about a month after planting they will begin to throw out runners, all of which must be pinched or cut off as they appear, so that by the end of the growing season (1st of November), each plant will have formed a complete bush one foot or more in diameter, having the necessary matured "crowns" for next June's fruit. By the middle of December, the entire beds of Strawberry plants should be covered up with salt meadow hay (straw, leaves or anything similar will do as well), to the depth of two or three inches, entirely corering up the plants and soil, so that nothing is seen but the hay. By April, the plants so protected will show indications of growth, when the hay over each plant is pushed a little aside, to assist it in getting through the covering, so that by May, the fully developed plant shows on the clean surface of the hay. This "mulching," as it is called, is indispensable to the best culture, as it protects the plants from cold in winter, keeps the fruit clean, keeps the roots cool by shading them from the hot sun in June, and, at the same time, saves nearly all further labor after being once put on, as few weeds can push through it. By this method, we prefer to plant new beds every year, though, if desired, the beds once planted may be fruited for two or three years, as by the old plans; but the fruit the first season, will always be the largest in size, if not greatest in quantity. Another advantage of this system is that, where the space is limited, there is quite time enough to get a crop of Potatoes, Peas, Beans, Lettuce, Radishes, or, in fact, any summer crop, off of the ground first, before planting the Strawberries, thus taking 
two crops from the ground in one year, if desired, and there is also plenty of time to crop the ground with Cabbage, Cauliflower, Celery, or other fall crop, after the crop of Strawberries has been gathered. The plan of getting the pot layers of Strawberries is very simple. Just as soon as the fruit is gathered, if the beds are well forked up between the rows, the runners, or young plants, will begin to grow, and in two weeks will be fit to layer in pots. The pots (which are about two inches in diameter), are filled with the soil in which the Strawberries are growing, and "plunged" or sunk to the level of the surface; the Strawberry layer is then laid on the pot at its joint, being held in place with a small stone. 'The stone not only serves to keep the plant in its place, so that its roots will strike into the pot, but it also serves to mark where each pot is ; for, being sunk to the level of the surface, rains wash the soil around the pots, so that they could not well be seen unless marked by the stone. In ten or twelve days after the Strawberry layers have been put down, the pots will be filled with roots. They are then cut from the parent plant, placed closely together, and shaded and watered for a few days before being planted out.

Strawberries for field culture are usually planted from the ordinary layers, either in August and September in the fall, or in March, April or May in the spring. They are usually planted in rows, two to three feet apart, and nine to twelve inches between the plants. In planting, every plant sbould be well firmed, or great loss is almost certain to ensue, as the Strawberry is a plant always difficult to transplant. They are usually worked by a horse cultivator, and generally two or three crops are taken before the beds are plowed under; but the first crop given (which is in the second year after planting), is always the best; that is, the Strawberry beds set out in March, April, or May will give the best crop in June of 
the next year. The same care must be taken as in planting the pot layers; the ground must be kept clear of weeds, and the runners pinched or cut off to make fruiting crowns. By the usual field method of culture, it will be seen that there is a loss of one season in about three; for in the year of planting of course no fruit is produced. Our own practice is to set aside enough to produce early plants, so that pot lavers can be obtained to set out by the 15th of July; thus a full crop of the finest fruit is had every season, and with less cost, we think; for the only labor, after planting, is to keep the ground clean and pinch off the runners, from July to October, with the certainty of getting a full crop next June, or in less than a year from the time of planting, while by planting by ordinary layers, if set out in $\mathrm{Au}$ gust, we have three months of fall culture, and six or seven months of the next summer's culture, before a crop is produced. Again, if the crop is continued to fruit the second or third year, every one who has had experience with the nature of the plant knows that the labor of keeping the plants free from weeds is enormons; while by the pot layering method of taking a fresh crop each year, much of such labor is dispensed with.

There are hardly two sections of the country, 100 miles apart, where the same varieties of Strawberries are grown. We can only offer those grown in the vicinity of New York as our standard.

The IIenderson.-(See figure 102.) This new Strawberry originated with Mr. George Seymour, South Norwalk, Conn., in 1883, who named it in honor of the author of this work. It is doubtful if there is another Strawberry in cultivation having such a combination of good qualities as the "Henderson." The fruit is of the largest size, rich, glossy crimson in color, looking as if varnished, early and exceedingly productive, but its excelling merit is its exquisite flavor and aroma. Whether for family or mar- 
ket use, the "Henderson" is almost certain to become a standard sort, and its strong and healthy growth will

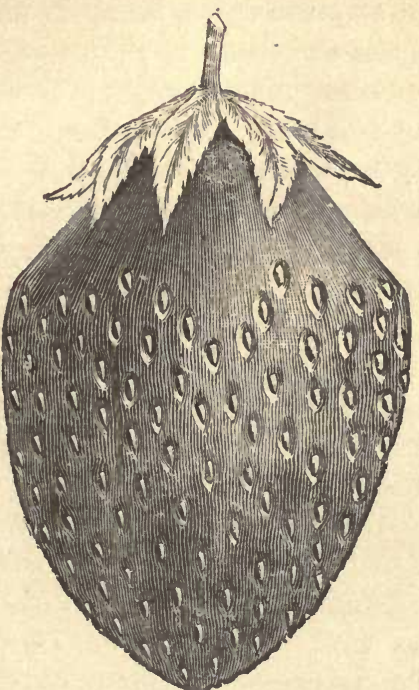

Fig. 102.-THE HENDERSON STRAWBERRY.

adapt it to almost every soil. It is a perfect-flowered variety, and, therefore, never fails to set its fruit.

Crimson Cluster.-(See figure 103.) On the 10th of June, 1886, I examined this Strawberry on the grounds of the raiser, Mr. E. W. Durand, and found 3,000 plants that had been planted on the 15th of August, 1885, which, in less than ten months from the date of planting, were producing a crop that would average fully a quart to each plant; 3,000 quarts from the 3,000 plants, or at the rate of orer 20,000 quarts per acre. The crop was so immense, and the size of the berries so large, that the pickers who were paid two cents per quart, areraged twenty-five quarts per hour, or $\$ 5.00$ per day-a fact beyond question, and which could he attested by a dozen affidavits. At the first picking, every yard of row 
yielded a quart of fruit. When to this extraordinary production we add the further facts, that this Strawberry is of the richest crimson color, borne in immense clusters (hence the name), and that it is one of the earliest as well as the latest-as its great vigor prolongs its season of fruiting-combined with its excellent quality, there is every reason to think that it is bound to be the most valuable Strawberry erer raised by Mr. Durand.

On the 10th of July, one month after my first examination, seventy quarts of splendid fruit were gathered

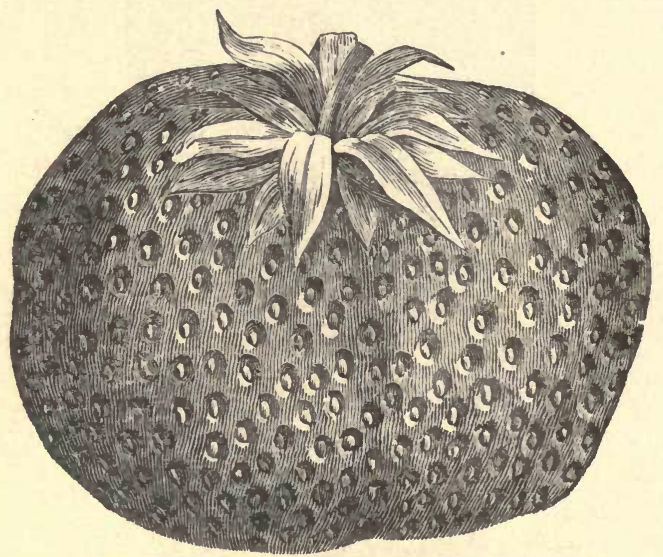

Fig. 103.-CRIMSON CLUSTER STRAWBERRY.

from the 3,000 plants above referred to, and furthermore, to show it still kept on fruiting, Mr. Durand sent me a large cluster of berries in all stages of development on the 30th of July; something entirely unknown in a Strawberry that had already given an immense early crop.

Mr. Durand says that the "Crimson Cluster" is so completely a pistillate variety that the stamens can hardly be seen, yet he says it may be planted five miles away from any other Strawberry and yet never fail to produce enormous crops. He further says that he has grown it in frames under glass in early spring, where it 
could not possibly be impregnated with any other variety, with the same results-an abundant crop.

He thinks that this fact, to a great extent, upsets the very prevalent notion that perfect stamens and pistils on the same plant are necessary to produce a crop of fruit. Without having personally given the matter much attention, I have long believed, from general observation, that there was more importance given to the necessity for "perfect flowers," as they are called, in strawberries than results warranted.

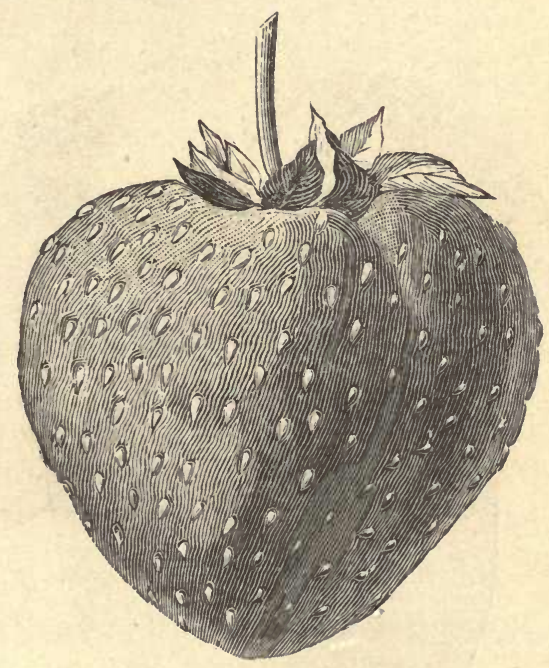

Fig. 104.-JERSEY QUEEN STRAWBERRY.

Jersey Queen.-(See figure 104.) This variety was sold for the first time in the fall of 1881, and is, perhaps, one of the very best late Strawberries thus far introduced. The size is immense, often measuring six inches in circumference. Shape, roundish conical ; color, a beautiful scarlet crimson; perfectly solid, and of excellent flavor. It is an enormous bearer, many plants averaging a quart of first quality fruit. It is one of the latest Strawberries, 
the crop in this vicinity being in perfection about the 25th of June, while the average crop of Strawberries is at its best by the 15 th of June.

Bidwell.-One of the earliest, most abundantly productive, of medium size, excellent flavor, and light scarlet in color: Plants set out from pot layers on August 5th, 1880, had fruit ripe June 5th, 1881, ten months from date of planting. The plants average one quart of fruit each.

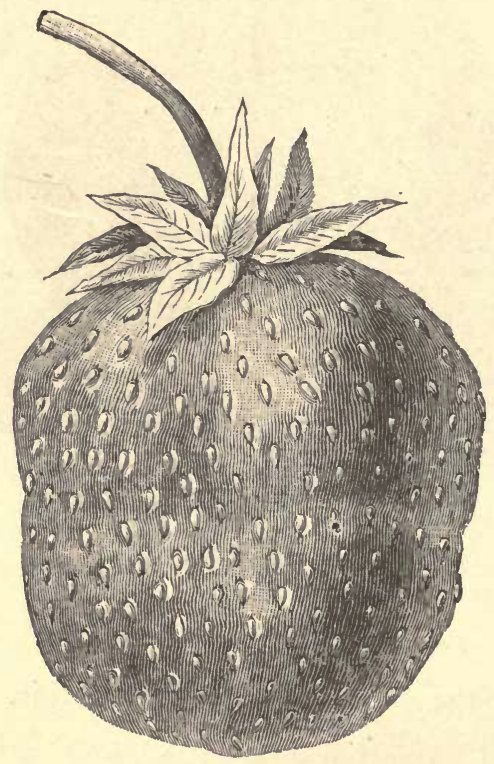

Fig. 105. - SHARPLESS STRAWBERRY.

Sharpless.-(See figure 105.) With the exception of Jersey Queen and "Crimson Cluster," the largest and one of the heaviest berries of this collection. It is of fine flavor, a good bearer, and has now become a standard sort.

Downing.-One of the best of the older sorts. It com- 
bines all the best qualities, being large, early, rich in color and flavor, and abundantly productive.

Parry.-One of the earliest large berries, of great beauty, excellent quality, prolific, and one of the very hardiest and strongest growers.

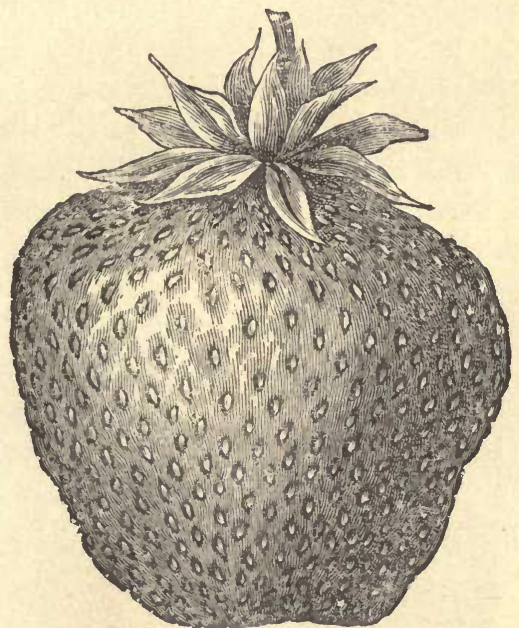

Fig. 106. - THF JEWELL STRAWBERRY.

Jewell.-(See figure 106.) A new variety, originated in 1880 ; is of the largest size, perfect form, coior bright red changing to crimson, of medium earliness ; enormous cropper, sometimes reaching 400 bushels per acre.

'The Ilofiman.-This is now the most popular berry for the Southern States. It is of medium size, arerage flavor, but it is a most abundant bearer and strong grower, and, above all, has the requisite solidity or firmness essential ior distant carriage.

Crescent and Wilson are yet popular varieties, the former being of a light, the other a dark, crimson. Both are inferior in size and quality to any of the large varieties above described, but they are both early, strong 
growing, doing well on nearly all soils, and are often used as early market sorts where the market is not critical as to quality.

Strawberries rarely sell at less than an average of $\$ 8$ per 100 quarts, and when retailed to the consumer, average one-third more. As about 20,000 plants are grown on an acre, and an average crop under good culture will give at least 5,000 quarts per acre, the crop, when sold even at lowest rates, is a fairly profitable one. But it is a crop that must be promptly attended to in hoeing and weeding. It never can be made profitable under slipshod culture, for, from the nature of the plant, it cannot defend itself against weeds, and if neglected will quickly get overwhelmed and destroyed. Thousands of acres of Strawberries are planted annually, which, from the want of prompt work at the proper time, are. allowed to be destroyed by weeds. At a small cost in labor, at the proper time, such crops might have paid a handsome profit.

\section{BLACKBERRIES.}

Although Blackberries are found in a wild state in almost all sections of the country, yet the varieties are so much inferior to the cultivated kinds, that it is poor economy to depend on them for a supply, no matter how abundant they may be. Cultivated Blackberries comprise varieties which are not only double the size of the wild kinds, but have the advantage of ripening in succession throughout the season, from the middle of July until the last of September. The distance apart to plant Blackberries may be, if in rows, five feet, with the plants two feet apart in the rows; or, if in separate hills, they may be set five feet apart each way. In either case they should be supported by strong stakes driven into the ground, having a height of from four to five fect, 
to which the canes or shoots should be tied. They may be set either in the fall or in the spring. If in the fall, a covering of four or five inches of rotted manure, leaves or soil (if covered with soil it is best to cut down the plants to four or five inches and cover up the whole), should be spread over the roots, to prevent them from being frozen too much. The plants of Blackberries set out either in fall or spring will not give fruit the first season, but, if a good growth has been made, they will give a full crop the next year.
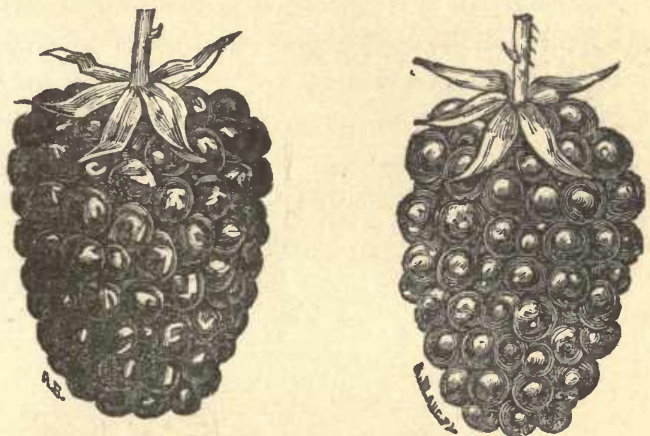

Fig. 107.-WILson BLACKBERRY. Fig. 108.-KITTATINNY BLACKBERRT.

That is, if planted, for instance, about the middle of April, 1886 (or the previous fall), by the middle of July in $183 \%$, a full crop should be obtained. After the fruit - has been picked the old canes or shoots should be cut out to give the new ones a chance to grow, about four or five of which only should be left. As the new shoots are very vigorous, when they reach a height of four feet or at most fire feet, they should be checked by pinching off the tops. This will cause an abundance of side shoots to start, which are to be pinched when about a foot long. This treatment increases the productiveness of the plants and keeps the fruit within easy reach for gathering. The bushes should be carefully tied to the stakes. Of 
the varieties, that known as Wilson's Early comes in a week before any of the others. It is a deep black, large, and of excellent quality, being destitute of that hard centre so peculiar to most wild sorts. The Kittatinny comes next in succession. It is an immensely large berry of fine flavor, of a deep shining black color-one of the very best. It is somewhat given to rust, which may be checked by removing all the rusted young shoots as they appear. The next is the old Lawton variety, which is hardly as good as either of the others, but has the merit of coming in after they are nearly done fruiting. There are a number of other kinds of Black berries offered, but the varieties above named are as yet standard sorts in most sections of the country. Any one growing Strawberries to.supply a local demand, must of necessity, have such fruits as Blackberries to succeed them as the season advances, and in most localities they will be found equally profitable with Strawberries, although, perhaps, for local demand, they could not be sold in as large quantities.

\section{RASPBERRIES.}

The culture of the Raspberry is almost identical with that of the Blackberry, except that they may be planted one-third closer, and that in some sections, the Raspberry is not quite so hardy, and it is better to take the precaution of laying the shoots down close to the ground in the fall, being careful not to break them, and cover them up with corn stalks, straw, leares or litter. This shonld not be done, however, until the weather is quite cold, say, in the latitude of New York, the first week in December. The covering may be from three to six inches thick, and should not be removed in the spring until the middle of April, as, if removed too soon, the shoots, which would then be beginning to start, might be hurt 
by the late spring frosts. Raspberries are of three colors -red, black and yellow. Of the red, Cuthbert, Hansell and Hudson River Antwerp are the favorites. Of the black varieties, the Gregg is of the largest size, an enor-

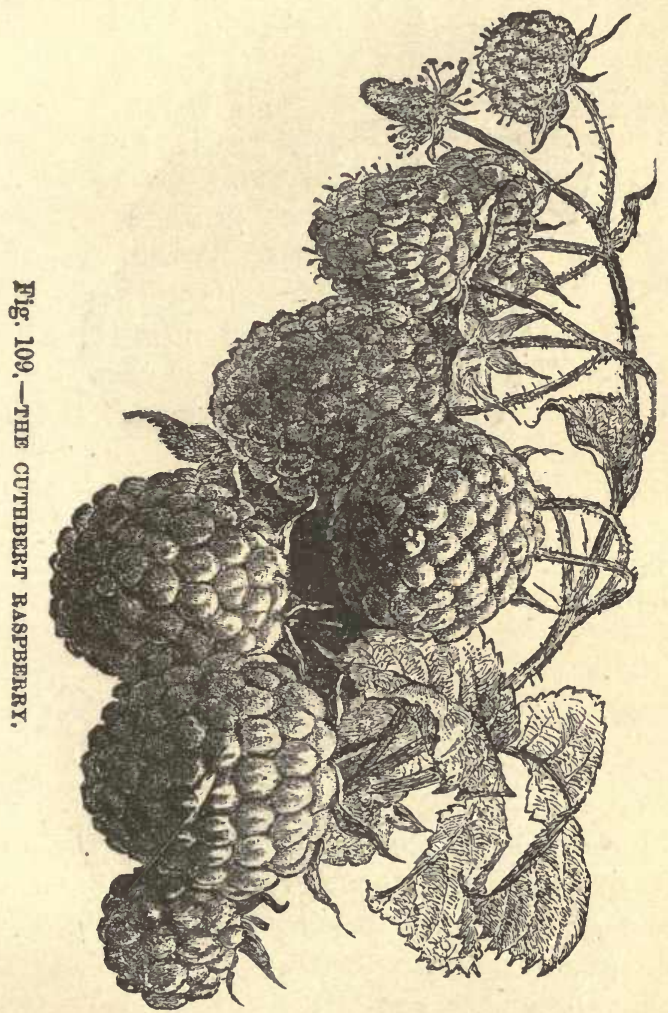

mous producer, of excellent flavor, and should, perhaps, be grown to the exclusion of all others of the "Black Caps." A yellow variety, known as "Caroline," is of rich orange color, entirely hardy, and of excellent flavor. Another yellow kind, known as "Brinkle's Orange," is 


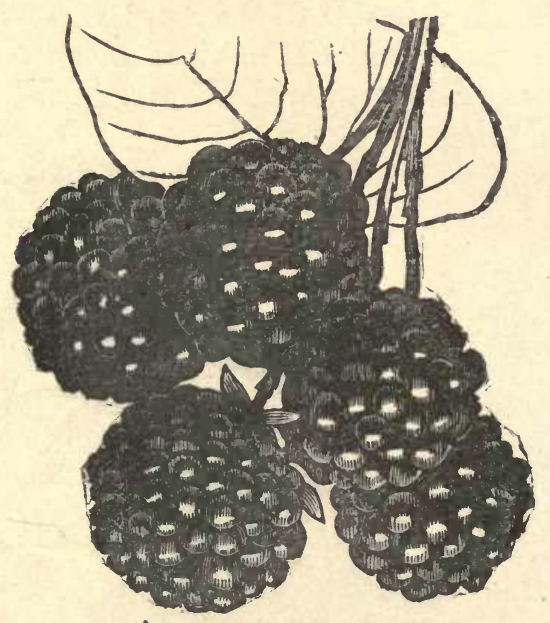

Fig. 1i0.-THE GREGG RASPBERRY.

of the most delicious flavor, but it is not hardy unless in well sheltered spots.

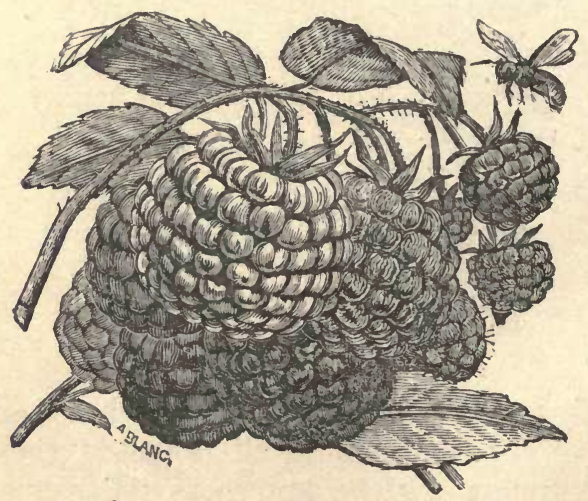

Fig. 111. THE HANSELL RASPBERRY. 


\section{CURRANTS.}

The Currant is but little used except for $y$ ies and for preserving purposes. There is, perhaps, no other small fruit that will give more weight of crop for the space it occupies than the Currant. However, as it is only used for these special purposes, and is but very little eaten at dessert, in an uncooked state, comparatively few are required. The plants should be set out in the garden in rows about four feet apart, and three feet between the plants ; for market purposes, these distances may be increased one-half. The young shoots require to be pruned in the fall, cutting off about one-third of their growth, and thinning out the old shoots when they become too thick. They are all trained in bush form, to a height of three or four feet. The best red varieties grown are known as the Fay, Red Dutch and the Cherry. Of the white kinds, that known as the White Dutch is the best. It is of a yellowish-white color. This variety is sweeter than the reds, and for that reason is better for dessert purposes. Black Currants are but little grown, and then exclusively for jams and jellies. They should be cultivated in the same way as the whites and reds, although they are an entirely different plant, belonging to a different species.

\section{GOOSEBERRIES.}

The Gooseberry is but little grown in this climate, as our summer is entirely too hot for it, and it is rarely seen in good condition, as it ripens just in the heat of summer, when the weather is the hottest, thus forcing it unnaturally to maturity, so that the fine flavor obtained in milder climates, such as Great Britain, is never found here. For that reason it is not much grown, except to be used in a green state for pies or tarts, and is 
in but little demand. Many of the English varieties are offered for sale here, but they are so subject to mildew, that they rarely do any good. Of the native varieties, that known as the Downing is of a greenish-white color when ripe, and of very fair quality. We have also a red

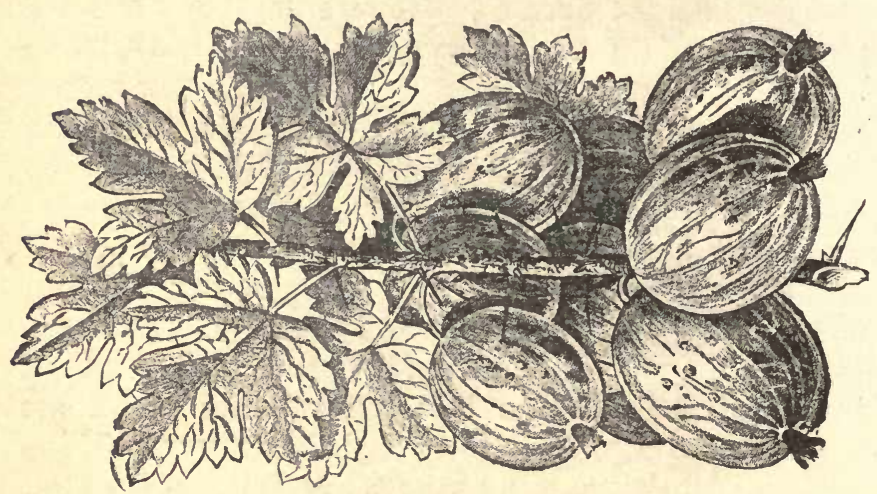

Fig. 112.-HOரGGHTON'S SEEDI.ING GOOSEBERRT.

native seedling known as Houghton's, which is of average size and flavor. The culture is same as that of the currant.

\section{GRAPES.}

Although grape-vines can be grown in almost any soil, yet if a position can be obtained on a sloping bank, facing south or southeast, running at a slope of ten or fifteen degrees, where the soil is stony or shaly, they will usually be found to do better than when planted on level lands, particularly if they can be manured. All the finest vineyards in Germany and France are so located, and the fruit is always better flavored and freer from mildew and other diseases than when on the level. However, such conditions are not always to be obtained, and the vines, of course, are not so easily worked as when planted on the level. There is now so much advance 


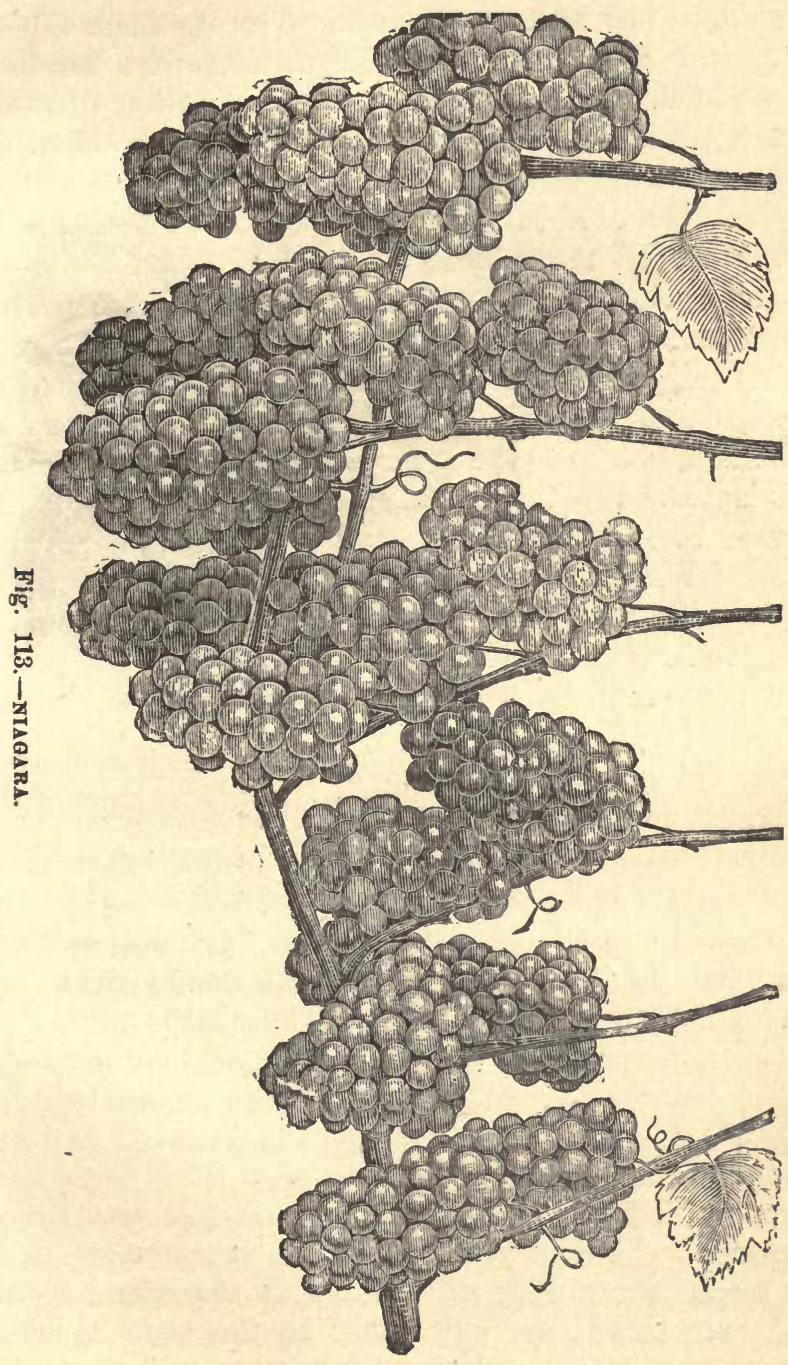


made in our hardy varieties of native Grapes, that those who have not had opportunities of seeing them will be surprised to find the vast improvement that has been made in this delicious fruit within the last ten or fifteen years. We have now Grapes of the finest flavor, of all colors, ranging through all the shades of green, amber, red and black, ripening in succession from the middle of August until the middle of October. Immense areas are now being planted with the kinds that have proved most profitable for market purposes, and as they can be safely shipped to almost any distance, there is no need of being dependent upon a local market. There is much misconception as to the age at which a grape-vine should be planted. It is the general impression that they should always be three or four years old. This is a popular error, for no matter how large a grape-vine may ke, it will never fruit to any extent the same season it is planted, and the larger it is the more it will suffer in being lifted and transplanted. Therefore, I always recommend purchasers to buy young plants, which not only can be bought at one-third the price of two or three year old ones, but are usually better, even at the same price. If a trellis is made for them, they should be planted at a distance of six feet apart. The trellis may be any height from six to twenty feet, as desired. If planted in vineyard style in the open field, without trellises, they may be set six feet between the rows and three or four feet between the plants, and tied up to strong stakes.

The first year after planting, if with vineyard culture, they should be cut down, and only one shoot left to reach to the top of the five or six foot stake. If it has grown strongly and ripened well, that shoot will give a few bunches the second year and may be pruned close, so as to resemble a walking stick, but with the lateral shoots cut back to one eye only-that is, the main shoot is allowed to stand, and the side shoots or laterals are 
trimmed to one bud or eye. This is what is called the Spur System, and will be found to be the most convenient for the inexperienced cultivator. There are special modes of pruning, which are best shown by illustration, and those who require fuller information on this subject, I will refer to my work, "Gardening for Pleasure," where the subject of pruning is fully treated. The eight kinds which we would recommend for general culture are the following :

Moore's Early. - This variety has large and compact bunches; berries large, black, and covered with a rich bloom ; excellent flavor, and is one of the earliest, ripening about the 1st of September, or a week before Concord.

Champion.-Another excellent black; medium early.

Niagara.-Is of greenish white color, sometimes tinted with rose ; of medium size for a white grape, flavor almost equal to the best hot-house grapes ; is immensely productive, and sold in the New York markets last year for twenty-five cents per pound, while Concord and other older varieties sold at six cents per pound; ripens the middle of September.

Martha.-Another white; not so good in quality, but a strong grower, which might suit in places where Niagara would fail.

Wilder.-Has berries of medium size; color reddish bronze; berry of exquisite flavor, ripening middle of September.

Salem.-Has large bunches; color, white, tinted with pink; of medium size; delicate flavor; ripening about 1st of October. A grand variety.

Brighton.-Color reddish bronze, bunch and berries of average size, flavor excellent; a most abundant bearer, and one of the very best. Ripens about the 1st of October. 
Concord, the last we name, is one of the best known of all the sorts. It is much inferior in flavor, but it has the valuable quality of seldom failing to bear abundant crops, and is indispensable in any collection, and if but one grape is grown, this should be chosen.

\section{CH A P T E R XI.}

\section{IMPLEMENTS.}

The tools or implements actually required for the market garden are comparatively few. The most important implements in use in the vegetable garden are plow and harrow, which should always be used to the

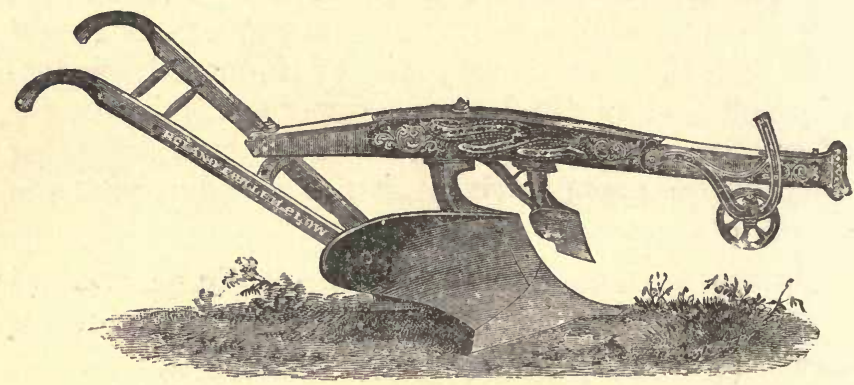

Fig. 114. - ROLAND. CHILled PLOW.

exclusion of the spade or digging fork, whenever it is practicable to do so. No digging in the ordinary way can pulverize the soil so thoroughly as can be done by the plow and harrow, nor does trenching by the spade, much surpass in its results, that done by thorough subsoiling.

Figure 114 represents a plow now largely used by market gardeners and known as the Roland Chilled Plow. So superior are its pulverizing powers to those of the 
spade that we know of no market gardener who would allow his ground to be dug, even if it were done free of cost.

'To avoid the frequent change of shares, and the extra

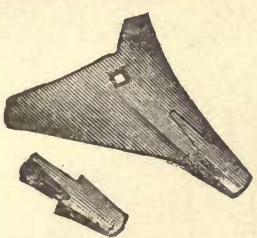
cost of replacing them, a reversible, self-sharpening slip point (see figure 115), is now made. When the bottom of this point is worn, and the plow tends to run out of the ground by reason of the rounded point, the slip point Fig. 115.-SLIP SHARE. is taken out and reversed, and thus doubles the length of its useful life.

Miner's Gold Medal Subsoil Plow (figure 116), is the best subsoil plow we know of. It involves new principles, and accomplishes the work of stirring, loosening and draining the soil beneath the furrow of the common

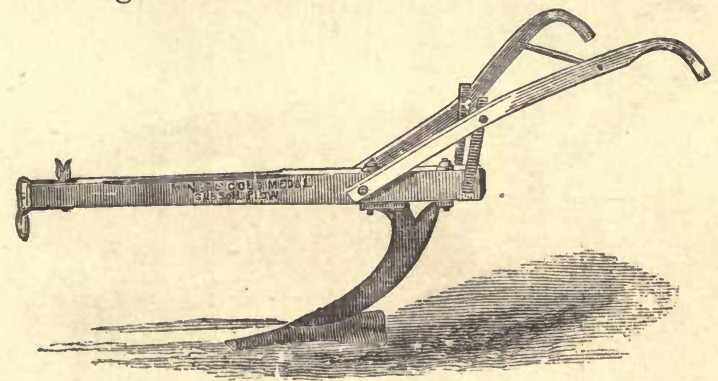

Fig. 116.-MINER'S SUBSOIL PLOW.

plow, lifting and hreaking (but not turning) the subsoil to the depth of fifteen to twenty inches, as may be desired. On very stiff soils, we use the subsoiler once in two years; in lighter soils not so often; although if time would always permit, there is no doubt but that it would ke beneficial to use it whenever piowing is done.

The Garden Harrow (figure 11\%) we find is well suited for garden work. It contains some forty teeth about ten inches long. These are driven through the 
wood-work, leaving five or six inches of the sharpened end on the one side, and one and a half to two inches of the blunt end on the other, as shown in figure 11\%. After

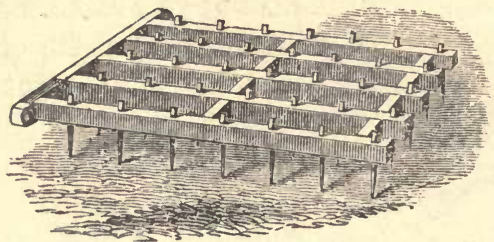

Fig. 117.-GARDEN HARROW.

the ground has been thoroughly pulverized by the teeth of the harrow it is turned upside down and "backed,"

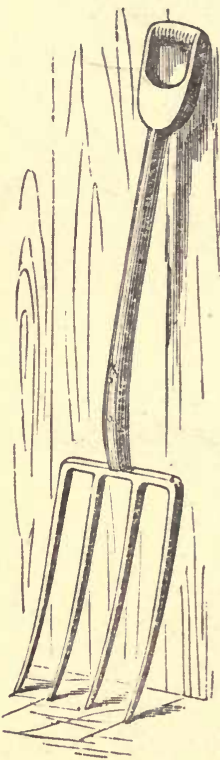

Fig. 118.-DIGGING FORK.

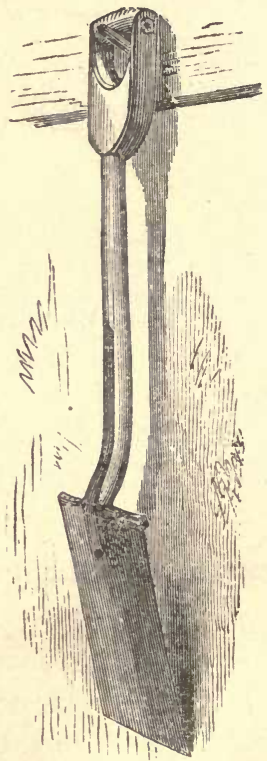

Tig. 119. -AMES' FIRST QUALITY.

as we term it, the short blunt teeth further breaking up the soil, and smoothing it to a proper condition to receive the seeds or plants. 
But there are many spots in the garden that it is impracticable to plow, such as our frames, borders, and occasionally between rows where the space is too narrow for a horse to walk. Such places must be dug, and here we use the Digging Fork, represented by figure 118, in

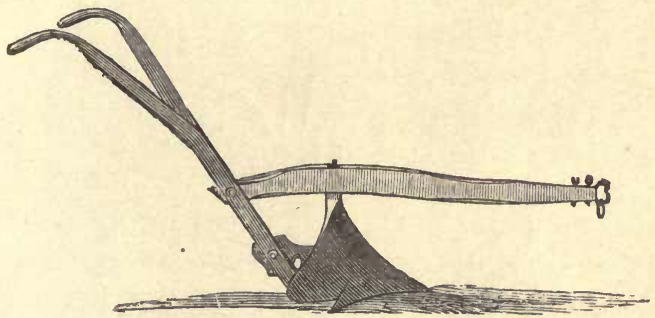

Fig. 120.-SKELETON PLOW。

preference to the spade. Its prongs enter the soil more easily than the blade of the spade, and by striking the turned over soil with the back of the fork, it pulverizes it better than can be done by the blade of the spade. Still there are many operations in the garden, such as the digging up of roots, earthing up of Celery, etc., for which the spade is indispensable. For such purposes the

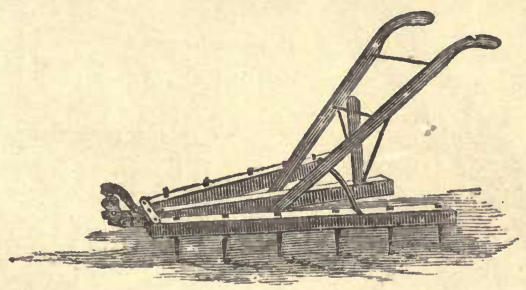

Fig. 121.-Triangular adjustable harRow.

one represented by figure 119, and known as "Ames' First Quality," we find the best.

For stirring between narrow rows of Cabbage, Celery, etc., we use a small one-horse plow before using the cultivator. This is represented by figure 120 , and is known 
as the Skeleton or Cabbage Plow. Following this, is our main implement for cultirating between rows, which is simply a Triangular Adjustable Harrow, represented by figure 121. This implement, we prefer to any variety oi cultivator we have ever used, on ground where there are

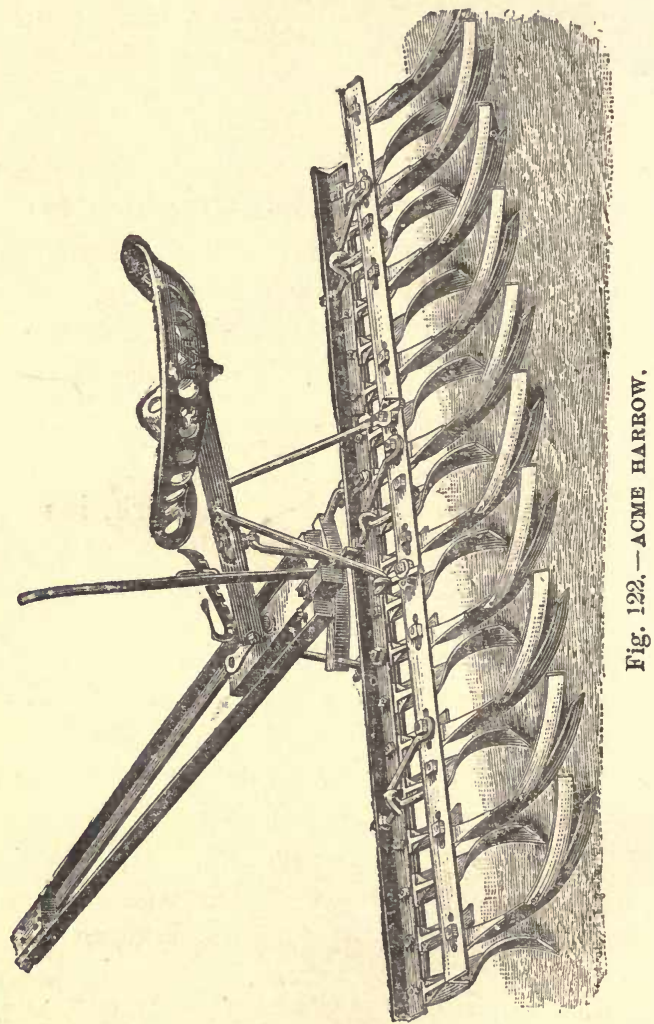

no weeds, as its teeth sink from three to four inches deep if kept sharpened; when extra depth is wanted, a weight is put on to sink it deeper. Another excellent implement, which we have used to great advantage in our market gardens, is the Acme Harrow (figure 122), which it will be 
seen is of an entirely different construction from the harrow just described. As a pulverizer or leveler we have found it one of the very best implements we have ever used for these purposes; for it is not only a harrow, but, under certain conditions of the soil, it is to all intents and purposes a gang of small plows; or, in other words, in a soft or light soil you can plow the ground just as thoroughly for six feet wide as you can do it with the ordinary plow eight inches wide. Although this implement has been recommended especially for farm work, our own experience with it convinces us that it is equally valuable in the market garden. Still another excellent smoothing harrow is that known as the Disc, which consists of some sixty sharp discs, placed on revolving shafts so as to cut the soil to a depth of three inches by one

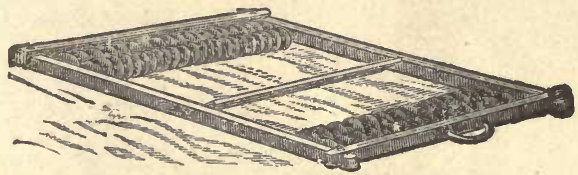

Fig. 123.-DISC HARROW.

inch in width, which levels the ground as completely as can be done with a steel rake in the hands of an expert workman. The use of this implement has saved us an immense deal of labor, which previously was done by hand rakes.

In all hoeing operations by hand, the Steel-Prong Hoe (figure 124), is used in preference to the old-fashioned blade hoe; yet superior as this implement is to the blade hoe, it is not much more than twenty years since it came into general use. A man can do fully onethird more work with it, do it better, and with greater ease than with the blade hoe. True, it is not so good for cutting weeds, but weeds should never be seen in a garden, whether it be for pleasure or profit ; it is shortsighted economy to delay the destruction of weeds until 
they start to grow. One man will hoe over in one day more ground where the weeds are just breaking through than six will do if they be allowed to grow six or eight inches in height, to say nothing of the injury done to the ground by feeding the weeds instead of the. planted crops. Another benefit of this early extirpation of weeds is, that taken in this stage, they, of course, never seed,

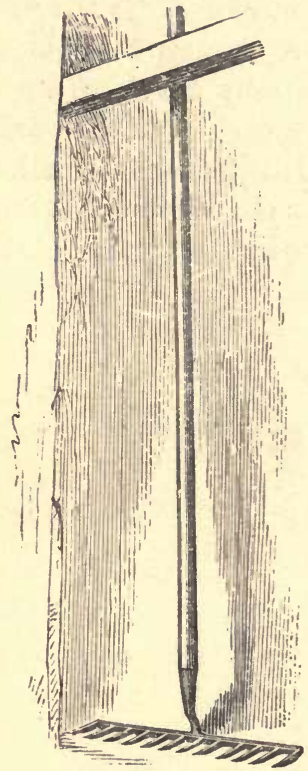

Fig. 125.-8TEEL RAKE.

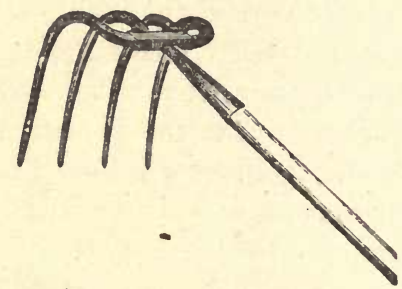

Fig. 124.-PRONG Hoz.

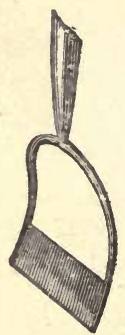

Fig. 126. - SCUFFLE HOE.

and in a few years they are almost entirely destroyed, making the clearing a much simpler task each succeeding year.

Another tool, used in place of the hoe, is the Steel Rake (figure 125), which we use in various sizes, from eight inches to twenty inches in width. Nearly all our first "hoeing" is done with rakes. That is, the ground is raked over and leveled in from two to three days after 
planting. This destroys the germs of the weeds. In from five to ten days, according to the state of the weather, the ground is again gone over with the rakes. I am no believer in deep hoeing on newly planted or sown crops; it is only when plants begin to grow that deep hoeing is beneficial.

For using between narrow rows of crops just starting from the ground, the Push or Scuffle Hoe (figure 126), is a most effective tool. We use them from six to twelve irches wide. They require to be always about three inches narrower than the rows; thus, in rows nine inches apart, we use the six-inch hoe. Another indispensable implement is the Roller (figure 12\%). It is of great importance, not only in breaking lumpy soil, but in firm-

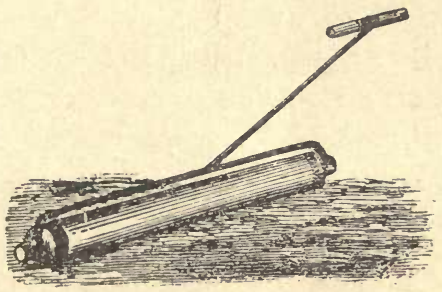

Fig. 127.-GARDEN ROILER.

ing it properly around newly sown seeds; besides, the ground leveled by the roller is much easier hoed than if the surface were uneven or irregular. The roller we use is made of hard wood, and is five or six feet long and nine inches in diameter. The roller is bored throngh its whole length, and through this hole is put a bar of two-inch round iron. This bar gives the necessary weight, and its projecting ends afford points to which to attach the handle.

The Double Marker (home-made), figure 128, is used to mark six or eight lines at once, as may be required, the spaces between the teeth being twelve inches on one side, and nine inches on the other. Where rows are re- 
quired only of these widths, every row is, of course, planted. But many of our crops require wider rows; thus, with a twelve-inch marker we plant our early Cabbages at twenty-four inches apart, the intervening rows being planted with Lettuce at the same time; or, with

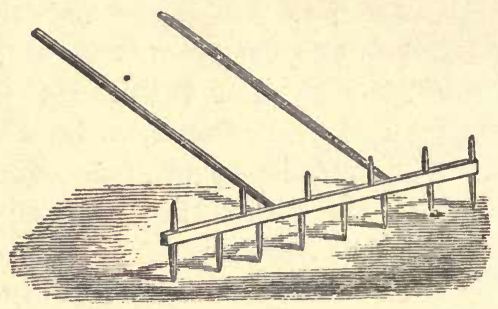

Fig. 128.-DOUBLE MARKER.

the narrow side of the marker, every row nine inches apart is planted with Onion sets; or, in such a crop as Beets, every alternate row only is used, making the rows eighteen inches part. This is the marker that has been

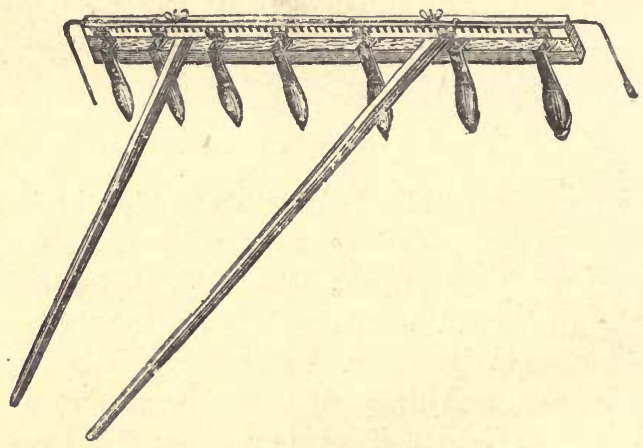

Fig. 129.-RAPP's ADJUSTABLE MAREER.

in use for many years. Within the last year, however, a new implement, known as Rapp's Adjustable Ground Marker, has been offered, and a large number of thom have been sold to the best market gardeners in our vicinit.v, all of whom, without exception, say that it effects a 
great saving in time and labor, compared with the old marker so long in use. Rapp's Marker is made of hard wood and iron. By means of thumb-nuts it is adjustable in all its parts, as its name implies. Tho entire leng'h of the hea: is divided into inches, plainly marked; thus the teeth may le set to any desired gauge with accuracy, while the depth of the trenches is regulated by two iron feet. An important advantage possessed by this marier over the old one is, that by raising the handle slightly the weight of the machine is thrown on the feet, thus allowing a shallower trench to be dug, and relieving the operator of the necessity of carrying the machine, as heretofore. This Marker, an illustratiun of which we give

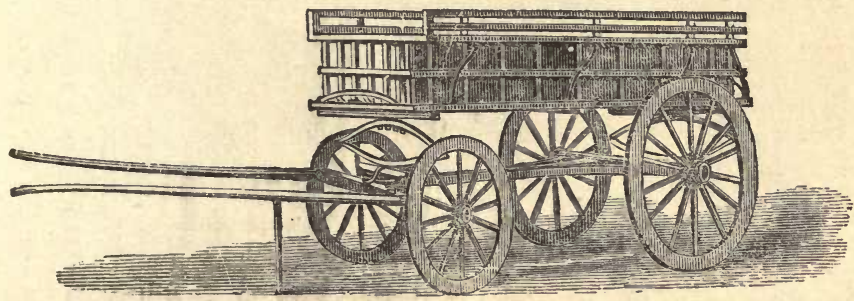

Fig. 130.-MARKET WAGON.

in figure 129, can be obtained from most of the seed or implement houses.

The Market Wagon (figure 130), is made after various patterns in different sections of the country. That shown in the engraving is the kind used by us, and is usually drawn by one heavy horse. It is strongly made, weighing about 1,400 pounds, and is capable of carrying from 2,000 to 3,000 pounds.

The "Planet Jr." Combined Drill, Wheel Hoe, Cultivator and Plow is really a most excellent and valuable implement, combining in one, three implements, all nearly as effective as any of them would be separately. The change; are easily and quickly adjustable. We have 

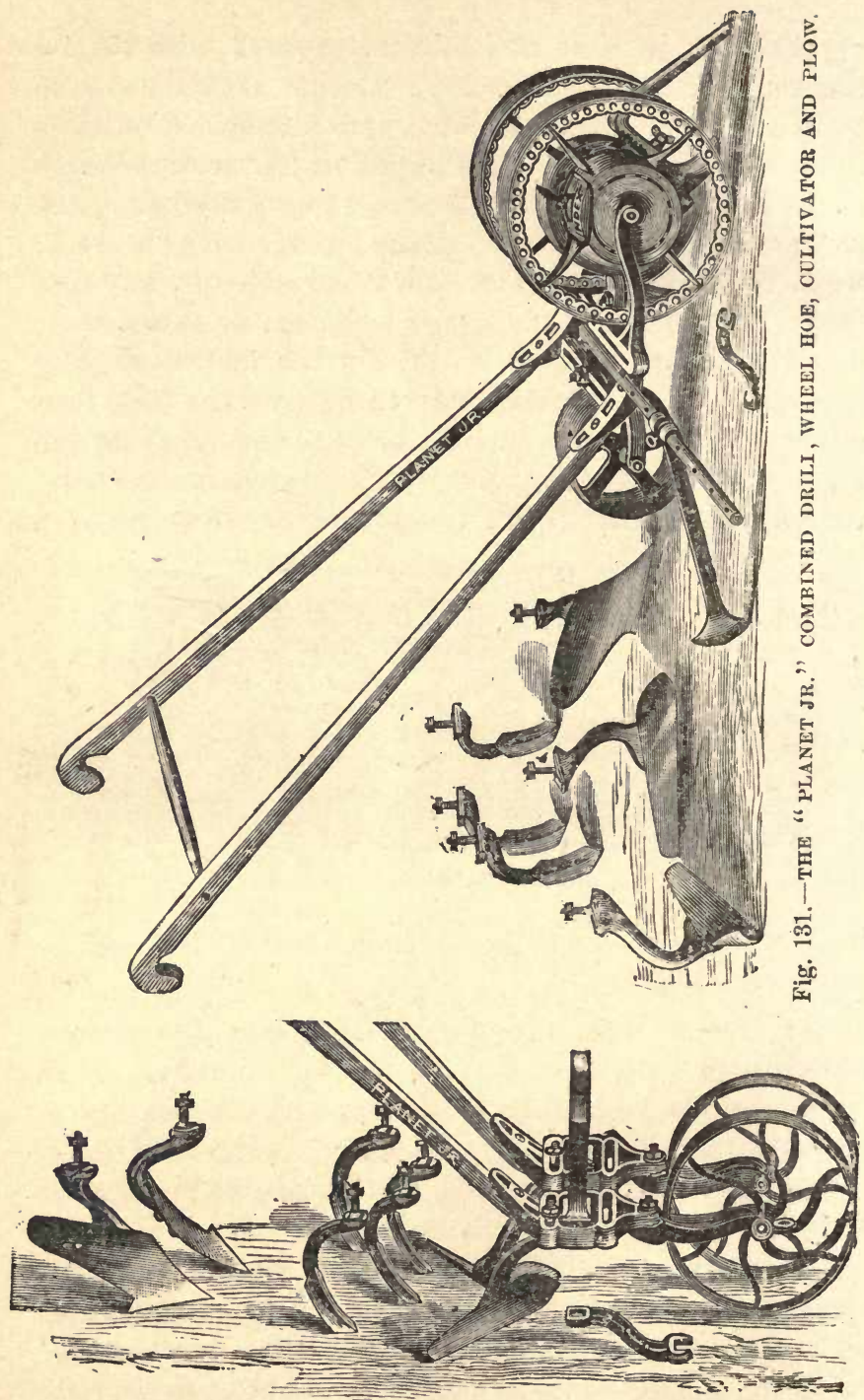

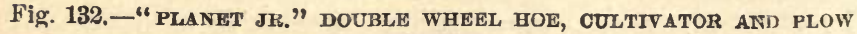
COMBINED. 
used this implement for the past two years with great satisfaction and profit.

Planet Jr. Double Wheel Hoe, Cultivator and Plow is on the same principle as the preceding, nearly identical, except wanting the Seed Drill Attachment.

The Asparagus Knife (figure 133), is a tool intended for cutting the Asparagus below the surface of the soil,

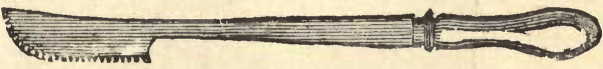

Fig. 133.-ASPARAGUS KNIFE.

the saw teeth being used where there is danger of injuring the edge of the knife.

The Asparagus Buncher, shown in figure 134, is the only implement of the kind that we know of, and while it is an improvement over the old process of tying by hand,

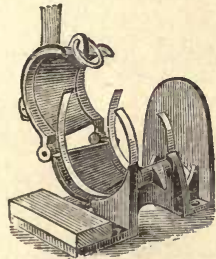

Fig. 134. - ASPAR AGUS BUNCHEK. it is not as perfect as itmight be.

The Garden Line Reel (îgure 135), is best described by our cut. The best sizo wo have used is one that will carry 150 feet of line.

I'igure 136 represents a Horscradish Grater; and

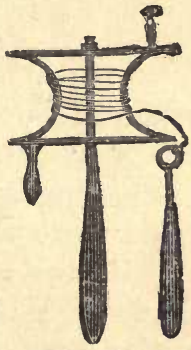

big. 125.GARDEN LITE REIL.

this machine is perhaps as convenient to use as any that can be found. It is easily operated by one person. The cylinder is covered with heavy perforated tin, and the roots, first cleaned by scraping, are held up against it and grated off in that way. Such a grater as we show will grate about fifteen pounds an hour.

The Dibber (figure 13\%), is a very simple but indispensable tool. It is of importance to have it made in the manner represented here. It can be formed from a crooked piece of any hard wood, and shod with a sharp 
iron point, which gives weight to it, besides it always keeps sharp. Dibbers are too often made from an old

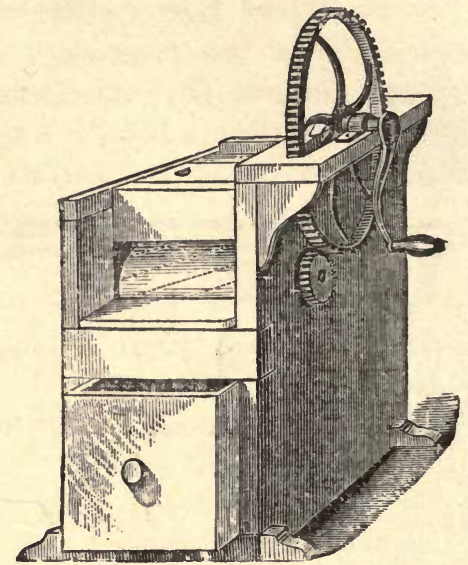

Fig. 13̈̈.-HORSERADISH GRATER.

spade or shovel handle, when they are awkward and unhandy affairs.

Planting is an operation that often requires the most rapid movement to get the crop in at the proper time, and the best appliances in working are not to be disregarded. With a Dibber of this style an expert planter with a boy to drop the plants, as we invariably practise, will plant from 6,000 to 10,000 per day, according to the kind of plants or the condition of the ground. I have on many occasions planted in one day three acres of Celery, holding about 90,000 plants with ten mell, each cf whom had a boy from ten to fourteen years of age, to drop the plants down before him. This plan of using boys is not generally adopted, but I have repeatedly proved that, by thus dividing the labor, a boy and a man will do more Fig. 137. planting than two men would do if planting singly, and each carrying his own plants. 
Awother valuable market garden tool is the Planet Jr. Horse Hoe and Cultivator. The frame will expand to twenty-four inches, or close to five inches, or it can be

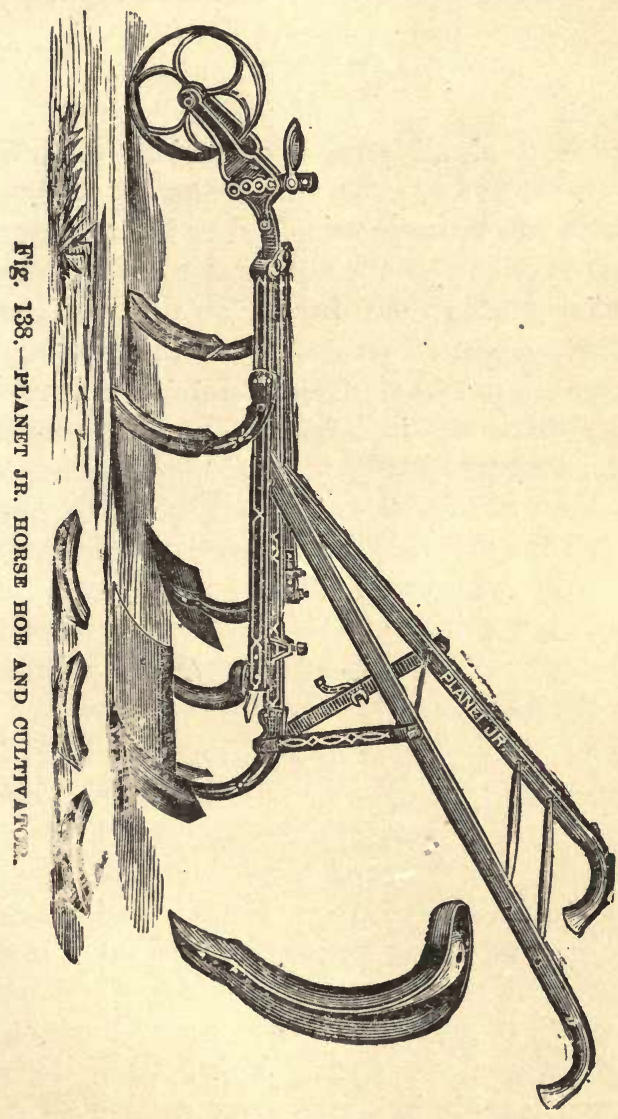

adapted to almost any wiath of row. The value of this tool is largely due to the peculiar shape of the teeth, which will be understood by referring to the engraving. 


\section{MONTHLY CALENDAR.}

The success of all garden operations depends upon preparatory measures; for this reason the beginner in the business can be much benefited by being reminded, as he goes along, of the work necessary to be done to ensure successful results in the future. To do this, I must, to some extent, repeat directions given in the body of the work, but as they will be presented here in a coudensed form, they will not tax the time of the reader. As in all other references made to dates, the latitude of New York is taken as a basis, that being not only the point from which our experience has mostly been derived, but also one that will best suit the majority of readers throughout the country. Those whose location is more southerly or northerly must use their judgment in adapting the directions to suit their locality.

JANCARY. - Vegetation in our Northern States is completely dormant during this month, so that, as far as operations in the soil are concerned, it might be a season of leisure ; but the business of gardening being one that so largely requires preparation, there is always plenty to do. The ground being usually frozen, and giving us good hauling, it is always the month in which our energies are given to getting manure, muck, lime, etc., into conrenient places for spring work. Care should be taken to get manure in heaps large enough to generate sufficient heat to prevent its being frozen, so that it can be turned and broken up thoroughly before it is spread upon the ground. This work is often very slovenly per- 
formed, and the value of manure much reduced by inattention to turning and breaking it up during winter. Sometimes it is injured by being thinly scattered, so that it freezes solid; and again, if tirown into large heaps, and left unturned, it burns by violent heating, getting in the condition which gardeners call "fire fanged." It is always an indication that the manure heap needs turning when it is seen to emit vapor, no matter how often it has been turned previously, for it should always be borne in mind that it quickly loses by heating, while it always gains by a thorough breaking up in turning.

January is usually the month in which we have our heaviest snow storms, which often entail on us an immense amount of necessary, though unprofitable labor, not only in clearing roads, but also in clearing off the snow from our cold frames and forcing-pits, for even at this season of dormant vegetation, light is indispensable to the well-being of our vegetable plants; unless they are in a frozen condition, that is, if we have had a continuation of zero weather, all our plants of Cabbage, Lettuce, Cauliflower, etc., are frozen in the cold frames; if in this stute, the glass is corered up by snow, it is unnecessary to remove it, even for two or three weeks, but if the weather has been mild so that the plants under the sashes have not been frozen when covered by snow, then the snow must be cleared from the glass as soon as practicable. In the greenhouses, hot-beds, or forcingpits, where artificial heat is used, the removal of the snow from the glass is of the utmost consequence.

If not done in December, the final covering up of Celery trenches, root-pits, and all things requiring protection from frost, should be attended to in the first week of this month.

Should the ground be open enough to allow of digging (which occasionally occurs here even in January), let all roots remaining in the ground be dug up and pitted, 
as another chance is not likely to occur before spring. Cold frames and forcing-pits, particularly the former, should be aired whenever the weather will permit, for it is necessary to carry them safely through until spring, that they may be properly hardened. (See Chapter on Cold Frames.) Sow, in greenhouse or hot-bed, Cabbage, Cauliflower and Lettuce. (See Chapter on "How to Raise Cabbage, Cauliflower and Lettuce," page 5l.)

FEBRUARY. - The gardening operations differ but little from those of January, except that in the latter part of the month, as the days lengthen and the sun gets brighter, more air may be given to framing and forcing-pits. Hot manure should now be got forward to be prepared for hot-beds, and if desired, some may be formed this month. (See Chapter on Hot-beds.) Have all tools purchased or repaired, so that no time may be lost in the more valuable days of next month. It is important to always have spare tools of the leading kinds, so that men may not be thrown idle, at a hurried season, by the breaking of a fork, spade, or hoe. In harness and implements, con nected with the teams, it is of great importance to have spare parts to replace those liable to be broken; otherwise, half a day is frequently lost by the breaking of a whiffle-tree, or plow share, causing more loss by delay than three or four times the cost of the article. Sow, for succession crops, Cabbage, Cauliflowér and Lettuce in greenhouse or hot-beds.

MARCH is one of the busiest months in the year with us. Hot-beds are made and planted or sown, and Lettuce crops may be planted in cold frames and forcingpits (see directions under these beads). In the latter part of the month we often begin, on dry suils, the sowing or planting in the open ground of such hardy vegetables as Horseradish, Cabbage, Lettuce, Onions, Radishes, Turnips, etc., etc. Although we gain but little in earliness by starting before April, yet it forwards our 
operations, so that it equalizes labor more than when starting late in spring. Enthusiastic beginners must aroid the too common error of beginning out-door operations too soon, when the soil is not sufficiently dry ; for, if the soil is dug or plowed while wet, it is highly injurious, not only destroying the present crop, but injuring the land for years after. Sow for succession, if wanted, Cabbage, Cauliflower, or Lettuce, in hot-beds, greenhouse, or cold frames.

New plantations of Asparagus, Rhubarb, Sea Kale, and Artichokes may be made, and old beds top-dressed by digging in short manure close around the plants; we consider it more economical of manure to do this in spring than in fall. (See Asparagtis.)

Such roots as Cabbage, Carrot, Celery, Leek, Lettuce, Onion, Parsnip, etc., planted to produce seed, may be set out the latter part of this month, on soils that are warm and dry, drawing earth up around the crowns so as to protect them from sharp frosts; in hoeing, in April, this soil is remored.

Where extra laborers are wanted for the garden, I have always considered it economy to secure them in the early part of March, even a week or two before they are really needed, for if the hiring of them is delayed until the rush of work is upon us, we often have to pay higher rates for inferior hands, and have less time to initiate them in their duties. To such as require large numbers of hands, and look to such ports as New York for emigrants, let me caution my friends from the rural districts not to believe too implicitly in the promises of these prospective American citizens. Much vexatious experience has taught me that one out of every three men is either worthless, or will run away, so that for many years back, if I wanted four hands, I made one job of it and hired six, well knowing that before a week had passed, my force would be reduced to the required number. 
APRIL brings nearly all the operations of the garden under way; the planting and sowing of all the hardy varieties of vegetables is completed this month. (See table in Chapter on Seed Sowing). Look well to the hotbeds, cold frames, or forcing-pits; they will require abundance of air, and (where artificial heat is used), plenty of water ; we have now bright sunshine, promoting rapid vegetation under glass, and to have heavy crops, they must not be stinted in water. Hot-beds are particularly critical in this month; an hour or two of neglect, in giving air, may quickly scorch the tender plants that you have been nursing with so much care for a month previous; and a balmy April day may terminate in a stinging frost at night, making short work of your hot-beds if they are not well covered up by straw mats.

Plantations of Asparagus, Rhubarb, etc., if not made last month, should now be done, as those set out later than April frill not make such a vigorous growth. Succession crops of Lettuce, Beets, Cabbage, Onions, Peas, Potatoes, Radishes, Spinach, Turnips, etc., may be planted or sown during the latter part of the month, to succeed those planted in March and early part of April.

The early sown crops should be hoed, and the ground stirred close to the young plants, so as to destroy the germ of the weeds now appearing.

MAY.-Although the bulk of the hardy vegetables is now planted, yet the tender varieties are still to come; they require more care, as they are more susceptible of injury, by too early or injudicious planting, than the others. In the early part of the month, the succession crops, named in April, may be yet planted so as to produce good crops, and the tender varieties, such as Bush Beans, Corn, Melon, Okua, Pepper, Squash, Tomato, may be sown or planted after the middle of the month ; but Egg Plants, Sweet Potatoes, Lima Beans and Peppers had better be delayed to the last week in May or 1st of 
June. The first produce of the spring plantings will now be ready for use. Lettuce or Radishes, planted in cold frames in March, are matured from 5th to 20 th May, and if covered up by straw mats at night, ten days earlier. In warm situations, on rich, light soils, the Radishes, Lettuce, Turnips, or Peas, planted in March, are fit for market. Rhubarb and Asparagus are also fit to be gathered, on early soils, the latter part of the month.

Additional labor is now beginning to be required, the marketing of crops occupying a large portion of the time, while the thinning out of sown crops, and the keeping down of weeds which are now showing themselves everywhere, entails an amount of labor not before necessary. 'I'o withhold labor at this critical time is shortsighted economy, whether by the owner of a private or market garden; for let the crops planted and sown once get enveloped by weeds, it will often cost more in labor to clean the crop than it will sell for. It is not at all an uncommon occurrence to see acres of Carrots or Parsnips plowed down, after being carefully manured and sown, from neglect or inability of the owner to procure labor at the proper time. The rapid development of weeds is, to the inexperienced, very deceptive ; a crop of Carrots, Parsnips, Beets, or Onıons, may appear to be easily manageable at a given day in May; but a few days of continued rain occurs, and the crop that could have been profitably cultivated on the 15 th is hopelessly overgrown on the 25 th.

JUNE is one of the months in which we reap the reward of our operations in the market garden; at this time the bulk of all the early crops matures in the Northern States. So far, nearly all has been outlay; now, we recelve the returns. In this district our early crops of Asparagus, Beets, Cauliflower, Cabbage, Lettuce, Onion, Peas, Radishes, Rhubarb, Spinach and 
Turnip are sold off, and the ground plowed for the second crop (except in the cases of Asparagus and Rhubarb), by the end of the month. For private gardens (or in special cases for local markets), succession crops of Beets, Bush Beans, Cabbages, Cucumbers, Lettuce, Peas, Radishes and Potatoes may still be planted, but, as a rule, it would hardly be profitable for market purposes, as it would occupy the land wanted by the market gardener for his sceond crop, besides the market buyer of the cities will lardy tonch a vegetable or fruit behind its season at rice. He will pay ten cents per bunch for Rali in May, and will pass by a far better article of t. wine kind in July or August, though offered at ont-ifth the price. He will give fifty cents per quart for Tomatoes (half-ripe), in June, that he could not be induced to touch in October, if he could buy them at twenty-five cents per bushel.

The Cucumbers, planted in cold frames and forcingpits, are also marketable in the latter part of this month. Great care must be taken to have them obundantly watered in dry weather; inattention to watering (particularly of all vegetables under glass), is sure to entail loss on the cultivator, by giving an imperfoct or partial crop. Watering had better be done in the erening, unless chilly, whenever the surface appears dry, not by a mere sprinkling, but by a thorough soaking-not less than a gallon to every square yard of surface. As coon as the Cucumbers are all cut from the frames, the sashes should be piled up at the ends of each section and covered with a shutter, and a weight of some kind put on the top, to prevent these from being blown off by high winds.

JULY. - The remaining part of the spring crops are cleared off in the early days of this month, and by the middle of it, unless the season is unusually dry, all the ground is planted with the second crops of Cclery, Sage, 
Thyme, Late Cabbage, Broccoli, Cauliflowes, or Leeks. Little is done to these crops this month, as but little growth is made during the hot, dry weather, and newly planted crops are merely stirred between the rows with the hoe or cultivator. Some of the other later crops are now maturing for market. Bush Beans, Cucumbers, Potatoes, Squashes, and, in early places, Tomatoes; also succession crops of Peas, Beets, Onions, Cabbages, etc., such of these as only mature during the end of the month, render the second crops rather late, unless for the later crops of Celery and Spinach.

August.-Except the months of January and February, August is a month requiring less labor in the market garden than any other. Usually all the planting has been done in July, and the long drouths, common at this season, stagnate the growth of eren our most luxuriant weeds, so that in this month, of all others, the garden ought to be clean.

Late plantings of Celery may be made to the middle of the month, and still give fair-sized roots for winter. Spinach may also be sown for an early crop, to be cut off in fi.l. Ruta Baga Turnips should be sown early in the month, and the white and yellow varieties during the later part. Be careful now, if the land is dry, to firm after sowing. (See "Use of the Feet in Sowing and Planting.") If the "fly" attacks them, it may be kept down, so as to do but little harm, by frequent applications of lime dusted lightly over the rows. Bush Beans and Peas may still be sown for late crops. For Peas for late sowing, we found our "First of All" variety the best. In 1886, a crop sown 25th of August was marketed late in October, and sold at excellent prices. The Onion crop will ripen off during this month, and when convenient to market, should be offered for sale as soon as gathered, as the price received for those first sold is frequently double that of those coming in ten days later. 
SEPtember.-The cool nights and moist atmosphere of this month begin to tell strikingly on the crops planted for fall use. Celery, Cabbage and Caulifiower now grow rapidly, and require repeated stirring of the soil with the plow, cultivator, or hoe. Celery that is wanted for use towards the latter part of the month may now be "handled" or straightened up, and the earth drawn to it by the hoe; in a week or so after it may be "banked up" by the spade to half its height, allowed to grow for another week or more, until it lengthens out a little further, when the banking should be continued as high as its top. In ten days (at this season), when thus finished, it is blanched sufficiently to use, and should then be used, or it will soon spoil. Care must be taken that no more is banked up than can be sold or used, as it is not only labor lost, but is decidedly hurtful to the Celery by making it hollow. The practice recommended by most authorities, and still followed by private gar. deners, is to keep earthing it up every two weeks from the time it begins to grow ; this is utter nonsense, resulting in making tough, stringy, and rusty Celeryutterly unfit to eat, while the expenditure in labor would be twice more than the price it would usually bring if sold; for further information on this important subject, see Chapter on Celery. The seeds of Canliflower, Cabbage and Lettuce should be sown this month, from the 15th to the 25th, for the purpose of being pricked out in cold frames to be wintered over. It is very important that the sowing should be done as near these dates as possible, for if sown much before the 15th the plants may run up to seed when planted out in spring; if much later than the 25th, they would be too weak to be wintered over. Shallots and Onions should also be planted this month, and Spinach and German Greens, or "Sprouts," sown to be wintered over, all now for spring use. 
OCTOBER. - This month corresponds in part to June of the summer months, being that in which the returns from the second crops come in. Celery that has been banked or earthed up, now sells freely and in considerable quantities. All the crop should this month be " handled," and, as much as possible, earthed up. Cauliflower is usually scarce and dear in the early part of this month, but unless the fall has been unusually moist, is generally not matured until towards the end of the month. Thyme, Sage and all Sweet Herbs should now be sold, from the beginning of the month, cutting out only every alternate row, as it gives the crop time to grow, so that the remaining rows spread sufficiently to fill the space. (See article on Thyme, etc.)

The crops planted or sown last month must now be carefully hoed and the weeds removed; for, though weeds are not quite so numerous in variety as in summer, Chickweed, now very abundant, is one of the most expensive weeds of the garden to eradicate.

The plants of Cabbage, Cauliflower and Lettuce, recommended to be sown last month, are now fit to be pricked out in the cold frames. (See detail of the process, page 45.)

November. - This month warns us that winter is approaching, and preparations should be carefully made towards securing all products of the garden that are perishable by frost. The process of putting away the Celery crop in trenches for winter use (see Celery article), should be begun about the 5th or 10th of the month in dry weather. 'That put in trenches then will be blanched sufficiently for use in six or eight weeks, but when sufficient help can be obtained, it will always pay well to bank or earth up a large portion of Celery by the spade, clear to the top; this will usually keep it safe from injury from any frost that we have in this month, and thus protected it need not be put away into winter 
quarters-the trenches-before the end of November. Put away thus late, it will keep usually without the loss of a root until March or April, when it is always scarce and high in price. The great difficulty most persons have is from stowing it away and covering it up too early; this practice of earthing it up to the top roughly in November we have only recently practised, but find the extra labor well repaid, as we are enabled thus to save this very valuable crop without loss. There is rarely need of applying any covering of leaves or litter to the trenches this month, and it cannot be too often told that the covering up of vegetables of all kinds in winter quarters should be delayed to the very last moment that it is safe to do so. Beets, Carrots, Cabbages and Cauliflowers must be dug up and secured this month in the manner recommended in "Preserving Vegetables in Winter." Horseradish, Salsify and Parsnips, being entirely hardy and frost proof, need not necessarily be dug, although from the danger of their being frozen in the ground next month, if time will permit the work had better be progressing.

All clear ground should be dug or plowed, and properly leveled, so that on the opening of spring operations can be begun with as little delay as possible. If draining is required this is the most convenient time to do it, the ground being clear and not yet much frozen.

Towards the end of the month the sashes should be put on the Cabbage and Lettuce plants in cold nights, but on no account should they be kept on in day-time, as it is of the utmost importance that they be not made tender at this time by being "drawn" under the sashes. I may again repeat that these plants are half hardy, and it is killing them with kindness to protect them from slight freezing. Cabbage and Lettuce plants may be exposed in any place without glass or other protection where the thermometer runs no lower than ten above 
zero. Rhubarb and Asparagus beds will be benefited by a covering of four or six inches of rough manure, or any other litter, to prevent the severity of the frost; the crop from beds thus covered will come in a few days earlier, and will be stronger than if left unprotected.

Deceuber.-Occasionally we have the ground open, so that digging and plowing can be done to nearly the end of the month, but it is not safe to calculate much after the first week; though by covering up the roots, still undug, with their own leaves or with litter, we are often enabled to dig our Horseradish or Parsnips rery late in the month, and, like all other vegetables, the later they remain in the soil they grow in the finer is the quality.

Celery trenches should receive the first covering early in the month, if the weather has bren such that it has been unnecessary before. The covering should not be less than four or five inches of litter or leaves, only taking care that the material is light; weight or closeness would prevent eraporation too much at this season, while the weather is not yet severe. The final covering should not be later than the end of the month.

The crops of Spinach, Kale, Onions, Shallots, etc., that have been planted or sown in September, should be covered up with hay or straw if their position is much exposed; if not, there is no particular necessity. When all has been secured safely in winter quarters, attention must be energetically turned to procuring manure, muck, and all available kinds of fertilizers. There is little danger of spending too much in this way if you have it to spend; depend upon it, there is no better investment if you are working your Garden for Profit. Straw and rope for straw mat making should always be on hand, so as to give employment to the hands in stormy weather. 


\section{N D E X.}

Capital Required

Climate, Ours Different from England

Crops, Rotation of

Cuttings, Variation of Plants from

Drainage

Drain, Boaird Flat Stone Rubble .................. Tile

Fcrtilizers (See Manures)..... Application of ........... Comparative Value of.... Preparation of ............ Special

Forcing Pits .................

Frames, Cold, and Hot-beds.. Airing ................... Cucumbers in ............ Frozen Plants in ........ Lettuce in ............... Protecting Cloth for...... Seed Sowing in

Shelter for -.............

Snow upon ............. Spring Raising of Cabbage Plants, Etc ............ Ground, Preparation of the ... "Hill," Meaning of the Term Hot-beds

Egg Plants in ..........

Frame for ..............

Forcing Lettuce in .......

Manure for ..............

Pepper Plants in .........

Sashes for

Straw Mats for..........

Sweet Potatoes in ........

Sowing in

Tomato Plants in

When to Plant in ........

Importance of Ventilation 105

Houses, Forcing and Greenhouse Buildings and Appurtenances

Greenhouse for Forcing John Hudson's. ....... Heating of ........... Heated by Flue ..... (3\%0)
17

105

110 273 28

224

56

58

56

58

57

58

56

61

60

108

58

45

\section{1}

\section{Heating by Return} Flue ...............

Flues, Danger from ...... 70

Flue, How to Build.....70, 87 Greenhouses, Profits of... 69

Pump for............ 66

Rotation in ........ 67

Soil for ............ 76

Vegetable........... 24

Watering in ......... 66

Sashes, How Fastened 65

Sashes, How to Glaze 75

Wells ............... 24

IMPLEMENTS.

Buncher, Asparagus ......... 355

Dibble or Dibber............. 3.56

Drill, Planet Jr. Combined . . . . 35\%

Fork, Digging ............. 346

Grater, Horseradish ......... 356

Harrow, The Acme .......... 348

The Disc................ 349

Garden .... 346

Triangular Adjustable.... 347

Hoe, Horse, and Cultivator... 357

Prong ................... 350

Push ................. 350

Scuffle _............. 350

Single Wheel, Etc . . . . . . . 358

Knife, Asparagus . ........ . . . 355

Line, Garden, and Reel . . . . . . 355

Marker, Adjustable .......... 352

Plow, Cabbage .............. 347

Roland Chilled.......... 344

Slip Share for............ 345

Subsoil ................. 345

Skeleton ................ 347

Rake, Steel .............. 350

Roller, Garden .............. 351

Spade, Ames' Flrst Quality ... 346

Wagon, Market ............... 353

Laying Out of Garden......... 24

Location of Garden ............ 23

Manures (See also Fertilizers) 33

Alternation of ........... 35

Ashes, Wood ............ 43

Bone Dust .............. . 85

Comparative Value of .... 56

Cotton-seed Meal ........ 42

Gas Lime.............. 42

3

5

2

42

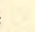

.

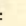

4

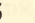

4


Manures, Green Crops as..... Peruviau Guano .......... Preparing Guano, Etc.... Hops, liefuse ............ Horn Shavings...........

Horse ......... . . . . . . . . .

Lime ...............

Marl ....................

Muck.................

Night Soil ..............

Plaster ....................

Poudrette.................

Salt as....................

Sugar-house Scum .......

Whalebone, Refuse ......

Men Suited to Gardening -....

Monthly Calendar, January -.

February

March

April

May

June

July

August .

September

October-

Novembew

December

Number of Plants to an Acre 113

Plants for Frames, When to Sow

Plants Propagated from Cuttings, Do they Vary? .......

Profits of Gardening .........

Rosebuds, Boston ............

Rosebuds, Madison ........... 273

Seeds and Seed Raising........ 89

Cabbage become Annual. 105

California, seed Growing

in ....................

Celery, Success in Sowing

Failing to Germinate .....

Feet, Use of, in Sowing .-

"Firming" the Soil over

Seeds .................

How, When and Where to

Sow ..................

91

84

94

95

96

Indiscriminate Sowing ... 103

Quantity to Sow an Acre - 111

Quantity for a Given Number of Plants. ........... 113

Soaking of ............... 95

Soil for Sowing ........... 107

Sown in Dry Weather ... 94

Testing .................. 89

Vitality of, Duration of .. 92

Wrongly Blaming the

Seedsmen............... 104

Situation of Gardeu.......... 24
SMALL FRUITS.

Blackberries ................. 334

Culture of ............. 325

Kittatinuy ............ 336

Lawton

Wilson's Early........... 336

Currants .................... उ3:

Black ............... 339

Cherry . . . . . . . . . . . . . 339

Fay .................... 339

Red Dutch ............... 339

White Dutch .............. 339

Gooseberries ................ 359

Downing ............. 340

Houghton ............. 340

Grapes _.................. 340

Age of Vines ......... 340

Planting -.............. 342

Brighton .................. 343

Champion .............. 343

Concord ............... 344

Martha ................. 343

Moore's Early ............. 343

Niagara . . . . . . . . . . . . . . 343

Salem ................ 343

Wilder................... 343

Raspberries .................. 336

Covering in Winter ...... 333

Brinkle's Orange ......... 337

Caroline . . . . . . . . . . . . . 337

Cuthbert .............. 337

Gregg (Black-cap) _....... _ 337

Hansell .... . . . . . . . . . 337

Hudson River Antwerp . . . 337

Strawberries, Forcing ........ 81

Forcing, Kinds for ........ 83

Layering in Pots ......... 327

Open Culture........... .325

Strawbelries, Varieties of .... 328

Bidwell ............... 332

Crescent .............. 333

Crimson Cluster......... 329

Downing .............. 332

Henderson ............. 328

Hoffman ............... 332

Jersey Queen ............. 333

Jewell ..................... 333

Parry .................. 333

Sharpless ............... \$32

Wilson -................. 333

Soil, Preparation of .......... 31

Resting the ........... 110

Selection of.............. 25

"Sports"

Southern States, When to Sow and Plant in ......... 311

Asparagus .............. 311

Beans .................. 311 
Beets

Cabbano

Cauliítower

Celery

Collards

Cueumbers -........ 313

Egg Plant ............. 313

Greens, German......... 314

Lettuce................... 314

Melon, Musk and Water .. 313

Okra or Gumbo .......... 314

Onion ................... 314

Peas ................... 314

Potató, White.......... 314

Potato, Sweet........... 314

Radish.................. 314

Rhubarb ............. 315

Turnips _................. 315

Spinach.................. 315

Squash .................. 315

Tomato ................. 315

Transplanting ................ 114

Variation in Plants ........... 273

Vegetables, Hardy -.......... 107

Vegetables, Tender ........... 107

Vegetable Plants, How to Plant 115

Vegetable Plants, How Much

Cold Will They Endure .... 116

Varieties of Vegetables-Too many

VEGETABLES, VARIETIES OF :

Artichoke

Chard .................. 128

Common Green . . . . . . 129

Green Globe ........... 129

Artichoke, Jerusalem ........ 130

Varieties ................. 130

Asparagus ................. 118

At the South . . . . . . . . 124

Beetle ................ 127

Buncher ............. 126

Fertilizers for ........... 125

Gathering the Crop ....... 126

Planting _............. 119

Profits of ........... 127

Propagation ............ 118

Salt for .............. 125

Van Siclen's Method ..... 120

Without Transplanting ... 122

Asparagus, Varieties of ....... 120

Colossal ................ 120

Giant ................. 128

Palmetto ............... 124

Balm

Basil

Bush

131

131

131

Swcet
Beans, Bush, Kidney and Pole 131

Beans, Dwarf Varieties ........ 133 Earliest Red Valentine ... 133 Early Red Valentine ..... 134 Early Mohawk. .......... 134

Gallega .................. 134

Large Refugee ............ 134

Long Yellow Six-Weels.. 134

Refugee ............... 134

Thousand to One......... 134

White Marrow fat ......... 134

Beans, Running or Pole ....... 135

Lima, Dreer's Improved _ 136 Jersey Extra Early . . 136 Large White ........ 136

Giant Wax ........... 137

German Wax ........... 137

Horticultural ............. 137

Scarlet Runner............ 136

Speckled Cranberry ...... 137

Beans, Wax, Black ......... 134

Flageolet . . . . . . . . . . 135

Golden ............. 135

Beet ......................... 138

Bastian's Blood Turnip ... 141

Dewing's Improved Blood Turnip .............. 141

Early Blood Turnip . . . . . 141

Eclipse ................. 140

Egyptian Turnip ........ 140

Long Smooth Blood ...... 141

Swiss Chard ............ 141

Borecole, or Kale ............ 142

Dwarf German Greens .... 142

Dwarf Green Curled Scoteh .................. 143

Purple................... 143

Siberian Dwarf Curled ... 142

Sprouts _............... 142

Very Early Dwarf......... 143

Broecoli ................... 144

Early Walcheren......... 145

Purple Cape ............ 145

White Cape ............. 145

Brussels Sprouts .............. 145

Cabbage and Cauliflower ..... 146

Aphis ................ 155

Black Flea .............. 155

Butterfly ................ 155

Caterpillar ............. 155

Club-root in . ............ 157

Green Fly on ............ 155

Insects ................. 155

In Southern States ....... 151

"Jumping Jack" ........ 155

Keeping in Winter ........ 154

Kinds for Early Crop..... 148

Late, Culture of .......... 152

Louse .................. 155 
Cabbage, Maggot.......... 156

Plants, What Cold They will Endure

Seed

Slug

155

Soil and Manures ........ 147

Wire Worm ........... 156

Cabbages, Early ............ 162

Early Flat Dutch .......... 165

Early Jersey Wakefield... 162

Early Winningstadt ....... 165

Henderscn's Early Summer.................... 164

Premier................. 164

Cabbages, Late ............. 165

American Drumhead Savoy

166

Felder Kraut............ 166

Fottler's Improved Brurswick

165

Mammoth Rock Red ..... 16r

Narblehead Mammoth _. . 166

Red Dutch ......... 167

Selected Late Flat Dutch. 165

Turnip-rooted ............. 212

Cardoon ................. 169

Carrot _.................. 170

Danvers ............. 17\%

Early French Forcing .... 171

Early Half-long Scarlet Carentan .............. 162

Larly Half-long Scarlet (Pointed Rooted) ....... 172

Halî-long Red (Stump Rooted) ............... 171

Jarge White Belgian..... 173

I.ong Orange, Improved . . 172

Yellow Belgian .......... 173

Cauliflower ............... 167

Extra Early Dwarf Erfurt 169

Extra Early Paris ........ 169

Half Early Paris ........ 169

Henderson's Early Snowball . 167

I.arge Late Algiers ....... . 169

Le Normand's Short stemmed............... 169

Nonpareil ................ 169

Celery _.................... 174

Close Planting .......... 179

Dwarf Kinds Preferred ... 179

Earthing up............... 178

"Handling" "......... 178

Planting Out............ 176

Profits of ............... 184

Rust on .............. 180

Shipping of ............ 184

Sowing the Seed ......... 174

Storing for Winter ....... 180
Celery, Storing in Trenches. - 180

In Cellars............ 182

Celery, Varieties of ........... 185

Boston Market............. 188

Giant White Solid........ 189

Henderson's Golden

Dwarf .................... 185

Henderson's Half-Dwarf - 187

Henderson's Rose......... 189

Major Clark's Pink........ 190

Sandringham ............ 188

Turnip-rooted . ........... 190

White Plume ............ 186

Celeriac _. . . .

Dwarf Apple-shaped ..... 190

Chervil, Turnip-rooted ....... 173

Chives .................... 191

Collards (Southern) . . . . . 195

Corn Salad. . ................... 191

Corn, Sw eet................... 195

Planting ................. 196

Profitable Crop of ........ 196

Corn, Sweet, Varieties of ..... 197

Cory _... . . . . . . . . . . . 197

Crosby's Early Sugar. ..... 197

Early Marblehead........ 197

Early Minnesota .......... 197

Egyptian ............... 198

Henderson ............... 197

Mammoth Sugar .......... 198

Squantum Sugar......... 197

Stowell's Evergreen ....... 198

Cress _............... 193

Upland .............. 194

Water ................ 192

Profits of .......... 194

Cucumbers ................. 199

How to Plant ............. 199

The Pickle Crop ........ 201

Cucumbers, Varieties of . ..... 201

Burr _................. 203

Early Cluster ............ 202

Early Russian ............. 202

Green Prolific............ 203

Improved White Spine ... 201

Nichols' Medium Green . - 202

Egg Plant ................. 203

Black Pekin............ 206

Long Purple ............. 206

New York Improved ..... 205

White-fruited .......... 206

Enclive ................. 206

Broad-leaved Batavian ... 208

Green Curled ............. 207

Moss Curled ............. 207

Fetticus ................... 191

Garlic .................... 208

Gherkin, West India ......... 203

Greens, Dwarf German....... 142 
Gumbo

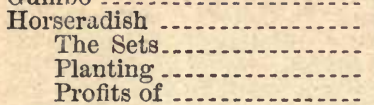

In lian Cress ................. 240

Jerusalem Artichoke.......... 130

Kale or Borecole ..........142,

Kohlrabi ................... 212

Early White Vienma...... 213

Early Purple Vienna ..... 213

Leek ....................... 213

London Flag ........... 214

Musselburgh ............. 214

Lettuee ................... 214

Forcing in Hot-beds..... $5 \tilde{5}$

New York "Salad Paúches" ............. 216

Profits of ............... 217

All the Year Round ...... 222

Lettuce, Varieties of .......... 219

Black-seeded Simpson .... 220

Black-seeded Tennis Ball. 220

Boston Market............ 221

Early Curled Simpson .... 219

Large White Summer Cabbage .................

New York .............. 221

Paris White Cos.......... 222

S.lamander .............. 521

White-seeded Tennis Ball 221

Yellow-seeded Butter .... 221

Marjoram .................. 308

Marjoram, Sweet............. 223

Martynia .................. 234

Melon, Musk ................. 223

Culture of ............ 224

Profit of . . . . . . . . . . . 2... 2:4

Soil for ................. 225

Insects Injurious to ...... 226

Melon, Musk, Varicties of .... 227

Baltimore ................. 228

Early Hackensack. . ...... . 227

Golden Netted Gem -.... 228

Green Citron............. 230

Hackensack ............ 228

Montreal Mariset.......... 229

Melon, Water............... 230

Profits of ............... 230

Melon, Water, Varieties of ... 231

Black Spanish ............. 232

Citron ..................... 233

Gypsy .................. 231

Ice Cream ............... 231

Icing .................. 232

Ice lind .............. 232

Kolb's Gem ............... 231

Mammoth Iron-clad ...... 231

Mountain Sweet........... 231
Melon, Water, Rattlesnake... 231 Phinney's Early .......... 231

Sealy Bark .............. 232

Mint ... B.

Mushroom ................ $2^{2} 4$

Making the Bed........... 330

Making the Spawn ....... 239

Preparing Manure for .... 256

Spawning the Bed........ 236

Mustard ................ 234

Black................ 234

White ............. 224

Nasturtium ................ 240

Dwarf ............... 240

Tall .................... 240

New Zealand Spinach ........ 290

Okra_.................... 241

Onions................... 241

Harvesting .............. 249

Insects Injurious to . ..... 249

Farm Crop, As a . ........ 243

Profits of . . . . _ _. 250

Manures for ............. 245

Planting ................ 249

Preparing the Ground... 246

Profits of ................ 243

Sowing the Seed ........ 247

Sowing in Fall ........... 243

Sets ................ 24:3

Storing the Crop......... 249

Weeding the Crop ........ 247

Onions, Varieties of .......... 251

Bermuda .............. 252

Extra Early Flat Red . . _. 252

Giant Rocea ............ 253

Large Red Wethersfield .. 251

Large Red Italian Tripoli . 254

LargeWhite Italian Tripoli 245

Neopolitan Marzajola .... 253

Queen ................ 253

Southport Large Yellow Globe ................ 251

Southport Red Globe.... 252

Southport White Globe .. 25:

Silver-skin ............... 253

White Portugal ........ 253

Yellow Dutch ............ 253

Yellow Globe Danvers.... 251

Onions, Potato ............. 254

Onions, Top ….......... 254

Orach

Oyster Plant

Parsley, in Winter............. 255

Pas sley, Varieties of.......... 256

Double Curled.......... 256

Fern-leaved ............. 256

Hamburgh ............. 257

Henderson's Emerald .... 256

Plain ................... 257 
Parsley, Turnip-rooted ....... 257

Parsnip _.................. 25y

Early Round ............ 258

Hollow-crowned ......... 258

The Student .............. 258

Pea, Varieties of ........... 258

Alaska.... . . . . . . . 261

American Wonder ....... 261

Black-eyed Marrowfat. . . 264

Bliss' Abundance ......... 263

Bliss' Everbearing......... 263

Champion of England... 263

First of All ............ 260

Improved Dan'l O'Rourke 261

Kentish Invicta ........... 261

McLean's Advancer...... 261

Premium Gem .......... 261

Stratagem _............. 263

Pride of the Market...... 264

Telephone ........... 263

Yorkshire Hero .......... 263

White Marrowfat ..... . . 264

Pepper, Varieties of ........ 264

Bull Nose................ 264

Cranberry .............. 26.5

Golden Dawn ............ 2635

Large Bell ................ . 264

Long Red Cayenne....... 265

Manmoth .............. 264

Ruby King............... 265

Squash _............... 265

Swect Mountain .......... 264

Tomato-shaped ......... 265

Pepper Grass ................ 193

Potato

Diseases of .

Colorado Beetle......... 266

Tubers, Cut or Whole.... 270

Potatocs, Varieties of ........ 267

Beauty of Hebron........ 267

Clark's No. 1............. 269

Early Rose............. 267

Einpire State ............. 268

Pearl of Savoy ............ 267

Perfect Peach Blow ....... 269

Rochester Favorite ....... 269

Rural Blush............. 269

St. Patrick . . . . . . . . . . 269

Triumph ............... 269

Vanguard............... 267

White Elephant............ 268

Potato Onions ............. 254

Pumpkin .................. 274

Radish as a Succession Crop.. 275

Foreing ............. 77

Radish, Varieties of .......... 275

Beckert's Chartier......... 2\%6

Chincse Rose-colored, Winter
Radish, Early Round Dark Red 276

French Breakfast ........ 27\%

Gray Summer Turnip .... 278

Long Black Spanish...... 278

Long Scarlet Short-top... 275

Olive-shaped ............. 278

Red Forcing Turnip _..... 279

Round Black Spanish .... $2 \% 8$

White-tipped Scarlet Turnip ................. 27 r

Yellow Summer Turnip _. 278

Rhubarb ................. 278

Foreing ............. 279

Linnæus . . . . . . . . . . . 281

St. Martins _............ 281

Victoria _............... 281

Ruta Baga .............. 307

Sage - . . . .

Salsify ................. 282

Salsify, Black .............. 283

Savory, Summer ............ 308

Scorzonera................. 283

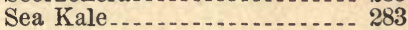

Blauching . ............ 284

Shallots ................. 285

Sorrel _.................. 285

Spinach . . .

Profits of ............ 287

Spinach, Varieties of ........ 289

Large Round Ieaf Viroflay 290

Long Standing .......... . . 290

Norfolk Savoy-leaved .... 289

Prickly . .................. 290

Round Leaf ............... 290

Thick-leaved............. 290

Spinach, New Zealand ....... 290

Spinach, Substitutes for..... . 290

Sprouts ................. 142, 291

Squash, Summer Varieties .... 291

Boston Marrow ....... 293

Bush Crookneck ..... 293

Yellow and White

Bush Scalloped ..... 2 2 2

Fall and Winter Varictics:

Essex Hybrid ......... 29:

Hubbard ............ 293

Mammoth Chili . . . . _ 294

Marblehead ......... 291

Vegetable Marrow .. - 294

Winter Crookneck ... 294

Summer Savory ............... 308

Swedes or Swedish Turnips... 307

Sweet Herbs ............. 308

Sweet Marjoram

Sweet Potato ................ 295

Starting the Plants....... 297

Sets or Draws............. 296

Nansemond.............. 297

Red Skinned ............. 297 
Sweet Potato, Yellow Skinned. 297 Swiss Chard (See Beet) ....... 141 Thyme ............... 308

Tomato _.......... 298

Earliness in ........... 300

Profits of ........... 299

Saving Seeds of ........ 300

Tomato, Varieties of . ....... 301

Acrne .................... 301

Canada Victor ........... 303

General Grant . ............ 303

Hathaway's Excelsior .... 303

Mikado _................ 301

Paragon .... . . . 301

Perfection .............. 303

Plum, Red und Yellow ... 303
Tomato, Trophy $\ldots . . . . . . . . .303$

Top Onions_............ 254

Turnip, Varieties of ......... 304

Amber Globe ........... 306

Extra Early Milan ...... 306

Golden Ball .............. 306

Purple-top Strap-leaf .... 306

Purple-top White Globe.. 306

Red-top Strap-leaf ....... 306

Seven-top................ 307

Snowball ................ 306

Snow-white ............ 307

Turnip, Ruta Baga Kinds .... 307

Improved American...... 307

Large White French ..... 308

Shamrock ................ 308 


\section{Alphabetical Catalogue}

\section{- …t. \\ 0. Judd Co., David W. Judd, Pres't,}

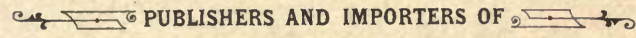

\section{All Works pertaining to Rural Life.}

751 Broadway, New Tork.

\section{Agriculture, Horticulture, Ete.}

\section{FAHEN ANID GARIDEN.}

Allen, R. L. and L. F. New American Farm Book... ......\$2.50 American Farmer's Hand Book .................. 2.50

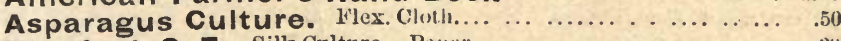

Bamford, C. E. Silk Culture. Paper............................

Barry, P. The Frnit Garden. New and Revisid Elition......... 2.00

Bommer. Method of Making Manures ..................... .25

Brackett. Farm 'lulk. Paper 50c. Cloth ................ . i5

Brill. Farm-Gadening and Seed-Growing............... 1.00

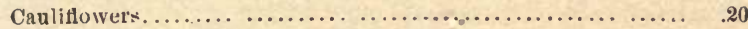

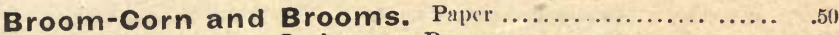

Curtis on Wheat Culture. Paper ..................... .50

Emerson and Flint. Manual of Agriculiure............ 1.50

Farm Conveniences ............................... 1.50)

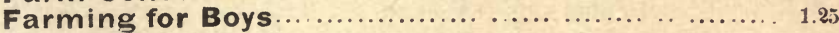

Farming for Profit... ............................

Fitz. Sweet Potato Culture. New and Enlarged Edition. Cloth..... .60

Flax Culture. Paper................................

French. Farm Drainage . ... ........................ 1.50

Fuller, A. S. Practical Forestry ........................ 1.50

Gregory. On Calbages ..................................30

On Carrots, Mangold Wurtzels, etc...................... 30

- Oı Fertilizers................................40

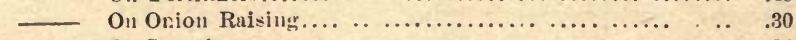

On Squashes ................................. 30 
Harlan. Farming with Green Manures .................. 1.00 Harris. Insects Injurious to Vegetation. Plain \$4. Col'd Engraviags. 651 ) Harris, Joseph. Gardening for Young and Old .............. 1.25

Talks on Manures. New and Revised Eilition... 1.75

Henderson, Peter. Gardening for P!easure................. 1.50

Gardening for Profit. New and Enlarged Eilition. 2.00

Garden and Farm Topics.... .. .................... 1.50

Henderson \& Crozier. How the Farm Pays.................. 2.50

Hop Culture. New and Revised Edition. Paper.... ......... . . .3]

Johnston. Agricultural Chemistry........................ 1.

Johnson, M. W. How to Plant. Puper.... ... ......... . . .50

Johnson, Prof. S. W. How Crops Feed ................ 2.00

How Crops Grow ... .............. 2.00

Jones, B. W. The Peanut Plant. Paper..........................

Lawn Planting. Paper ..... .. ...................... .

Leland. Furm Homes, In-Doors. and Out-Doors. New Edition. .... 1.50

Long, Elias A. Ornæmental Gardening for Americans ............ 2.00

Morton. Furmer's Calendar .......................... 5.00

Nichols. Chemistry of Furm nnd Sea.................... 1.25

Norton. Eluments of Scientilic Agriculture................... .75

Oemler. Truck-Furming at the South..................... 1.50

Onions. How to Ratise them Profitilbly................... .20

Our Farm of Four Acres. Pilpur................. . .30

Pabor, E. Colorado as an Agricultural Siate............... 1.50

Pedder. Land Measurer fir Farmers. Cluth................. . $\quad .60$

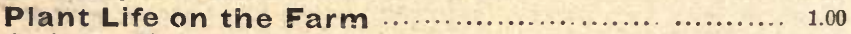

Quinn. Money in the Garden .............. ............. 1.50

Register of Rura| Affairs. 9 vols. Each.............. 1.50

Riley. Potalis Pests. Paper ................................ $\quad .50$

Robinson. Facts for Farmers............................ 5.00

Roe. Play and Profit in iny Garden ... ... ................... 150

Roosevelt. Five Acres Too Much....................... 1.50

Silos and Ensilage. New and Enlarged Edition............ $\quad .50$

Starr. Farm Echues.................................. 1.00

Stewart. Irrigation for the Farm, Garden and Orchard ......... 1.50

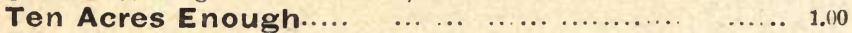

The Illustrated Dictionary of Gardening. Vol. 1 .. 5.100

The Soil of the Farm................................ 1.60

Thomas. Farm Implements and Machinery .................... 1.50

Tim Bunker Papers; or, Yankee Farming ......... 1.50

Tobacco Culture. Paper................................. ${ }^{.25}$

Treat. Injurious Insects of t!le Farm ond Garden.............. 2.00

Villes. School of Chemical Mamnes ........................ 1.25

_- Higlı Furming without Maunres.........................

Artlficial Manures.... ............................. 6.00

Waring. Book of the Farm ......................... 2.00

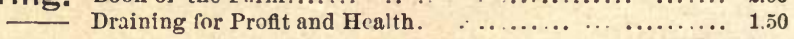

- Elements of Agriculture.......................... 1.00

-

— Sanitary Drainage of Houses und Towns. ............... 2.00

Sanitary Condition in City and Conntry Dwelling ........... .50

Warington. Chemistry of the Farm ..................... 1.00

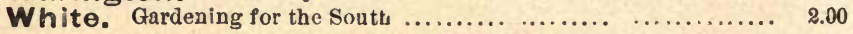




\section{FIR UITS, FLo wVIRS, ETC.}

A merican Rose Culturist ......................... $\quad .30$

A merican Weeds and Useful Plants ................ 1.75

Boussingault. Rural Economy .......................... 1.60

Chorlton. Grape-Grower's Guide..........................

Collier, Peter. Sorinnm, its Culture and Manufactire............ 2.90

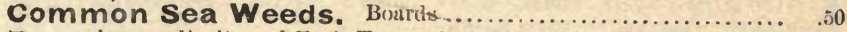

Downing. Frits and Fruit Trees of Ameriva. New Edilion.... . 5.00

Rural Essajs............................... 3.00

Elliott. Hand Buok for Fruit-Growers. Paper 60c. Clowh.... . . . . . 1.00

Every Woman her own Flower Gardener........... 1.00

Fern Book for Everybody ............................ $\quad .50$

Fuller, A. S. Grape Culıurist............................ 1.50

fllustrated Stmwberry Culturist . ............... .20

Suall Fruit Culurist. New Elition. ............. 1.50

Fulton. Peach Culture. New and Revised Eulitlon ............... 1.50

Heinrich. Window Flower Garlen........................

Henderson, Peter. Hund Book of Plints... ............... 3.00

Practical Floriculture ................ 1.50

Hibberd, Shirley. The Amatenr"s Flower Garlen ............ 2.50

The Amatenr's Greenlouse anci Conservatory. 250

The Amateur's Rose Book................. 2.50

Hoopes. Bonk of Everereens.. .......................... 3.00

Husmann,Prof.Geo. American Grape growing and Wine Making 1.50

Johnson. Winte: Greeneries at IIme....................... 1.00

Moore, Rev. J. W. Orange Culture..................... 1.00

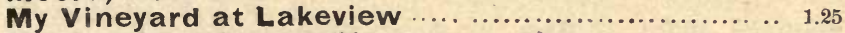

Origin of Cultivated Plants ........................ 1.75

Parson 3. Ou the Rose............................... 1.50

Quinn. Pear Culture for Profit. New and Revised Edition. ........ 1.00

Rivers. Miniature Fruit Garden $\ldots \ldots \ldots \ldots \ldots \ldots \ldots \ldots \ldots \ldots, \quad \ldots \ldots$

Rixford. Wine Press and cellar ........................ 1.50

Robinson. Ferns in their Hsmes anl Ours. ................. 1.50

Roe. Success with Small Fyruits............................ 5.00

Saunders. Insects Injurions to Fruits... . . . . . . . . . . . . . . 3.00

Sheehan, Jas. Your Plants. Paper....................... $: 40$

Stewart. Sorgh $\cdots$ and Its Prodncts........................ 1.50

Thomas. Amerienn Fruit Cultmirt....................... 2.00

Vick. Flower and Vegetable Garden. Cluth. . .............. 1.00

Warder. Hed qes and Evergreens ....... $\quad \ldots \ldots \ldots \ldots \ldots \ldots, 1.50$

Webb, Jas. Cupe Cod Cranberries. Paper. ................. $\quad .40$

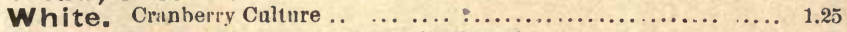

Williams, B. S. Orelind Grower's Manual... .............. 6.50

Wood, Samuel. Moderu Window Garkening ............... 1.25 


\section{Cattle, Dogs, Horses, Sheep, Swine, Poultry, Etc.}

\section{CA'THE, SHERP, AND SWINE.}

Allen, L. F. American Cuttle. New and Revised Edition......... 2.50

Armatage, Prof. Ceo. Every Mau His Own Cattle Doctor. 8vo.. 7.50

Armsby. Manmal of Cattle Feeding...................... 2.50

Cattle. The Varielies, Breeding, and Munagement.............. .75

Coburn, F. D. Swine Husbandry. New nuci Revised Edition...... 1.75

Clok. Diseases of Sheep............................. 1.25

Dadd, Prof. Geo. H. Americu Cattle Doctor. 12mo.......... 1.50

American Cattle Doctor. 8vo. Clotlı..... 2.50

Fleming. Veterinary Obstetrics...................... 6.00

Guenon. On Milch Cows ................................ 1. .

Harris, Joseph. On the Pig........................ 150

Jennings. On Cattle and their Diseases................... 1 2.5

On Sheep, Swine, and Poultry, ................. 1.25

Jersey, Alderney, and Guernsey Cow ............ 1.50

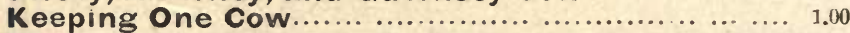

Macdonald. Food liom the Far West.................... 1.50)

McClure. Diseases of the American IIorse, Cattle, and Sheep....... 2.00

McCombie, Wm. Cattle and Cattle Breders............. . 1.50

Martin, R. B. Hour-R ising und Pork-Making............. $\quad .40$

Miles. Stock Breeding.... ... ........................ 1.50

Powers, Stephen. The American Merino for Wool and Mutton.

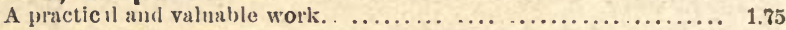

Quincy, Hon. Josiah. On Soilin Cattle............... 1.25

Randall. Fine Wonl Sheep Insbandry. .................... 1.00

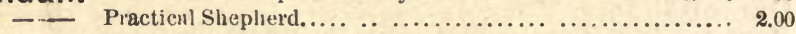

Reasor On the Hoo

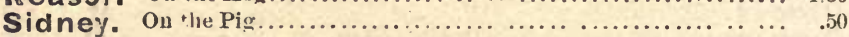

Shepherd, Major W. Prairic Exporience in Hundling Cattle... 1.00

Stewart, Hen ry. Shepherd's Manual. New and Enlaryed Edition. 1.50

Stewart, E. W. Feeding Animals ..................... 2.00

The Sheep. Its Varieties and Mamrement. Boards . . ......... .7\%

Youatt and Martin. On the Hog.. . .................. 1.00

Youatt. On Slieep.... ....... ...................... 1.00

\section{HDST, E:TC:}

Burgess. American Kennel nud Sporting Furli. 8 ro . . . . . . . . 3.00

Dog-The Varieties and Management........... . .50

Dogs of Great Britain, America, and Other Countries, Compled from Stonelsenge and other Standard Writers. The most Complete Work ever Publisheit on the Dog: $12 \mathrm{mo}$.......... 2.00

Forester, F. 'The Dog, lyy Dinks, Mayhew, and Hutchinson. 8vo ... 3.00

Floyd, Wm. Hints on Dog Breaking. $12 \mathrm{mo} \ldots \ldots \ldots \ldots \ldots \ldots \ldots \ldots . .50$ 
Hallock, C. Dog Fanciers' Directory and Medical Guid:• 18.113... . .25

Hammond, S. Dog Traintng. 12mo ... ............. 1.00

Hill, J. W. Mamagrement and Disenses of the Dog. $12 m, \ldots . . . .2 .2 .00$

Hooper, J.J. Dog and Gum. Paper................... .30)

Hutchinson, G. N. Dog Breaking. $8 v 0 \ldots \ldots \ldots \ldots \ldots \ldots \ldots . . . . .3 .60$

Idstone. 'The Dog. Illustrated. 12mo................... 1.25

Laverack; E. The Setter. 4to ... . . . . . . . . . . . . .

Mayhew, E. Dogs ; Their Mana _ement. 16mo....... . . . . . .75

Points for Judging Different Varieties of Dogs.

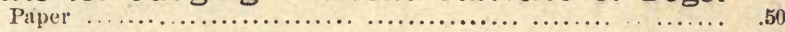

Richardson. Dows; Their Origin and Vuricties. Pap r 30c. Cloth . (i0

Shaw, T. Vero. Illnstrated Book of the Dog. 4 to............. 8.00

Stables, Cordon. On Friend the Dog. Svo... ............. 3.00

Practical Kennel Guide... ................ 1.50

Ladies' Dors as Companions..... ......... 2.00

Stonehenge. The Dog in Health and Disease. 8 vo .......... 3.00

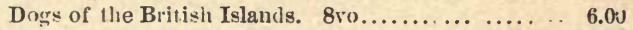

'T'he Greyhonnd .......................... 5.50

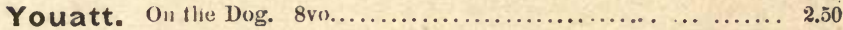

\section{HORENES, HRIDING, FTC.}

Anderson, E. L. Molern Horsemanslip. 8vo ........... 7.00

Thie Gallop. 4to. Paper ................ 1.00

Armatage, Geo. Every Man His Own Horse Doctor, fogether wilh

Bluine's Veterinary Art. 8vo. $\frac{1}{2}$ morocen.................. 7.50

Armatage. Geo. Horse Ownur and Stableman's Companion. 12mo 1.50

Battersby, Col. J. C. T'he Bridle Bits. A valuable litlle work

on horsemanship. Fully illustrated. 12mo................. 1.00

Baucher, F. New Method of Horsemanship. $12 m 0 \ldots \ldots \ldots \ldots . .1 .00$

Bruce. Sum-Book. 4 vols........................... 35.00

Chawner, R. Disenses of the Horse and How to Treat 'Them. $12 m 01 .: 5$

Chester. Complete 'Trotting and Preing Record .............. 10.00

Dadd, G. H. American Reformed Horse Buok. 8ro............. 2.50

Modern Horse Doctor. 12mo................ 1.50

Day, W. The Race Horse in 'J'rining. 8vo................

Du Hays, C. Pelcheron Horse. New anı Revised Elition. 12mu.. 1.00

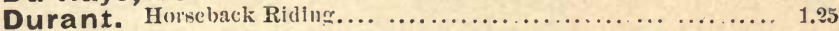

Famous Horses of America. Cloth. 4 to............. 1.50

Gleason, O. R. How to Handle and Encate Vicions Hurses.... 1.00

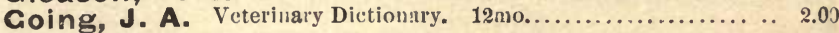

Herbert, H. W. Hints to Horse Keepers. $12 m$............... 1.\%

Helm, H. T. American Roadsters and Trotting Horses. $\left.8 \mathrm{r}^{\prime}\right) \ldots \ldots . .5 .00$

Horse, The; Its Varteties and Management. Boarcls. .. ........ .7.

Howden, P. How to Buy and Sell the Horse. $12 m 0 \ldots \ldots \ldots \ldots \ldots . . .60$

Jennings, $R$. Horse Training Made Easy. 16 mo ............ 1.25

The Horse and His Disenses. 12mo............ 1.25

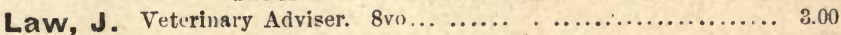

Liautard. Cliart of Age of Domestic Animils............... .50

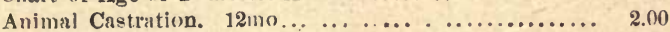

Manning. The Illustrated Stock Doctor.................. 5.00 
Mayhew, E. Illustrated Horse Manåcment. 8vo............ 3.00

" Horse Ductor. $8 \mathrm{ro}, \ldots \ldots \ldots \ldots \ldots \ldots \ldots . .3 .00$

Meclure, $\mathbf{R}$. Discases of American Horse's. $12 m 0 \ldots \ldots \ldots \ldots \ldots . . .2 .00$

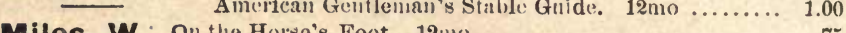

Miles, $W$. On the Horse's Font. 12mo...................... .75

Rarey. Horse Tauer und Farrier. 16mo.................... .50

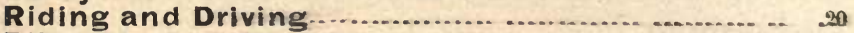

Riley, H. Ou the Mnle. I2mo............................. 1.50

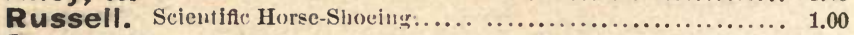

Saddle Horse, The. Complete Gudde to Riding and Truining.... 1.00

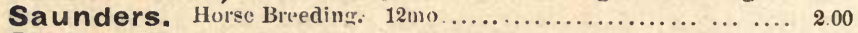

Stewart, R. American Furmer's Horse Book. 8 vo ............. 300

Stonehénge. Every Horse Owmer's Cyclopædia. Evo........... 3.75

On the Horse in the Stable ant the Field. English

Eslition. 8vo...................... 3.50

On the Horse in the Stable and the Field. American

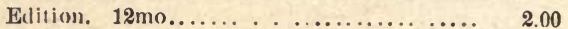

Tellor. Disenses of Live Stock. Cpoth, 2.50; Sheep.............. 300

Wallace. American Stnd Book. Per vol................... 10.00

Williams. Veterinary Medicine.......................... 5.00

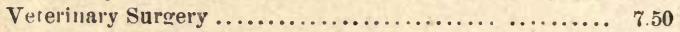

Woodruff. Ille 'lrotting Horse in Am rica. 12mo.. ......... . 2.50

Woods, Rev. J. G. Horse and Mn.................... 2.50

Youatt \& Skinner. The Horse. 8 vo..................... 1.75

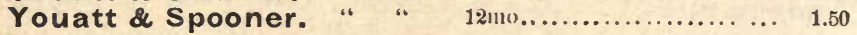

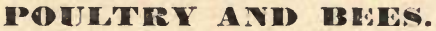

Burnham. New Ponltry Book........................ 1.50

Cook, Prof. A. J. Bee-Keeper's Ginde or Manual of the Apiary .... 1.25

Cooper, Dr. J. W. Game Fowls..................... 5.00

Corbett. Pouluy Yard and Market. Paper....................$_{50}$

Felch, I. K. Poultry Culture......................... 1.50

Halsted. Artificial Incubation and Inculators. Paper ...........

Johnson, G. M. S. Practical Ponltry Keeper. Paper.......... .50

King. Bee-Keeper's Text Book........................... 1.00

Langstroth. On the Honey und Hive Bee................... 2.t0

Poultry. Biceding, Rearing, Feeding etc. Boarcls ........ ... $\quad .50$

Profits in Poultry and their Profitable Manage-

ment. Most complete Work extant..................... 1.00

Quin by. Mysteries of Bee-Keeping Explained (Edited by L. C. Root). 1.50

Renwick. Thermostatic Incubator. Paper 36c. Clorh........... .56

Root, A. I. A, B, C, of Bee-Culmre....................... 1.25

Standard Excellence in Poultry.................... 1.00

Stoddard. All Erg-Farm. Revised and Enlargid............... $\quad .50$

Wright. Illustrated Book of Ponltry..................... 8.00

Practical Ponltry-Keeper........................... 2.00

— Practical Pigeon Keeper.......................... 1.50 


\section{ARCHITECTURE, ETO.}

Allen, L. F. Rural Architecture ........................ 1.50

American Cottages............................... 5.011

Ames. Alphabets . .................................. 1.50

Atwood. Country and Sulurban Houses.................... 150

Barn Plans and Out-Buildings $\ldots \ldots \ldots \ldots \ldots \ldots \ldots, 1.50$

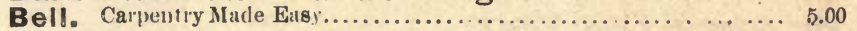

Bicknell. Cottage and Villa Architecture................ 400

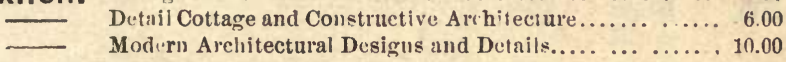

— Public Buildings. New....................... 2.50

- Street, Store, and Bank Fronts. New............... 2.50

School-House and Ciutrch Architecture............... 2.50

- Stabies, Ont-buildings, Fences, etc................ 2.50

Brown. Building, Table and Extimate Burk................. 1.50

Burn. Drawing Books, Architectural. Illnstrated and Oruanental.

8 Vols. Each.................................. 1.00

Cameron. Plastercr's Manuai........................... . .

Camp. How Can I Learn Architecture......................... .50

Copley. Pluin and Ornamental Alplaaluets .................... 300

Cottages. Hints on Economical Building... .................. 1.00

Cummings. Architectural Details ....................... 6.00

Elliott. Ilund Book of Practicai Landscape Gir lening.............. 1.50

Eveleth. Sclionl-House Architecture ....................... 4.0)

Fuller. Artistic Homes.. ..... .......................... 8.50

Gilmore, Q. A. Roads and Street Pavements.................. 2.50

Gould. Americin Stair-Builder"s Guide. .................... 2.50

C Carpenter's and Builder's Assista:t.................... 2.50

Hodgson. Steel Square .................................. 1.00

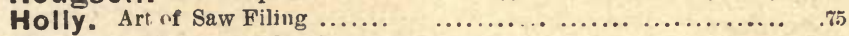

Harney. Barns, Out-Buildin:s, and Fences .. ................ 4.00

Hulme. Mathematienl Drawing Instruments.. ................. 1.50

Hussey. Home Building.. ............................... 2.50

National Cottage Arehitecture.... ..................... 4.00

Homes for Home Builders. Just Published. Fuly Illusirated. 1.50

Interiors and Interior Details ....................... 7.50

Lakey. Village and Country Holses ..................... 500$)$

Modern House Painting ........................ 500

Monckton. National Carpenter and Joiner .................. 5.00

National Stair-Builder....................... 5.00

Painter, Cilder, and Varnisher's Companion..... 1.50

Palliser. American Cottage Homes............................ 3.00

Model Homes.................................. . 1.00

Useful Details................................ 2.00

Plummer. Carpenters' and Builders' Guide.................. To

Powell, Foundations and Fonndation Walls................. 2.06

Reed. Cottage Houses.................................... 1.25

Honse Plans for Everylody. ... ..................... 1.50

Dwellings...... $\ldots \ldots \ldots \ldots \ldots \ldots \ldots \ldots \ldots \ldots \ldots \ldots, 8.00$ 


\section{Our Very Latest Publications.}

Through the Yellowstone Park on Horseback. By

GEN. ( 1.6 . WINGATE ............................ 1.50

Fly-Fishing and Fly-Making. By Keene... ............ 1.50

How to Handle and Educate Vicious Horses. By

O. R. Gleason...................................... 1.00

The Law of Field Sports. By Geo. P. Sмıти ............ 1.00

Bridle Bits. A Trealisc on Practical Ilorsemanship. By CoL. J. C.

BatTEusBy. .................................. 1.00

The Percheron Horse in America and France ... . 1.00

Profits in Poulicry. Useful and Ornamental Breeds .. ......... 1.:0

Cape Cod Cranberries. By James Webb. Paper.......... .

How to Plant. By M. W. Johnson.......................... . .50

The American Merino for Wool and Mutton. By

STEPHEN PowERS................................ 1.75

\section{$\longrightarrow \infty-\infty$ \\ New and Revised Editions.}

Hallock. Sportsman's Gazetteer.......................... 3.10

Stewart. Irrigation for hle Furm, Garden and Orchard........... 1.50

Farm Implements and MachInery. Bу Tномаз...... 1.50

Egg Farm. By Stoddard. Cloth........................ $\quad .50$

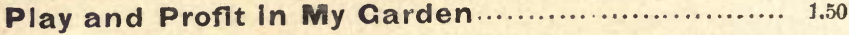

Silos and Ensilage ............................... .50

Send Postal for Complete Catalogua of our Publleations regarding Horses and Horsemanship, Hnnting, Fishing, and all other Out-Door Sports and Pastimes.
0. JUDD CO.
DAVID W. JUDD, Pres't.

751 BROA WUY NEW YORK. 





\section{RETURN CIRCULATION DEPARTMENT 2469}

TO $\longrightarrow 202$ Main Library

\begin{tabular}{c|l|l}
\hline LOAN PERIOD & 2 & 3 \\
\hline 4 & 5 & 6 \\
\hline
\end{tabular}

\section{ALL BOOKS MAY BE RECALLED AFTER 7 DAYS}

Renewals and Recharges may be made 4 days prior to the due date. Books may be Renewed by calling 642-3405.

\section{DUE AS STAMPED BELOW}

AUTO. DISC.

\section{JUN 20 1989.}

AUTODISCCIRC J.10194

JANO4 1994 HAY 111994 


\section{U.C. BERKELEY LIBRARIE}

C020985209 


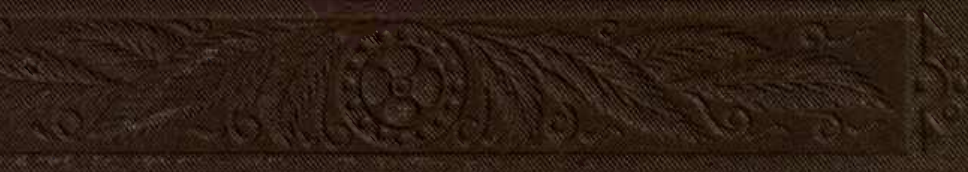

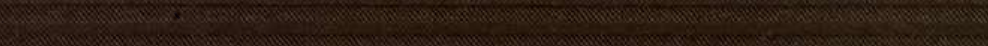

